TAILORING RUBBER COMPOUND AND PROCESSING FOR BALANCING THE PROPERTIES OF AIRCRAFT TIRE RETREADS

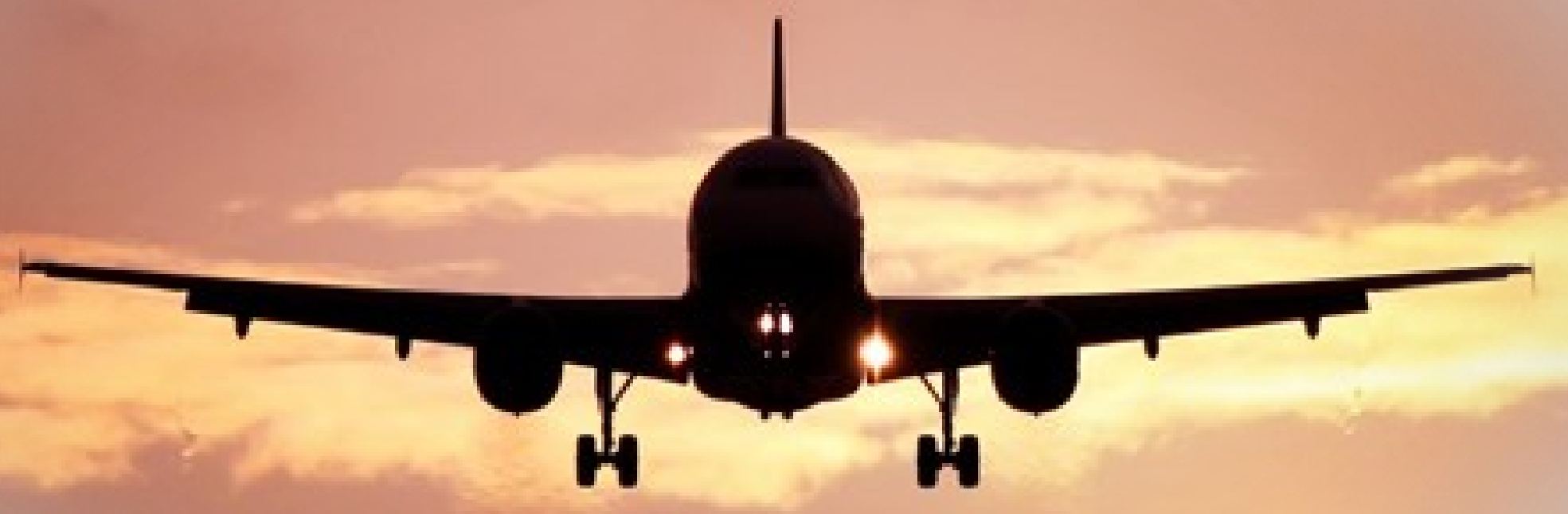




\section{TAILORING RUBBER COMPOUND AND PROCESSING FOR BALANCING THE PROPERTIES OF AIRCRAFT TIRE RETREADS}

Indriasari 


\section{ET:}

UNIVERSITY OF TWENTE.
Elastomer Technology and Engineering

This research was funded by the scholarship program for Research and Innovation in Science and Technology Project (RISET-Pro).

\section{Graduation Committee:}

Chair / secretary: Prof. Dr. Ir. H.F.J.M. Koopman

Supervisor:

Co-supervisors:

Committee Members:

Prof. Dr. Ir. W.K. Dierkes

Prof. Dr. A. Blume

Prof. Dr. A.R. Thornton
Prof. Dr. Ir. J.W.M. Noordermeer

Prof. Dr. Ir. J.E. ten Elshof

Prof. S. Wiessner

Prof. D. Katrakova-Krüger

Dr. J. Bertrand
University of Twente, ET, the Netherlands

University of Twente, ET, the Netherlands

University of Twente, ET, the Netherlands

University of Twente, ET, the Netherlands

University of Twente, ET, the Netherlands

University of Twente, TNW, the Netherlands

Technische Universität Dresden, Institut für Werkstoffwissenschaft, Fakultät Maschinenwesen, Leibniz Institut für Polymerforschung

Technical University Cologne, Informatikund-Ingenieurwissenschaften, Institut für Allgemeinen Maschinenbau Behn Meyer Europe GmbH, Hamburg, Germany 


\title{
TAILORING RUBBER COMPOUND AND PROCESSING FOR BALANCING THE PROPERTIES OF AIRCRAFT TIRE RETREADS
}

\author{
DISSERTATION \\ to obtain \\ the degree of doctor at the Universiteit Twente, \\ on the authority of the rector magnificus, \\ Prof. Dr. Ir. A. Veldkamp, \\ on account of the decision of the Doctorate Board \\ to be publicly defended \\ on Wednesday 20 October 2021 at 12.45 hours
}

by

\section{Indriasari}

born on the 9th of April, 1979

in Banyumas, Indonesia 
This dissertation has been approved by:

Supervisor

Prof. Dr. Ir. W.K. Dierkes

Co-supervisors

Prof. Dr. A. Blume

Prof. Dr. Ir. J.W.M. Noordermeer

Cover design: www.klipartz.com

Printed by: IPSKAMP Printing, Auke Vleerstraat 145, 7547 PH Enschede, the Netherlands

Lay-out: Indriasari

ISBN: 978-90-365-5261-5

DOI: $10.3990 / 1.9789036552615$

URL: https://doi.org/10.3990/1.9789036552615

(c) 2021 Indriasari, The Netherlands. All rights reserved. No parts of this thesis may be reproduced, stored in a retrieval system or transmitted in any form or by any means without permission of the author. Alle rechten voorbehouden. Niets uit deze uitgave mag worden vermenigvuldigd, in enige vorm of op enige wijze, zonder voorafgaande schriftelijke toestemming van de auteur. 
Chapter 1 Introduction 1

$\begin{array}{lll}\text { Chapter } 2 & \text { Literature review }\end{array}$

Chapter 3 Defining key factors for improving properties of aircraft tire retreads produced from carbon black-filled NR/BR blends

Chapter 4 Optimization of the mixing parameters for NR/BR blends with a hybrid carbon black/silica and a silica filler system

Chapter 5 The effect of zinc oxide and diphenyl guanidine addition 95 sequence on processing, mechanical and dynamic properties

Chapter 6 The influence of different types of butadiene rubber on processing, mechanical and dynamic properties of aircraft tire retreads

Chapter 7 Incorporation of resins for improving the properties of 145 aircraft tire retreads

Chapter 8 Aging properties of aircraft tire retreads

Chapter 9 Summary in English and Dutch

Symbols and abbreviations

Bibliography

Acknowledgements 



\section{INTRODUCTION}

\subsection{INTRODUCTION}

The demand for aircraft (AC) tires, including retreaded ones, increases following the constantly growing air passenger traffic $[1,2]$. India and China are projected to emerge as the leaders in the market of AC tires in the near future, surpassing the US aviation industry by 2022. Based on the aircraft type, the market of AC tires/retreaded tires is separated into commercial and military applications. The commercial segment had a share of $54.34 \%$ in 2018 due to the increasing number of air passenger traffic and the growing number of aircrafts manufactured worldwide [3]. The global AC tire market was valued at US\$1,260 million in 2017 [1], while the global retreaded tire market was valued at US\$ 692 million in 2018 [2].

The global market of AC tires/retreaded tires can be divided into bias ply and radial tires. Bias ply tires dominated the market with a share of $61 \%$ in 2018 . However, based on the forecast from 2019 till 2025, the share of radial tires is expected to grow. These tires offer low weight, but tend to be less retreadable than bias ply tires. The radial tires help to reduce operating cost, generate less heat, and last longer than bias ply tires [3].

The tires are one of the most complex engineered components of an aircraft. They need to withstand heavy loads at high velocities and extreme temperatures during service. Due to the severe operating conditions of AC tires, thus short service life, it is common that AC tires are retreaded. Tire retreading, also known as remolding or recapping, is the process to replace the worn tread with a new one. Retreading AC tires is a very economical and ecological solution.

Based on the process, the retreading market is segmented into pre-cure and moldcure technology. Pre-cure is a tire retreading process in which the tread of the worn-out tire is removed before a new already vulcanized tread with a new tread pattern is wrapped and spliced around the carcass by making use of a bonding agent known as a cushion gum. Thus, the process enables tire manufacturers to produce different sizes and treads at the same time. In the mold-cure tire process, the original tread is removed, and unvulcanized rubber is wrapped around the carcass and vulcanized. Due to the low investment costs, pre-cure dominated the global market in 2017 [2].

An AC tire life is measured by the number of flight cycles. For example, the average number of flight cycles of a set of tires on a Boeing 737 (B737) airplane is around 250 to 300 under ideal conditions. In reality, it is difficult to reach those numbers. Factors such as temperature, runway types, and operational conditions (speed, load, pressure) have a great 
influence on the durability of a tire. Table 1.1 depicts the AC tire consumption per type of aircraft by the Garuda Indonesia Airline (GIA) company in 2015 [4]. The B737 aircraft is the most frequently used type at GIA with a total number of 280 aircrafts. The B737 Next Generation (NG) main tires are to be changed when they reach 194 flight cycles or approximately every one month and six days. GIA consumed 25,450 tires with a value of US\$13.4 million in 2015. This demonstrates the benefit for the airline, if the service life of AC tires can be increased.

Table 1.1 Garuda Indonesia AC tire consumption in 2015 [4].

\begin{tabular}{|c|c|c|c|c|c|c|c|c|}
\hline $\begin{array}{c}\text { Aircraft type } \\
\text { \& position }\end{array}$ & $\begin{array}{c}\text { Tires/ } \\
\text { aircraft }\end{array}$ & $\begin{array}{l}\text { Number } \\
\text { of } \\
\text { aircrafts }\end{array}$ & $\begin{array}{c}\text { Aircraft } \\
\text { utilization } \\
\text { (flight } \\
\text { cycles/yr.) }\end{array}$ & $\begin{array}{c}\text { Rate } \\
\text { removal } \\
\text { of } \\
\text { tires/yr. }\end{array}$ & $\begin{array}{c}\text { Tire service } \\
\text { life (flight } \\
\text { cycles/tire) }\end{array}$ & $\begin{array}{l}\text { Cost/tire } \\
\text { (US\$) }\end{array}$ & $\begin{array}{c}\text { Total } \\
\text { tires/ } \\
\text { yr. }\end{array}$ & $\begin{array}{c}\text { Total } \\
\text { cost/yr. } \\
\text { (US\$) }\end{array}$ \\
\hline A330 Nose & 2 & \multirow[t]{2}{*}{26} & \multirow[t]{2}{*}{927} & 4 & 232 & 713 & 208 & 148,335 \\
\hline A330 Main & 8 & & & 3 & 309 & 1,115 & 624 & 695,885 \\
\hline A320 Nose & 2 & \multirow[t]{2}{*}{100} & \multirow[t]{2}{*}{2084} & 8 & 261 & 436 & 1600 & 697,680 \\
\hline A320 Main & 4 & & & 8 & 261 & 812 & 3200 & $2,597,600$ \\
\hline $\begin{array}{l}\text { B747-400 } \\
\text { Nose }\end{array}$ & 2 & \multirow[t]{2}{*}{3} & \multirow[t]{2}{*}{704} & 6 & 117 & 699.5 & 36 & 25,184 \\
\hline $\begin{array}{l}\text { B747-400 } \\
\text { Main }\end{array}$ & 16 & & & 6 & 117 & 699.5 & 288 & 201,470 \\
\hline $\begin{array}{l}\text { B737 classic } \\
\text { Nose }\end{array}$ & 2 & \multirow[t]{2}{*}{65} & \multirow[t]{2}{*}{1142} & 6 & 190 & 167 & 780 & 129,948 \\
\hline $\begin{array}{l}\text { B737 classic } \\
\text { Main }\end{array}$ & 4 & & & 6 & 190 & 385 & 1560 & 600,678 \\
\hline B737 NG Nose & 2 & \multirow[t]{2}{*}{215} & \multirow[t]{2}{*}{1935} & 11 & 176 & 167 & 4730 & 788,018 \\
\hline B737 NG Main & 4 & & & 10 & 194 & 478.5 & 8600 & $4,115,530$ \\
\hline ATR-72 Nose & 2 & \multirow[t]{2}{*}{70} & \multirow[t]{2}{*}{1635} & 6 & 273 & 281 & 840 & 236,334 \\
\hline ATR-72 Main & 4 & & & 5 & 327 & 953 & 1400 & $1,334,700$ \\
\hline $\begin{array}{l}\text { CRJ-1000 } \\
\text { Nose }\end{array}$ & 2 & \multirow[t]{2}{*}{18} & \multirow[t]{2}{*}{1818} & 12 & 152 & 810 & 432 & 349,942 \\
\hline $\begin{array}{l}\text { CRJ-1000 } \\
\text { Main }\end{array}$ & 4 & & & 9 & 202 & 1,336 & 648 & 865,858 \\
\hline B777 Nose & 2 & \multirow[t]{2}{*}{9} & \multirow[t]{2}{*}{799} & 4 & 200 & 810 & 72 & 58,324 \\
\hline B777 Main & 12 & & & 4 & 200 & 1,336 & 432 & 577,238 \\
\hline \multicolumn{7}{|c|}{ Total } & 25,450 & $13,432,723$ \\
\hline
\end{tabular}

In 2000, the Federal Aviation Administration (FAA) signed an executive order that required federal agencies to replace Original Equipment Manufacturer (OEM) tires with retreaded tires rather than new tires whenever possible. In the United States, almost all major airlines use retreaded tires and nearly $80 \%$ of all $A C$ tires in use nowadays are retreads. The FAA released strict and clear guidelines to support the use of retreaded AC tires in 2006. Most retreading plants throughout the world are franchised, licensed, or affiliated with the major suppliers. With the same standard procedure of testing, FAA's Technical Standard Order (TSO) TSO-C62, retreaded tires have demonstrated to provide the same reliability and performance as original equipment tires [5]. 


\subsection{BACKGROUND OF THE THESIS}

The development of $A C$ tire retreads aims at extending the service life. The tire can be retreaded up to 7 times with an average number of flight cycles of up to 200/retread. In terms of material improvement, compound formulation development provides a means to improve existing products and also to develop new products: Designing rubber formulations for cool running and higher heat resistance, thus decreased tread wear, for higher ultravioletprotection to improve the tire's ability to resist weather, for increased tire resistance to contaminated runways (oil, grease, ice, snow), and for lowered tire damage from cuts or tear; just a few examples of increasing the performance and service life of AC tire retreads. The properties of the tread rubbers are determined not only by the right composition of the formulation, but also by correct processing in terms of mixing conditions and addition sequence during mixing. Hence, proper selection of rubber ingredients and processing parameters are essential to balance the properties, i.e., low hysteresis, decreased treadwear, high stress-strain properties, and ease in processability.

\subsection{AIM OF THE THESIS}

The research covered in this thesis aimed at providing a comprehensive study related to the development of rubber processing and formulations for $\mathrm{AC}$ tire retreads. The objectives of the research are listed below:

1. To use a reliable method to optimize rubber mixing for different types of filler systems: Carbon Black (CB), Silica (SI) and a hybrid of Carbon Black/Silica (CB/SI) by identifying and optimizing the most significant factors to produce a rubber material with the desired properties and consistent quality for AC tire retreads.

2. To investigate the effect of different addition sequences of specific materials, in this case Zinc Oxide (ZnO) and DiPhenyl Guanidine (DPG), on the properties of a NR/BR blend reinforced by a hybrid $\mathrm{CB} / \mathrm{SI}$ filler system for $\mathrm{AC}$ tire retreads.

3. To select a suitable type of Butadiene Rubber (BR) to be blended with Natural Rubber (NR) to be used in AC tire retread formulations. It is essential to investigate the macroand micro-structure of the polymers and how these properties influence the final properties.

4. To select a suitable type of oligomeric resin to be used as an additive to improve processing, tackiness of the compounds as well as the final properties crucial for AC tire retreads.

5. To characterize the aging properties of $A C$ tire retreads to give valuable information on how these selected materials perform at high service temperatures. 


\subsection{STRUCTURE OF THE THESIS}

\section{Chapter 1: Introduction}

This chapter describes the demand of AC tires including retreaded ones, followed by the background of this project and the aim of the thesis.

\section{Chapter 2: Literature review}

Chapter 2 reviews the developments of AC tires/retreaded tires, the structure of these tires, the operation conditions and problems related to $\mathrm{AC}$ tire treads/retreads, the retreading process and the procedure for testing and certification. The types of rubbers and fillers, vulcanization systems and resins used in the formulations, as well as several examples of compounding of $\mathrm{AC}$ tire treads are reviewed based on patents.

\section{Chapter 3: Defining key factors for improving properties of aircraft tire retreads produced from carbon black-filled NR/BR blends}

$C B$ is the most common reinforcing filler used in $A C$ tire tread formulations. For $C B-$ reinforced NR/BR compounds, the processing parameters such as mixing temperature, time, rotor speed, addition sequence, and ram pressure are important factors that need to be controlled as they can influence both, processing as well as vulcanizate properties. In the present study, the type of $B R$, mixer set temperature, rotor speed, and filler mixing time were selected as the key factors, and investigated for CB-filled NR/BR blends. Properties such as Mooney Viscosity (MV), Payne Effect (PE), $\tan \delta$ at $100^{\circ} \mathrm{C}$ as an indication of hysteresis/heat build-up, and stress-strain properties were chosen as the responses. A complete Design of Experiment (DOE) procedure comprising a two-level full factorial setup for screening followed by an optimization process and confirmation runs are performed.

\section{Chapter 4: Optimization of the mixing parameters for NR/BR blends with a hybrid carbon black/silica and a silica filler system}

The following factors are investigated:

- Two types of BR: High-Cis BR (HC BR) and High-Cis Long-Chain Branched BR (HC LCB BR)

- Two types of fillers: a hybrid CB/SI and SI

- Silanization temperature

- Silanization time

in order to optimize the properties of AC tire retreads. 
Chapter 5: The effect of zinc oxide and diphenyl guanidine addition sequence on processing, mechanical and dynamic properties

Partial substitution of CB by SI needs to be accompanied by adjustment of the manufacturing process, as the rubber performance is not only determined by the right choice of the formulation ingredients, but also by correct processing such as optimum parameter settings and addition sequence. This study investigates the influence of the addition sequence of $\mathrm{ZnO}$ and DPG to $\mathrm{CB} / \mathrm{SI}$-filled NR/BR blends on the compound as well as mechanical and dynamic properties of the vulcanizates.

\section{Chapter 6: The influence of different types of butadiene rubber on processing, mechanical and dynamic properties of aircraft tire retreads}

The properties of compounds and vulcanizates are strongly affected by the polymer choice. The polymer architecture determines the performance of the final properties as well as the processability. Therefore, proper selection of the polymers to be blended with NR determines the best compromise in compound and vulcanizates properties. Four types of $B R$, namely High-Cis BR (HC BR), High-Cis Long-Chain Branched BR (HC LCB BR), Low-Cis starbranched BR (LC BR) and High-Vinyl (HV BR), are investigated to study their effect on processing, mechanical and dynamic properties in a hybrid CB/SI filler system.

\section{Chapter 7: Incorporation of resins for improving the properties of aircraft tire retreads}

This chapter focuses on the evaluation of the effect of oligomeric resins on processing, mechanical and dynamic properties of a NR/HC LCB BR blend with different filler systems, and their potential to improve the properties of AC tire retreads. Two types of resin, namely a modified Terpene Phenol (TP) and an aromatic hydrocarbon C9 resin (C9), are investigated concerning their effect on $\tan \delta$ at different temperatures, stress-strain properties and processability depending on the filler systems: CB, CB/SI and SI.

\section{Chapter 8: Aging properties of aircraft tire retreads}

This chapter investigates the aging properties of AC tire retread vulcanizates. A higher service temperature causes accelerated aging for most rubbers. This means that the generated heat in aviation tires accelerates the degradation of the mechanical and dynamic properties of the rubber. The amount of degradation by aging is dependent on a set of variables, e.g., exposure to oxygen/ozone, elevated temperatures, and time. Two series of rubber formulations are investigated to study the effect of aging on ultimate and dynamic properties: 
Series 1: vulcanizates of NR blended with different types of BR reinforced by a CB/SI filler system, and

Series 2: vulcanizates of NR blended with HC LCB BR and reinforced by different filler systems: $\mathrm{CB}, \mathrm{CB} / \mathrm{SI}$ and $\mathrm{SI}$.

Chapter 9: Summary

\subsection{REFERENCES}

1. Aircraft Tires: Worldwide Market Opportunity Analysis \& Forecast 2018-2026 Continually Rising Aircraft Orders from India \& China - ResearchAndMarkets.com, Available online: https://www.businesswire.com/news/home/20181130005156/en/ Aircraft-Tires-Worldwide-Market-Opportunity-Analysis-Forecast (accessed on 29 June 2020).

2. $\quad$ Aircraft Tire Retreading Market Research Report: Information by Process (Pre-Cure and Mold-Cure), Aircraft Type (Commercial and Military), and Region (North America, Europe, Asia-Pacific, and the Rest of the World) - Global Forecast till 2023, Available online: $\quad$ https://www. marketresearchfuture.com/reports/aircraft-tire-retreadingmarket-7594 (accessed on 29 June 2020).

3. Global Aircraft Tire Market Research Report: Information by Platform (Fixed-Wing and Rotary-Wing), Product Type (Bias Ply and Radial Ply), Aircraft Type (Commercial Aircraft, Military Aircraft and Business \& General Aviation Aircraft), End-User (OEM and Aftermarket) and Region (North America, Europe, Asia-Pacific, Middle East \& Africa and Latin America) - Forecast till 2025, Available online: https://www.marketresearchfuture.com/reports/aircraft-tire-market-2192 (accessed on 29 June 2020).

4. Sudaryo, A., Developing Aircraft Tire Retread in Indonesia, in Focus Group Discussion - PTM BPPT, Jakarta, Indonesia (2015).

5. Old Made New: Airplane Tire Retreading and Reuse, Available online: https://www.tirerecappers.com/tire-recappers-news/old-made-new-airplane-tireretreading-and-reuse/ (accessed on 29 June 2020). 


\section{LITERATURE REVIEW}

\subsection{RECENT DEVELOPMENTS IN AIRCRAFT TECHNOLOGY}

The aircraft industry is looking for technologies to continuously innovate its products, businesses and services. This industry aims to design more efficient and advanced aircrafts. Using new composite materials to make the aircraft lighter and more fuel-efficient, or redesigning aircrafts by imitating nature's best examples such as birds and sharks to design winglets/sharklets to improve aerodynamics are some examples of innovation in the development of the new generation of aircrafts [1]. The aviation industry contributes about $2 \%$ to the global $\mathrm{CO}_{2}$ emissions. The aircraft manufacturers are committed to improve fleet efficiency with at least $1.5 \%$ annually in order to achieve a carbon neutral growth from 2020 on and reducing net $\mathrm{CO}_{2}$ emissions by $50 \%$ till 2050 relative to 2005 [2]. Driven by fuel costs and environmental pressure, the trend towards electrical power systems for propulsion is also progressing in the aircraft industry [3]. Airbus initiated a zero-emissions project to bring the electric aircraft into reality under the 'E-Fan X project' to explore the possibilities to develop hybrid-electric propulsion.

A direct consequence of the rise of aircraft production is the demand for more robust and safe aircraft components [4]. One of these components is the main landing gear system. Aircraft landing gear systems are designed to support the entire weight of an aircraft on the ground and enables the aircraft for taxiing, landing, and takeoff [2]. These systems account for over $7 \%$ of the total weight of the aircraft and represent nearly $20 \%$ of the overall maintenance costs, which makes them a significant component of an efficient aircraft [4]. Designing aircraft tires is an immense effort. The tire manufacturer designs a tire according to the requirements of the customers and other regulations [5]. After the tires passed all mandatory tests and met the requirements of the aircraft manufacturer, the tires are brought into production. 


\subsection{CONSTRUCTION OF AIRCRAFT TIRES}

Based on the construction, there are two types of aircraft (AC) tires: radial and bias, the same as for passenger and truck tires. Figures 2.1 and 2.2 show the structures of bias ply and radial $\mathrm{AC}$ tires.

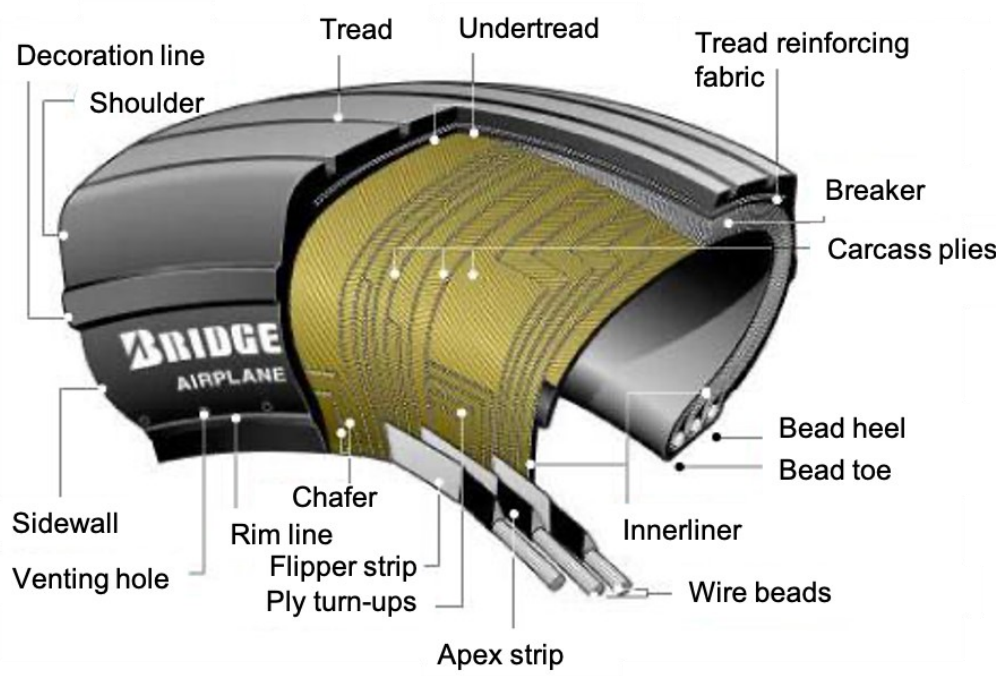

Figure 2.1 Structure of bias ply AC tire [6].

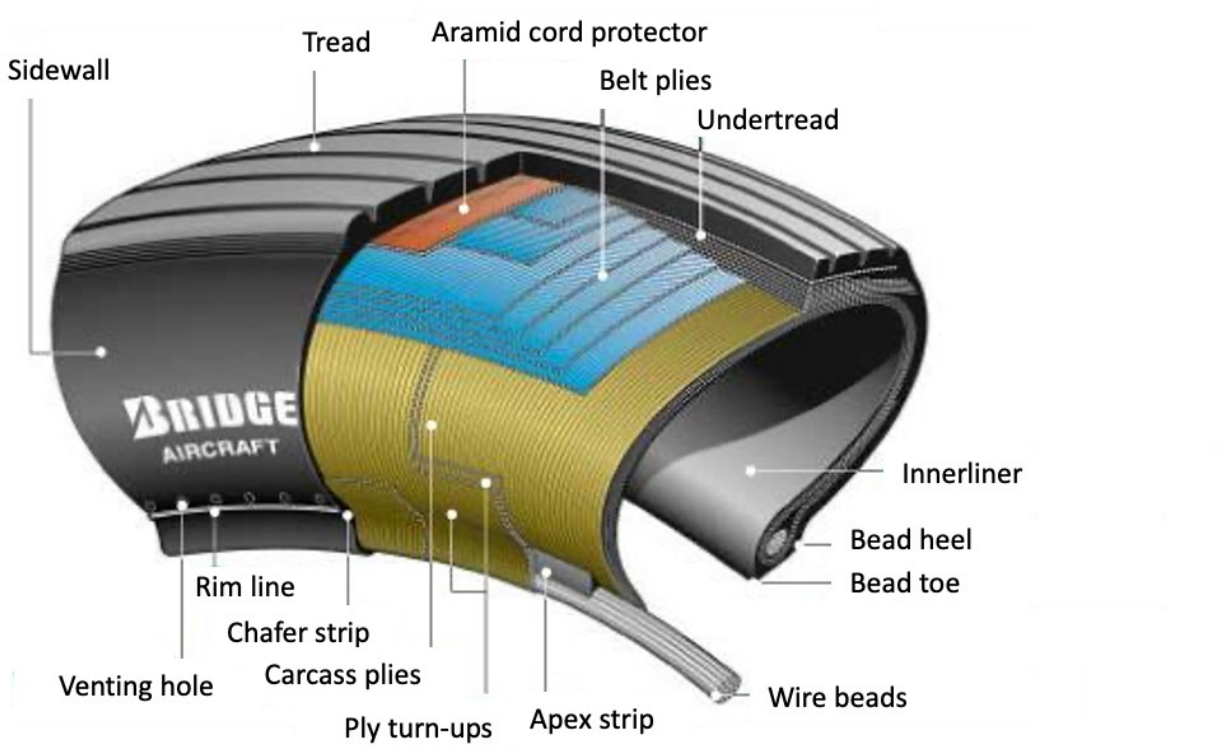

Figure 2.2 Structure of radial AC tire [6].

The difference lies in the direction of the cord plies. In bias tires, the carcass plies are arranged in the range of 30 to 60 degrees, while in radial tires, the cord plies are 90 degrees to the centerline or direction of rotation of the tire. The advantages of radial over bias tires are a lower heat build-up because no sidewall flex is transmitted to the tread, and greater comfort to users due to the flexibility and strength of the tire so that the tire absorbs considerable shock and impact. This type of tires helps in reducing operating cost, generates less heat, and lasts longer than bias tires. 


\subsection{OPERATING CONDITIONS OF AC TIRES INCLUDING RETREADED TIRES}

Dissimilar to tires used for cars, trucks or busses, AC tires experience their main impact during relatively short time intervals such as takeoff, landing and taxiing, and undergo comparatively severe conditions. AC tires are designed to support a substantially high load; however, the size of AC tires should be as small as possible as they should be light. Figure 2.3 shows the operating range of $\mathrm{AC}$ tires and other tire applications in terms of speed versus load. Most tires are designed to work at high speed with a relatively low load or vice versa. For example, racing cars can reach $400 \mathrm{~km} / \mathrm{h}$, but the load per tire is relatively small, and OffThe-Road (OTR) trucks operate at a low speed, but the load can reach up to 100 tons/tire. Meanwhile, AC tires used for narrow- or wide-body aircrafts are designed for a combination of large loads (20 to 30 tons/tire) and high speeds as fast as tires of racing cars: the speed can reach $380 \mathrm{~km} / \mathrm{h}$ [7].

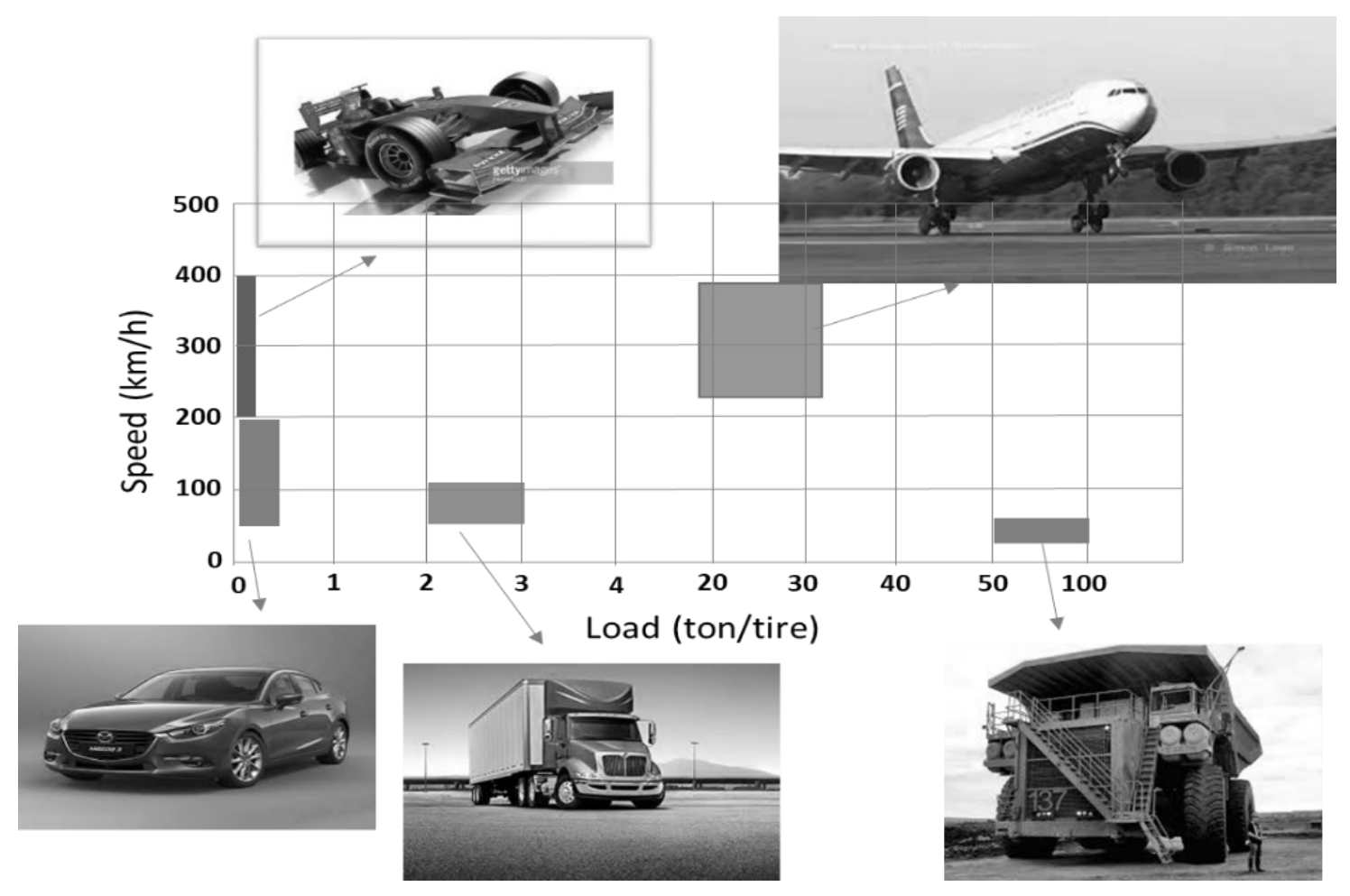

Figure 2.3 Tire operating range (load versus speed) of various vehicle applications [7].

AC tires operate at a relatively high speed coupled with a substantial load. Table 2.1 depicts the difference between AC tires and Passenger Car Tires (PCT) with the same size. From this table, it can be seen that the load on an AC tire can reach six times the load on PCT, with the velocity of the AC tire over two times faster than the velocity of the PCT. It is also clear that the operating pressure of $A C$ tires is almost six times higher compared to the one of PCT, and the deflection is $32 \%$, which is almost three times higher than the deflection of a PCT. 
Table 2.1 Similar size tire comparison of aircraft versus passenger [6].

\begin{tabular}{|l|c|c|}
\hline \multicolumn{1}{|c|}{ Parameter } & AC tire & PCT \\
\hline Size & $27 \times 7.75-15$ & P205/75R15 \\
\hline Diameter (in/cm) & $27.0 / 68.6$ & $27.1 / 68.8$ \\
\hline Section width (in/cm) & $7.75 / 19.7$ & $7.99 / 20.3$ \\
\hline Ply rating & 12 & - \\
\hline Load rating (lb./kg) & $9650 / 4377$ & $1598 / 724.8$ \\
\hline Pressure (Psi/MPa) & $200 / 1.38$ & $35 / 0.24$ \\
\hline Deflection (\%) & 32 & 11 \\
\hline Max speed (mph/km/h) & $225 / 362$ & $112 / 180$ \\
\hline Load/tire weight & 244 & 78 \\
\hline
\end{tabular}

During takeoff, the tire should be able to endure not only the load but also the forces produced by a high angular speed while resisting heat generation and wear. During landing, the $A C$ tire has to sustain heavy loads and impact forces as well as deceleration from a relatively high speed to stop the airplane during braking at a very short period of time. It undergoes sudden temperature rising. Heat generation in an AC tire is much higher than in any other tire. Figure 2.4 shows the effect of different wheel rotation conditions on the temperature distribution on the surface of an AC tire simulated by ANalysis SYStem (ANSYS) [1]. The initially static wheel, in Figure 2.4(a), recorded the highest temperature in its contact area at $307^{\circ} \mathrm{C}$. The small area surrounding the contact patch had a temperature of $260^{\circ} \mathrm{C}$, and the majority of the tread temperature was less than $165^{\circ} \mathrm{C}$. The static wheel had the highest temperatures, because the affected area was fully sliding with a speed equal to the aircraft's forward speed until the longitudinal friction force increased to spin the wheel and change its position. The hottest spot represents the most affected area, it became sticky and heavy wear occurred.

(a)

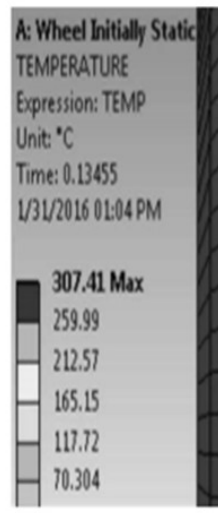

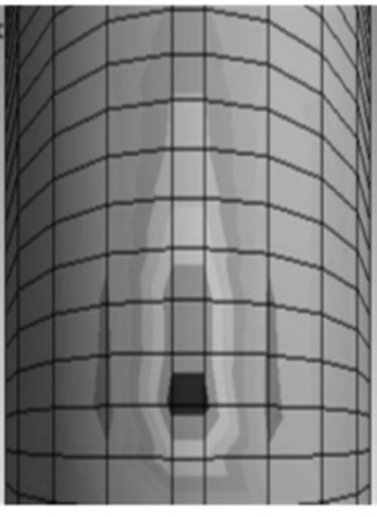

(b)

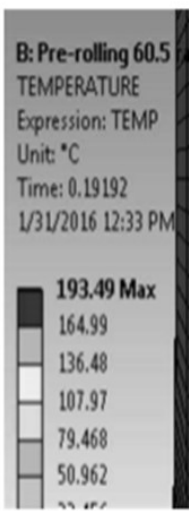

(c)

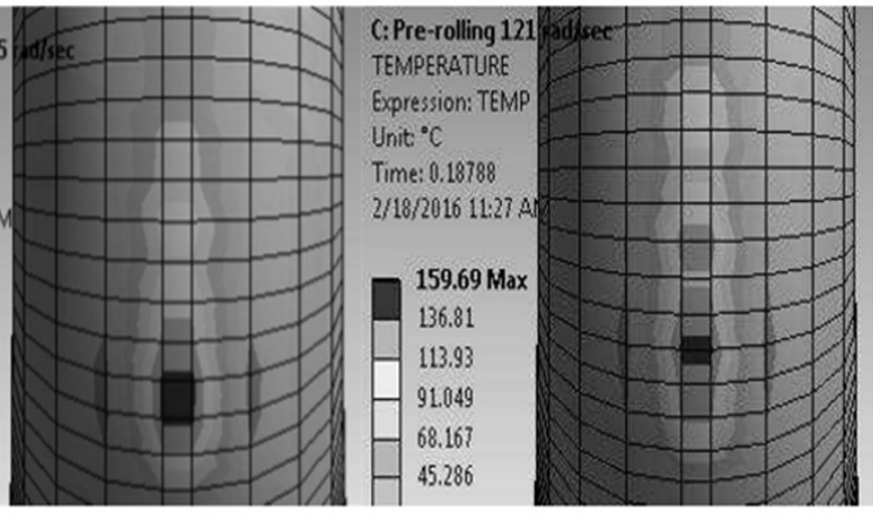

Figure 2.4 AC tire tread temperature profiles of a Boeing 747-400 at $0 \mathrm{rad} / \mathrm{sec}(\mathrm{a}) ; 60.5 \mathrm{rad} / \mathrm{sec}$ (b); $121 \mathrm{rad} / \mathrm{sec}(\mathrm{c})$ [8]. 
Figure 2.5 shows a comparison of tire wear for a typical landing ( $0 \mathrm{rad} / \mathrm{sec})$, for $50 \%$ $(60.5 \mathrm{rad} / \mathrm{sec})$ and $100 \%$ rolling $(121 \mathrm{rad} / \mathrm{sec})$. The highest wear of a typical landing occurs when the wheel touches the ground with zero rotational speed. When the wheel is initially rotated at $50 \%$ and $100 \%$ of its free-rolling speed, the total tire rubber wear is reduced by $37 \%$ and $51 \%$ respectively, which increases the tire's service life [9].

The AC tire's service life is measured by the number of flight cycles. For example, the ideal number of flight cycles of a Boeing 737 with one set of tires is around 250 to 300 . In reality, it is difficult for AC tires to reach those ideal numbers. Factors such as temperature, runway types, operational conditions (speed, load, pressure) have a large influence on the durability of the tire. Due to the necessity of frequent replacement, it is very common for $\mathrm{AC}$ tires to be retreaded.

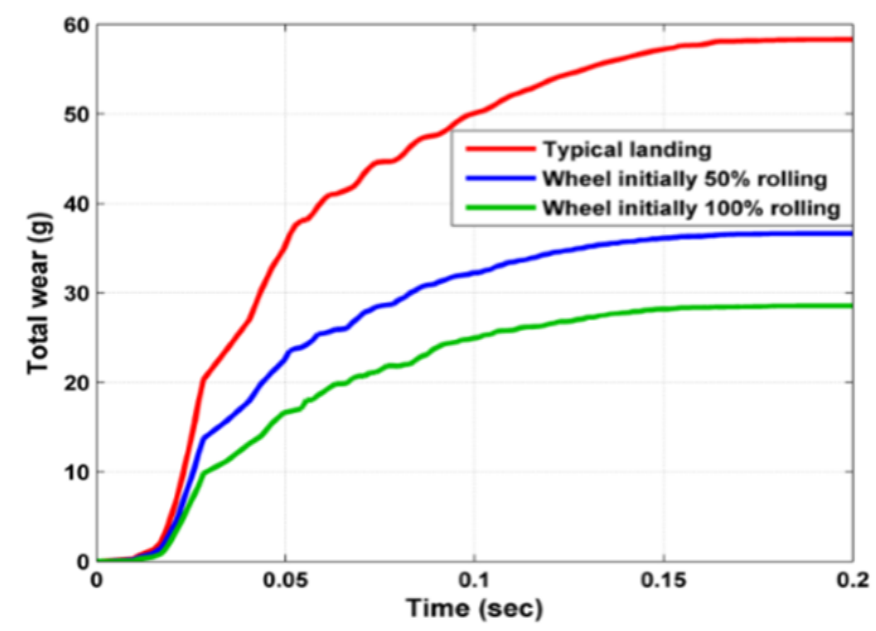

Figure 2.5 Total wear of a tire under initially static conditions, $50 \%$ and $100 \%$ pre-rotated wheel vs. time simulated by ANSYS for a Boeing 737-400 at a landing speed of $75.6 \mathrm{~m} / \mathrm{s}$ [9].

\subsection{RETREADING AC TIRES}

The term retreading refers to the method of restoring a worn tire for operation by renewing the tread rubber, or by renewing the tread rubber plus the reinforcing plies (bias) or protector ply (radial) [10]. During the retreading process, the remaining tread part is removed and replaced by a new one. Tire retreading is an effort to extend the service life of AC tires. Cross retreading is the practice of one manufacturer retreading tire casings of other tire manufactures, in addition to its own casings [10]. This practice is based upon customer agreements and manufacturer restrictions. The current practice of cross retreading applies only to bias casings, not to radial AC tires. The Federal Aviation Administration (FAA), European Aviation Safety Agency (EASA), Directorate General of Civil Aviation (DGCA) and regulatory organizations in other countries require retreading and/or repair of $A C$ tires to be performed only by a certified facility [11-13]. The certification is determined by the governing authority under which the operator is authorized. 
Figure 2.6 depicts the steps of the mold-cure aircraft tire retreading process. In this process, the original tread is removed, and raw rubber is wrapped around the tire. First of all, a worn tire is inspected visually as well as by the Non-Destructive Inspection (NDI) Shearography. These inspections ensure that the tire meets the retreading specifications. The accepted tire is then placed in the buffing machine, in which the remaining old tread is removed from the tire casing. The new fabric reinforcement/protector ply (if required) and the new tread are adhered to the casing to cover it perfectly. The tire is then loaded into the curing mold. Lastly, the cured tire undergoes balancing and final inspection using the NDI Shearography.

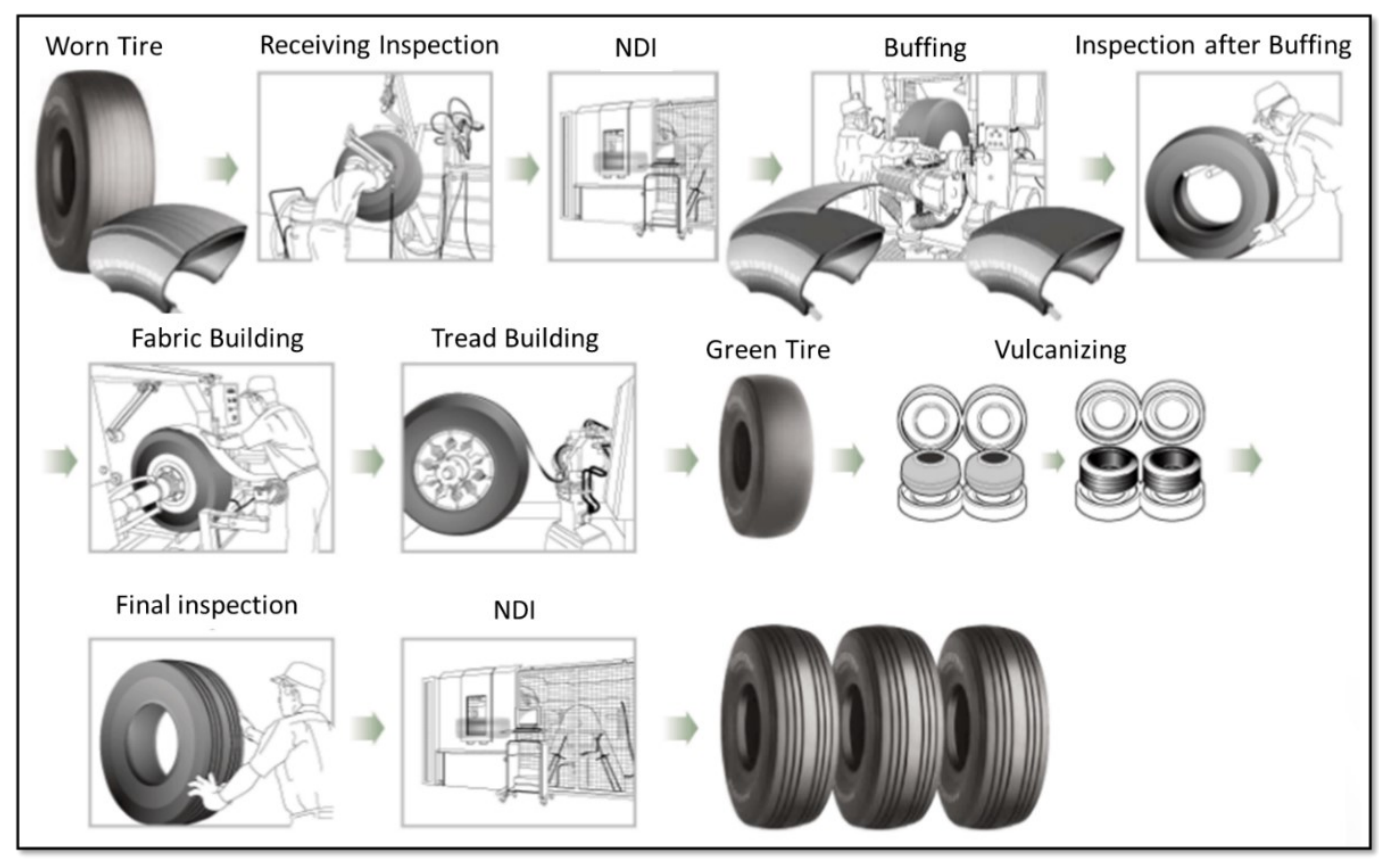

Figure 2.6 Tire retreading process [14].

The following list outlines some of the conditions which can disqualify a tire from being retreaded [15]:

1. Any injuries to the beads or in the bead area.

2. Weather or ozone cracking of tread or sidewall that results in exposed body cords.

3. Protruding bead wire or kinked bead.

4. Ply separation.

5. Internal damage or broken cords.

6. Flat spots and skid burn that have penetrated to the top carcass ply. Wearing the tire beyond the protector ply or reinforcing plies can leave insufficient interface rubber to allow retreading.

7. Punctures that penetrate the inner liner.

8. Excessive brake heat damage, such as experienced in a rejected takeoff.

9. Tires that are heavily oil contaminated.

10. Tires that have experienced a major pressure loss. 
The retreading qualification process refers to the Technical Standard Order TSO-C62e. Retreaded tires selected for use on a specific aircraft must demonstrate suitability through appropriate laboratory tests. The tire must withstand the dynamometer cycles as shown in Table 2.2 [16]: all AC tires including retreaded tires must withstand 58 dynamometer cycles as a demonstration of overall performance, plus 3 overload dynamometer cycles as a demonstration of the casing's capability under overload. The 58 dynamometer cycles consist of 50 takeoff and landing cycles and 8 taxi cycles. The overload cycles consist of 2 taxi cycles at 1.2 times rated load and 1 overload takeoff cycle starting at 1.5 times rated load. The dynamometer cycles can be done in any order. However, if the overload takeoff cycle is not run as the last one, the tire must not show detectable signs of deterioration after the cycle completion other than the normally expected tread surface abrasion as depicted in Figure 2.7.

Table 2.2 Dynamometer test cycles for AC tires [16].

\begin{tabular}{|l|c|c|c|c|}
\hline Test conditions & $\begin{array}{c}\text { Number of } \\
\text { Cycles } \\
\text { (Rated load) }\end{array}$ & $\begin{array}{c}\text { Number of } \\
\text { Cycles } \\
\text { (overload) }\end{array}$ & Rated load & Overload \\
\hline $\begin{array}{l}\text { Taxi during } \\
\text { takeoff/landing }\end{array}$ & 8 & 2 & $100 \%$ & $120 \%$ \\
\hline Takeoff \& landing & 50 & - & $100 \%$ & - \\
\hline Takeoff & - & 1 & - & $150 \%$ \\
\hline Total cycles & & 61 & - & - \\
\hline
\end{tabular}

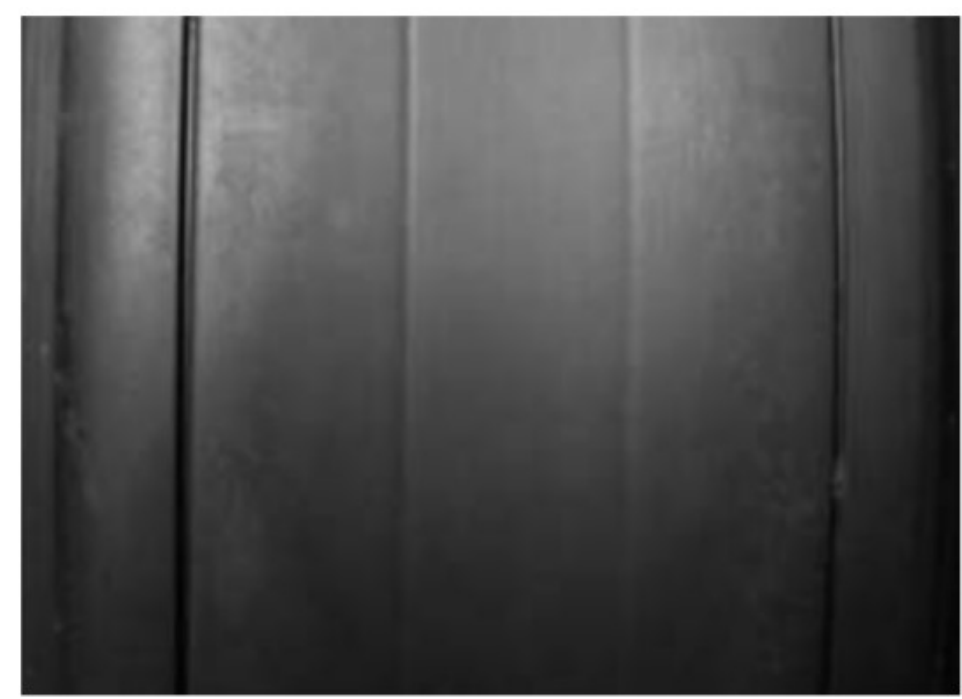

Figure 2.7 Normal wear on an AC tire tread [6]. 


\subsection{PROCEDURES AND REGULATIONS FOR RETREADING AC TIRES}

Retreading of AC tires can only be done in a certified facility. A certified facility can apply one of certification processes below:

1. Type Certificate (TC) or Supplement Type Certificate (STC) is a type of certificate which is issued by a regulatory authority such as the Federal Aviation Association (FAA, USA), European Aviation Safety Agency (EASA, Europe), Civil Aviation Safety Authority (CASA, Australia), Directorate General Civil Aviation (DGCA, Indonesia) or similar regulatory organizations in other countries. The TC is issued to signify the airworthiness of the approved design or "type" of an aircraft part to be manufactured $[17,18]$. The STC defines a product design change, and states how the modification affects the existing type design.

2. Technical Standard Order (TSO) is a minimum performance standard for specified materials, parts, and appliances used on civil aircrafts. Applicant for this type of certificate can be a manufacturer or any person. Receiving a TSO authorization means that the applicant is authorized to manufacture the article based on the TSO standard, but it does not include the approval to install and use the article in the aircraft [17].

3. Part Manufacture Approval (PMA) is an approval granted by a regulatory authority to a manufacturer of aircraft parts [17].

4. Maintenance organizations approval is an approval for organizations to carry out maintenance under both, the Civil Aviation Safety Regulations (CASR) 1998 and Civil Aviation Regulations (CAR) 1988 (CAR 30 maintenance) [19]. Applicants for this type of certificate are for example the Garuda Maintenance Facility (GMF) AeroAsia in Indonesia, SAMCO Aircraft Maintenance in The Netherlands, Heston Maintenance Repair and Overhaul in Australia (Heston MRO).

\subsection{PROBLEMS RELATED TO AC TIRE TREADS/RETREADS}

The tread is the outer part of the tire and in direct contact with the ground. Due to the extreme conditions AC tires experience during operation, their treads must be designed to resist high abrasion, excessive heat build-up and to provide excellent traction while braking. Figure 2.8 depicts the physical properties of AC tire treads, for which improvements are desirable. The properties in focus for improvements are hysteresis (rebound or $\tan \delta$ at $100^{\circ} \mathrm{C}$ ), tread wear (abrasion resistance), stiffness (tensile and dynamic shear modulus), tear resistance, and processability (e.g. smooth rubber extrudates) [20]. 


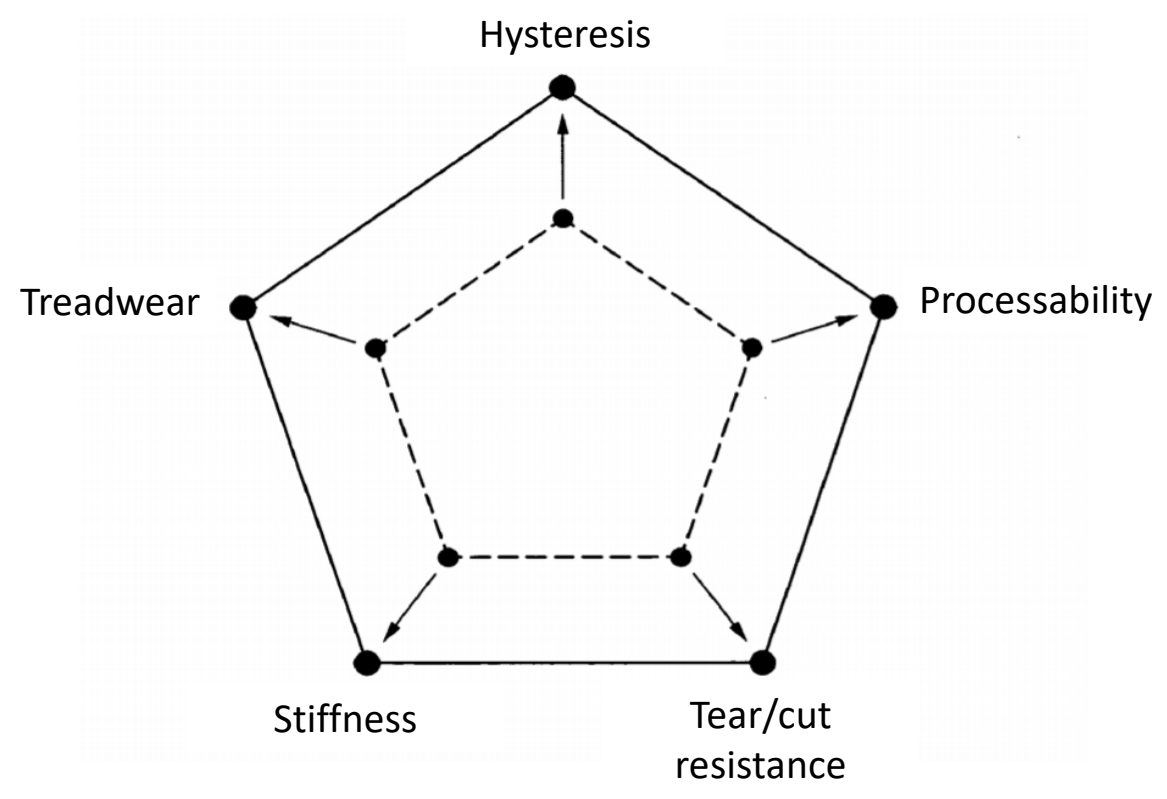

Figure 2.8 Crucial properties of AC tire treads [20].

During operation, AC tire treads are subjected to continuous deformations under substantial load and high frequencies. This combination of severe operation conditions leads to a high generation of heat. Heat generation is a dynamic property, in which the mechanical energy, which is applied to a material, is converted into heat.

Heat generation leads to a higher temperature of AC tires: heat build-up. It is one of the critical parameters in $A C$ tire treads that need to be taken into account in their development. Depending on the mode of deformation, the modulus can be represented by $\mathrm{G}^{\prime}$, $\mathrm{G}^{\prime}$, and $\mathrm{G}^{*}$, when the deformation is in shear. $\mathrm{G}^{\prime}$ is the "storage shear modulus"; $\mathrm{G}^{\text {" the "loss }}$ or viscous shear modulus"; and G* the "complex modulus in shear". The symbol E is used when the mode of deformation is compression or elongation. The viscous part is the component responsible for mechanical energy loss. The correlations are given in Equations $2.1-2.3[21,22]:$

$$
\begin{aligned}
& \left|G^{*}\right|=\sqrt{G^{\prime 2}+G^{\prime 2}} \\
& \tan \delta=G^{\prime \prime} / G^{\prime} \\
& E^{*}=2(1+v) G^{*} \sim 3 G^{*}
\end{aligned}
$$

$\delta$ is called the phase angle and $v$ is the Poisson ratio accounting for volume change on deformation. As the latter is commonly practically absent for rubbery materials, is $v \sim 0.5$ [22]. The tangent of the phase angle: $\tan \delta$, as a function of temperature can be used as an indicator of tire performance [21, 23-25], as shown in Figure 2.9. At sufficiently low temperature (or high frequency), the natural movements of polymer segments are so slow or frozen, that they cannot follow the mechanically imposed motions anymore. The polymer behaves as a glass. At the transition from glassy to rubbery state, either by raising the 
temperature or decreasing the frequency, excessive friction happens inside the polymer so that $\tan \delta$ reaches a maximum. Consequently, the $\tan \delta$ peak can be used as an indication of the glass transition temperature $(\mathrm{Tg})$ and abrasion resistance, the latter related to the ability of the polymer to absorb deformation and consequent energy absorption without damage. At temperatures above $\mathrm{Tg}$ or lower frequencies, $\tan \delta$ decreases again. Tan $\delta$ in the transition region from glassy to rubbery can be used as an indication of low temperature properties such as ice traction. In this zone, several relaxation processes occur, including long polymer chain relaxations, rearrangement of short segments including branching, and reorientation of pendant side groups [21]. Elastomers are generally used in the rubbery state at a temperature above the transition zone, in the plateau region. In the rubbery region, the chains and chain segments slip past each other. In the terminal region at even higher temperature or lower frequencies, the polymers behave as (highly viscous) liquids, and movement of polymer chains past each other occurs. The deformation in the terminal region is irrecoverable [26].

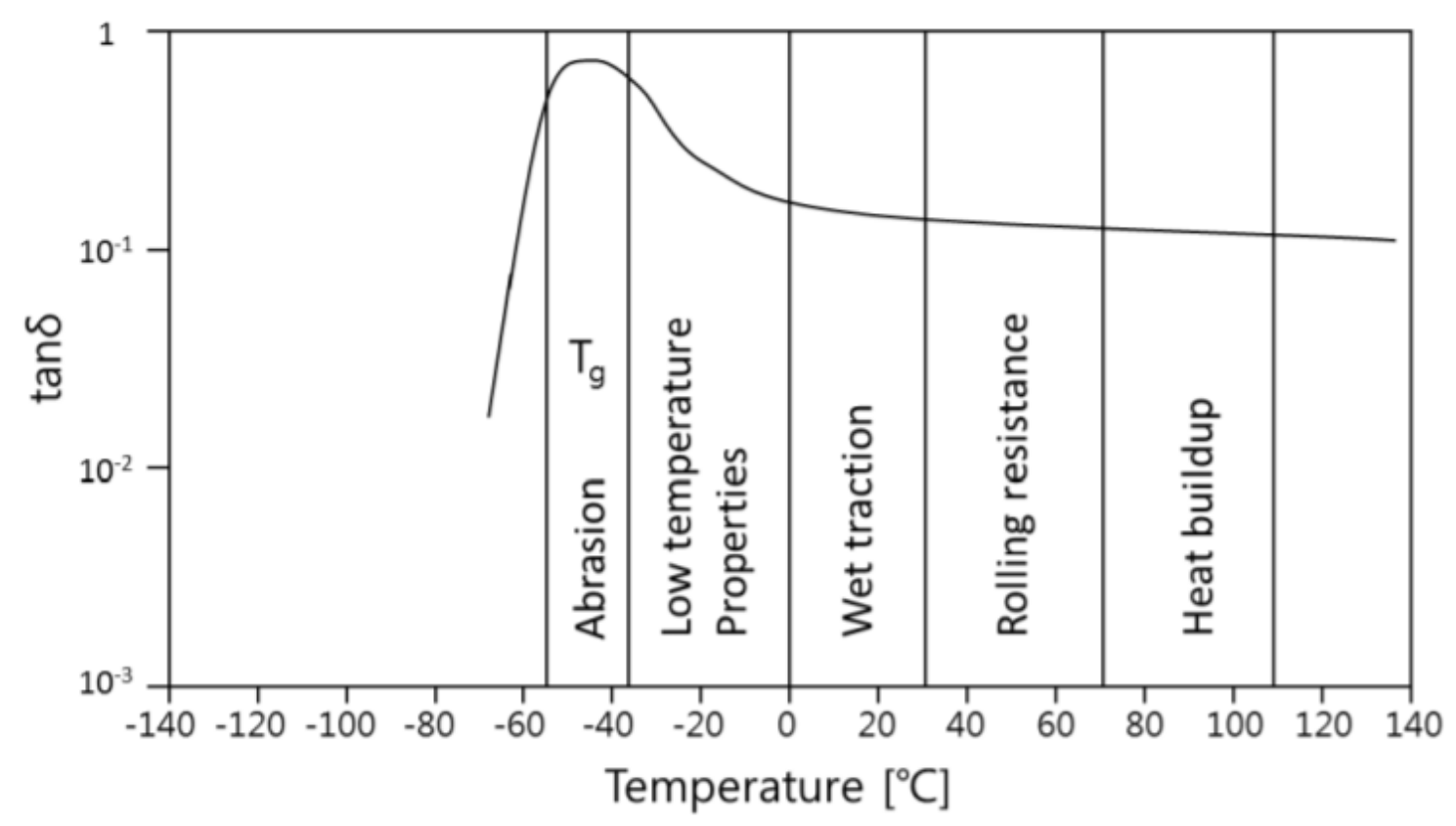

Figure 2.9 Tan $\delta$ as a function of temperature as tire performance indicator [24].

A high temperature increase has directly physical consequences, i.e. a decrease of tensile strength: see Figure 2.10, accelerated treadwear, decreased static and elastic moduli in filled vulcanizates. A more severe consequence of high peak temperatures is a thermochemical effect: Depending on the type of polymers, the presence of oxygen in combination with a high temperature leads to oxidation, which may cause chain scission and softening of Natural Rubber (NR). Alternatively, these may also lead to hardening due to the formation of additional crosslinks as in Butadiene Rubber (BR) or Styrene-Butadiene Rubber (SBR) [21, 27, 28]. In severe cases, thermal degradation of rubber can lead to explosive rupture (blow-out). 


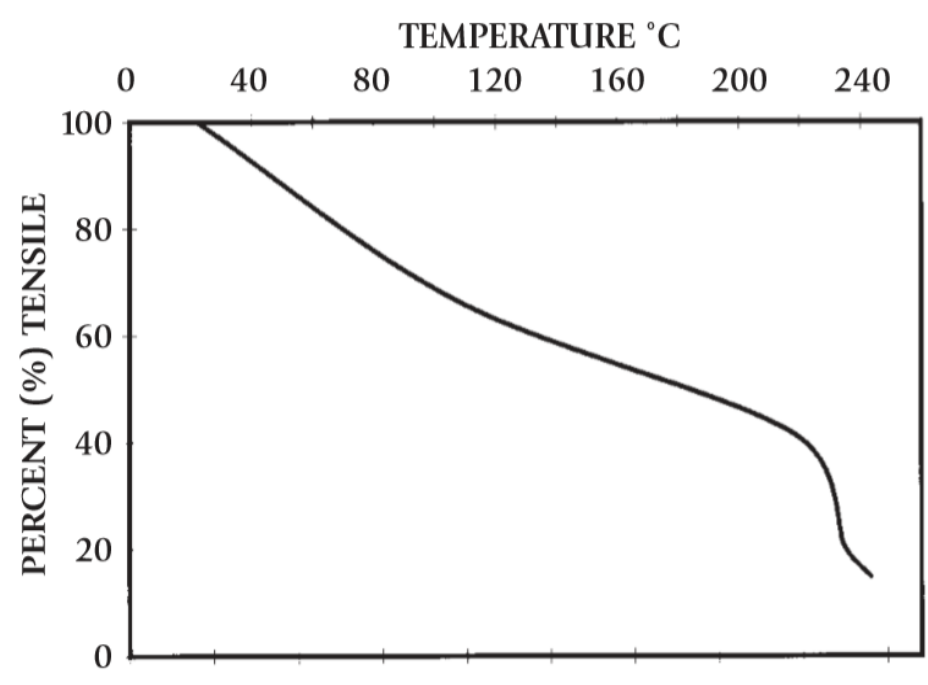

Figure 2.10 The effect of temperature on the reduction of tensile strength [29].

At a very high localized temperature, smearing of rubber might occur. The smearing increases as the load and the sliding velocity increase. Even though rubbers do not have an apparent melting point, smearing can occur under tire sliding conditions, as proven by black deposits left on the road/runway. Figure 2.11 shows the effect of surface temperature of an abrasive plate on the loss of rubber after 100 revolutions for NR and Emulsion Styrene Butadiene Rubber (ESBR) tread compounds [30]. It can be seen from the graph that the loss of NR begins to rise rapidly at $300^{\circ} \mathrm{F}\left(150^{\circ} \mathrm{C}\right)$, while ESBR shows a gradual loss even up to $400^{\circ} \mathrm{F}\left(204^{\circ} \mathrm{C}\right)$. The abrasive plate was heavily smeared by NR at $320^{\circ} \mathrm{F}\left(160^{\circ} \mathrm{C}\right)$.

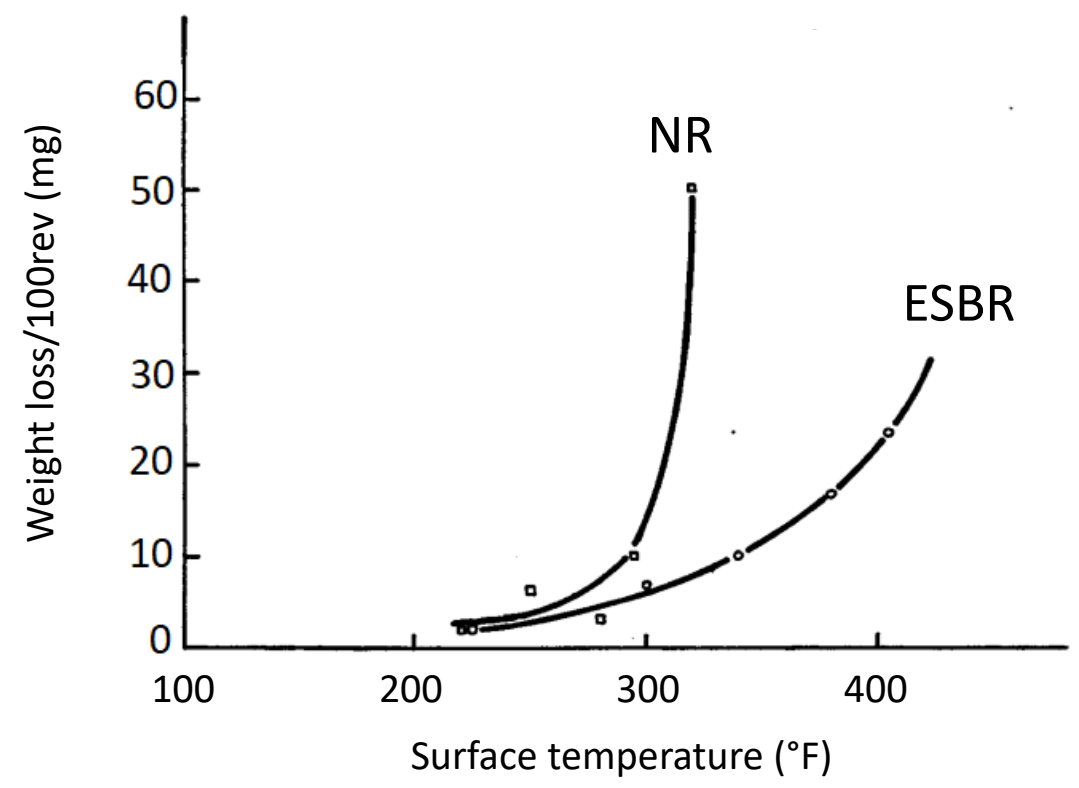

Figure 2.11 Weight loss of rubber as a function of surface temperature [30]. 


\subsection{TYPES OF RUBBER}

\subsubsection{NATURAL RUBBER}

Eng et al. reported that Natural Rubber (NR) molecules consist of an $\omega$-terminal group, two or three trans-1,4 isoprene units, $10000-30000$ cis-1,4 isoprene units, and an $\alpha$-terminal moiety as shown in Figure 2.12 [31]. The $\alpha$-terminal moiety is arranged from mono- or diphosphate groups linked with phospholipids $[32,33]$. The $\omega$-terminal moiety was postulated to be a modified dimethylallyl unit linked with a functional group to create crosslinks through intermolecular hydrogen bonding [34].

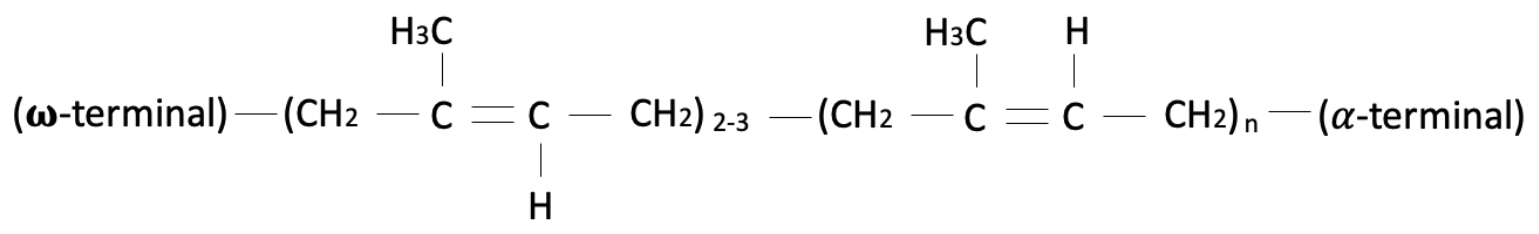

Figure 2.12 Structure of NR [31].

NR from Hevea brasiliensis latex consists for $30-45 \mathrm{wt} \%$ of cis-1,4 polyisoprene, 3 $5 \mathrm{wt} \%$ of non-rubber constituents, with the remaining part being water. The non-rubber constituents comprise proteins, amino acids, carbohydrates, phospholipids, amines, nucleic acids, as well as inorganic or mineral components [35]. Amnuaypornsri et al. [36] proposed that the non-rubber constituents composed of proteins and phospholipids are presumed to be major constituents to form temporary network nodes by interaction with rubber chains at both chain ends as shown in Figure 2.13.

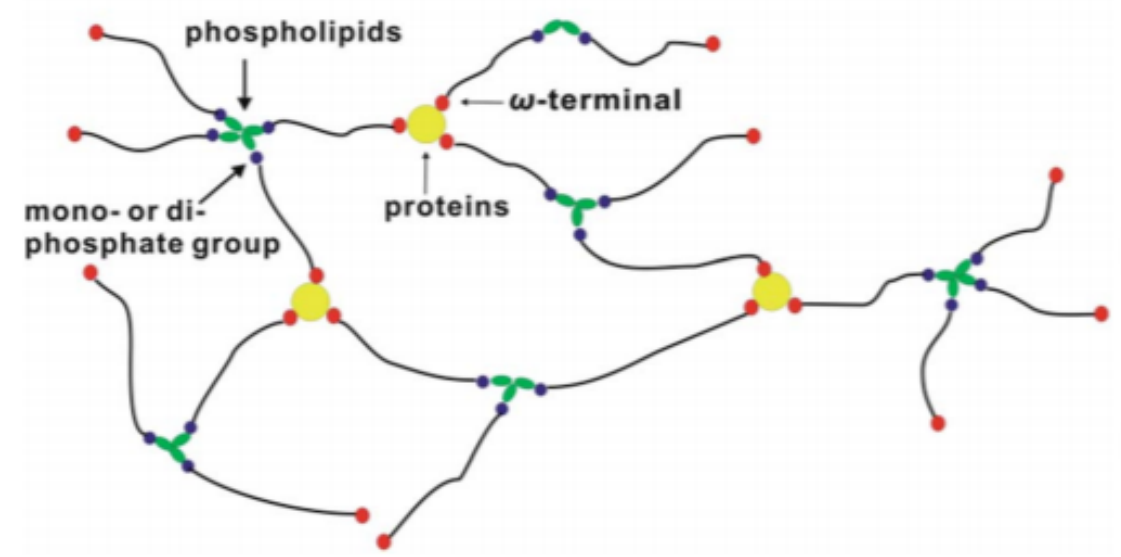

Figure 2.13 Proposed structure of the temporary network in NR [36].

The non-rubber constituents, particularly proteins and phospholipids, are natural accelerators and cause shorter cure times and higher crosslink densities compared to deproteinized NR [37]. Proteins and phospholipids are presumed to form a naturally occurring network, and the network plays a significant role in strain-induced crystallization [35]. This phenomenon results in high reinforcement appearing as a strong increase of the modulus on stretching, as well as a high tensile strength [38]. Figure 2.14 shows the stress strain curves 
of NR and SBR. Stretching a piece of NR at room temperature turns the amorphous rubber into a semi crystalline material. The strain-induced crystallization in NR leads to an upturn at high strains and enhances the ultimate properties, while SBR does not show this phenomenon [39].

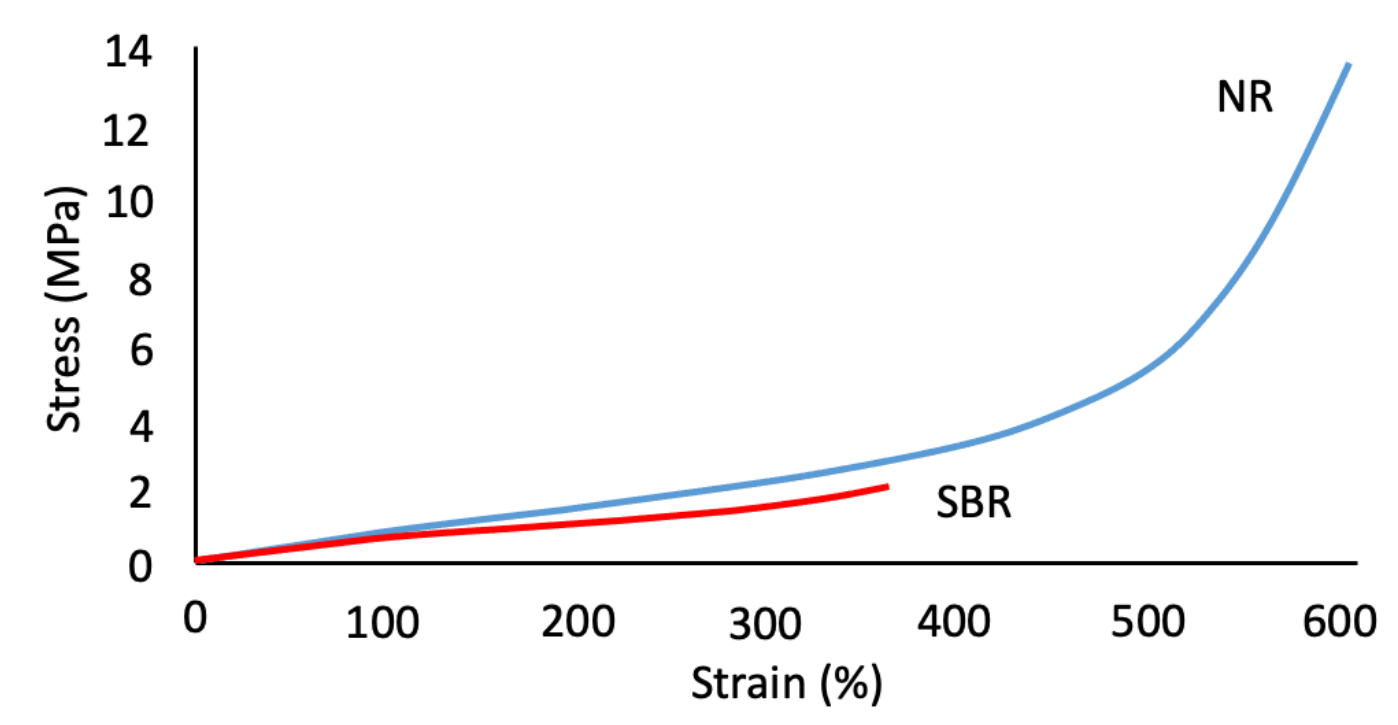

Figure 2.14 Stress-strain curves of NR and SBR [39].

NR also exhibits high tear strength and tack for tire building, and low hysteresis under dynamically loaded conditions [40]. The high strength of NR has a beneficial effect on supporting the substantial load when used as aircraft tires. An excellent tear strength provides aircraft tires more resistance to cutting, chipping or chunking (pieces of the tread rubber are torn from the tire). Lower hysteresis reduces the heat build-up and results in a lower service temperature, in this way enhancing durability [20]. The problems of NR are its tendency to thermal degradation and the limited flexibility at very low temperatures, as it has a higher glass transition temperature $(\mathrm{Tg})$ compared to high-cis BR. Hence, blending of NR with a polymer with a lower $\mathrm{Tg}$ is usually done to prevent a rapid change of properties with temperature during operation.

The concentration of NR in an elastomer blend for treads depends on the specific application of the tires. According to the usage, there are two main types of tires: those for commercial vehicles and those for consumer applications. Figure 2.15 depicts the range of NR contents for each class of tires. It can be seen that for consumer tires such as for Radial Light Truck (RLT) and passenger cars, a lower concentration of NR is used than for tires used for commercial vehicles: Radial Medium Trucks (RMT), Off-The-Road (OTR), and aircrafts. 


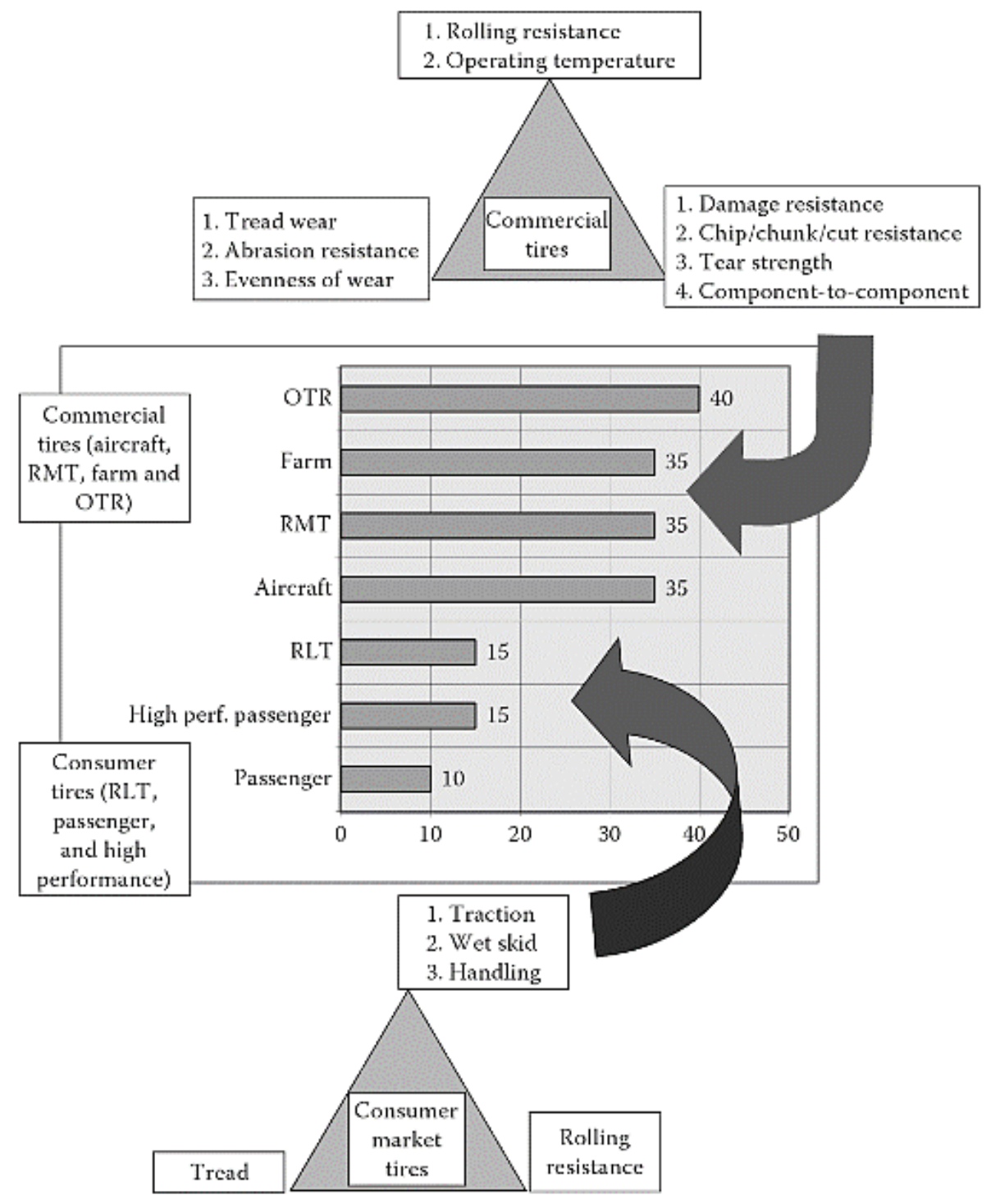

Figure 2.15 NR content as percentage of total tire weight and relationship to the tire performance triangle [41].

Table 2.3 describes the level of NR in several components of a tire, which is reported by The Malaysian Natural Rubber Producers Association and Smithers Scientific Services [41].

Table 2.3 NR content (phr) in selected types of tires and tire components [41].

\begin{tabular}{|c|c|c|c|}
\hline Component & $\begin{array}{c}\text { Automobile } \\
\text { Tires }\end{array}$ & $\begin{array}{c}\text { Radial } \\
\text { Medium } \\
\text { Truck Tires }\end{array}$ & $\begin{array}{c}\text { Bias Truck } \\
\text { Tires }\end{array}$ \\
\hline Non-silica tread & 45 & 90 & 50 \\
\hline Base & 70 & 100 & - \\
\hline Sidewall & 45 & 55 & 40 \\
\hline Wire Coat & 100 & 100 & 70 \\
\hline
\end{tabular}


The range of NR contents in tire treads can vary from 10 to 100 parts per hundred rubber (phr) depending on the desired final properties. For example, up to $100 \mathrm{phr}$ of NR can be used for making commercial truck tire treads when hysteresis and tear strength are the most important features. Other tires need blending of NR with BR for resistance to abrasion and fatigue or blending with SBR for traction and stiffness [41].

Tables 2.4 and 2.5 show the classification of the NR grades Ribbed Smoked Sheet (RSS) and Technical Specified Rubber (TSR). There is a correlation between types of NR and their properties: RSS is superior to TSR regarding physical properties such as tensile strength. The treatments of latex to produce dry rubber causes differences in the final characteristics. For example, TSR from latex (TSR L) or the first grade of RSS (RSS 1X) are commonly used in the production of transparent rubber articles. If the mixing capacity is limited and batch to batch uniformity is desired, a Constant Viscosity (CV) rubber is the best choice. If a high flex resistance is wanted, a TSR 5 would be the most convenient one [41].

Table 2.4 Classification of RSS rubber [41].

\begin{tabular}{|c|c|c|c|c|c|c|l|}
\hline RSS & $\begin{array}{c}\text { Rubber } \\
\text { mildew }\end{array}$ & $\begin{array}{c}\text { Wrapping } \\
\text { mildew }\end{array}$ & $\begin{array}{c}\text { Opaque } \\
\text { spots }\end{array}$ & $\begin{array}{c}\text { Over- } \\
\text { smoked } \\
\text { spots }\end{array}$ & $\begin{array}{c}\text { Oxidized } \\
\text { spots }\end{array}$ & $\begin{array}{c}\text { Burned } \\
\text { sheets }\end{array}$ & Comments \\
\hline $1 \mathrm{X}$ & No & No & No & No & No & No & $\begin{array}{l}\text { Dry, clean, no } \\
\text { blemish }\end{array}$ \\
\hline 1 & $\begin{array}{c}\text { Very } \\
\text { slightly }\end{array}$ & $\begin{array}{c}\text { Very } \\
\text { slightly }\end{array}$ & No & No & No & No & $\begin{array}{l}\text { Dry, clean, no } \\
\text { blemish }\end{array}$ \\
\hline 2 & Slight & Slight & No & No & No & No & $\begin{array}{l}\text { No sand or } \\
\text { foreign matter }\end{array}$ \\
\hline 3 & Slight & Slight & Slight & No & No & No & $\begin{array}{l}\text { No sand or } \\
\text { foreign matter }\end{array}$ \\
\hline 4 & Slight & Slight & Slight & Slight & No & No & $\begin{array}{l}\text { No sand or } \\
\text { foreign matter }\end{array}$ \\
\hline 5 & Slight & Slight & Slight & Slight & N/A & No & N/A \\
\hline
\end{tabular}


Table 2.5 Specifications for TSR defined in ISO [41].

\begin{tabular}{|l|c|c|c|c|c|c|}
\hline \multirow{2}{*}{ Property } & \multicolumn{7}{c|}{ Grade } \\
\cline { 2 - 7 } & TSR CV & TSR L & TSR 5 & TSR 10 & TSR 20 & TSR 50 \\
\hline Dirt content, max, wt\% & 0.05 & 0.05 & 0.05 & 0.1 & 0.2 & 0.5 \\
\hline Ash content, max, wt\% & 0.6 & 0.6 & 0.5 & 0.75 & 1 & 1.5 \\
\hline Nitrogen content, max, wt\% & 0.6 & 0.6 & 0.5 & 0.6 & 0.6 & 0.6 \\
\hline Volatile matter, max, wt\% & 0.8 & 0.8 & 0.8 & 0.8 & 0.8 & 0.8 \\
\hline Initial Wallace plasticity, Po & 30 & 30 & 30 & 30 & 30 & \\
\hline $\begin{array}{l}\text { Plasticity retention index } \\
\text { (min) }\end{array}$ & 60 & 60 & 60 & 50 & 40 & 30 \\
\hline Color, max Lovibon units & & 6 & & & & \\
\hline Mooney viscosity & $60+5$ & & & & & \\
\hline
\end{tabular}

\subsubsection{BUTADIENE RUBBER}

Butadiene Rubber (BR) is a polymer which consists of only one type of monomer: 1,3 butadiene. The latter can form three different types of linkages, namely cis-1,4 (m), trans 1,4 (n) and 1,2-vinyl (o) as seen in Figure 2.16.

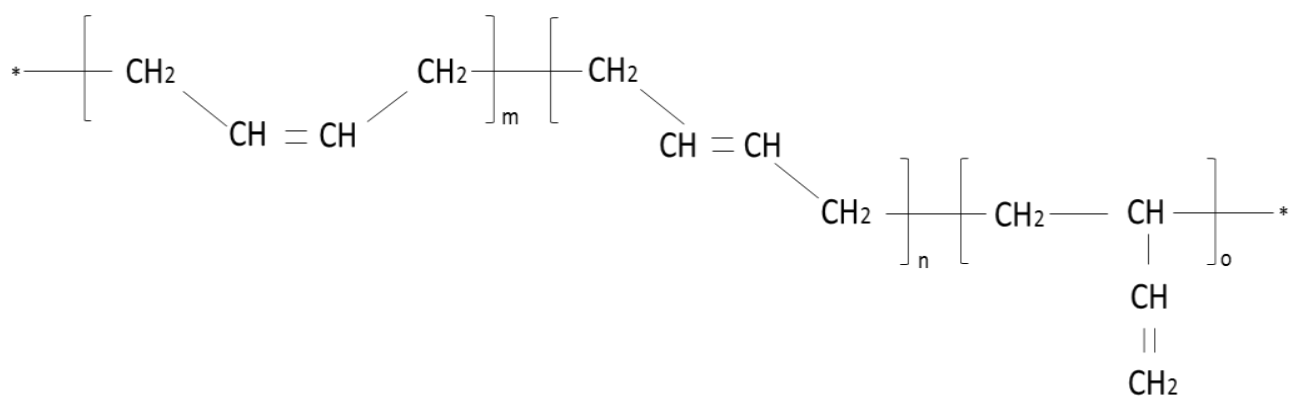

Figure 2.16 Chemical structure of BR [38].

Nowadays, most BRs are made by a solution process, using either a transition metal complex from Titanium (Ti), Nickel (Ni), or Cobalt (Co), or an alkyl metal like butyl-lithium, as a catalyst. The usage of Ziegler-Natta transition metals and alkyl-lithium can produce very distinct products. Transition metal catalysts produce a high-cis configuration BR, while BR made by using butyl-lithium generates a polymer with a medium to high-vinyl content. A highcis BR typically has a cis content higher than 95\%. Table 2.6 shows typical compositions of different types of BR. 
Table 2.6 Typical compositions of various BR types [38].

\begin{tabular}{|l|c|c|c|}
\hline Catalyst used & Cis (\%) & Trans (\%) & Vinyl (\%) \\
\hline Nickel (Ni) & 98 & 1 & 1 \\
\hline Neodymium (Nd) & 97 & 2 & 1 \\
\hline Cobalt (Co) & 97 & 2 & 1 \\
\hline Titanium (Ti) & 92 & 4 & 4 \\
\hline Butyl-lithium (Li) & 36 & 54 & 10 \\
\hline
\end{tabular}

It is imperative to select a proper type of BR for a particular application since the type of BR will determine the properties of a final product. High-cis BR imparts excellent abrasion resistance, low rolling resistance but poor wet skid resistance. It also features better "green strength" which is important in the tire building process, and it increases cut growth resistance which is one of the important aspects of tire performance [42]. High-vinyl BR provides good wet skid resistance and low rolling resistance, but abrasion resistance is poor. The balance of wet skid, rolling and abrasion resistance can be achieved by using a medium-vinyl BR [43].

The problem related to compounding with a major portion of high-cis Nd-BR is poor processability, and the incorporation of the filler into a compound containing a highly linear $\mathrm{Nd}-\mathrm{BR}$ is also difficult.

\subsection{FILLERS}

Rubbers in general cannot be used alone to produce end-products, because they do not have sufficient strength. Hence, fillers are added to rubber compounds to improve properties such as tensile and tear strength as well as abrasion resistance of the vulcanizates. Fillers are divided into three categories according to their reinforcing effect: non-reinforcing, semi-reinforcing and reinforcing. The key parameters influencing the reinforcement efficiency of fillers are:

\section{Primary particle size}

Figure 2.17 depicts the classification of fillers based on their primary particle size. Precipitated silica has a very small particle size below 0.05 micron, while Carbon Black (CB) has particles sizes in the range of 0.01 to 0.5 micron. Precipitated silica and CB with a particle size below 0.1 micron are classified as reinforcing fillers and can significantly improve rubber properties. Semi- and non-reinforcing fillers have particle sizes in the range of 0.1 to 5 micron and 5 to 100 microns, respectively. Fillers with a particle size larger than 10 micron are generally avoided, because they cause a localized stress concentration leading to elastomer rupture on flexing or stretching [44]. 


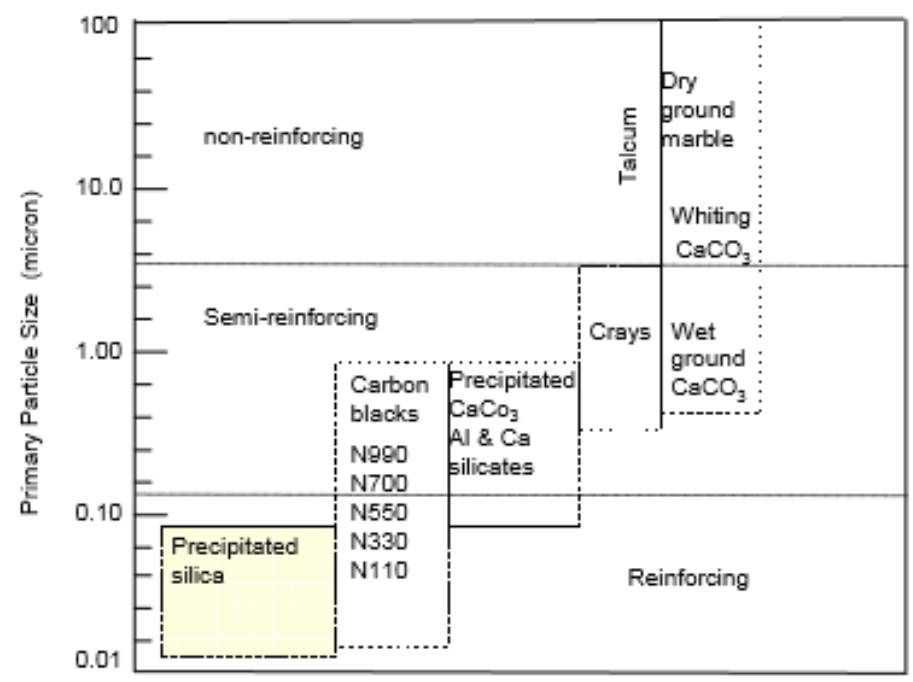

Figure 2.17 Filler classification based on particle size [44]

\section{Specific surface area}

The specific surface area of fillers can be measured by different adsorption methods. For silica, it can be determined by using three different methods: Nitrogen Surface Area (NSA), Statistical Thickness Surface Area (STSA) and Cetyl-Trimethyl-Ammonium Bromide (CTAB) adsorption. The first two measurements are based on the theory of Brunauer-Emmet-Teller (BET). Compared to CTAB and STSA, which measure the external surface of filler particles, the NSA method measures the outer and inner surface of a filler, thus provides the overall surface area. Currently, the CTAB method is most relevant for silica; this method was withdrawn for the measurement of CB surface area according to ASTM D3765 because of poor testing precision and labor-intensity [45]. Specific surface area increases with decrease of particle size.

\section{Filler structure}

Fillers seldomly appear as individual primary particles; they form in general clusters in the form of aggregates or agglomerates. CB can cluster through Van der Waals forces, while silica forms larger units through hydrogen bonding. The "structure" of fillers is used to describe the aggregate shape, size and density. DiButylPhthalate (DPB) adsorption according to ASTM D6845 was used in the past to measure the structure. This method is replaced by the oiladsorption method using paraffinic oil according to ASTM D2414 due to toxicity of DBP. The higher the structure, the higher the reinforcement. 


\subsubsection{CARBON BLACK}

Carbon Black (CB) is the most widely used filler in the rubber field because of its capability to reinforce elastomers. It is composed of carbon atoms, of which a small portion carries functional groups as shown in Figure 2.18.

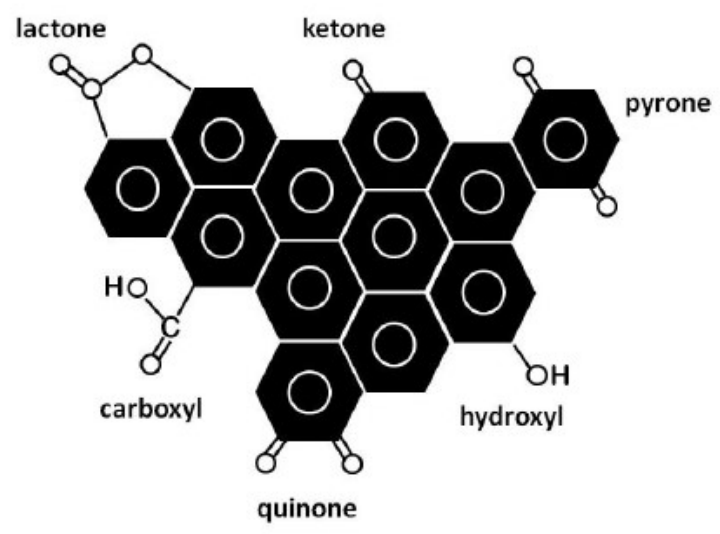

Figure 2.18 Surface structure of $C B$ [46].

Figure 2.19 shows the morphology of $\mathrm{CB}$. The primary carbon particles tend to form aggregates or agglomerates. Aggregates are the smallest stable structural units of CB. CB is supplied in the form of compacted agglomerates. During mixing, the $C B$ agglomerates are broken up to the dimension of aggregates.

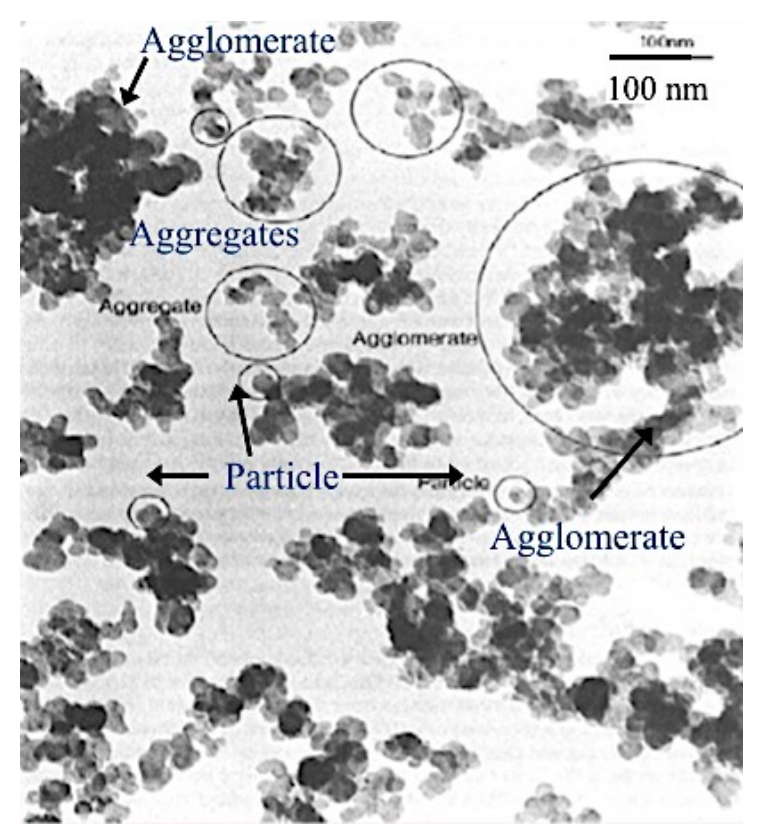

Figure 2.19 Morphology of CB [47]. 


\subsubsection{SILICA}

Silica (SI) is composed of siloxane and silanol groups. Silanol groups are very polar and chemically active. The degree of chemical interaction between SI and the rubber matrix relies on the type of functionality on the filler surface. Silanol groups are present on the surface of SI primary particles in three different forms as shown in Figure 2.20. Isolated and geminal silanols are the most reactive ones [48].

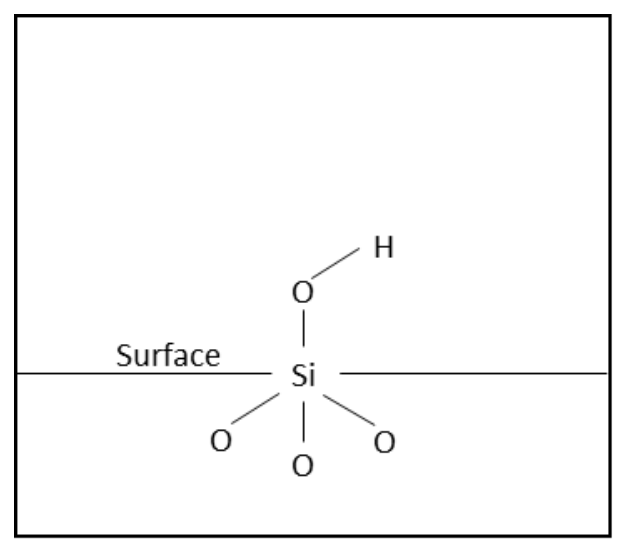

Isolated

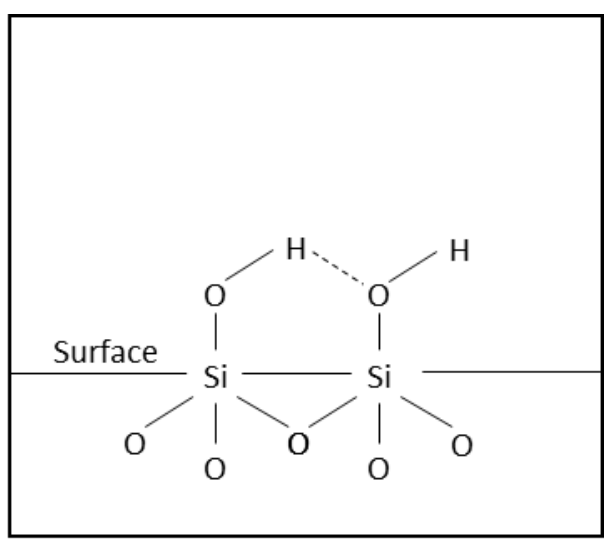

Vicinal

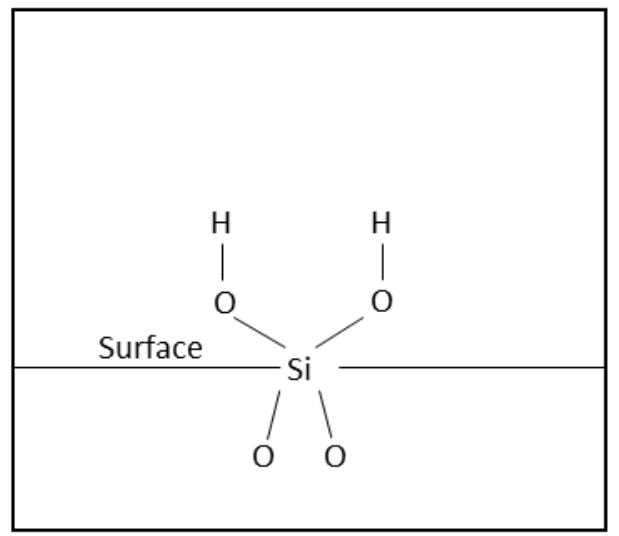

Geminal

Figure 2.20 Three different forms of silanol groups on the SI surface [48].

The difference in polarity between the surface of SI and the rubber matrix creates a major problem in rubber compounding. With the development of coupling agents such as bifunctional organosilanes, which act as a bridge between the SI surface and the rubber matrix, filler-rubber interaction can be improved. Generally, there are three types of sulfurfunctionalized silanes which are most commonly used in sulfur-cured rubber compounds: see Figure 2.21. The coupling agents have double functionalities: The organo-functional groups can react with the rubber matrix, and the ethoxy groups split off and create a reactive site on the silicon atom able to couple with silanol groups of the SI to form a chemical bond. 


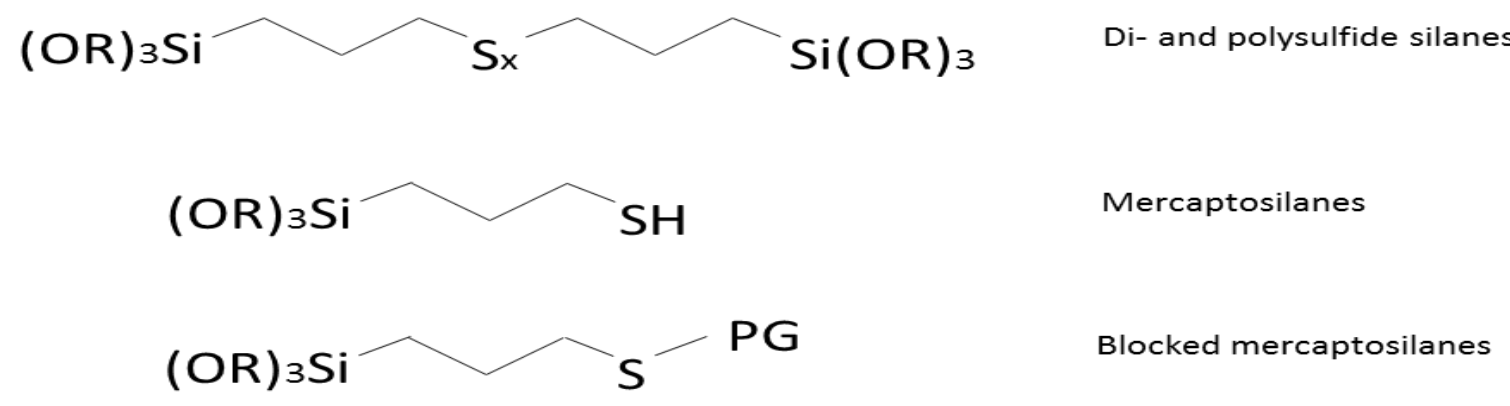

Where $\mathrm{R}=-\mathrm{CH} 3,-\mathrm{C}_{2} \mathrm{H} 5$, alkylpolyether; $\mathrm{x}=2-8$; $\mathrm{PG}=\mathrm{CN}$, octanoyl

Figure 2.21 Representative sulfur-functional silanes [48].

\subsection{VULCANIZATION AGENTS}

Sulfur is the most widely used vulcanization chemical for unsaturated rubbers such as $\mathrm{NR}, \mathrm{BR}$, and SBR. During the vulcanization process, the individual rubber molecules are crosslinked to form a three-dimensional network of interconnected chains through sulfur crosslinks as described in Figure 2.22. However, vulcanization of rubber using sulfur alone is very slow. Therefore, accelerators are added to boost the vulcanization.

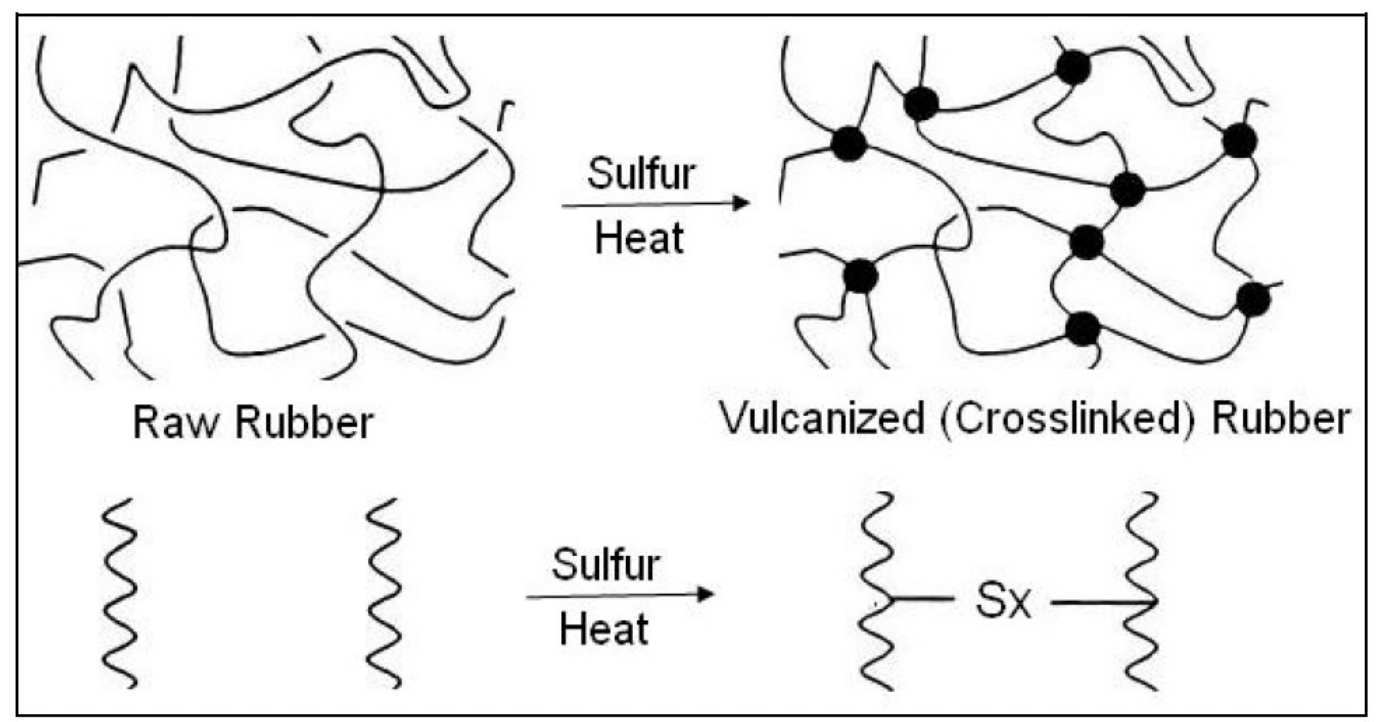

Figure 2.22 Model of an NR-sulfur network [49].

Sulfur vulcanization systems typically consist of 3 to 10 phr Zinc Oxide (ZnO), 1 to 4 phr stearic acid, 0.5 to $4 \mathrm{phr}$ accelerators and 0.5 to $3 \mathrm{phr}$ sulfur. Proper selection of accelerators for a particular rubber compound is an essential task, since the type as well as the amount of accelerator significantly influence the processing and vulcanizate properties of the rubber compound. The changes in vulcanizate properties as a function of crosslink density are depicted in Figure 2.23. As the crosslink density of the vulcanizate increases, properties such as static modulus, dynamic modulus at high velocities and hardness increase. Hysteresis, 
permanent set and friction coefficient decrease as the crosslink density increases. Other properties such as tear strength and tensile strength show a maximum value and then decrease [50].

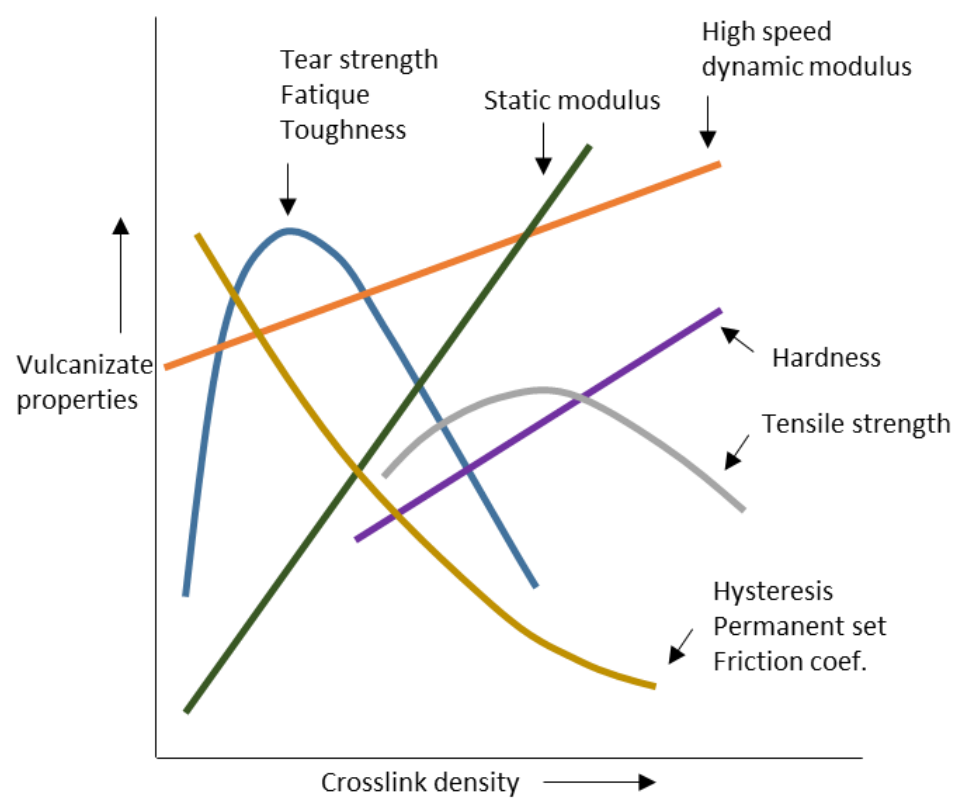

Figure 2.23 Vulcanizate properties as a function of the degree of crosslinking [50].

Vulcanization systems with a high sulfur dosage and low accelerator dosage are denoted as Conventional Vulcanization (CV) systems, and the counterpart as Efficient Vulcanization (EV) systems. Semi EV is a system, in which sulfur and accelerator concentrations are in-between those of a CV and an EV system: see Table 2.7.

Table 2.7 Classification of sulfur vulcanization systems [49].

\begin{tabular}{|c|c|c|c|}
\hline Vulcanization system & $\begin{array}{c}\text { Conventional } \\
\text { (CV) }\end{array}$ & $\begin{array}{c}\text { Semi-Efficient } \\
\text { (Semi EV) }\end{array}$ & $\begin{array}{c}\text { Efficient } \\
\text { (EV) }\end{array}$ \\
\hline Sulfur dosage, phr & $2-3.5$ & $1-1.7$ & $0.4-0.8$ \\
\hline Accelerator dosage, phr & $0.4-1.2$ & $1.2-2.4$ & $2-5$ \\
\hline Accelerator/Sulfur ratio & $0.1-0.6$ & $0.7-2.5$ & $2.5-12$ \\
\hline
\end{tabular}

Typical CV systems form polysulfidic crosslinks which exhibit higher tensile, tear and flex-fatigue resistances. EV systems feature a high number of monosulfidic crosslinks, and such vulcanizates are characterized by better heat stability and lower compression set than polysulfidic systems. Table 2.8 summarizes the influence of the selected cure system on the properties of the vulcanizates. 
Table 2.8 Effect of cure systems on crosslink types and vulcanizate properties [49].

\begin{tabular}{|l|c|c|c|}
\hline \multicolumn{1}{|c|}{ Cure System } & $\begin{array}{c}\text { Conventional } \\
(\mathbf{C V})\end{array}$ & $\begin{array}{c}\text { Semi-Efficient } \\
\text { (Semi EV) }\end{array}$ & $\begin{array}{c}\text { Efficient } \\
\text { (EV) }\end{array}$ \\
\hline Poly + disulfidic crosslinks, \% & 95 & 50 & 20 \\
\hline Monosulfidic crosslinks, \% & 5 & 50 & 80 \\
\hline Cyclic sulfidic concentration & High & Medium & Low \\
\hline Reversion resistance & Low & Medium & High \\
\hline Heat aging resistance & Low & Medium & High \\
\hline Flex-Fatigue resistance & High & Medium & Low \\
\hline Heat build-up & High & Medium & Low \\
\hline Tear resistance & High & Medium & Low \\
\hline Compression set & High & Medium & Low \\
\hline
\end{tabular}

\subsection{THE USE OF NR/BR BLENDS FOR AC TIRE TREADS/RETREADS}

Stephens [51] developed two compounds, a top cap and a sub-tread as depicted in Figure 2.24, to provide an AC tire which resists casing-damage and chunking out as well as providing improved wear resistance, as seen in Table 2.9. A blend of NR and BR is used to improve wear resistance. The sub-tread is composed of NR, which provides low heat and thus less temperature generation during tire operation.

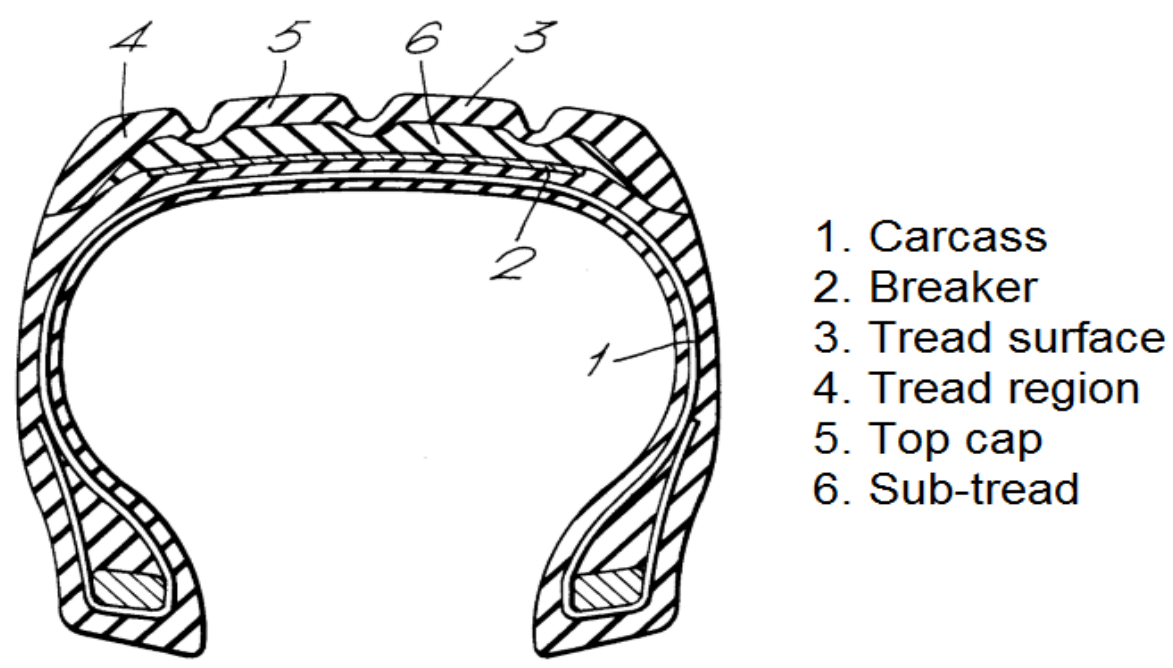

Figure 2.24 Cross sectional view of an AC tire [51]. 
Table 2.9 Top cap and sub-tread formulation [51].

\begin{tabular}{|l|c|c|}
\hline \multirow{2}{*}{ Component } & Top cap & Sub-tread \\
\cline { 2 - 3 } & \multicolumn{2}{|c|}{ Parts per hundred rubber (phr) } \\
\hline NR & 60 & 100 \\
\hline BR & 40 & - \\
\hline ZnO & 5 & 4 \\
\hline Stearic acid & 2 & 2 \\
\hline CB N375 & 52 & - \\
\hline CB N110 & - & 30 \\
\hline CB N326 & - & 25 \\
\hline Process oil & 8 & - \\
\hline Tackifier resin & 2.5 & - \\
\hline Antidegradants & 2.2 & 3.5 \\
\hline Sulfur & 1 & 1 \\
\hline 2-(4-Morpholinothio)- Benzothiazole (MBS) & & 1.5 \\
\hline Properties: & 63 & 65 \\
\hline Hardness (IRHD) & 69 & 38 \\
\hline Resilience @50 ${ }^{\circ} \mathrm{C}$ (\%) & 140 & 65 \\
\hline Abrasion resistance index (ARI) & 23 & \\
\hline Tear strength (MPa) & & \\
\hline
\end{tabular}

Another development in AC tire tread formulations is shown in Table 2.10, based on a patent of Sandstrom et al. [20]. The development focuses on enhancing the abrasion resistance and hysteresis, and it provides a smooth rubber extrudate and minimum defects during tire assembly. 
Table 2.10 AC tire tread rubber compositions [20].

\begin{tabular}{|c|c|c|c|}
\hline Material & Sample 1 & Sample 2 & Sample 3 \\
\hline \multicolumn{4}{|l|}{$1^{\text {st }}$ non-productive mixing step } \\
\hline Cis 1,4 BR (Budene ${ }^{\circledR} 1280$ ) & 80 & 75 & 70 \\
\hline RSS\#2 & 20 & 25 & 30 \\
\hline CB N347 & \multicolumn{3}{|c|}{40} \\
\hline Paraffinic wax & 2 & \multicolumn{2}{|c|}{1.5} \\
\hline Rubber process oil and fatty acid & \multicolumn{2}{|c|}{10} & 7 \\
\hline $\mathrm{ZnO}$ & \multicolumn{3}{|c|}{3} \\
\hline \multicolumn{4}{|l|}{$2^{\text {nd }}$ non-productive mixing step } \\
\hline Tackifying resin & \multicolumn{3}{|c|}{3} \\
\hline Antidegradant & \multicolumn{3}{|c|}{2.5} \\
\hline Silica coupling agent & 3.5 & \multicolumn{2}{|c|}{4} \\
\hline Silica & 17.5 & \multicolumn{2}{|c|}{20} \\
\hline \multicolumn{4}{|l|}{ Productive mixing step } \\
\hline Sulfur & 1.2 & 1.4 & 1.2 \\
\hline Accelerators (sulfenamide, guanidine type) & 2.4 & 2.7 & 2.7 \\
\hline \multicolumn{4}{|l|}{ Properties } \\
\hline $\mathrm{G}^{\prime}$ at $100^{\circ} \mathrm{C}, 10 \%$ strain, $1 \mathrm{~Hz}(\mathrm{MPa})$ & 1.392 & 1.773 & 1.541 \\
\hline $\operatorname{Tan} \delta 100^{\circ} \mathrm{C}, 10 \%$ strain, $1 \mathrm{~Hz}$ & 0.127 & 0.130 & 0.136 \\
\hline Tensile strength (MPa) & 16.27 & 16.17 & 17.57 \\
\hline Elongation at break (\%) & 521 & 501 & 537 \\
\hline \multicolumn{4}{|l|}{ Hardness shore $A$} \\
\hline $23^{\circ} \mathrm{C}$ & 67 & 73 & 70 \\
\hline $100^{\circ} \mathrm{C}$ & 60 & 55 & 62 \\
\hline \multicolumn{4}{|l|}{ Rebound (\%) } \\
\hline $23^{\circ} \mathrm{C}$ & 47 & 45 & 44 \\
\hline $100^{\circ} \mathrm{C}$ & 58 & 55 & 55 \\
\hline Tear strength (MPa) & 29.5 & 43.5 & 31.5 \\
\hline Abrasion resistance, relative volume loss & 49 & 58 & 76 \\
\hline
\end{tabular}

Based on the patent, an $A C$ tire tread should have a relative abrasion resistance (volume loss relative to the reference rubber) of less than about $80 \%$, and a hot rebound value at $100^{\circ} \mathrm{C}$ in the range of $45-70 \%$. In addition, the $\mathrm{AC}$ tire tread rubber should have a $\tan \delta$ value $\left(100^{\circ} \mathrm{C}, 10 \%\right.$ strain, $\left.1 \mathrm{~Hz}\right)$ in the range of 0.07 to 0.17 . Preferably, the $\mathrm{AC}$ tire tread has a storage modulus $\left(100^{\circ} \mathrm{C}, 10 \%\right.$ strain, $\left.1 \mathrm{~Hz}\right)$ in the range of 0.750 to $2 \mathrm{MPa}$ and an Instron Tear $\left(100^{\circ} \mathrm{C}\right)$ value from 13.5 to $54.5 \mathrm{MPa}$. 


\subsection{RESINS}

Resins are oligomers which have a weight-average molecular weight $\left(M_{w}\right)$ in the range of 800 to 4000 . They can function as processing aids, plasticizers, extenders, reinforcing agents, and tackifiers [52], of which the latter one is the most important one. Tack is the ability of two materials to withstand separation after bringing their surfaces into contact for a short time under light pressure [53]. Figure 2.25 shows the process that happens when two surfaces are brought into contact under light pressure. The surfaces have a rough topography on a microscale level with entrapped gases between them, which will diffuse to the top compound (blue) or with adsorbed gas inside the compound (yellow). The actual contact occurs in the area where asperities of one surface meet those of the other. The molecular contact of polymeric chains between two surfaces will be prevented until the gases diffuse into the bulk of the material. The material must undergo viscous flow and displace the entrapped gases to increase the contact area. After achieving molecular contact, the interdiffusion of polymeric chains from each surface may take place [54]. The bond that is formed between polymeric chains of the two surfaces is capable of resisting stress before rupture.

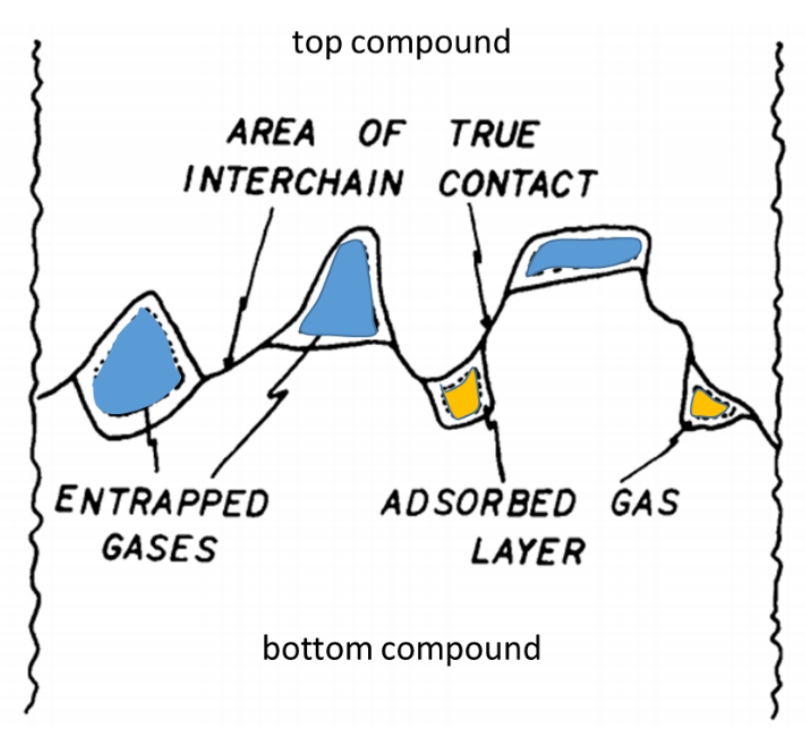

Figure 2.25 The process of two surfaces brought into contact for a short time under a light pressure [54].

Two types of resins are available: naturally derived resins and hydrocarbon resins originating from coal distillation or steam cracking of heavy petroleum feedstock. Terpenes and rosins are examples of natural resins produced from the distillation of pine gum and the side stream of the Kraft pulping process. Another source of terpene such as D-limonene is orange juice or peel extract. Coumarone-indene resins are the most popular hydrocarbon resins obtained from the coal tar fractionation process. C5 aliphatic and C9 aromatic are examples of petroleum-based resins. The classification of resins is depicted in Figure 2.26. 


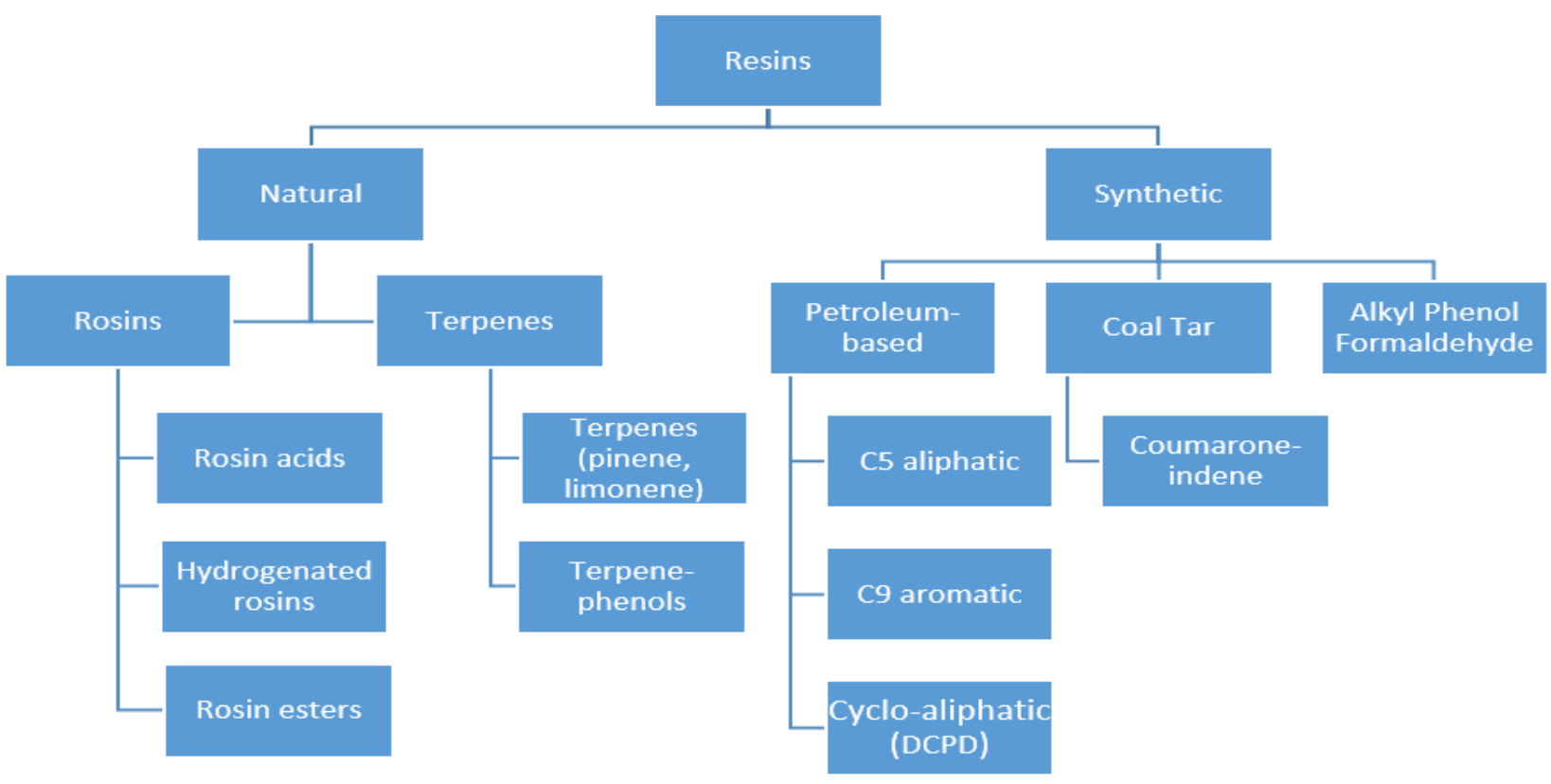

Figure 2.26 Classification of resins [55].

\subsubsection{RESIN STRUCTURES}

\section{Rosins}

Rosins consist of turpentine oil and colophony. They have a chemical composition of $\mathrm{C}_{19} \mathrm{H}_{29} \mathrm{COOH}$. Figure 2.27 shows the structure of rosins including abietic and pimaric types. Abietic acid is primarily present in rosins. The melting point of the monomers varies from 150 to $175^{\circ} \mathrm{C}$, while the glass transition temperature $(\mathrm{Tg})$ is in the range of 65 to $80^{\circ} \mathrm{C}$ [56]. Rosin esters are very effective tackifiers and compatible with many polymers. Because of their superior stickiness, rosin esters are used in a wide variety of products including sealants, hot melts, pressure sensitive adhesives, printing inks, varnishes and lacquers.

\section{Abietic-type}

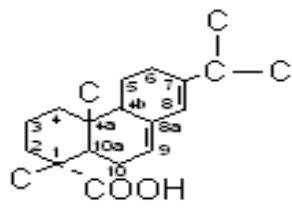

Abietic<smiles>CC(C)c1ccc2c(c1)CC1(C)C3(C)CCCC2(C)C(=O)OC31C</smiles><smiles>CCCC1(C)C(=O)Oc2cc(C(C)C)ccc2C1C(C)C</smiles><smiles>CC(C)C1=CC2=C(CC1)C1C(O)C3(C)CCCC1(C)C3(C)C2</smiles>

Palustric<smiles>CC(C)C1C=C2C(O)C3C4(C)CCCC3(C)C2(CO)C4CC1</smiles>

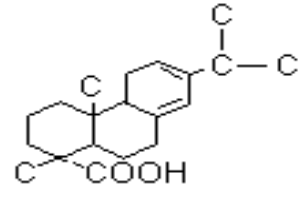

Levopimaric<smiles>CC(C)C1CCC2=C(C1)C(O)C13CCCC1(C)CCC23CO</smiles><smiles>CC(C)C1CCC2C(CCC3(C)CCCC23C)C1</smiles> 


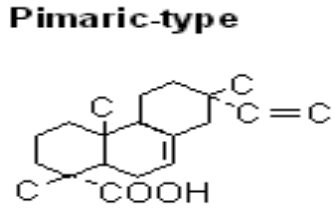

Isopimaric<smiles>C=CC1(C)C=C(O)C2CCC(C)(CO)C2C12CCCC2</smiles>

Pimaric<smiles>CCC1(C)C=C(O)C2CCC3(C)CCCC(C)(C3)C2C1O</smiles>

Dihydropimaric

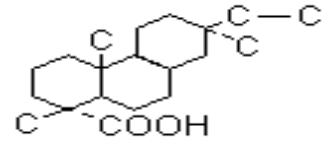

Tetrahydropimaric

Figure 2.27 Rosin types [57].

\section{Terpenes}

Terpene resins are derived from natural terpene monomers, a byproduct from paper and pulp production and citrus juice production. Figure 2.28 shows the chemical structure of monoterpenes. Of the 14 most commonly occurring monoterpenes ( $\alpha$-pinene, $\beta$-pinene, $\Delta^{3}$ carene, $d$-limonene, camphene, myrcene, $\alpha$-terpinene, $\beta$-phellandrene, sabinene, $\rho$-cymene, ocimene, $\alpha$-thujene, terpinolene, and $y$-terpinene), the first six are usually found to be the most abundant ones.
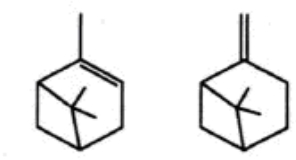

$\alpha$-pinene

$\beta$-pinene<smiles>C=C1C=CC(C(C)C)CC1</smiles>

$\beta$-phellandrene

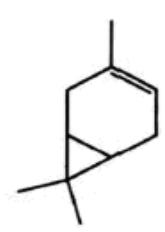

$\Delta^{3}$-carene

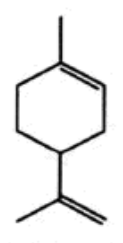

d-limonene

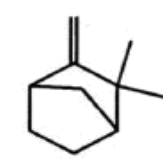

camphene<smiles>C=CC(=C)CCC=C(C)C</smiles>

myrcene<smiles>CC1=CCC(=C(C)C)CC1</smiles>

terpinolene<smiles>CC1=CC=C(C(C)C)CC1</smiles>

$\alpha$-terpinene

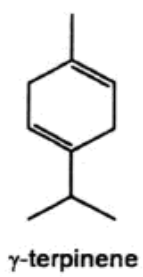

Figure 2.28 Chemical structures of monoterpenes [58].

\section{Terpene phenol}

Terpene phenol resins are copolymers of a terpene and phenol. The reaction proceeds via a Friedel-Craft mechanism, which results in the linkage of two or three terpene molecules in the para- and ortho-position of the phenol molecule. A typical structure of terpene-phenol resin is shown in Figure 2.29. Terpene-phenol resins are often categorized according to their melting point, molecular weight and hydroxyl value. The softening points of terpene phenol resins are in the range of $75-150^{\circ} \mathrm{C}$ [56]. 


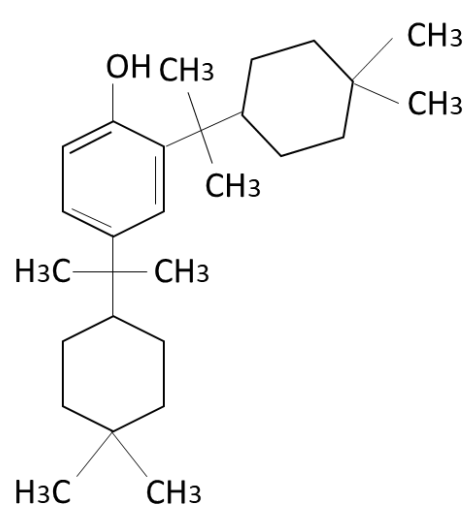

Figure 2.29 Structure of terpene-phenol resin [59].

\section{C5 aliphatic resins}

C5 aliphatic resins are derived from hydrocarbons consisting of a five-carbon chain with two double bonds known as piperylene. It is obtained as by-product of naphtha cracking. Figure 2.30 shows the various monomers of $\mathrm{C} 5$ aliphatic resins.<smiles>C=C/C=C/C</smiles><smiles>C1=CC2C3C=CC(C3)C2C1</smiles>

Dicyclopentadiene<smiles>C1=CCC=C1</smiles>

Cyclopentadiene<smiles>C1=CCCC1</smiles>

Cylcopentene

Figure 2.30 Chemical structures of monomers in C5 aliphatic resin [60].

\section{Aromatic resins: $\mathrm{C9}$ aromatic and Coumarone Indene}

Figure 2.31 shows the chemical structures of monomers in an aromatic hydrocarbon resin. The main monomers are of styrene and indene types. Aromatic C9 resins are derived from a fraction of naphtha cracking, while coumarone indene is derived from coal-tar. They differ only in the proportion of indene-type structures, which are present at higher concentrations in coumarone indene, typically around $48 \%$ of indene. C9 resin in general has the following composition: 2 wt\% of styrene, 4 wt\% of $\alpha$-methylstyrene, 20 wt $\%$ of vinyltoluene, $6 \mathrm{wt} \%$ of dicyclopentadiene, $20 \mathrm{wt} \%$ of indene, $5 \mathrm{wt} \%$ of methylindenes, $5 \mathrm{wt} \%$ of naphthalene, $38 \mathrm{wt} \%$ of other nonreactive aromatics [56]. 
<smiles>C=Cc1ccccc1</smiles>

Styrene<smiles>C=Cc1ccc(C)cc1</smiles>

Vinyltoluene<smiles>C=C(C)c1ccccc1</smiles>

$\alpha$-methylstyrene<smiles>C1=Cc2ccccc2C1</smiles>

Indene<smiles>CC1=Cc2ccccc2C1</smiles>

Metylindene<smiles>c1ccc2occc2c1</smiles>

Coumarone<smiles>C1CC2CC1C1CCC21</smiles>

Dyclopentadiene

Figure 2.31 Chemical structures of monomers in aromatic hydrocarbon resin [56].

\subsubsection{PROPERTIES OF RESINS}

Several properties of resins provide valuable information about their suitability for specific applications:

\section{Softening point}

The softening point is defined as the temperature at which the resin flows under a given load on heating. The resins are non-crystalline, thus amorphous materials which soften gradually over a range of temperatures. The softening point is controlled by the average molecular weight of the resin. The softening point is also related to the intrinsic viscosity, hardness and brittleness of resins $[56,61]$.

\section{Glass transition temperature}

Resins are amorphous polymers exhibiting a glass transition $(\mathrm{Tg})$ due to the reduction of molecular mobility by the collapse of free volume with decreasing temperature [56]. $\mathrm{Tg}$ values of resins are around 30 to $90^{\circ} \mathrm{C}$. In contrast, NR and high-cis BR for example have a $\mathrm{Tg}$ around -60 and $-100^{\circ} \mathrm{C}$, respectively. The addition of a resin to a rubber compound affects the $\mathrm{Tg}$. In immiscible systems, two separate $\mathrm{Tg}$ peaks will appear; one related to the rubber and the other related to the resin. In a homogeneous system, the $\mathrm{Tg}$ will shift according to the Fox Equation 2.4 [62].

$$
\frac{1}{T_{g}}=\frac{w_{A}}{T_{g A}}+\frac{w_{B}}{T_{g B}}
$$

Where $w_{A}, w_{B}$ are weight fractions of the resin and the rubber, respectively. $T_{g A}, T_{g B}, T_{g}$ are the glass transition temperatures of the resin, the rubber and the resin-rubber blend, respectively. 


\section{Thermal stability}

The thermal stability of resins is an important property, especially when they are used in applications where heat is applied, for example in hot melts (mixing), hot-applied road marking plastics, jointing, sealants, bituminous roofing compounds, and similar applications [61]. The degradation of resin may result in property changes such as deterioration of tack and peel strength as well as flexibility, and in oxidation, while depolymerization may also occur.

\section{Viscosity \\ Dilute Solution viscosity}

Dilute solution viscosity is the viscosity of a dilute solution of polymers. The solution viscosity of resins is influenced by many factors such as: concentration, softening point, average molecular weight, molecular weight distribution, the chemical composition of the resin, and the type of solvent. Resins with similar softening points may have different molecular weight distributions, thus may be different in viscosity of the solution. The molecular weight distribution has a tremendous influence on the resin solution viscosity. The narrower the molecular weight distribution, the higher the viscosity of the resin solution [56].

\section{Melt viscosity}

Melt viscosity measures the viscosity of a solid resin when it is in the molten state. Melt viscosity is important in rubber compounding, where modifying resins are used as tackifiers. They are used as viscosity regulators to facilitate mixing (processing aid). Melt viscosity is influenced by the softening point, average molecular weight and its distribution, and resin type [61].

\section{Solubility}

Solubility parameters are often used to predict the compatibility of polymers, chemical resistance, swelling of cured elastomers by solvents, permeation rates of solvents, and even to characterize the surfaces of pigments, fibers, and fillers [63]. The solubility of a polymer in various solvents is particularly determined by its chemical structure. Polymers will dissolve in solvents whose solubility parameters are close to their own. Hildebrand defined the solubility parameter $\delta$ as the square root of the cohesive energy density, Equation 2.5 [64]. The Cohesive Energy Density (CED), Equation 2.6, is the vapor energy $U$ divided by a unit volume of the material $\mathrm{V}$. $\Delta \mathrm{H}_{\text {vap }}$ is the enthalpy of vaporization, $\mathrm{R}$ is the ideal gas constant, and $\mathrm{T}$ is the temperature. Table 2.11 shows the molar vaporization energy $U$ and molar volume for group contributions $\mathrm{V}$.

$$
\delta=(C E D)^{1 / 2}
$$




$$
C E D=\frac{U}{V}=\frac{\left(\Delta H_{v a p}-R T\right)}{V}
$$

Table 2.11 Group contributions to the molar vaporization energy and molar volume at $25^{\circ} \mathrm{C}$ [65].

\begin{tabular}{|l|r|r|}
\hline \multicolumn{1}{|c|}{ Group } & $\Delta \mathrm{U}(\mathrm{KJ} / \mathrm{mol})$ & \multicolumn{1}{|c|}{$\mathrm{V}\left(\mathrm{cm}^{3} / \mathrm{mol}^{\prime}\right)$} \\
\hline$-\mathrm{CH}_{3}$ & 4.71 & 33.5 \\
\hline$-\mathrm{CH}_{2}{ }^{-}$ & 4.94 & 16.1 \\
\hline$>\mathrm{CH}-$ & 3.43 & $-1 . *^{*}$ \\
\hline$>\mathrm{C}<$ & 1.47 & $-19.2^{*}$ \\
\hline $\mathrm{H}_{2} \mathrm{C}-$ & 4.31 & 28.5 \\
\hline$-\mathrm{CH}=$ & 4.31 & 13.5 \\
\hline$>\mathrm{C}=$ & 4.31 & $-5.5^{*}$ \\
\hline $\mathrm{HC} \equiv$ & 3.85 & 27.4 \\
\hline$-\mathrm{C} \equiv$ & 7.07 & 6.5 \\
\hline Phenyl & 31.9 & 71.4 \\
\hline Phenylene (ortho, meta, para) & 31.9 & 52.4 \\
\hline Ring closure, 5 or more atoms & 1.05 & 16 \\
\hline Ring closure, 3 or 4 atoms & 3.14 & 18 \\
\hline Conjugated in ring, for each double bond & 1.67 & $-2.2^{*}$ \\
\hline
\end{tabular}

*Negative molar volume: contribution of the group is less when mixed than in a pure state

Hansen proposed the solubility parameter by counting several individual contributions such as atomic dispersion force $E_{D}$, polar cohesive energy $E_{P}$, and hydrogen bonding $E_{H}$. The total cohesion energy $E$, is shown in Equation 2.7.

$$
E=E_{D}+E_{P}+E_{H}
$$

Equation 2.7

The total Hansen solubility parameter $\delta$ as shown in Equation 2.8 is obtained from the sum of the square roots of each contribution divided by the molar volume V, Equation 2.9.

$$
\begin{gathered}
\delta=\delta_{D}+\delta_{P}+\delta_{H} \\
\delta=\left(\frac{E}{V}\right)^{1 / 2}=\left(\frac{E_{D}}{V}\right)^{1 / 2}+\left(\frac{E_{P}}{V}\right)^{1 / 2}+\left(\frac{E_{H}}{V}\right)^{1 / 2}
\end{gathered}
$$

Equation 2.8

Equation 2.9

The difference in solubility parameters $\left(\delta_{1}-\delta_{2}\right)$ must be small for miscibility or dissolution over the entire volume fraction range. Polymer miscibility is possible only when the difference in solubility parameters $<1.8 \mathrm{~J}^{1 / 2} / \mathrm{cm}^{3 / 2}[66]$.

Small [67] developed a group contribution method for calculating solubility parameters based on molar attraction $\mathrm{F}$ as shown in Equations $2.10-2.11$.

$$
E_{c o h}=\frac{\left(\sum F\right)^{2}}{V}
$$




$$
\delta_{\text {Small }}=\left(\frac{E_{c o h}}{V}\right)^{1 / 2}=\sum \frac{F}{V}
$$

\section{Flory-Huggins parameter $(\chi)$}

The Flory-Huggins parameter $\chi_{12}$ has been used for many years to describe the polymer-solvent interaction. The $\chi_{12}$ can be derived from the Hildebrand solubility parameters for a nonpolar solvent and a nonpolar polymer [63]:

$$
\chi_{12}=\frac{\left[V\left(\delta_{1}-\delta_{2}\right)^{2}\right]}{R T}+\beta
$$

where $\mathrm{V}$ is the molar volume of the solvent, $\delta$ is the Hildebrand solubility parameter for the solvent (1) and polymer (2), R is the gas constant, $T$ is the absolute temperature, and $\beta$ is an empirical constant. $\beta$ has a generally accepted average value near 0.34 . The $\chi_{12}$ can be calculated using Hansen solubility parameters which include dispersive, polar and hydrogen bonding [63] effects as depicted in Equation 2.13.

$$
\chi_{12}=\frac{V\left[\left(\delta_{D 2}-\delta_{D 1}\right)^{2}+0.25\left(\delta_{P 2}-\delta_{P 1}\right)^{2}+0.25\left(\delta_{H 2}-\delta_{H 1}\right)^{2}\right]}{R T}
$$

Equation 2.13

According to the value of $\chi_{12}$, there are three different kind of behaviors:

$$
\begin{array}{ll}
\chi_{12}<0.5 & : \text { the polymer chain is expanded: polymer in a good solvent; } \\
\chi_{12}=0.5 \quad \begin{array}{l}
: \text { the repulsive effect is cancelled by the attractive effect of } \\
\text { polymer/solvent interactions, known as theta condition; }
\end{array} \\
\chi_{12}>0.5 \quad \begin{array}{l}
: \text { there is separation into two coexisting phases, one richer in polymer } \\
\text { but poorer in solvent than the other [68]. }
\end{array}
\end{array}
$$

\subsubsection{RESINS IN TIRE FORMULATIONS}

Hilner [69] reported the improvement of dynamic mechanical properties of cured SBR compounds with the addition 10 phr of various hydrocarbon resins to replace $10 \mathrm{phr}$ of separately added aromatic process oil. The SBR used in this study contains $37.5 \mathrm{phr}$ of aromatic oil. Table 2.12 shows the formulation used in this study. The use of C9 and aliphaticmodified C9 resin improve wet grip and high-speed performance, while maintaining rolling resistance at a comparable level for the compound with separately added aromatic oil as shown in Table 2.13. 
Table 2.12 Composition of tread compound [69].

\begin{tabular}{|l|c|c|}
\hline \multicolumn{1}{|c|}{ Ingredient } & $\begin{array}{c}\text { Base } \\
\text { formulation } \\
\mathbf{( p h r )}\end{array}$ & $\begin{array}{c}\text { Resin } \\
\text { Based } \\
\text { (phr) }\end{array}$ \\
\hline SBR (Buna EM1712) & 137.5 & 137.5 \\
\hline CB N339 & 80 & 80 \\
\hline ZnO & 3 & 3 \\
\hline Stearic acid & 2.5 & 2.5 \\
\hline Sulfur & 1.8 & 1.8 \\
\hline N-Isopropyl-N'-Phenyl-1,4-PhenylenDiamine (IPPD) & 1.5 & 1.5 \\
\hline N-Cyclohexyl-2-Benzothiazole Sulfenamide (CBS) & 1.2 & 1.2 \\
\hline DiPhenyl Guanidine (DPG) & 0.4 & 0.4 \\
\hline Aromatic process oil & 10 & - \\
\hline Resin & - & 10 \\
\hline
\end{tabular}

Table 2.13 Dynamic mechanical properties of vulcanizates containing hydrocarbon resins or aromatic oil [69].

\begin{tabular}{|l|c|c|c|}
\hline & $\begin{array}{c}\text { Rolling } \\
\text { resistance }\end{array}$ & Wet grip & $\begin{array}{c}\text { High-speed } \\
\text { performance }\end{array}$ \\
\hline Petroleum-based C9 resin & +++ & +++ & ++ \\
\hline Aliphatic-modified C9 resin & ++ & ++ & ++ \\
\hline Coumarone-indene resin & + & - & + \\
\hline Aromatic process oil & +++ & -- & $\mathrm{a}$ \\
\hline \multicolumn{1}{|c|}{ Note: } \\
-- = worse than - \\
$\begin{aligned} \text { - }=\text { worse than a } \\
\text { a }=\text { average }\end{aligned}$ \\
$\quad+=$ better than a \\
$++=$ better than + \\
$+++=$ better than ++
\end{tabular}

Resins can significantly improve the service life of AC tires. One of the types of AC tire damage is chevron cutting as shown in Figure 2.32, which is caused by cross-grooved runways. These grooves help drain water from runways and prevent hydroplaning, but they can severely damage the tire: the edges of the grooves can cut the AC tire when the tire touches the ground. During landing, as the tire is loaded and accelerated, large forces are exerted on the tire, which cause the chevron cutting. It was proven in a field test of AC tire treads manufactured with rubber compositions having both a polyterpene resin and a polythiosulfate anti-reversion agent, that these additives provide a tire tread that better withstands chevron cutting as well as wear [70]. 

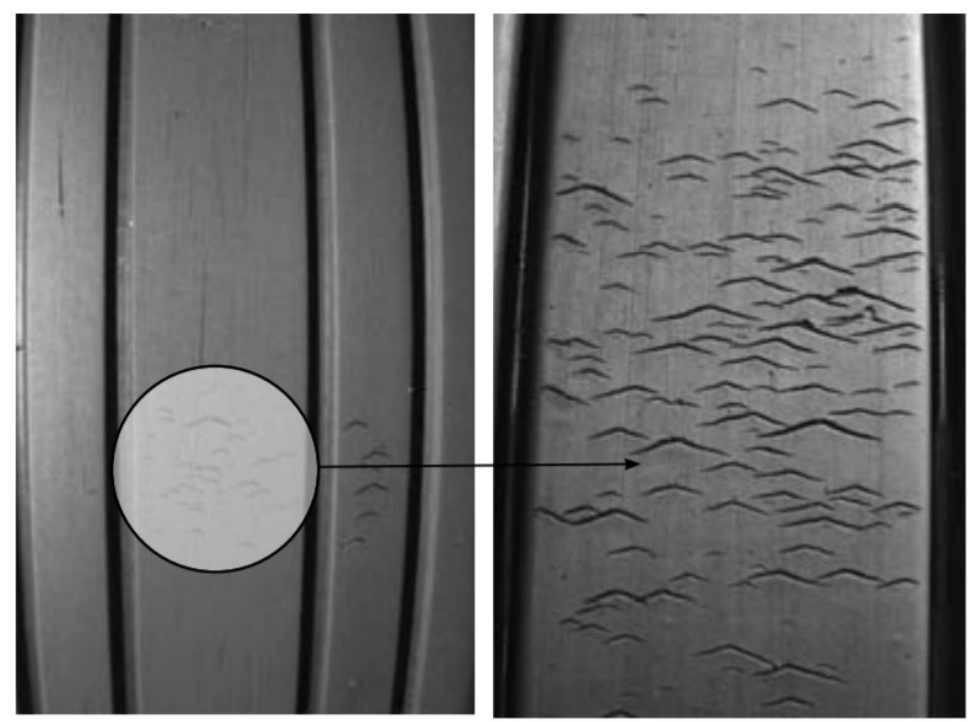

Figure 2.32 Chevron cutting [10].

A comparison of test results between a compound without resin and anti-reversion agents $\mathrm{R}$, and a rubber mixture consisting of a polyterpene and a poly-thiosulfate anti-reversion agent $\mathrm{F} 1$ is seen in Table 2.14. Both compounds were mixed in a factory scale mixer and then used to manufacture $A C$ tires. These $A C$ tires were then mounted on a nose and main landing gear and tested concerning their wear resistance in terms of Landing per Tread (LPT) and their resistance to chevron cutting. It seems that a compound having a polyterpene and a polythiosulfate anti-reversion agent withstood a higher number of landings and field chevron cutting index compared to a compound without those materials.

Table 2.14 Rubber formulations for AC tire treads and testing results [70].

\begin{tabular}{|l|c|c|}
\hline \multicolumn{1}{|c|}{ Composition } & R & F1 \\
\hline NR & 70 & 70 \\
\hline BR & 30 & 30 \\
\hline CB N234 & 54 & 55 \\
\hline Mild Extracted Solvate (MES) oil & 6 & 0 \\
\hline Polylimonene resin L120 & 0 & 8 \\
\hline Additives: & 3 & 3 \\
Wax, N-Phenyl-Para-Phenylenediamine (6PPD), & & \\
2,2,4-TriMethyl-1,2-dihydroQuinoline (TMQ) & & \\
\hline Stearic acid and ZnO & 8 & 8 \\
\hline N-Tert-Butyl-2-Benzothiazole Sulfenamide (TBBS) & 0.81 & 0.81 \\
\hline Sulfur & 1.35 & 1.35 \\
\hline Poly-thiosulfate anti reversion agent & 0 & 1.5 \\
\hline Physical properties: & & \\
\hline LPT Index for Nose Tires & 100 & 112 \\
\hline LPT Index for Main Tires & 100 & 108 \\
\hline Field Chevron Cutting Index* & 100 & 145 \\
\hline
\end{tabular}

* higher=better 


\subsection{MOTIVATION OF THE THESIS}

Tires are one of the main components of aircrafts that undergo frequent replacement due to the severe conditions during utilization. Retreading $A C$ tires is by far the most environmentally friendly and efficient way of extending the service life of AC tires. It is also economical since it saves more than $50 \%$ of the costs compared to a new tire. Almost all airline companies in the world use retreaded tires to reduce their operating costs.

The ultimate goal of improvements of retreading technologies and systems is to provide a high and consistent quality of retreaded tires. The development of innovative tread materials aims at cooler running and higher heat-resistance, while simultaneously improve tire service life. Heat generation, thus a high temperature increase within the tires, has direct consequences for other crucial properties such as tensile strength and tread wear. From a compounding point of view, it is imperative to provide rubber formulations with low hysteresis at the temperature and frequency ranges of service. The selection of ingredients determines the final properties of rubber products. Besides the ingredients, the correct processing in terms of mixing conditions and addition sequence during mixing also determines the properties. Therefore, proper selection of ingredients and optimized processing to balance the properties of AC tire retreads: low hysteresis while maintaining high stress-strain properties and ease of processing, are the goals of the study reported in this thesis.

\section{Rubber processing}

The first part of the study is dedicated to investigating the factors influencing the mixing behavior of:

i) CB-filled NR/BR blends;

ii) SI-filled and a hybrid CB/SI-filled NR/BR blends.

To enhance the properties of AC tire retreads, it is essential to investigate the parameters for rubber mixing influencing the material properties for those specific filler systems. The aim is to carefully optimize the parameter settings to successfully produce the desired or intended property profiles, with consistency in quality and minimum time expense (efficient). A Design of Experiments (DOE) approach is used because it covers many factors and a wide range of settings at the same time. The results are statistically accountable. Moreover, DOE is a widely used approach for optimizing quality and product performance. The outcome of this mixing optimization enables the rubber manufacturer to produce $A C$ tire retreads in a similar high quality as the material produced in the research stage. 


\section{Addition sequence}

Several researchers found that ZnO and DPG can interact with SI. The addition sequence of $\mathrm{ZnO}$ and DPG is investigated in compounds with a hybrid $\mathrm{CB} / \mathrm{SI}$ filler system to study the effect on the rubber properties of $A C$ tire retreads. It is essential to elucidate how different addition sequences affect the rubber properties. Finally, it will be possible to identify the best addition sequence of $\mathrm{ZnO}$ and DPG suitable for AC tire retreads.

\section{Properties of polymers and resins}

Related to the material selection, the investigations are divided into:

i) A first investigation to study the effect of different types of BR in terms of macroand micro-structure on the properties of AC tire retreads. It is also essential to have a better understanding of how the structure of polymers influence the properties in unfilled and filled systems.

ii) The second focus of this part of the investigation is related to the use of resins in different filler systems. Two types of resins with different polarity, solubility, viscosity and softening point are used in order to study how the resins interact with polymers as well as with different filler systems, and how they influence the compound and the final properties of AC tire retreads.

\section{Aging properties}

Due to high service temperatures of AC tires, the tread/retread is prone to aging/oxidation. The knowledge about aging of these rubber vulcanizates will lead to better understanding of the influence on the material properties during service.

\subsection{REFERENCES}

1. Technology and Innovation: Passenger Aircraft, Available online: https://www.airbus.com (accessed on 19 June 2020).

2. Chatterjee, B. and Bhowmick, S., in Sustainable Engineering Products and Manufacturing Technologies, Chapter 9: Evolution of Material Selection in Commercial Aviation Industry - $A$ Review, 2nd ed., Kumar, K., Davim, P., and Zindani, D., Ed., Academic Press: Massachusetts (2019).

3. Aerospace Technology Institute, Emerging Technologies in Commercial Aircraft Systems, Available online: https://www.ati.org.uk/media//33piOri/ati-insight-03emerging-technologies-in-commercial-aircraft-systems.pdf (accessed on 12 June 2020).

4. W. Saloni, Aerospace Landing Gears Continue to Remain Significant in Aircraft Safety and Maintenance, Available online: https://www.intelligent-aerospace.com (accessed on 19 June 2020).

5. Understanding the Basics of Aircraft Tire Construction and Maintenance, Available online: https://www.aviationpros.com (accessed on 20 June 2020). 
6. Goodyear Aviation, Aircraft Tire Care and Maintenance, Available online: https://www.goodyearaviation.com/resources/tirecare.html (accessed on 11 June 2019).

7. Hirata, Y., et al., in Chemistry, Manufacture and Application of Natural Rubber, Chapter 12: Natural Rubber (NR) for the Tyre Industry, 1st ed., Kohjiya, S. and Ikeda, Y., Ed., Woodhead Publishing: Cambridge (2014).

8. Alroqi, A.A., et al., Aircraft Tyre Temperature at Touchdown With Wheel Prerotation, J. Aircraft, 54, 3, 926 (2017).

9. Alroqi, A.A. and Wang, W., Reduction of Aircraft Tyre Wear by Pre-rotating Wheel using ANSYS Mechanical Transient, Adv. Eng. Forum, 7, 89 (2016).

10. Michelin Aircraft Tire Care and Service Manual, Available online: https://www.airmichelin.com (accessed on 16 January 2017).

11. FAA, Advisory Circular, Inspection, Retread, Repair, and Alterations of Aircraft Tires Standard, AC145-4A (2006).

12. EASA, European Technical Standard Order, Aircraft Tires, Standard, ETSO-C62d (2003).

13. DGCA, Civil Aviation Safety Regulation, Certification Procedures for Product and Parts, Standard, CASR 21 (2015).

14. Bridgestone, Aircraft Tires Manufacturing Process - Retread, Available online: https://www.bridgestone.com/products/speciality tires/aircraft/products/process/ind ex.html (accessed on 11 March 2019).

15. Retreading and Repairing Aircraft Tires, Available online: http://www.skytreads.com/retreading.htm (accessed on 30 June 2020).

16. FAA, Technical Standard Order, Aircraft Tires, Standard, TSO-C62e (2006).

17. Design Approvals Information for Applicants and Design Approval Holders, Available online: https://www.faa.gov/aircraft/air cert/design approvals/dah/ (accessed on 19 November 2020).

18. CASR Part 21 - Certification and airworthiness requirements for aircraft and parts, Available online: https://www.casa.gov.au/regulations-and-policy/standardpage/casr-part-21-certification-and-airworthiness-requirements (accessed on 19 November 2020).

19. Becoming a Part 145 Approved Maintenance Organisation (AMO), Available online: https://www.casa.gov.au/standard-page/becoming-part-145-approved-maintenanceorganisation-amo (accessed on 19 November 2020).

20. Sandstrom, P.H., et al., Aircraft Tire, to The Goodyear Tire and Rubber Company, US7367369B2 (2008).

21. Medalia, A.I., Heat Generation in Elastomer Compounds: Causes and Effects, Rubber Chem. Technol., 64, 3, 481 (1991).

22. Sperling, L.H., Introduction to Physical Polymer Science, 4th ed., Wiley: Ney York (2006).

23. Duperray, B. and Leblanc, J.L., The Time-Temperature Superposition Principle as Applied to Filled Elastomers, Kautsch. Gummi Kunstst., 35, 298 (1982).

24. Nordsiek, K.H., The "Integral Rubber" Concept - an Approach to an Ideal Tire Tread Rubber, Kautsch. Gummi Kunstst., 38, 178 (1985).

25. Wang, M.J., Effect of Polymer-Filler and Filler-Filler Interactions on Dynamic Properties of Filled Vulcanizates, Rubber Chem. Technol., 71, 3, 520 (1998).

26. Bolton, W., Engineering Material 3, Heinemann Professional Publishing Ltd.: Oxford (1988).

27. Conant, F.S., Tire Temperatures, Rubber Chem. Technol., 44, 2, 397 (1971).

28. Thermal-Oxidative Degradation of Rubber, Available online: http://polymerdatabase.com/polymer\%20chemistry/Thermal\%20Degradation \%20Elastomers.html (accessed on 11 March 2020). 
29. Goodyear, The Aircraft Tire Data Book, Available online: https://www.goodyearaviation.com (accessed on 17 May 2018).

30. Gehman, S.D., et al., Smearing of Vulcanized Rubber, Rubber Chem. Technol., 28, 2, 508 (1955).

31. Eng, A.H., et al., Trans-Isoprene Units in Natural Rubber, Rubber Chem. Technol., 67, 1,159 (1994).

32. Tarachiwin, L., et al., Structural Characterization of a-Terminal Group of Natural Rubber. 1. Decomposition of Branch-Points by Lipase and Phosphatase Treatments, Biomacromolecules, 6, 4, 1851 (2005).

33. Tarachiwin, L., et al., Structural Characterization of a-Terminal Group of Natural Rubber. 2. Decomposition of Branch-Points by Phospholipase and Chemical Treatments, Biomacromolecules, 6, 4, 1858 (2005).

34. Mekkriengkrai, D., et al., Structural Characterization of Terminal Groups in Natural Rubber: Origin of Nitrogenous Groups, Rubber Chem. Technol, 79, 2, 366 (2006).

35. Sarkawi, S.S., Nano-Reinforcement of Tire Rubbers: Silica-Technology for Natural Rubber, PhD thesis, Elastomer Technology and Engineering, University of Twente, Enschede, The Netherlands (2013).

36. Amnuaypornsri, S., et al., Strain-Induced Crystallization of Natural Rubber: Effect of Proteins and Phospholipids, Rubber Chem. Technol., 81, 5, 753 (2008).

37. Smitthipong, W., et al., Effect of Non-Rubber Components on Properties of Sulphur Crosslinked Natural Rubbers, Adv. Mater. Res., 844, 345 (2014).

38. Noordermeer, J.W.M. and Spit, R.S.H., Elastomeric Technology, Dept. of Elastomer Technology and Engineering, University of Twente: The Netherlands (2011).

39. Strain-Induced Crystallization in Natural Rubber, Available online: http://www.ipfdd.de/en/organization/departments/institute-of-polymer-materials/

mechanics-and-composite-materials/fields-of-work/strain-induced-crystallization-innatural-rubber/ (accessed on 26 June 2020).

40. Rodgers, B. and D'Cruz, B., in Rubber Compunding Chemistry and Applications, Chapter 14: Tire Technology, 2nd ed., CRC Press: Boca Raton, Florida (2016).

41. Rodgers, B., in Rubber Compunding Chemistry and Applications, Chapter 1: Natural Rubber and Other Naturally Occuring Compounding Materials, 2nd ed., CRC Press: Boca Raton, Florida (2016).

42. Polybutadiene - Properties, Applications, Processing and Types of Polybutadiene (BR), Available online: https://www.azom.com/article.aspx?ArticleID=1719 (accessed on 11 June 2018).

43. Ciullo, P.A. and Hewitt, N., The Rubber Formulary, Noyes Publications/William Andrew Publishing: New York (1999).

44. Non Black Fillers, Available online: http://www.vanderbiltchemicals.com (accessed on 8 April 2019).

45. Magee, R.W., Evaluation of the External Surface Area of Carbon Black by Nitrogen Adsorption, Rubber Chem. Technol., 68, 4, 590 (1995).

46. Wolff, S., Chemical Aspects of Rubber Reinforcement by Fillers, Rubber Chem. Technol., 69, 3, 325 (1996).

47. Araby, S., et al., Elastomeric Composites Based on Carbon Nanomaterials, Nanotechnology, 26, 11, 1 (2015).

48. Meon, W., et al., in Rubber Compounding: Chemistry and Applications, Chapter 7: Silica and Silanes, 2nd ed., Rogers, B., Ed., Marcel Decker: New York (2004).

49. Penot, C., Rubber Composition for a Tire Comprising a Reinforcing Inorganic Filler and an (Inorganic Filler/Elastomer) Coupling System, to Michelin Recherche et Technique S.A, US6951897B2 (2005). 
50. Ignatz-Hoover, F. and To, B.H., in Rubber Compounding Chemistry and Application, Chapter 11: Vulcanization, 2nd ed., Rogers, B., Ed., CRC Press: Boca Raton, Florida (2016).

51. Stephens, P., Aircraft Tires, to Sumitomo Rubber Industries Limited, EP0370664B1 (1992).

52. Duddley, J.E., in Rubber Compounding Chemistry and Applications, Chapter 9: Resins, 2nd ed., Rogers, B., Ed., CRC Press: Boca Raton, Florida (2016).

53. Wake, W.C., Adhesion and the Formulation of Adhesives, 2nd ed., Applied Science Publishers: London (1979).

54. Hamed, G.R., Tack and Green Strength of Elastomeric Materials, Rubber Chem. Technol., 54, 3, 576 (1981).

55. Kim, S.W., et al., Identification of Tackifying Resins and Reinforcing Resins in Cured Rubber, Rubber Chem. Technol., 72, 1, 181 (1999).

56. Martinez, J.M.M., in Adhesion Science and Engineering 2: Surfaces, Chemistry and Applications, Rubber Base Adhesives, 1st ed., Chaudhury, M. and Pocius, A.V., Ed., Elsevier Science B.V.: Amsterdam (2002).

57. Rosin Esters and Polymers, Available online: https://polymerdatabase.com (accessed on 24 June 2020).

58. Ma, S., Production of Secondary Organic Aerosol from Multiphase Monoterpenes, InTech, Available online: https://intechopen.com (accessed on 19 June 2020).

59. Tackifiers in Adhesives (Teaser), Available online: https://www.slideshare.net/evertsmit/tackifiers-in-adhesives-teaser (accessed on 29 November 2020).

60. Donker, C., The Chemistry of Tackifying Resins, Hercules B.V., Technical report, Available online: https://www.scribd.com/document/275466927/The-Chemistry-ofTackifying-Resins-Donker (accessed on 23 June 2020).

61. Mildenberg, R., et al., in Hydrocarbon Resins, Resin Structure and Properties, VCH Verlagsgesellschaft $\mathrm{mbH} / \mathrm{VCH}$ Publishers: Weinheim (1997).

62. Wypych, G., in Handbook of Plasticizers, Specialized Analytical Methods in Plasticizers Testing, Chem. Tech. Publishing: Toronto (2004).

63. Hansen, C.M., Hansen Solubility Parameters: A User's Handbook, CRC Press: Boca Raton, Florida (2000).

64. Bicerano, J., Prediction of Polymer Properties, Marcel Dekker: New York (1993).

65. Barton, A.F.M., Handbook of Solubility Parameters and Other Cohesion Parameters, CRC Press: Boca Raton, Florida (1991).

66. Krevelen, D.W.V. and Nijenhuis, K.T., in Properties of Polymer, Chapter 7: Cohesive Properties and Solubility, 1st ed., Elsevier Science B.V.: Amsterdam (2009).

67. Small, P.A., Some Factors Affecting the Solubility of Polymers, Appl. Chem., 3, 71 (1953).

68. Jones, R.A.L., Soft Condensed Matter, Oxford University Press: New York (2002).

69. Hilner, K., The Action of Hydrocarbon Resins in Rubber Formulations for the Tire Industry, Tire Technol. Int., 106, 56 (1994).

70. Yang, X.S., Rubber Compositions for Aircraft Tire Treads, to CGEM and MRT, US 2012/0252929A1 (2012). 


\title{
DEFINING KEY FACTORS FOR IMPROVING PROPERTIES \\ OF AIRCRAFT TIRE RETREADS PRODUCED FROM CARBON BLACK-FILLED NR/BR BLENDS*
}

\begin{abstract}
Carbon Black (CB) is the most common reinforcing filler used in aircraft tire tread formulations. For CB-reinforced Natural Rubber/Butadiene Rubber (NR/BR) blends, material and processability parameters are important factors that need to be controlled as they can influence both, processing as well as vulcanizate properties. It is essential to investigate and optimize the key factors in order to achieve the target properties while maintaining an acceptable trade-off for other characteristics. In the present study, the type of BR, mixer set temperature, rotor speed, and filler mixing time were selected as input factors. A complete Design of Experiments (DOE) process is performed, comprising the following: a two-level full factorial setup for initial screening, Response Surface Method (RSM) for optimization, and validation runs for confirmation.

This evaluation procedure is used to study the impact of factors and their interactions on the properties of CB-filled NR/BR compounds and vulcanizates. From the DOE optimization and later confirmed by the DOE validation, rotor speed and filler mixing time are the most significant factors in improving Mooney Viscosity (MV), Modulus at 300\% elongation (M300\%), hysteresis ( $\tan \delta$ ) as well as in reducing Payne Effect (PE). In the case of Tensile Strength (TS), high mixer set temperature has an adverse effect, thus deteriorating the properties. Therefore, it is recommended to mix at a temperature of $50^{\circ} \mathrm{C}$ and during a moderate filler mixing time of 7 mins combined with a rotor speed of $130 \mathrm{rpm}$. In terms of type of $B R$, a High-Cis and Long-Chain Branched grade (HC LCB BR) shows better processability, lower PE and $\tan \delta$ compared to a linear High-Cis grade (HC BR), while maintaining acceptable $M 300 \%$ and TS.
\end{abstract}




\subsection{INTRODUCTION}

Aircraft (AC) tire treads experience severe operating conditions in which they must be able to endure high forces upon landing of an aircraft: the tire touches the ground with zero rotational speed which creates high friction under substantial load, thus causing high temperatures within the AC tire tread. During takeoff, aircrafts also experience significant forces from rapid acceleration to relatively high speeds under load [1]. Because of these extreme working conditions, AC tire treads need to be resistant against heat generation and wear. Based on the simulation done by Alroqi et al. at zero rotational speed during landing, the temperature of a tire tread in the main area of contact is around $300^{\circ} \mathrm{C}$, while the majority of the tread temperature is less than $165^{\circ} \mathrm{C}$ [2].

The selection of compound ingredients plays a crucial role in the performance of $\mathrm{AC}$ tire treads. The main requirements for AC tire treads are low hysteresis, superior tensile and tear strength, good retreadability, good adhesion to the underlayer, and high wear resistance [1]. Therefore, the treads of AC tires generally contain Natural Rubber (NR). This polymer is essential in AC tire tread compounds due to several advantages such as superior tensile and tear properties, low tire temperature (hysteresis) under dynamic load, as well as good component-to-component adhesion and green strength for tire retreadability [3]. Another essential requirement is high wear resistance; therefore, a blend of NR and Butadiene Rubber (BR) is typically used for AC tire treads. BR gives better low temperature flexibility, higher resilience, and superior abrasion resistance compared to most other tire rubbers. Reinforcing fillers such as high surface area Carbon Black (CB), in particular High Abrasion Furnace (HAF), Intermediate Super Abrasion Furnace (ISAF) and Super Abrasion Furnace (SAF) types, can be added to enhance abrasion resistance.

Besides ingredients, processing of rubber is also a crucial aspect in material preparation. Research has shown that variation of the controlled mixing parameters of the internal mixer such as mixing time [4-8], rotor speed [4], mixing set temperature $[4,8]$ and fill factor $[7,9]$ significantly influence the rubber properties. A proper selection of these mixing parameters will further optimize the properties of rubber materials.

It is therefore essential to investigate and optimize the compounding and processing key factors in order to achieve the target properties while maintaining an acceptable trade-off for other characteristics. Design of Experiments (DOE) is used for this purpose instead of a conventional experimental method, which is done by varying all relevant factors simultaneously. Moreover, an approach such as One Factor At a Time (OFAT) does not lead to a real optimum for the investigated system and fails for choosing the optimum setting conditions. Although OFAT can directly reveal how certain factors affect the product performance, it very poorly covers the whole factor space and does not disclose if there are interactions between specific factors [10]. In contrast, by a DOE approach, the entire factor space can be explored using as many factors as necessary at the same time. Thus, a more substantial space volume response is covered, and factor interactions will also be revealed 
[11]. Some applications of DOE in rubber technology are described in literature, aiming at modelling and optimizing the properties of rubber materials [10, 12-17].

In the present study, four factors: the type of $B R$, mixer set temperature, rotor speed and filler mixing time are selected and investigated in CB-filled NR/BR blends. Aiming to identify the most significant factor for balancing the properties of $A C$ tread compounds, $a$ complete DOE process comprises a two-level full factorial setup for screening. The properties of AC tire treads such as Mooney Viscosity (MV), Payne Effect (PE), hysteresis (tan $\delta 100^{\circ} \mathrm{C}$, $10 \%, 1 \mathrm{~Hz}$ ), and stress-strain properties are chosen as the responses. Finally, after the screening process, the two most notable factors were optimized and validation runs for confirmation performed.

\subsection{EXPERIMENTAL}

\subsubsection{MATERIALS}

The rubber types used are NR: Ribbed Smoked Sheet (RSS-1) obtained from Weber \& Schaer GmbH \& Co. KG, Germany; BR: High-Cis BR (HC BR) CB 22, as well as High-Cis LongChain Branched BR (HC LCB BR) Nd 22 EZ from ARLANXEO, Germany. Other compounding ingredients are high structure CB N234 from CABOT, USA, and Treated Distillate Aromatic Extract (TDAE) oil from Hansen \& Rosenthal, Germany. N-Cyclohexyl-2-Benzothiazole Sulfenamide (CBS), 2,2,4-TriMethyl-1,2-dihydroQuinoline (TMQ), N-Phenyl-paraPhenyleneDiamine (6PPD), Zinc Oxide (ZnO), stearic acid and sulfur are of technical quality.

For DOE screening purposes, it was decided to use two types of BR as given in Table 3.1 to study the effect of the type of BR on the properties. The compound formulation used for this study is depicted in Table 3.2, adopted from a patent for AC tire tread formulations [18].

Table 3.1 Properties of Butadiene Rubbers.

\begin{tabular}{|l|c|c|}
\hline \multicolumn{1}{|c|}{ Properties } & HC BR & HC LCB BR \\
\hline Catalyst type & Neodymium & Neodymium \\
\hline $\mathrm{ML}(1+4) 100^{\circ} \mathrm{C}, \mathrm{MU}$ & 63 & 63 \\
\hline Cis content, $\%$ & min 96 & min 96 \\
\hline Branching & highly linear & Long-chain branched \\
\hline Weight average molecular weight $(\mathrm{Mw}), \mathrm{g} / \mathrm{mol}$ & $6.0 \times 10^{5}$ & $5.3 \times 10^{5}$ \\
\hline $\mathrm{Mw} / \mathrm{Mn}$ & 2.0 & 2.2 \\
\hline
\end{tabular}


Table 3.2 Rubber compound formulations.

\begin{tabular}{|l|c|c|}
\hline \multicolumn{1}{|c|}{ Ingredients } & Level -1 (phr) & Level +1 (phr) \\
\hline NR & 70 & 70 \\
\hline HC BR & 30 & - \\
\hline HC LCB BR & - & 30 \\
\hline CB N234 & 55 & 55 \\
\hline ZnO & 5 & 5 \\
\hline Stearic acid & 3 & 3 \\
\hline 6PPD & 2 & 2 \\
\hline TMQ & 1 & 1 \\
\hline TDAE & 7.5 & 7.5 \\
\hline Sulfur & 1.5 & 1.5 \\
\hline CBS & 1.5 & 1.5 \\
\hline
\end{tabular}

\subsubsection{COMPOUND PREPARATION}

For the DOE screening, mixing was performed in an internal mixer (Brabender Plasticorder 350s, Brabender GmbH \& Co KG, Germany) with mixer set temperature, rotor speed, and filler mixing time varied according to the defined experimental design (see Table 3.4, DOE screening method in section 3.2.4). The mixer was operated at a fill factor of $70 \%$.

Two-stage mixing was performed as shown in Table 3.3. NR is initially masticated prior to the addition of BR to have a MV close to the one of BR. The masticated NR and BR were blended for 1 minute (min). Then half of $C B$ and TDAE oil were added and mixed for $1 \mathrm{~min}$. After that specific time, the other half of $C B$ and TDAE oil were added and mixed for the remaining time according to the DOE parameter settings in Table 3.4. Mixer rotor speed and set temperature were also DOE parameters. Finally, the other ingredients: ZnO, stearic acid, 6PPD and TMQ were added and mixed for 2.5 mins. The compounds were discharged, sheeted off on a two-roll mill and kept overnight before incorporation of sulfur and CBS in the same internal mixer at a set mixer temperature of $70^{\circ} \mathrm{C}$ and initial rotor speed of 50 revolutions per minute (rpm). For this, the masterbatch was mixed for $1 \mathrm{~min}$, then the rotor speed was decreased to $30 \mathrm{rpm}$ and the curatives added to the compound and mixed for a final 2 mins. 
Table 3.3 Two-stage mixing procedure.

\begin{tabular}{|c|c|c|}
\hline \multicolumn{2}{|c|}{ Mixing procedure } & Time (mins) \\
\hline \multicolumn{3}{|l|}{ Step 1: Internal mixer } \\
\hline \multirow{4}{*}{$\begin{array}{l}\text { Mixer set temperature and } \\
\text { rotor speed: varied } \\
\text { depending on the DOE } \\
\text { factor level settings }\end{array}$} & $\begin{array}{l}\text { - Mixing of masticated-NR } \\
\text { and BR }\end{array}$ & 1 \\
\hline & $\begin{array}{l}\text { - Addition of half (CB and } \\
\text { TDAE oil) }\end{array}$ & 1 \\
\hline & $\begin{array}{l}\text { - Addition of half (CB and } \\
\text { TDAE oil) }\end{array}$ & Remaining time setting \\
\hline & $\begin{array}{l}\text { - Addition of } \mathrm{ZnO} \text {, stearic } \\
\text { acid, 6PPD and TMQ }\end{array}$ & 2.5 \\
\hline \multicolumn{3}{|l|}{ Step 2: Internal mixer } \\
\hline \multirow{2}{*}{$\begin{array}{l}\text { Mixer set temperature: } 70^{\circ} \mathrm{C} \\
\text { Initial rotor speed: } 50 \mathrm{rpm}\end{array}$} & Masterbatch & 1 \\
\hline & $\begin{array}{l}\text { Addition of curatives } \\
\text { (sulfur and CBS) }\end{array}$ & 2 \\
\hline
\end{tabular}

\subsubsection{TESTING OF COMPOUND AND VULCANIZATE PROPERTIES}

The following compound and vulcanizate properties were chosen as the defined responses for DOE:

Mooney Viscosity (MV) - The compounds were tested for their MV by using a Mooney Viscometer 2000VS (Alpha Technologies, USA) at $100^{\circ} \mathrm{C}$ with a large rotor for 4 mins with 1 min of pre-heating according to ASTM D1646. The value is represented as $\mathrm{ML}(1+4) 100^{\circ} \mathrm{C}$.

Payne Effect (PE) - The storage modulus ( $\left.\mathrm{G}^{\prime}\right)$ of the compounds was measured using a Rubber Processing Analyzer (RPA 2000 Alpha Technologies, USA). A strain sweep test was done in the range of 0.56 to $100 \%$ strain at $0.5 \mathrm{~Hz}$ and $100^{\circ} \mathrm{C}$. The difference of $\mathrm{G}^{\prime}$ at $0.56 \%$ and at $100 \%$ strain $\left(\Delta G^{\prime}\right)$ was taken as measure of filler-filler interaction.

Hysteresis $(\tan \delta)$ - The compounds were cured to their $\left(t_{90}+2\right)$ mins at $150^{\circ} \mathrm{C}$ in the RPA. After curing in situ, the temperature was decreased to $100^{\circ} \mathrm{C}$ for the hysteresis measurement. The $\tan \delta$ was then recorded in a frequency sweep of $0.5-33 \mathrm{~Hz}$ and a fixed strain of $10 \%$.

Stress-strain properties -All compounds were vulcanized at a cure time $\left(t_{90}+2\right)$ mins at $150^{\circ} \mathrm{C}$ in a Wickert Laboratory Press (WLP1600, Wickert Maschinenbau GmbH, Germany). The sheets having a thickness of 2 millimeters $(\mathrm{mm})$ were die-cut into dumbbells type 2 for the Modulus at 300\% elongation (M300\%) and Tensile Strength (TS) measurements. The tests were done with a Zwick Roell Z1.0 tensile testing machine using a crosshead speed of $500 \mathrm{~mm} / \mathrm{min}$ according to ISO 37. 


\subsubsection{DOE SCREENING}

A DOE screening was employed in the first stage of experiments. The objective at this stage was to explore if factors influence the selected responses and to identify the appropriate ranges. A two-level full factorial approach comprising four factors is shown in Table 3.4. Each factor has two levels: low -1 and high +1 with an additional Center Point (CP) 0 , chosen for replication, except for the BR type. Table 3.5 shows the rubber properties as defined responses.

Table 3.4 Experimental design for optimizing mixing conditions.

\begin{tabular}{|l|c|c|c|}
\hline \multicolumn{1}{|c|}{ Parameters } & $\mathbf{- 1}$ & $\mathbf{0}$ & $\mathbf{+ 1}$ \\
\hline A: BR type & HC BR & - & HC LCB BR \\
\hline B: Mixer set temperature $\left({ }^{\circ} \mathrm{C}\right)$ & 50 & 75 & 100 \\
\hline C: Rotor speed $(\mathrm{rpm})$ & 60 & 90 & 120 \\
\hline D: Filler mixing time $(\mathrm{min})$ & 2 & 6 & 10 \\
\hline
\end{tabular}

Table 3.5 Defined responses.

\begin{tabular}{|c|c|c|}
\hline Responses & Rubber properties & Abbreviation \\
\hline $\mathrm{Y} 1$ & Mooney Viscosity & $\mathrm{MV}$ \\
\hline $\mathrm{Y} 2$ & Payne Effect & $\mathrm{PE}$ \\
\hline $\mathrm{Y} 3$ & $\tan \delta$ at $100^{\circ} \mathrm{C}$ & $\tan \delta$ \\
\hline $\mathrm{Y} 4$ & Modulus $300 \%$ & $\mathrm{M} 300 \%$ \\
\hline $\mathrm{Y} 5$ & Tensile Strength & $\mathrm{TS}$ \\
\hline
\end{tabular}

Figure 3.1 depicts the two-level full factorial design with four factors, denoted $2^{4}$, which is geometrically represented in a cube. The cube is representative for each of the two different types of BR. The three axes are dedicated to mixer set temperature, rotor speed and filler mixing time. The total number of experiments for this stage is 22 runs. 


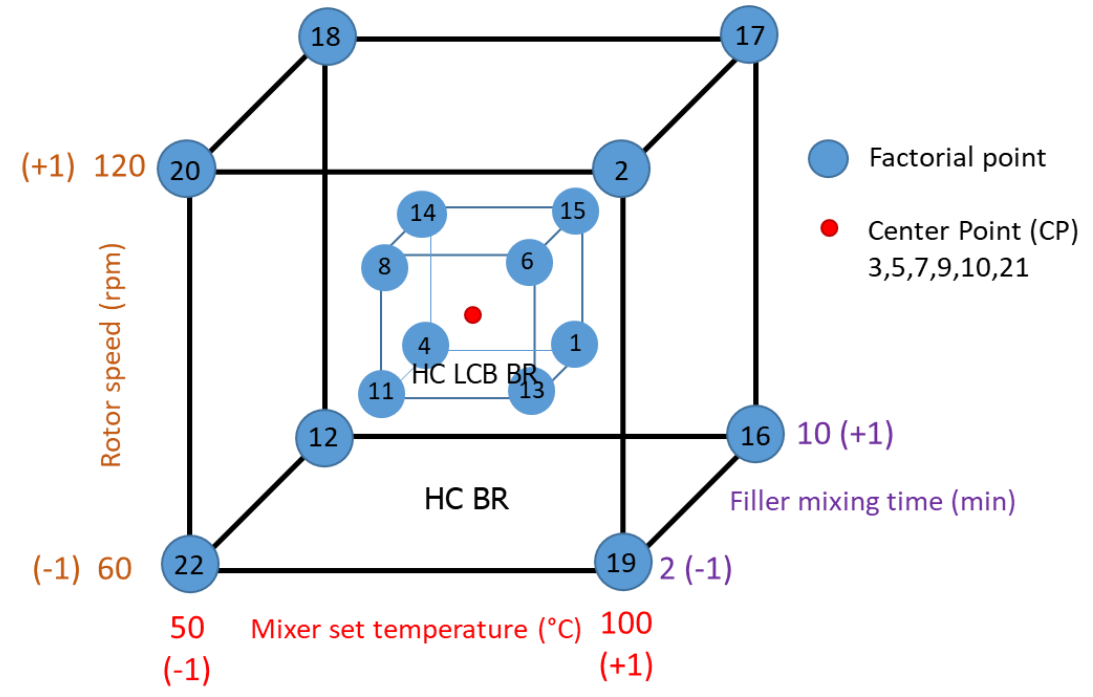

The cube represents a single type of $B R$

( $\mathrm{HC} B \mathrm{BR}$ and $\mathrm{HC}$ LCB BR)

$\mathrm{DOE}$ full factorial $+3 \mathrm{CP}$ replication

No. of factors $=4$

No. of levels $=2$

No. of experiments $=2^{4}+(2 \times 3)=22$

Figure 3.1 Two-level full factorial DOE setup with center points.

After completion of the experimental runs, the data were analyzed by a Pareto approach to find out which factors and/or interactions significantly influence the responses. Pareto calculations comprise the following steps [19]:

$$
\begin{aligned}
& \text { Effect }=\frac{\sum Y_{+}}{n_{+}}-\frac{\sum Y_{-}}{n_{-}} \\
& \text {Sum of Squares }(S S)=\frac{\left(n_{+}+n_{-}\right)}{4} x(\text { Effect })^{2} \\
& \text { Mean of Squares }(M S)=\frac{S S}{d f} \\
& M S_{\text {residual }}=\frac{S S_{\text {residual }}}{d f_{\text {residual }}} \\
& t-\text { value }=\frac{\mid \text { Effect } \mid}{\sqrt{M S_{\text {residual }} x\left(\frac{1}{n_{+}}+\frac{1}{n_{-}}\right)}}
\end{aligned}
$$

$Y_{+}:$the results of observed response in level +1

$Y_{-}:$the results of observed response in level -1

$n_{+}:$the total number of experiments in level +1

$n_{-}:$the total number of experiments in level -1

df : degrees of freedom 
The effect of factors and the interaction between factors on the rubber properties $(Y)$ were analyzed using Analysis of Variance (ANOVA) and then modeled by fitting a polynomial model to the data as described in Equation 3.6 [20]:

$$
\begin{aligned}
Y= & \beta_{o}+\beta_{A} A+\beta_{B} B+\beta_{C} C+\beta_{D} D+\beta_{A B} A B+\beta_{A C} A C+ \\
& \beta_{A D} A D+\beta_{B C} B C+\beta_{B D} B D+\beta_{C D} C D+\varepsilon
\end{aligned}
$$

where $A, B, C$, and $D$ are the independent factors (BR type, mixer set temperature, rotor speed, filler mixing time), $\beta_{o}$ is a constant, $\beta_{A}, \beta_{B}, \beta_{C}, \beta_{D}$ are linear coefficients, $\beta_{A B}, \beta_{A C}$, $\beta_{A D}, \beta_{B C}, \beta_{B D}, \beta_{C D}$ are interaction regression coefficients, and $\varepsilon$ is the residual response variation not explained by the model.

Contour and interaction plots were used to describe the effects of factors and/or interactions on responses in more detail.

\subsubsection{DOE OPTIMIZATION}

The two most significant factors on defined-responses: rotor speed and filler mixing time, from the DOE screening were further optimized using the Response Surface Method (RSM). A Central Composite Circumscribed (CCC) design was selected for the DOE optimization, with the level settings as shown in Figure 3.2. A total of 11 runs was performed to elucidate in more detail the effect of the two most significant factors and their interactions on the defined responses.

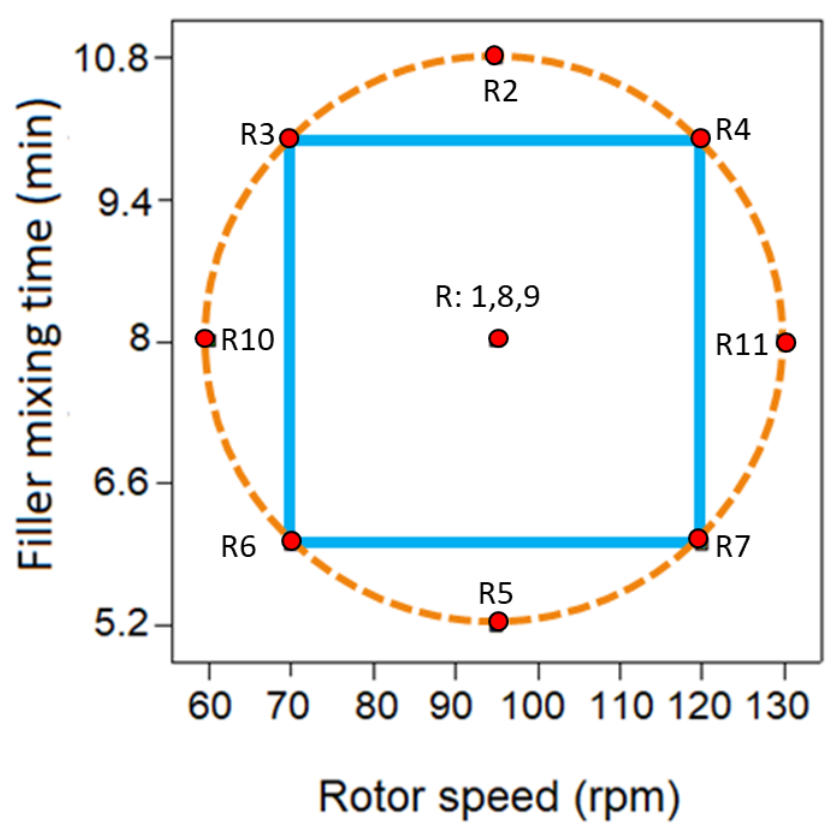

Figure 3.2 CCC design setup. 
The assessment of the significance of the factors and their interaction in the DOE optimization was the same as in the DOE screening. The difference lies only in the model used for fitting; this permits the response to be modeled with a second order polynomial equation, allowing the analysis of main, quadratic (curvature), and interactive effects [17]. The equation used in the central composite design for fitting the effect of factors ( $C$ and $D)$ on the response $(\mathrm{Y})$ is described by Equation 3.7. The symbols are the same as mentioned in Equation 3.6, with the additional quadratic coefficients.

$$
\begin{aligned}
Y= & \beta_{o}+\beta_{C} C+\beta_{D} D+\beta_{C D} C D+\beta_{C C} C^{2}+\beta_{D D} D^{2}+\beta_{C^{2} D} C^{2} D+ \\
& \beta_{C D^{2}} C D^{2}+\beta_{C^{2} D^{2}} C^{2} D^{2}+\varepsilon
\end{aligned}
$$

Equation 3.7

\subsection{RESULTS AND DISCUSSION}

\subsubsection{DOE SCREENING}

Table 3.6 shows the values of each response resulting from the DOE screening. The effect, Sum of Squares (SS), and Mean of Squares (MS) were calculated using Equations 3.1 - 3.4. Table 3.7 shows an example of the calculated effect, SS, MS for Mooney Viscosity (MV).

\begin{tabular}{|c|c|c|c|c|c|c|c|c|c|}
\hline No. & $\begin{array}{c}\text { A: } \\
\text { BR } \\
\text { type }\end{array}$ & $\begin{array}{c}\text { B: } \\
\text { Mixer set } \\
\text { temperature } \\
\left({ }^{\circ} \mathrm{C}\right)\end{array}$ & $\begin{array}{c}\text { C: } \\
\text { Rotor } \\
\text { speed } \\
(\mathbf{r p m})\end{array}$ & $\begin{array}{c}\text { D: } \\
\text { Filler } \\
\text { mixing } \\
\text { time } \\
(\text { min) }\end{array}$ & $\begin{array}{l}\text { Y1: } \\
\text { MV } \\
\text { (MU) }\end{array}$ & $\begin{array}{l}\text { Y2: } \\
\text { PE } \\
(\mathrm{kPa})\end{array}$ & $\begin{array}{c}\text { Y3: } \\
\tan \delta \text { at } \\
100^{\circ} \mathrm{C} \\
(-)\end{array}$ & $\begin{array}{c}\text { Y4: } \\
\text { M300\% } \\
\text { (MPa) }\end{array}$ & $\begin{array}{c}\text { Y5: } \\
\text { TS } \\
\text { (MPa) }\end{array}$ \\
\hline 1 & 1 & 1 & -1 & 1 & 81 & 494 & 0.120 & 17 & 25 \\
\hline 2 & -1 & 1 & 1 & -1 & 75 & 479 & 0.127 & 16 & 30 \\
\hline 3 & -1 & 0 & 0 & 0 & 84 & 581 & 0.132 & 17 & 31 \\
\hline 4 & 1 & -1 & -1 & 1 & 91 & 764 & 0.144 & 17 & 30 \\
\hline 5 & 1 & 0 & 0 & 0 & 81 & 529 & 0.122 & 16 & 32 \\
\hline 6 & 1 & 1 & 1 & -1 & 76 & 578 & 0.121 & 17 & 25 \\
\hline 7 & 1 & 0 & 0 & 0 & 78 & 559 & 0.134 & 17 & 31 \\
\hline 8 & 1 & -1 & 1 & -1 & 86 & 588 & 0.128 & 16 & 26 \\
\hline 9 & -1 & 0 & 0 & 0 & 82 & 622 & 0.136 & 17 & 31 \\
\hline 10 & -1 & 0 & 0 & 0 & 87 & 686 & 0.138 & 17 & 29 \\
\hline 11 & 1 & -1 & -1 & -1 & 102 & 1000 & 0.152 & 13 & 26 \\
\hline 12 & -1 & -1 & -1 & 1 & 101 & 914 & 0.138 & 14 & 25 \\
\hline 13 & 1 & 1 & -1 & -1 & 94 & 850 & 0.144 & 16 & 30 \\
\hline 14 & 1 & -1 & 1 & 1 & 66 & 383 & 0.103 & 18 & 25 \\
\hline 15 & 1 & 1 & 1 & 1 & 50 & 278 & 0.110 & 15 & 24 \\
\hline 16 & -1 & 1 & -1 & 1 & 91 & 544 & 0.133 & 17 & 29 \\
\hline 17 & -1 & 1 & 1 & 1 & 60 & 332 & 0.106 & 19 & 25 \\
\hline 18 & -1 & -1 & 1 & 1 & 64 & 369 & 0.113 & 17 & 27 \\
\hline 19 & -1 & 1 & -1 & -1 & 108 & 966 & 0.143 & 14 & 25 \\
\hline 20 & -1 & -1 & 1 & -1 & 92 & 641 & 0.132 & 15 & 26 \\
\hline 21 & 1 & 0 & 0 & 0 & 78 & 546 & 0.132 & 17 & 32 \\
\hline 22 & -1 & -1 & -1 & -1 & 101 & 891 & 0.148 & 11 & 28 \\
\hline
\end{tabular}

Table 3.6 Results of defined responses from DOE screening. 
Table 3.7 Example of calculated effect, SS, MS, F-value for MV

\begin{tabular}{|l|r|r|r|r|}
\hline $\begin{array}{c}\text { Factors and two-factor } \\
\text { interaction }\end{array}$ & Effect & \multicolumn{1}{c|}{$\begin{array}{c}\text { Sum of } \\
\text { Squares } \\
\text { (SS) }\end{array}$} & $\begin{array}{c}\text { Degrees of } \\
\text { freedom } \\
\text { (df) }\end{array}$ & $\begin{array}{c}\text { Mean of } \\
\text { Squares } \\
\text { (MS) }\end{array}$ \\
\hline Model & & 4379.52 & 10 & 437.95 \\
\hline A: BR type & -5.85 & 185.60 & 1 & 185.60 \\
\hline B: Mixer set temperature & -8.65 & 299.29 & 1 & 299.29 \\
\hline C: Rotor speed & -25.28 & 2555.30 & 1 & 2555.30 \\
\hline D: Filler mixing time & -16.50 & 1089.00 & 1 & 1089.00 \\
\hline AB & -2.30 & 21.16 & 1 & 21.16 \\
\hline AC & 2.58 & 26.52 & 1 & 26.52 \\
\hline AD & -1.55 & 9.00 & 1 & 9.00 \\
\hline BC & -3.33 & 44.22 & 1 & 44.22 \\
\hline BD & -1.50 & 9.00 & 1 & 9.00 \\
\hline CD & -5.93 & 140.42 & 1 & 140.42 \\
\hline Residual & & 157.71 & 9 & 17.52 \\
\hline Total & & 4537.23 & & \\
\hline
\end{tabular}

Figure 3.3 shows the Pareto charts of factors for defined responses from the DOE screening. A t-test compares the observed t-value according to Equation 3.5 to a t-value limit derived from the t-distribution table for $\mathrm{df}_{\text {residual }} 9$ and alpha 0.05 [19], in order to determine whether the difference between the estimated and hypothesized values of the factor or interaction is statistically significant. Alpha 0.05 means having $5 \%$ probability of incorrectly rejecting the null. The null states that there is no difference or no effect of the parameters being studied. If the t-value is higher than the t-value limit, it means that the factor/interaction is statistically significant.

The graphs show that rotor speed and filler mixing time are the most significant factors influencing $\mathrm{MV}, \mathrm{PE}, \tan \delta$ at $100^{\circ} \mathrm{C}$, and $\mathrm{M} 300 \%$. The mixer temperature has an influence on $M V$ and PE, but less of an effect on tan $\delta$ and $M 300 \%$. The type of BR has an effect on MV and $\mathrm{M} 300 \%$. For TS, the effect of these factors is not conclusive as seen from their $\mathrm{t}$-values being below the $t$-value limit. Note that the colored bars without notation are the interactions that are not included in the model (examples: $A B C, A B D, A B C D$ ) because they are not twofactor interactions (examples: $A B, A C, A D$ ). 
(a)

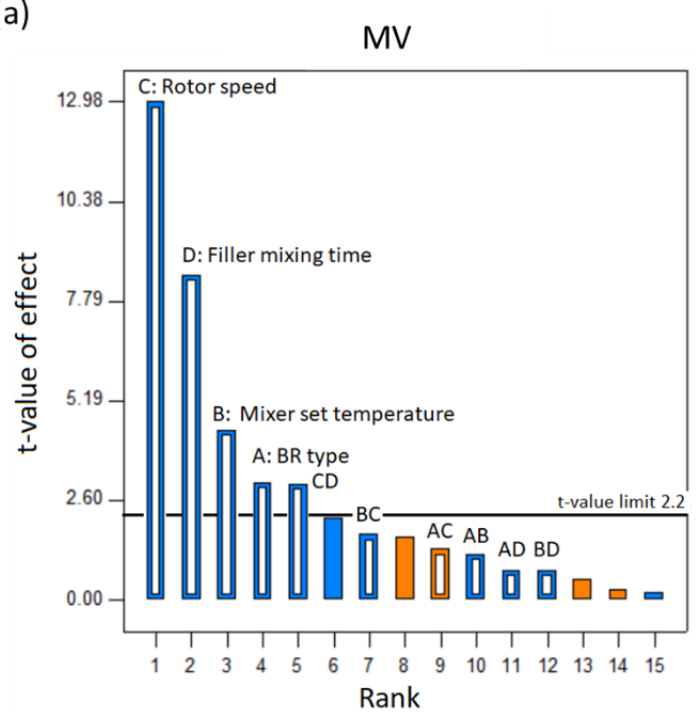

(c)

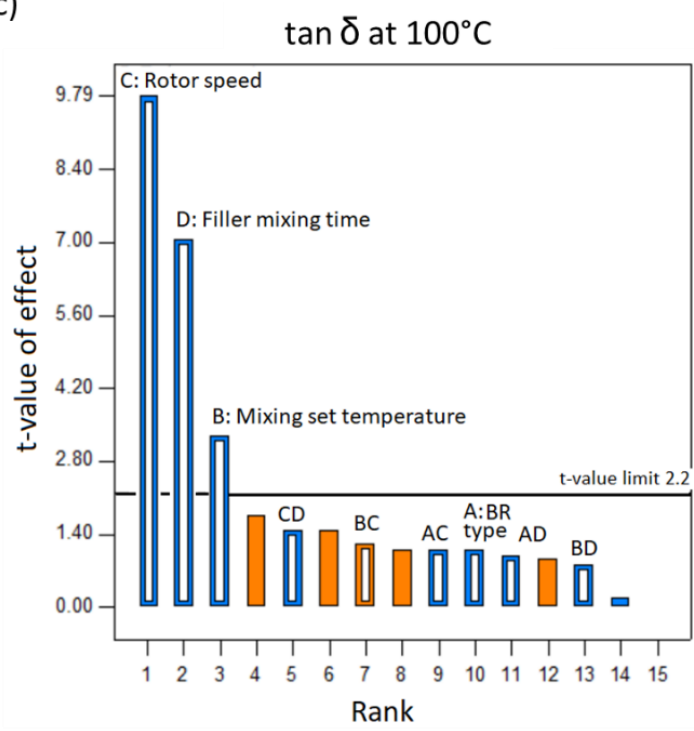

(b)

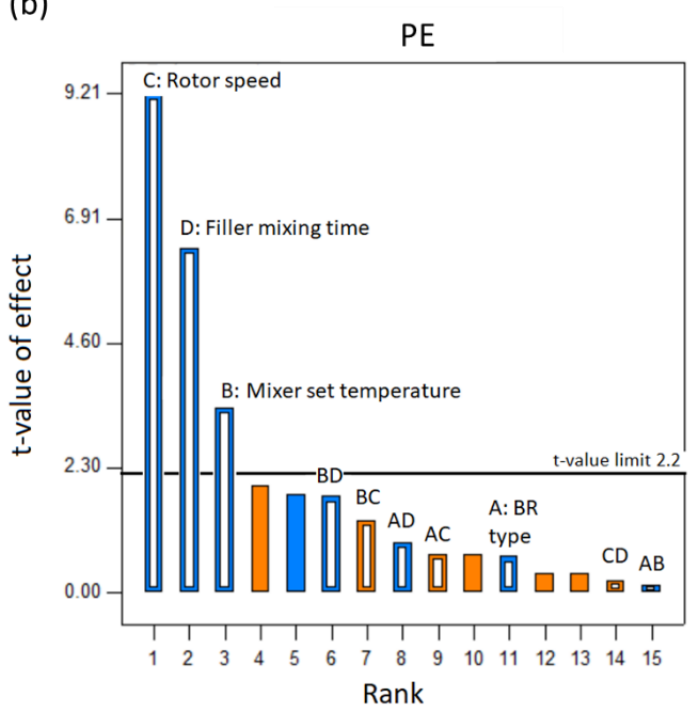

(d)

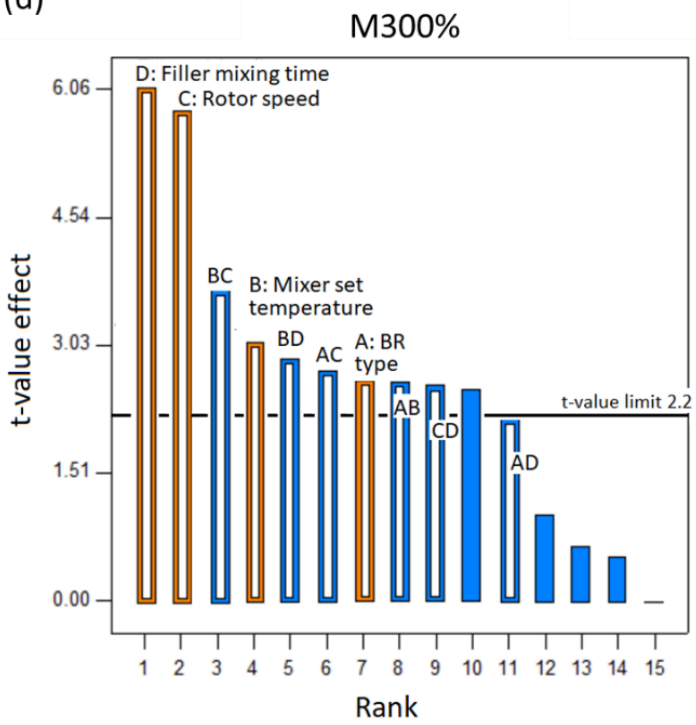

(e)

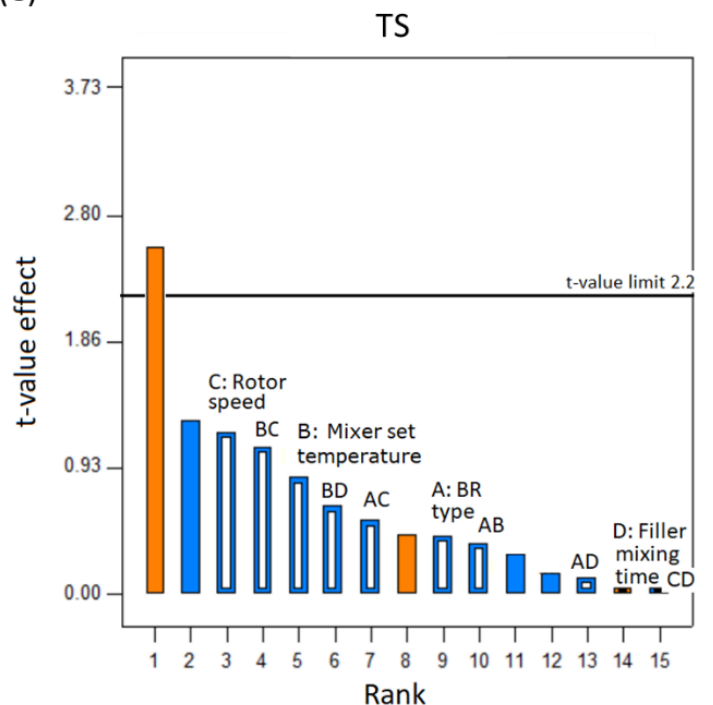

Figure 3.3 Pareto charts of factors for the properties: MV (a); PE (b); $\tan \delta$ at $100^{\circ} \mathrm{C}(\mathrm{c})$; M300\% (d); TS (e). 
Table 3.8 parts 1 and 2 show the coefficients of the parameters studied, obtained from ANOVA. Rotor speed (C) and filler mixing time (D) are statistically significant factors ( $p$-value $\leq 0.05$, written in blue) for $\mathrm{MV}, \mathrm{PE}, \tan \delta$ at $100^{\circ} \mathrm{C}$ and $\mathrm{M} 300 \%$. The P-value is the probability of obtaining a sample "more extreme" than the ones observed in the data assuming that the null hypothesis is true. The Null hypothesis states that there is no difference or no effect of the parameters being studied. The effect of the studied factors on the properties is strongly related to a R-squared of 0.9 or above, except for the M300\% values. R-Squared is a statistical measure of how close the data are to the fitted regression line. An increase of rotor speed increases the shear stress, thus enables a decrease of MV and a low filler-filler interaction [21, 22]. M300\% correlates with the parameters studied with a R-squared value slightly below 0.9 , while TS shows no linear correlation with the studied factors: The R-squared is 0.16 . There are two possible explanations for this:

1. The TS of the materials might not follow a linear model as described in Equation 3.6. Indeed, during the optimization, when a quadratic model was used (Equation 3.7), the R-squared value increased to 0.93 , see Table 3.9.

2. This property is influenced by a variety of other factors which are not covered in the model. TS depends not only on the degree of filler dispersion, but also on crosslink density, rubber-filler interaction, and filler loading [23], to mention only a few. At equal filler loadings, TS depends on the degree of filler dispersion and is closely related to the degree of rubber-filler interaction. Therefore, changes in any parameter that improves filler dispersion and rubber-filler interaction will also influence TS [17].

Table 3.8 Coefficients of parameters studied by DOE screening (part 1).

\begin{tabular}{|c|c|c|c|c|c|c|}
\hline \multirow[t]{3}{*}{ Responses } & & \multirow[b]{2}{*}{ Constant } & \multicolumn{4}{|c|}{ Variables } \\
\hline & & & $\begin{array}{c}\text { BR } \\
\text { type } \\
\text { A }\end{array}$ & $\begin{array}{c}\text { Mixer set } \\
\text { temperature } \\
\text { B }\end{array}$ & $\begin{array}{l}\text { Rotor } \\
\text { speed } \\
\text { C }\end{array}$ & $\begin{array}{c}\text { Filler } \\
\text { mixing } \\
\text { time } \\
\text { D }\end{array}$ \\
\hline & & $\beta_{o}$ & $\boldsymbol{\beta}_{A}$ & $\boldsymbol{\beta}_{B}$ & $\boldsymbol{\beta}_{C}$ & $\boldsymbol{\beta}_{D}$ \\
\hline \multirow[t]{3}{*}{$\mathrm{MV}, \mathrm{MU}$} & HC BR & 116.80 & - & 0.12 & -0.15 & 0.91 \\
\hline & HC LCB BR & 112.42 & - & 0.03 & -0.06 & 0.53 \\
\hline & p-value & - & 0.004 & 0.001 & $<0.0001$ & $<0.0001$ \\
\hline \multirow[t]{3}{*}{$\mathrm{PE}, \mathrm{kPa}$} & $\mathrm{HC} \mathrm{BR}$ & 1633.10 & - & -3.48 & -8.96 & -3.70 \\
\hline & HC LCB BR & 1579.69 & - & -3.70 & -8.07 & -12.40 \\
\hline & p-value & - & 0.22 & 0.006 & $<0.0001$ & $<0.0001$ \\
\hline \multirow[t]{3}{*}{$\tan \delta$ at $100^{\circ} \mathrm{C}$} & HC BR & 0.19 & - & $-3.2 \mathrm{E}-04$ & $-4.6 \mathrm{E}-04$ & $-4.6 \mathrm{E}-04$ \\
\hline & HC LCB BR & 0.20 & - & $-3.7 E-04$ & $-5.2 \mathrm{E}-04$ & $-8.1 \mathrm{E}-04$ \\
\hline & p-value & - & 0.21 & 0.04 & $<0.0001$ & 0.0002 \\
\hline \multirow[t]{3}{*}{$\mathrm{M} 300 \%, \mathrm{MPa}$} & HC BR & -0.46 & - & 0.13 & 0.12 & 0.94 \\
\hline & HC LCB BR & 5.95 & - & 0.10 & 0.09 & 0.77 \\
\hline & p-value & - & 0.18 & 0.05 & 0.001 & 0.001 \\
\hline \multirow[t]{3}{*}{ TS, MPa } & $\mathrm{HC} \mathrm{BR}$ & 23.99 & - & 0.62 & 0.02 & 0.03 \\
\hline & HC LCB BR & 29.29 & - & 0.59 & -0.03 & 0.02 \\
\hline & p-value & - & 0.95 & 0.73 & 0.44 & 0.98 \\
\hline
\end{tabular}


Table 3.8 Coefficients of parameters studied by DOE screening (part 2).

\begin{tabular}{|c|c|c|c|c|c|c|c|c|}
\hline \multirow[t]{3}{*}{ Responses } & & \multicolumn{6}{|c|}{ Variables } & \multirow{3}{*}{$\begin{array}{c}\text { R- } \\
\text { Squared }\end{array}$} \\
\hline & & \multirow{2}{*}{$\begin{array}{l}\mathbf{A B} \\
\beta_{A B} \\
\end{array}$} & \multirow{2}{*}{$\begin{array}{l}\mathbf{A C} \\
\beta_{A C}\end{array}$} & \multirow{2}{*}{$\begin{array}{l}\mathbf{A D} \\
\beta_{A D}\end{array}$} & \multirow{2}{*}{$\begin{array}{l}\mathrm{BC} \\
\beta_{B C}\end{array}$} & \multirow{2}{*}{$\begin{array}{c}\text { BD } \\
\beta_{B D}\end{array}$} & \multirow{2}{*}{$\begin{array}{l}\mathrm{CD} \\
\beta_{C D}\end{array}$} & \\
\hline & & & & & & & & \\
\hline \multirow[t]{3}{*}{$\mathrm{MV}, \mathrm{MU}$} & $\mathrm{HC} \mathrm{BR}$ & - & - & - & $-2.2 \mathrm{E}-03$ & $-7.5 \mathrm{E}-03$ & -0.02 & \multirow[t]{3}{*}{0.97} \\
\hline & HC LCB BR & - & - & - & $-2.2 \mathrm{E}-03$ & $-7.5 \mathrm{E}-03$ & -0.02 & \\
\hline & p-value & 0.25 & 0.20 & 0.44 & 0.10 & 0.44 & 0.01 & \\
\hline \multirow[t]{3}{*}{$\mathrm{PE}, \mathrm{kPa}$} & HC BR & - & - & - & 0.03 & -0.33 & 0.04 & \multirow[t]{3}{*}{0.93} \\
\hline & HC LCB BR & - & - & - & 0.03 & -0.33 & 0.04 & \\
\hline & p-value & 0.89 & 0.50 & 0.38 & 0.21 & 0.11 & 0.83 & \\
\hline \multirow[t]{3}{*}{$\tan \delta$ at $100^{\circ} \mathrm{C}$} & HC BR & - & - & - & $2.5 \mathrm{E}-06$ & $-2.5 \mathrm{E}-06$ & $1.3 \mathrm{E}-05$ & \multirow[t]{3}{*}{0.90} \\
\hline & HC LCB BR & - & - & - & $2.5 \mathrm{E}-06$ & $-2.5 \mathrm{E}-06$ & $1.3 \mathrm{E}-05$ & \\
\hline & p-value & 0.67 & 0.56 & 0.74 & 0.22 & 0.87 & 0.32 & \\
\hline \multirow[t]{3}{*}{$\mathrm{M} 300 \%, \mathrm{MPa}$} & HC BR & - & - & - & $\begin{array}{l}-7.5 \mathrm{E}-04 \\
\end{array}$ & $-4.4 \mathrm{E}-03$ & $-3.2 \mathrm{E}-03$ & \multirow[t]{3}{*}{0.86} \\
\hline & HC LCB BR & - & - & - & $-7.5 \mathrm{E}-04$ & $-4.4 \mathrm{E}-03$ & $-3.2 \mathrm{E}-03$ & \\
\hline & p-value & 0.08 & 0.07 & 0.13 & 0.02 & 0.06 & 0.09 & \\
\hline \multirow[t]{3}{*}{$\mathrm{TS}, \mathrm{MPa}$} & HC BR & - & - & - & $-3.4 \mathrm{E}-03$ & $-5.1 \mathrm{E}-03$ & $3.9 \mathrm{E}-05$ & \multirow[t]{3}{*}{0.16} \\
\hline & HC LCB BR & - & - & - & $-3.4 \mathrm{E}-03$ & $-5.1 \mathrm{E}-03$ & $3.9 \mathrm{E}-05$ & \\
\hline & p-value & 0.81 & 0.48 & 0.94 & 0.65 & 0.57 & 0.97 & \\
\hline
\end{tabular}

Contour plots are used to see the effect of factors and interactions on responses more clearly. The interaction factor 'interaction between rotor speed and filler mixing time' on MV is depicted in Figure 3.4 for the two types of $B R$ at $100^{\circ} \mathrm{C}$ of mixer temperature. A synergistic effect of rotor speed and filler mixing time was found at the high-level settings, in which the combination of high rotor speed and long filler mixing time decreases MV of compounds considerably, as can be seen more clearly in Figure 3.5, where the distance between the lines is not the same at low- and high-level settings of rotor speed and filler mixing time. A high rotor speed provides higher shear stresses and results in higher stock temperatures, both lowering MV.

At the same rotor speed and filler mixing time, the MV of the rubber compounds containing $\mathrm{HC}$ BR is higher than the one of the compounds containing HC LCB BR. The high MV values are due to the slightly higher molecular weight of $H C B R$, thus higher viscosity compared to HC LCB BR, which has a lower molecular weight. Branching of HC LCB BR also improves the processability resulting in lower MV compared to the linear chain $\mathrm{HC} B R$ compounds. 

$A: B R$ type $=\mathrm{HCBR}$
B: Mixer set temperature $=100^{\circ} \mathrm{C}$

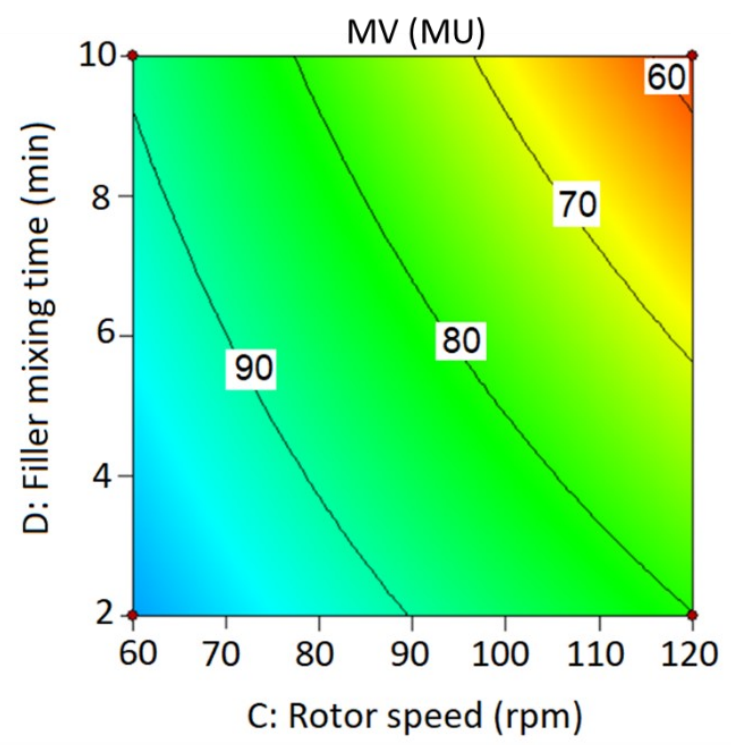

A: BR type $=\mathrm{HC} L C B$ BR

B: Mixer set temperature $=100^{\circ} \mathrm{C}$

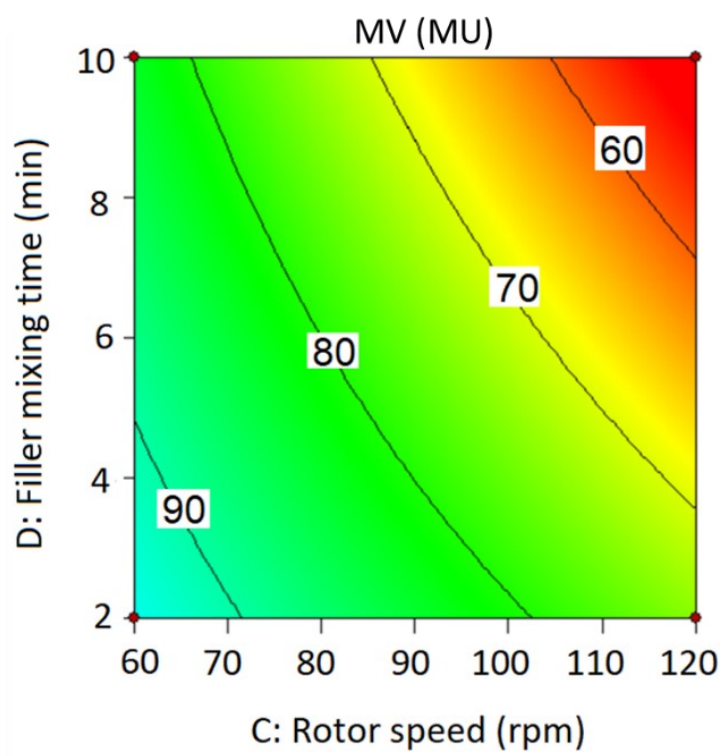

Figure 3.4 The effect of rotor speed and filler mixing time on MV.

A: $B R$ type $=H C B R$

B: Mixer set temperature $=100^{\circ} \mathrm{C}$

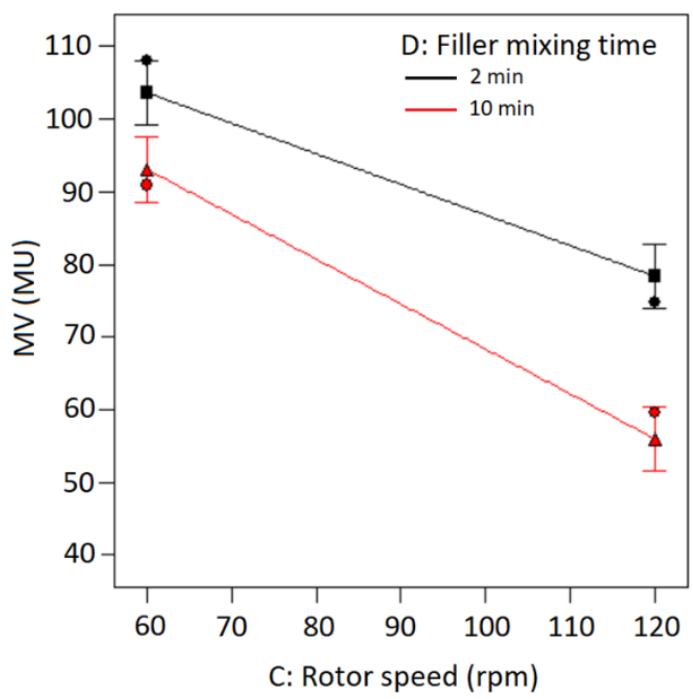

A: $B R$ type $=H C L C B B R$

B: Mixer set temperature $=100^{\circ} \mathrm{C}$

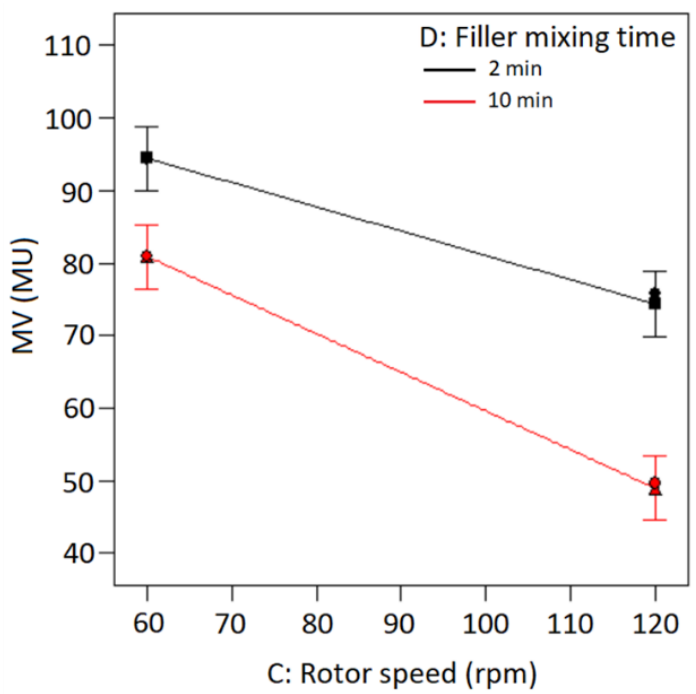

Figure 3.5 Interaction plot between rotor speed and filler mixing time on MV.

The effect of the two most significant factors on PE is shown in Figure 3.6. The higher the rotor speed and the longer the filler mixing time, the lower the PE. High rotor speed provides high shear rate, which is necessary for dispersive mixing and enhances the fragmentation of $\mathrm{CB}$ agglomerates down to $\mathrm{CB}$ aggregates. Longer mixing times increase the inter-aggregate distance of $\mathrm{CB}$, leading to reduced formation of filler networks [24]. The combination of both factors results in an even lower PE compared to using only one single factor (rotor speed or filler mixing time) at high level settings. HC LCB BR shows a lower PE compared to HC BR due to branching which enhances processability. 
A: $B R$ type $=\mathrm{HC} B R$

B: Mixer set temperature $=100^{\circ} \mathrm{C}$

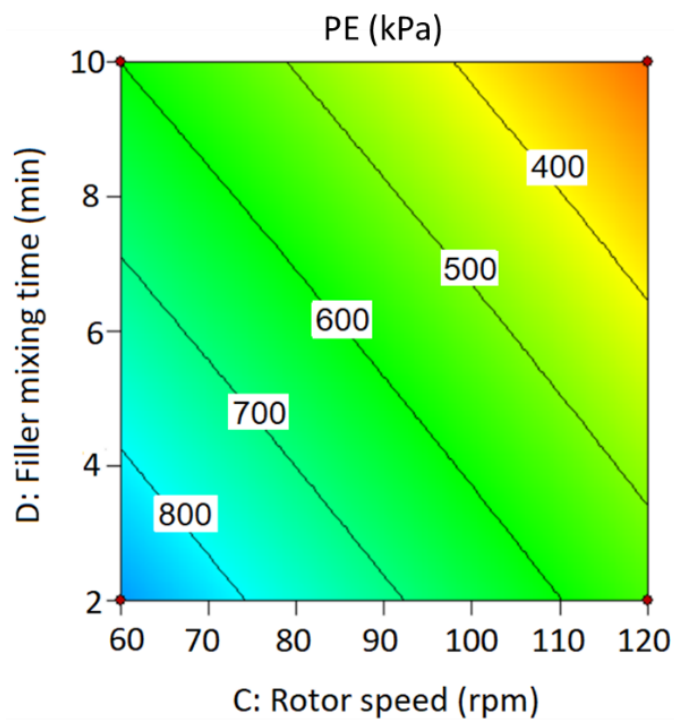

A: BR type $=\mathrm{HC} L C B$ BR

B: Mixer set temperature $=100^{\circ} \mathrm{C}$

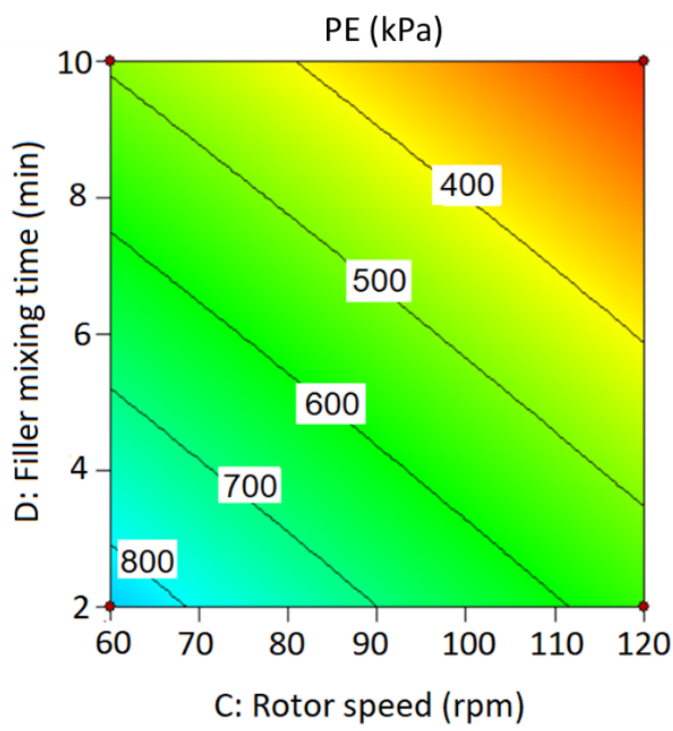

Figure 3.6 The effect of rotor speed and filler mixing time on PE.

Tan $\delta$ at $100^{\circ} \mathrm{C}$ is used as an indication of hysteresis: a lower tan $\delta$ indicates less hysteresis and lower heat generation. Figure 3.7 shows the effect of rotor speed and filler mixing time on $\tan \delta$ at $100^{\circ} \mathrm{C}$ : high rotor speed and long filler mixing time decrease tan $\delta$. The $\tan \delta$ values correlate well with Payne effect values, as low $\tan \delta$ values correspond to low filler-filler interaction.

A: BR type $=\mathrm{HC} B R$

B: Mixer set temperature $=100^{\circ} \mathrm{C}$

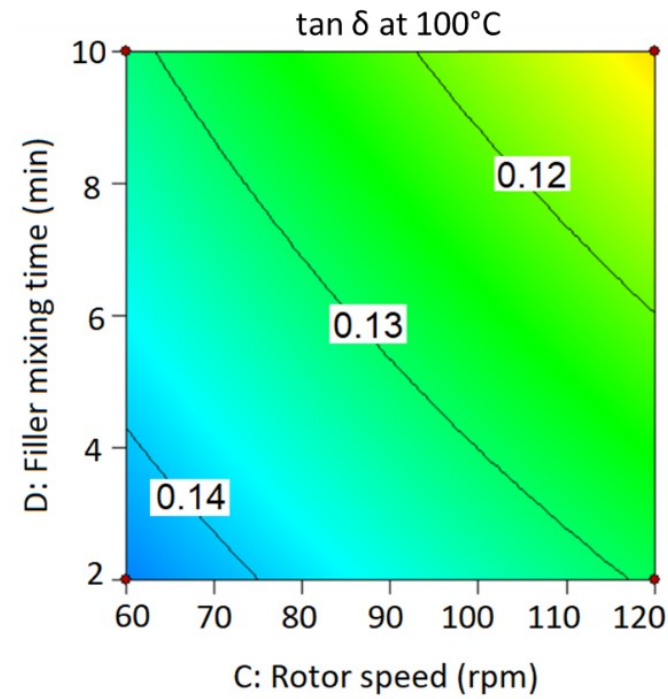

A: $B R$ type $=\mathrm{HC} L C B$ BR

$B$ : Mixer set temperature $=100^{\circ} \mathrm{C}$

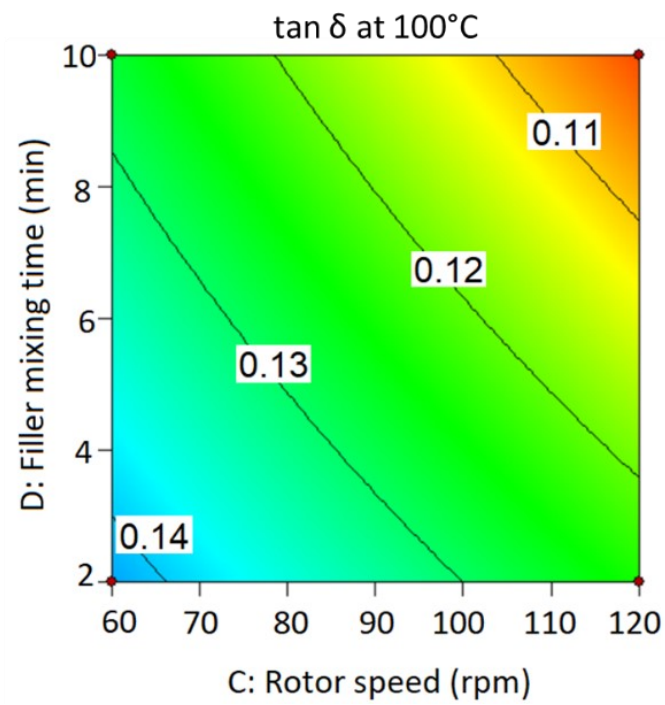

Figure 3.7 The effect of rotor speed and filler mixing time on $\tan \delta$. 
High M300\% values were observed in the HC BR compounds, which were mixed at high rotor speed and long filler mixing time as shown in Figure 3.8 left. Like TS, M300\% is influenced by many factors such as filler-filler interaction, filler-rubber interaction, and the type of polymers used. The linear chain of HC BR has a simple structure, and it can be packed tightly, while the branched HC LCB BR has a complex structure and is packed loosely [25]. As a result, $\mathrm{HC}$ BR exhibits higher mechanical properties compared to HC LCB BR. However, HC BR shows poor processability: $\mathrm{HC}$ BR requires more severe mixing conditions (temperature and filler mixing time) than HC LCB BR to achieve high filler dispersion and optimum $\mathrm{M} 300 \%$.
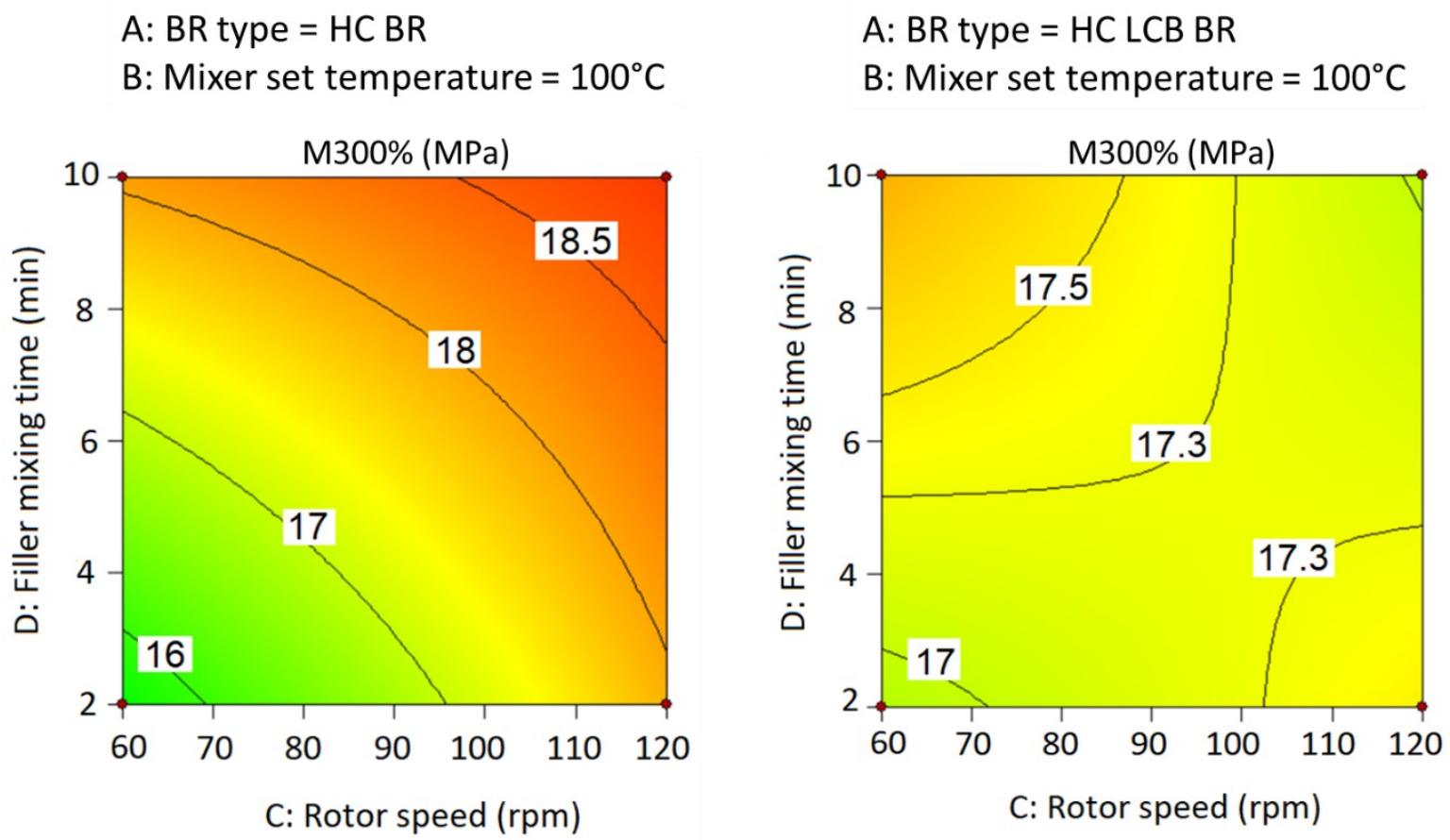

Figure 3.8 The effect of rotor speed and filler mixing time on $\mathrm{M} 300 \%$.

In contrast, M300\% values of HC LCB BR are relatively independent of rotor speed and filler mixing time at a mixer set temperature of $100^{\circ} \mathrm{C}$ : Figure 3.8 (right). At lower mixer set temperatures of $50^{\circ} \mathrm{C}$ and $75^{\circ} \mathrm{C}$, the rotor speed and filler mixing time do influence $\mathrm{M} 300 \%$ values of HC LCB BR. Due to the branching, thus better processability, the maximum $\mathrm{M} 300 \%$ value is already reached at a mixer set temperature of $50^{\circ} \mathrm{C}$. Increasing mixer set temperature to $70^{\circ} \mathrm{C}$ decreases the maximum $\mathrm{M} 300 \%$ values of $\mathrm{HC}$ LCB BR, see Figure 3.9 (right), and at a mixer set temperature of $100^{\circ} \mathrm{C}$ no difference in $\mathrm{M} 300 \%$ values is observed within the investigation range of rotor speed and filler mixing time: Figure 3.8 (right). 
A: $B R$ type $=\mathrm{HC} L C B$ BR

B: Mixer set temperature $=50^{\circ} \mathrm{C}$

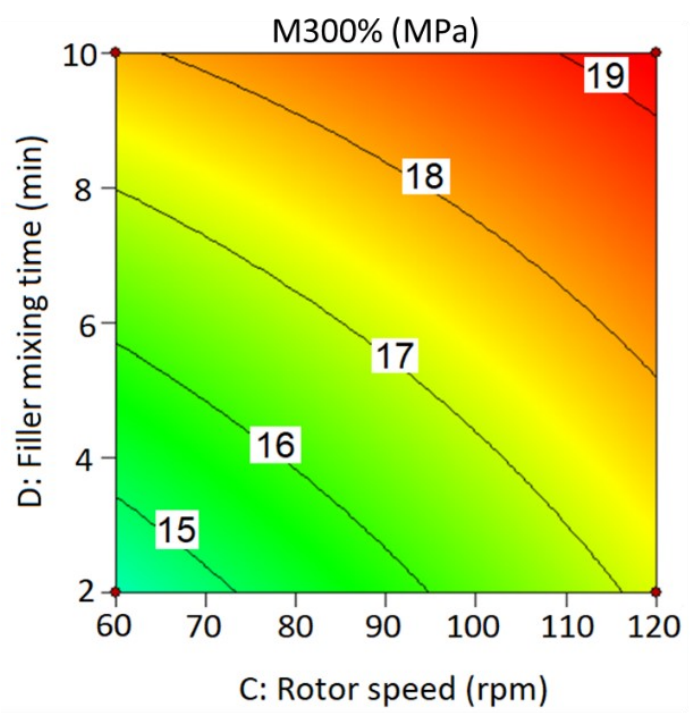

A: BR type $=$ HC LCB BR

B: Mixer set temperature $=75^{\circ} \mathrm{C}$

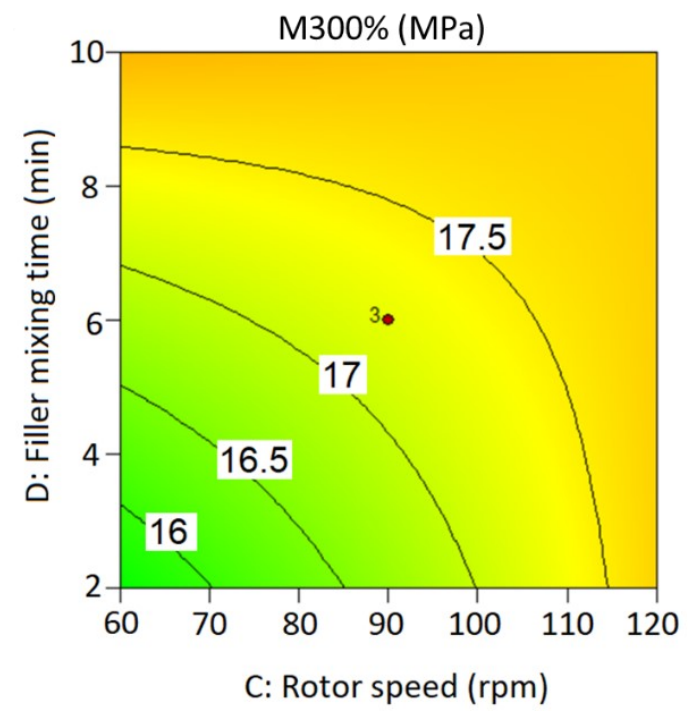

Figure 3.9 The effect of rotor speed and filler mixing time on M300\% of HC LCB BR at a mixer temperature of $50^{\circ} \mathrm{C}$ and $75^{\circ} \mathrm{C}$.

Although the effect of rotor speed and filler mixing time on TS as depicted in the Pareto chart and ANOVA are not conclusive, there is a slight indication in the contour plot in Figure 3.10 that low rotor speed and mixer set temperature are preferable for increased TS. The decrease of TS is attributed to thermal polymer degradation, in particular for NR at high temperatures, and to shearing forces breaking the polymer chains [26].

A: $B R$ type $=\mathrm{HC} B R$

D: Filler mixing time $=10 \mathrm{~min}$

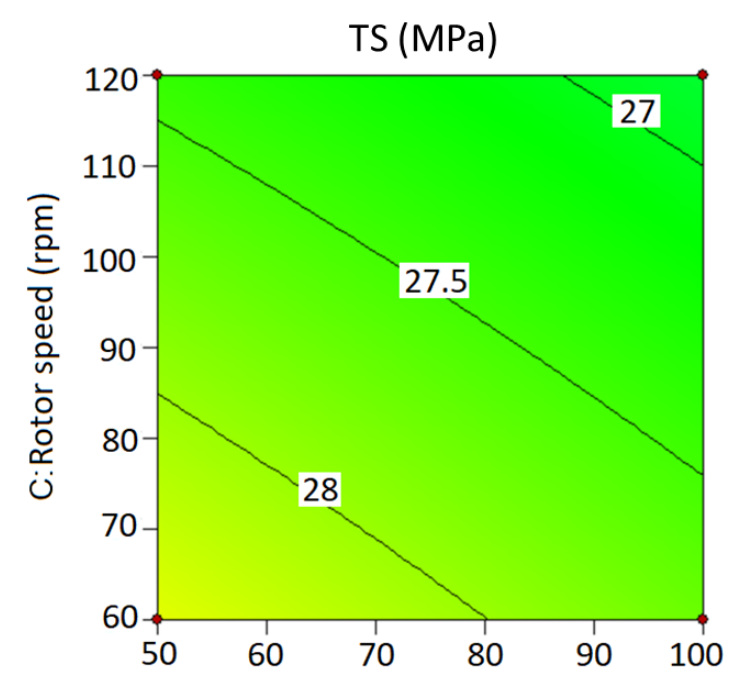

B: Mixer set temperature $\left({ }^{\circ} \mathrm{C}\right)$
A: $B R$ type $=\mathrm{HC}$ LCB BR

D: Filler mixing time $=10 \mathrm{~min}$

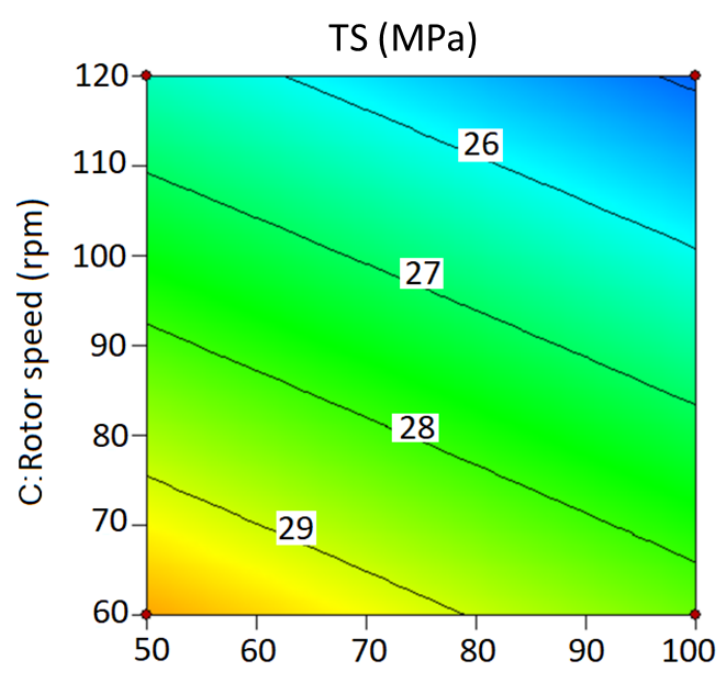

B: Mixer set temperature $\left({ }^{\circ} \mathrm{C}\right)$

Figure 3.10 The effect of mixer temperature and rotor speed on TS. 


\subsubsection{DOE OPTIMIZATION}

Rotor speed and filler mixing time were further optimized, while mixer set temperature was set at $50^{\circ} \mathrm{C}$ since a higher setting of this parameter has a negative effect on $\mathrm{M} 300 \%$ and TS based on the DOE screening: Figures 3.9 and 3.10. HC LCB BR was chosen because the properties are comparable to $\mathrm{HC}$ BR, but showed better processability. The RSM-CCC design was used, see Figure 3.2, in order to find the best level setting for optimizing all properties.

Table 3.9 parts 1 and 2 show the coefficient parameters of the DOE optimization. The correlation factors between the parameters rotor speed and filler mixing time, and the responses increase following a quadratic instead of a linear correlation. All responses show Rsquared of above 0.9 .

Table 3.9 Coefficients of parameters studied by DOE optimization (part 1).

\begin{tabular}{|c|c|c|c|c|c|c|c|}
\hline \multirow[t]{3}{*}{ Responses } & & \multirow[t]{2}{*}{ Constant } & \multicolumn{5}{|c|}{ Variables } \\
\hline & & & C & D & CD & $\mathbf{C}^{2}$ & $D^{2}$ \\
\hline & & $\beta_{o}$ & $\beta_{C}$ & $\boldsymbol{\beta}_{D}$ & $\beta_{C D}$ & $\beta_{c c}$ & $\beta_{D D}$ \\
\hline \multirow[t]{2}{*}{ MV, MU } & Coef. & 157.83 & $\begin{array}{l}-0.99 \\
\end{array}$ & $\begin{array}{l}-1.14 \\
\end{array}$ & -0.01 & $4.5 \mathrm{E}-03$ & 0.01 \\
\hline & p-value & & 0.0006 & 0.004 & 0.88 & 0.02 & 0.07 \\
\hline \multirow[t]{2}{*}{$\mathrm{PE}, \mathrm{kPa}$} & Coef. & 3118.31 & -36.32 & -312.89 & 4.56 & -0.16 & 20.52 \\
\hline & p-value & & 0.0001 & 0.0005 & 0.003 & 0.0008 & 0.04 \\
\hline \multirow[t]{2}{*}{$\tan \delta$ at $100^{\circ} \mathrm{C}$} & Coef. & 0.62 & $-8.1 \mathrm{E}-03$ & -0.10 & $-1.8 \mathrm{E}-03$ & $6.9 \mathrm{E}-03$ & $6.9 \mathrm{E}-03$ \\
\hline & p-value & & 0.001 & 0.005 & 0.18 & 0.01 & 0.03 \\
\hline \multirow[t]{2}{*}{$\mathrm{M} 300 \%, \mathrm{MPa}$} & Coef. & -7.43 & 0.26 & 1.82 & $-6.0 \mathrm{E}-03$ & $-1.3 \mathrm{E}-03$ & -0.01 \\
\hline & p-value & & 0.001 & 0.01 & 0.01 & 0.007 & 0.003 \\
\hline \multirow[t]{2}{*}{$\mathrm{TS}, \mathrm{MPa}$} & Coef. & 115.01 & -2.17 & -15.83 & 0.41 & 0.01 & 0.65 \\
\hline & p-value & & 0.005 & 0.04 & 0.03 & 0.52 & 0.06 \\
\hline
\end{tabular}

Table 3.9 Coefficients of parameters studied by DOE optimization (part 2).

\begin{tabular}{|c|c|c|c|c|c|}
\hline \multirow[t]{3}{*}{ Responses } & & \multicolumn{3}{|c|}{ Variables } & \multirow[t]{3}{*}{ R-Squared } \\
\hline & & $C^{2} D$ & $\mathrm{CD}^{2}$ & $C^{2} D^{2}$ & \\
\hline & & $\boldsymbol{\beta}_{C^{2} D}$ & $\beta_{C D^{2}}$ & $\boldsymbol{\beta}_{C^{2} D^{2}}$ & \\
\hline \multirow[t]{2}{*}{$\mathrm{MV}, \mathrm{MU}$} & Coef. & $-4.1 \mathrm{E}-04$ & $-9 \mathrm{E}-04$ & $3.5 \mathrm{E}-05$ & \multirow[t]{2}{*}{0.99} \\
\hline & p-value & 0.71 & 0.30 & 0.85 & \\
\hline \multirow[t]{2}{*}{$\mathrm{PE}, \mathrm{kPa}$} & Coef. & -0.03 & -0.4 & 2.7E-03 & \multirow[t]{2}{*}{0.99} \\
\hline & p-value & 0.02 & 0.05 & 0.13 & \\
\hline \multirow[t]{2}{*}{$\tan \delta$ at $100^{\circ} \mathrm{C}$} & Coef. & $-9.1 \mathrm{E}-06$ & $-1.3 \mathrm{E}-04$ & $6.5 \mathrm{E}-07$ & \multirow[t]{2}{*}{0.99} \\
\hline & p-value & 0.15 & 0.61 & 0.15 & \\
\hline \multirow[t]{2}{*}{$\mathrm{M} 300 \%, \mathrm{MPa}$} & Coef. & $-1.3 \mathrm{E}-03$ & -0.02 & $9.2 \mathrm{E}-05$ & \multirow[t]{2}{*}{0.99} \\
\hline & p-value & 0.12 & 0.13 & 0.04 & \\
\hline \multirow[t]{2}{*}{$\mathrm{TS}, \mathrm{MPa}$} & Coef. & $-2.6 \mathrm{E}-03$ & -0.02 & $1.2 \mathrm{E}-04$ & \multirow[t]{2}{*}{0.93} \\
\hline & p-value & 0.02 & 0.05 & 0.12 & \\
\hline
\end{tabular}


Figure 3.11 (a.1 and a.2) to (e.1 and e.2), shows the response surfaces and the contour plots for rotor speed and filler incorporation time derived from the DOE optimization. Similar trends as in the DOE screening were found for MV: a higher rotor speed and longer filler mixing time decrease $\mathrm{MV}$. For $\mathrm{PE}$, $\tan \delta$ at $100^{\circ} \mathrm{C}$ and $\mathrm{M} 300 \%$, an optimum filler mixing time in combination with high rotor speed is needed to improve those properties. In the case of $\mathrm{TS}$, high rotor speed and long filler mixing time have an adverse effect, thus decreasing those properties.

(a.1)

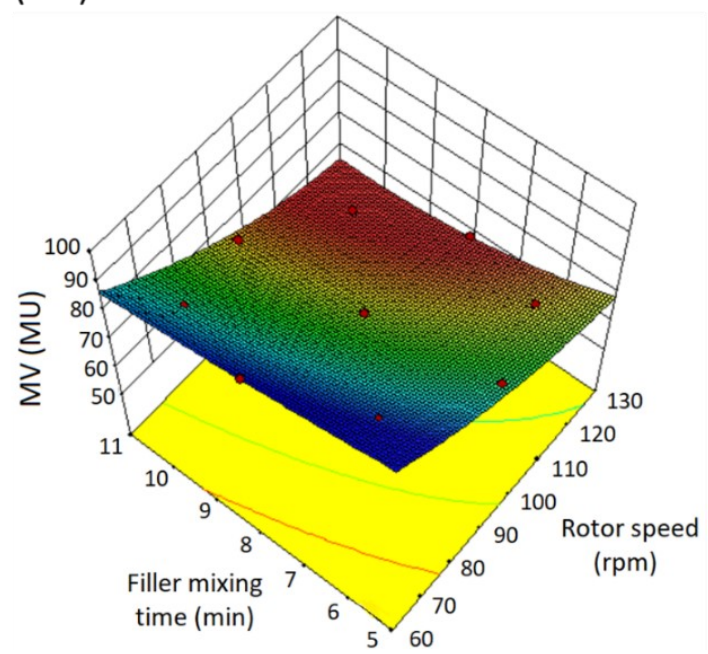

(b.1)

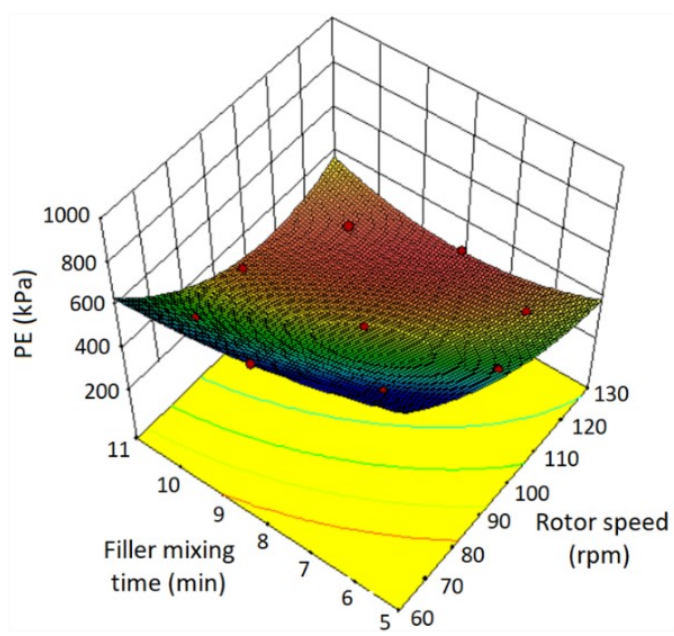

(a.2)

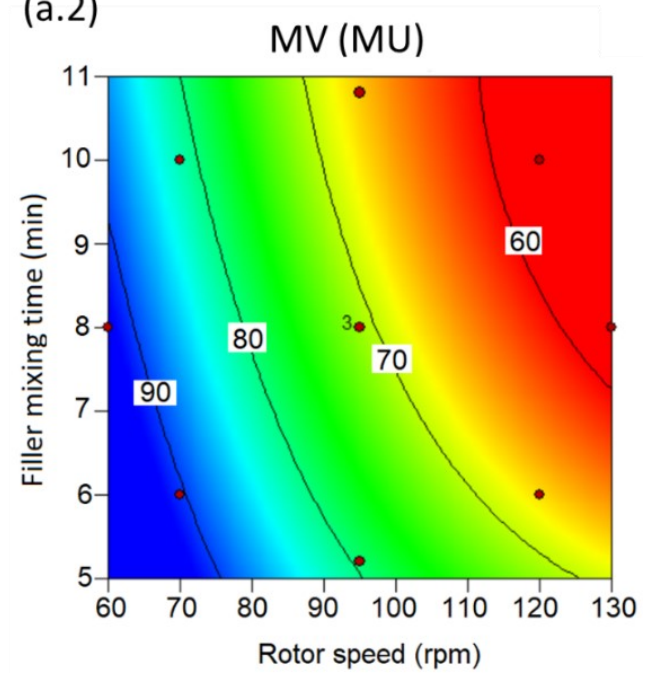

(b.2)

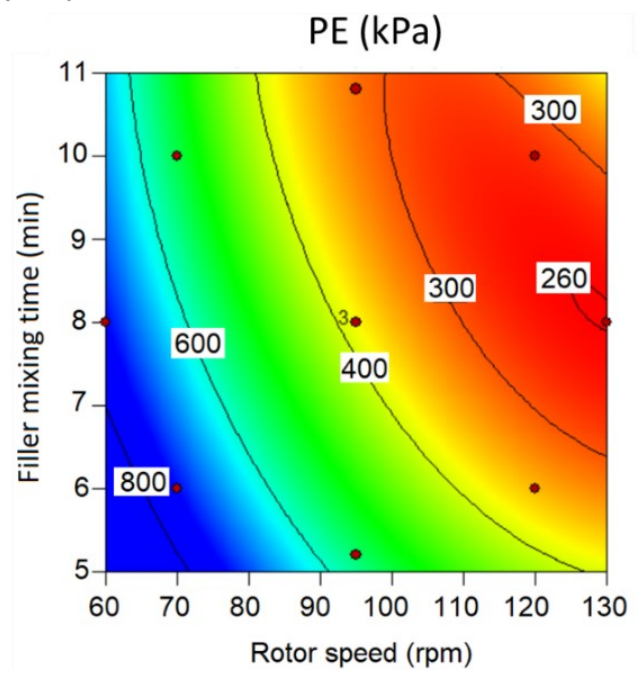


(c.1)

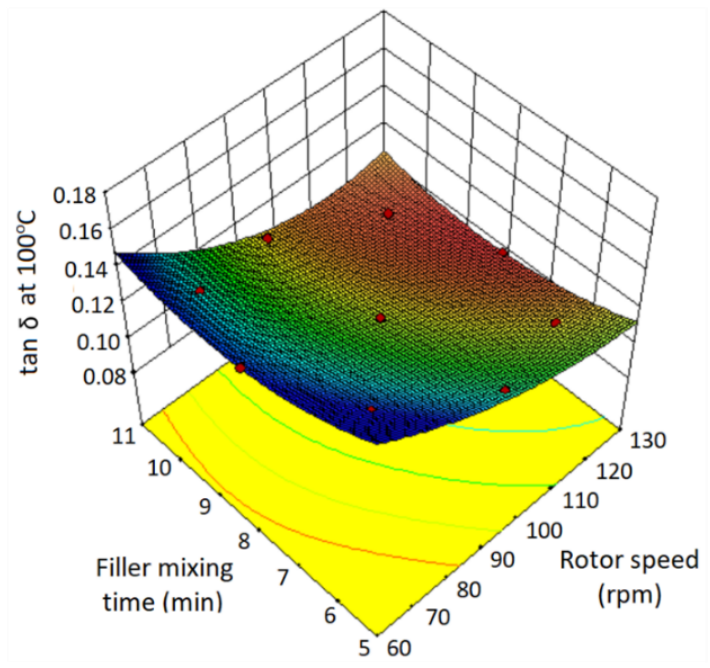

(d.1)

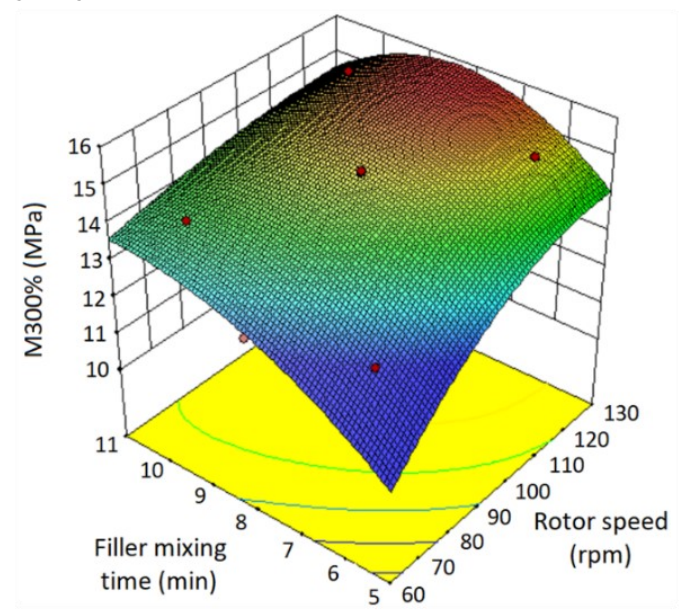

(e.1)

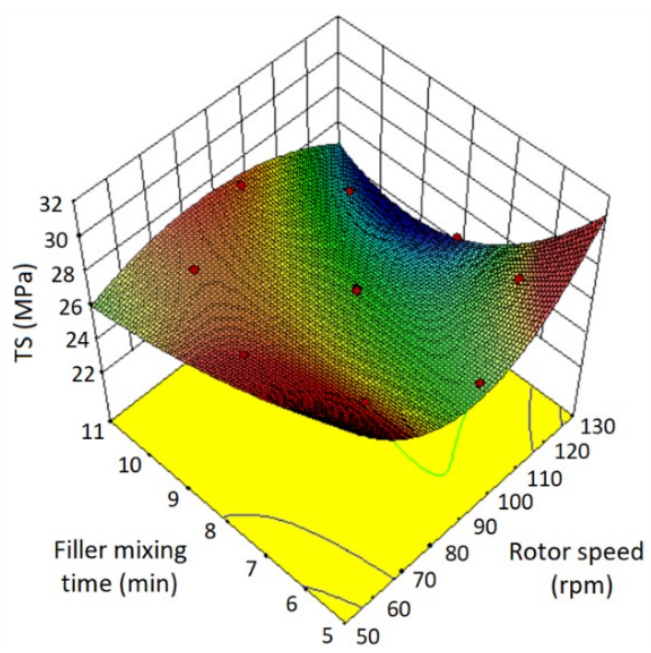

(c.2)

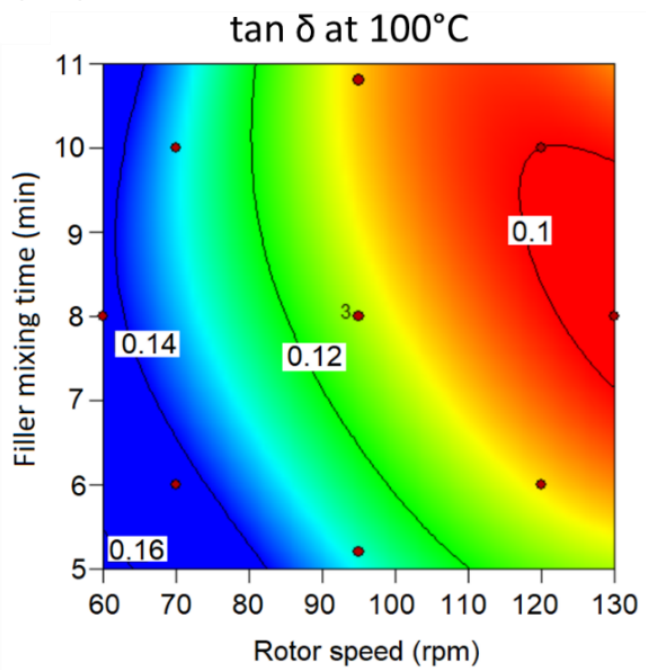

(d.2)

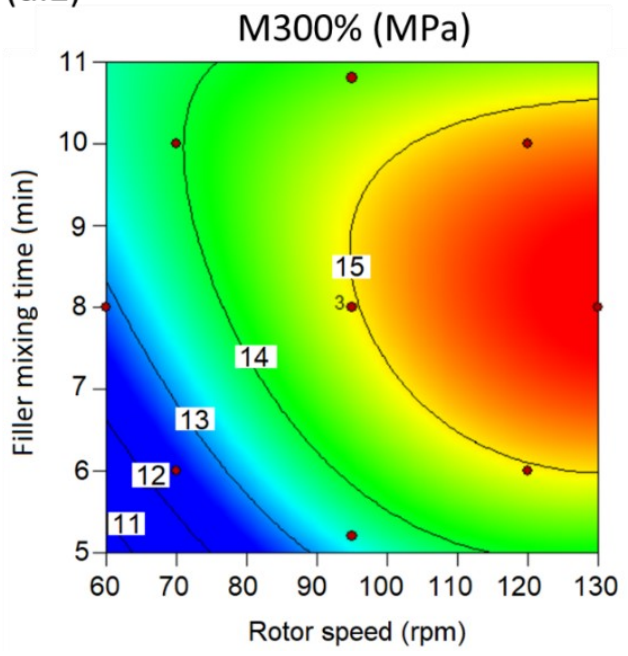

(e.2)

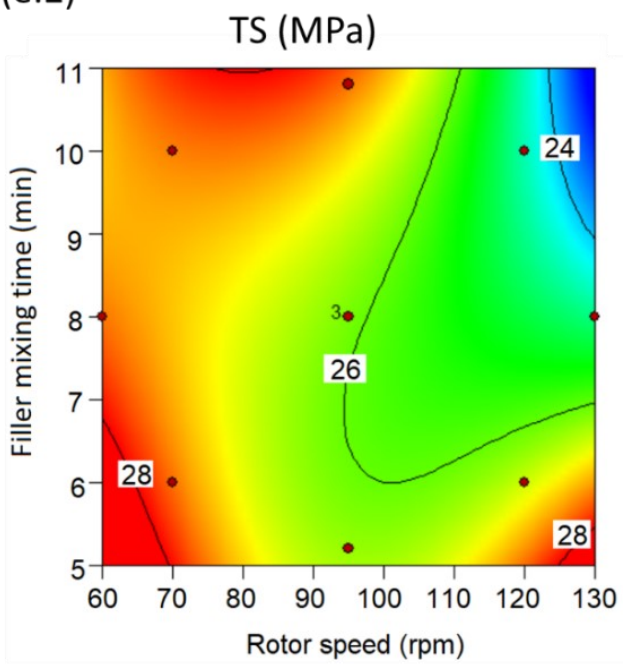

Figure 3.11 Response surfaces and contour plots of: MV 9 (a.1, a.1); PE (b.1, b.2); $\tan \delta$ (c.1, c.2); M300\% (d.1, d.2); TS (e.1, e.2). 


\subsubsection{DOE VALIDATION}

The DOE validation was performed at the last stage of the DOE process. This is the final check on how close the predicted values from the model are to the actual values from experimental runs. The overlay plot shows the parameter settings for obtaining the target values of each of the rubber properties (responses): see the yellow area in Figure 3.12. The target value is the individual goal of each property. In this project, the goal is to get the optimum setting of each factor to balance the properties of AC tire retreads: MV for ease in processability, low PE and low tan $\delta$ while maintaining acceptable M300\% and TS values. Table 3.10 shows the target values, the predicted values, and actual values of defined responses from mixing of $\mathrm{HC} L C B$ BR filled with $\mathrm{CB}$ at $50^{\circ} \mathrm{C}, 130 \mathrm{rpm}$, and 7 mins. The predicted values from the model are close to the actual values, indicating that the predicting model from optimized DOE factors was accurate.

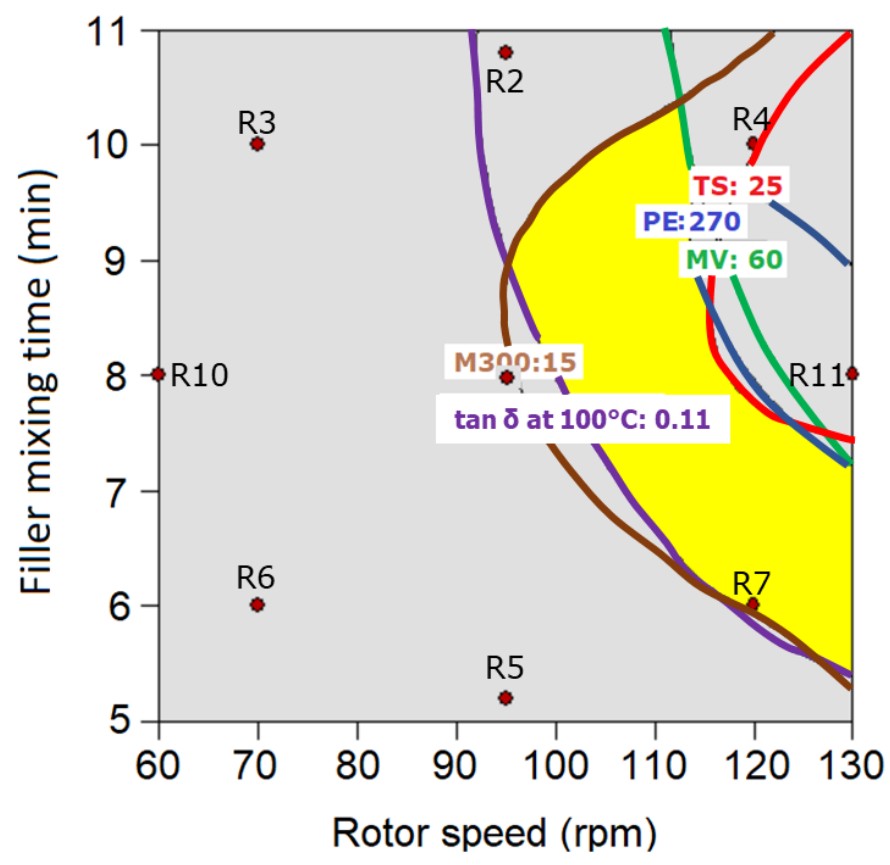

Figure 3.12 Overlay plot of all properties.

Table 3.10 Target values, predicted values and actual values of envisaged properties.

\begin{tabular}{|c|c|c|c|}
\hline Properties & Target values & $\begin{array}{c}\text { Predicted values } \\
(\mathbf{1 3 0} \mathbf{~ r p m}, \mathbf{7} \text { mins })\end{array}$ & $\begin{array}{c}\text { Actual values } \\
(\mathbf{1 3 0} \mathbf{~ r p m}, \mathbf{7} \text { mins })\end{array}$ \\
\hline $\mathrm{MV}(\mathrm{MU})$ & $60-75$ & 60 & 58 \\
\hline $\mathrm{PE}(\mathrm{kPa})$ & $<270$ & 270 & 260 \\
\hline $\mathrm{TS}(\mathrm{MPa})$ & $\min 22[27]$ & 25 & 24 \\
\hline $\mathrm{M} 300 \%(\mathrm{MPa})$ & $8-16[27]$ & 15 & 15.7 \\
\hline $\tan \delta$ at $100^{\circ} \mathrm{C}$ & $0.07-0.17[1]$ & 0.099 & 0.098 \\
\hline
\end{tabular}




\subsection{CONCLUSIONS}

A comprehensive study by means of DOE to determine the most significant factors influencing the properties of CB-filled NR/BR compounds for AC tire treads was carried out. As a general conclusion, it can be stated that DOE is a suitable tool for elaborating the optimum parameter settings to balance the properties as desired. This approach results in predictive models giving values close to the actually measured ones.

Among four factors studied in $\mathrm{DOE}$, rotor speed and filler mixing time are the most significant. All required properties needed for the AC tire tread application were fulfilled by optimizing the setting conditions for these two factors. At the same time, the mixer temperature can be set at a low value, and HC LCB BR should be used since it imparts better properties.

\subsection{REFERENCES}

1. Sandstrom, P.H., et al., Aircraft Tire, to The Goodyear Tire and Rubber Company, US7367369B2 (2008).

2. Alroqi, A.A., et al., Aircraft Tyre Temperature at Touchdown With Wheel Prerotation, J. Aircraft, 54, 3, 926 (2017).

3. Arayapranee, W., in Abrasion Resistance of Materials, Chapter 8: Rubber Abrasion Resistance, 1st ed., Adamiak, M., Ed., InTech: Rijeka, Croatia (2012).

4. Le, H.H., et al., Online Characterization of the Effect of Mixing Parameters on Carbon Black Dispersion in Rubber Compounds Using Electrical Conductivity, Rubber Chem. Technol., 77, 1, 147 (2004).

5. Sirisinha, C. and Sittichokchuchai, W., A Study of Relationships Between State-of-Mix, Rheological Properties, Dynamic Properties, and Bound Rubber Content, J. Appl. Polym. Sci., 76, 1542 (2000).

6. Serizawa, H., et al., Surface Modification Effects of Carbon Black on Reinforced Natural Rubber, Polym. J., 15, 543 (1982).

7. Wiedmann, W.M. and Schmid, H.M., Optimization of Rubber Mixing in Internal Mixers, Rubber Chem. Technol., 55, 2, 363 (1982).

8. Zhang, A., et al., A Study on Rheological Properties of Carbon Black Extended Powdered SBR Using a Torque Rheometer, Polym. Test., 22, 2, 133 (2003).

9. Freakley, P.K. and Idris, W.Y.W., Visualization of Flow during the Processing of Rubber in an Internal Mixer, Rubber Chem. Technol., 52, 1, 134 (1979).

10. Risi, F.R.D., The Role of Co-Agents in Peroxide Cured Thermoplastic Vulcanizates, PhD thesis, Elastomer Technology and Engineering, University of Twente, The Netherlands (2007).

11. Phadke, M.S., in Quality Engineering using Robust Design, Applications and Benefits of Robust Design, Prentice-Hall: Englewood Cliffs, New Jersey (1989).

12. Balachandran, M., et al., Design of Experiments for Optimizing NBR Nanocomposite Formulations, in Int. Conf. on Adv. Polym. Technol., Cochin, India (2008).

13. Graf, H.J., et al., Simulated Design of Experiment in Rubber Compound Development, in Int. Rubber Conf., Nuremberg, Germany (2015).

14. Graf, H.J., Compound Development with Design of Experiments or the Graf Compounder?, RFP Rubber Fibres Plastics, Dr. Gupta Verlags GmbH: Germany, 8, 2 (2013). 
15. Atashi, H. and Shiva, M., Statistical Analysis, Modeling and Optimiziton of Silica, Rubber Ratio and Sulfur Levels in Truck Tire Tread Compound, Asian J. Chem., 22, 8, 6451 (2010).

16. Rajan, R., et al., Response Surface Methodology: A Tool for Assessing the Role of Compounding Ingredients in Peroxide Vulcanization of Natural Rubber, Rubber Chem. Technol., 89, 2, 211 (2016).

17. Narongthong, J., et al., Effects of Mixing Parameters and Their Interactions on Properties of Carbon Black Filled Styrene-Butadiene Rubber, Rubber Chem. Technol., 91, 3, 521 (2018).

18. Yang, X.S., Rubber Composition for Aircraft Tire Treads, to Compagnie Generale des Etablissements Michelin, US Patent 2012/0252929 A1 (2012).

19. Anderson, M.J. and Whitcomb, P.J., DOE Simplified Practical Tools for Effective Experimentations, 3rd ed., CRC Press: Boca Raton, Florida (2007).

20. Eriksson, L., et al., Design of Experiments Principles and Applications, Umetrics AB: Sweden (2000).

21. Campanelli, J.R., et al., Dispersion, Temperature and Torque Models for an Internal Mixer, Polym. Eng. Sci., 44, 7, 1247 (2004).

22. Cotten, G.R., Mixing of Carbon Black with Rubber I. Measurement of Dispersion Rate by Changes in Mixing Torque, Rubber Chem. Technol., 57, 1, 118 (1984).

23. Sajjayanukul, T., et al., Experimental Analysis of Viscoelastic Properties in Carbon Black-filled Natural Rubber Compounds, J. Appl. Polym. Sci., 97, 6, 2197 (2005).

24. Cotten, G.R., Mixing of Carbon Black with Rubber II. Mechanism of Carbon Black Incorporation, Rubber Chem. Technol., 85, 4, 774 (1985).

25. Difference Between Branched Polymer and Linear Polymer, Available online: https://pediaa.com/difference-between-branched-polymer-and-linear-polymer/ (accessed on 21 Dec 2017).

26. Kaewsakul, W., et al., Optimization of Mixing Condition for Silica-Reinforced Natural Rubber Tire Tread Compounds, Rubber Chem. Technol., 85, 2, 277 (2012).

27. Scriver, R.M. and Ross, W.A., Pneumatic Tire with Medium Vinyl Polybutadiene/ Polyisoprene Blend Tread, to The Goodyear Tire \& Rubber Company, US4192366A (1978). 


\title{
OPTIMIZATION OF THE MIXING PARAMETERS FOR NR/BR BLENDS WITH A HYBRID CARBON BLACK/SILICA AND A SILICA FILLER SYSTEM
}

\begin{abstract}
Two types of Butadiene Rubber (BR): High-Cis BR (HC BR) and High-Cis Long-Chain Branched BR (HC LCB BR), and two types of fillers: Silica (SI) and a combination of Carbon Black and Silica (CB/SI), as well as silanization temperature and time are investigated in order to optimize the properties of aircraft tire retreads. The silanization temperature turns out to be the most significant factor defining the properties of rubbers. A sufficient silanization time is beneficial to enhance the hydrophobation of silica by bis-(TriEthoxySilylPropyl)Tetrasulfide (TESPT) as a coupling agent. The use of HC LCB BR enhances processability by lowering the viscosity, and better silanization results in a lower Payne Effect (PE) compared to the HC BR counterpart. High filler-rubber interactions of HC LCB BR lead to higher crosslink density, lower $\tan \delta$ at $100^{\circ} \mathrm{C}$, as well as higher Modulus at $300 \%$ elongation (M300\%) and Tensile Strength (TS) compared to the HC BR based rubber. CB/SI-filled vulcanizates show slightly improved mechanical properties, i.e., TS and hardness. However, the tan $\delta /$ heat-build-up values of $\mathrm{CB} / \mathrm{SI}$-filled vulcanizates are still higher compared to ones of the pure SI-filled vulcanizates, while the filler-rubber interactions are not only chemical but also physical.
\end{abstract}




\subsection{INTRODUCTION}

Natural rubber (NR) still is the primary ingredient in aircraft tire tread formulations. The excellent properties of NR provide superior stress-strain properties as well as low heat build-up and wear resistance as required for Aircraft (AC) tires. In the filled system, NR works best with $\mathrm{CB}$ since both have a relatively small difference in polarity. Therefore, it is relatively easy to disperse CB in NR. In the previous study: Chapter 3, we elaborated on optimizing rotor speed and filler mixing time for the main property required for $\mathrm{AC}$ tire retreads, which is low heat build-up measured as $\tan \delta$ at $100^{\circ} \mathrm{C}$, without sacrificing stress-strain properties, hardness, or processability.

It is crucial to decrease the hysteresis in Aircraft (AC) tire treads to lower the temperature build-up in the tire, which finally decreases tread wear and increases service life of the tire. Silica (SI) together with a silane as coupling agent gained popularity in the rubber world since the introduction of the "green tire" by Michelin [1]. The use of SI yields a lower rolling resistance and better traction than $\mathrm{CB}$ filled rubber, especially for Passenger Car Tires (PCT) $[2,3]$. The substitution of low levels of 5 to 10 phr of CB by SI can enhance tear, cut growth resistance, and adhesion properties [4].

Incorporation of SI in compounds containing non-polar rubbers such as NR and BR is challenging. Due to the difference in polarity between SI and these polymers, the degree of dispersion of SI is lower compared to the dispersion of CB. The interaction between the SI particles themselves is stronger than the interaction between the polar siloxane or silanol moieties on the SI surface and the rubber [5]. The SI surface comprises silanol groups, which create hydrogen bonds between other surface silanol groups, resulting in strong SI clusters causing poor dispersion of the SI in rubber compounds [6] which deteriorates the properties $[6,7]$. Moreover, the viscosity of compounds will increase substantially, when a large portion of SI is added, which makes them more challenging to process [8]. Both processing properties can significantly be improved by the addition of a coupling agent like a silane.

To ensure that the silanization reaction occurs, SI in combination with the silane needs to be mixed into the rubber under optimal conditions $[8,9]$ using a suitable formulation. Bis(TriEthoxySilyIPropyl)Tetrasulfide (TESPT) is the most widely used bifunctional organosilane in the tire industry and was studied by many researchers [8-14]. Optimized silanization conditions will lead to a high degree of bonding of the silane onto the SI surface. Subsequently, the coupling reaction between silane and elastomer is formed during vulcanization. The fillerelastomer network in combination with elastomer crosslinks leads to low hysteresis of rubber vulcanizates [15].

To optimize the properties of AC tire retreads containing SI, four parameters are investigated comprising two types of Butadiene Rubber (BR), two types of filler, as well as time and temperature of silanization. The objective of this research is to study the effect of 
these factors on the compound and vulcanizate properties, and to derive general guidelines for mixing optimization of the in-situ modification reaction between TESPT and silica.

\subsection{EXPERIMENTAL}

\subsubsection{MATERIALS}

In Chapter 3, the following ingredients were specified: NR, BR: HC BR and HC LCB BR, $\mathrm{CB}$, Zinc Oxide (ZnO), stearic acid, TDAE oil, TMQ, 6PPD, CBS, and sulfur. The silica used in this study was ULTRASIL 7005, and the silane coupling agent TESPT, both supplied by Evonik, Germany. 1,3-DiPhenylGuanidine (DPG) was obtained from Flexsys, Belgium.

The compound formulation for this study is depicted in Table 4.1. A two-level Design of Experiments (DOE) was used for optimizing the mixing process of the compounds containing SI. The two types of BR were used as specified in Chapter 3. Fillers used in this study are a blend of CB/SI (level -1 ) and SI only (level +1 ).

Table 4.1 Compound formulation.

\begin{tabular}{|l|l|c|c|}
\hline \multicolumn{1}{|c|}{ Mixing } & Ingredients & Level -1 & Level +1 \\
\hline $1^{\text {st }}$ stage & NR & 70 & 70 \\
\hline & HC BR & 30 & - \\
\hline & HC LCB BR & - & 30 \\
\hline & CB & 27.5 & - \\
\hline & SI & 27.5 & 55 \\
\hline & TESPT & 2.5 & 5.0 \\
\hline & ZnO & 5 & 5 \\
\hline & Stearic acid & 3 & 3 \\
\hline & 6PPD & 2 & 2 \\
\hline & TMQ & 1 & 1 \\
\hline & TDAE & 7.5 & 7.5 \\
\hline $2^{\text {nd }}$ stage & Sulfur & 1.5 & 1.5 \\
\hline & CBS & 1.5 & 1.5 \\
\hline & DPG & 0.6 & 1.1 \\
\hline
\end{tabular}

Amount of TESPT and DPG were calculated according to the following equations: TESPT (phr) $=0.00053 \times \mathrm{Q} \times \mathrm{A}$ and DPG $(\mathrm{phr})=0.00012 \times \mathrm{Q} \times \mathrm{A}$ Where $Q$ is the amount of SI (phr) and $A$ is the CTAB surface area of the SI $\left(171 \mathrm{~m}^{2} / \mathrm{g}\right)$.

\subsubsection{COMPOUND PREPARATION}

Mixing was performed in an internal mixer Brabender Plasticorder 350s. The mixer was operated with a fill factor of $70 \%$. The initial temperature and rotor speed were set at $100^{\circ} \mathrm{C}$ and $60 \mathrm{rpm}$. Two-stage mixing was performed as shown in Table 4.2. NR was initially masticated prior to the addition of BR to have a viscosity close to the one of BR. The masticated NR and BR (level -1 or level +1 ) were blended for $1 \mathrm{~min}$. Then, half of the filler (level -1 or +1 ), TESPT and TDAE oil were added and mixed for $1 \mathrm{~min}$. After $1 \mathrm{~min}$, the remaining filler (level -1 or +1 ) and all other rubber ingredients except curatives were added and mixed for $1 \mathrm{~min}$. The rotor 
speed was adjusted in order to reach the targeted temperature for silanization. The temperature and time of silanization were maintained depending on the level settings as shown in Table 4.3. The compounds were discharged, sheeted off on a two-roll mill and kept overnight prior to incorporation of sulfur, CBS and DPG in the internal mixer at a set temperature of $70^{\circ} \mathrm{C}$ and initial rotor speed of $50 \mathrm{rpm}$. After the masterbatch was mixed for 1 min, the rotor speed was decreased to $30 \mathrm{rpm}$ before curatives were added and mixed for 2 mins.

Table 4.2 Two-stage mixing process conditions.

\begin{tabular}{|c|c|c|}
\hline & Mixing procedure & Time (mins) \\
\hline Step 1: Internal mixer & Mixing of masticated NR and BR & 1 \\
\hline $\begin{array}{l}\text { Initial mixer set temp. } \\
100^{\circ} \mathrm{C}\end{array}$ & $\begin{array}{l}\text { - Addition of SI and silane (level }-1 \text { ) or } 1 / 2 \text { (SI } \\
\text { and silane) (level }+1), 1 / 2 \text { TDAE }\end{array}$ & 1 \\
\hline Initial rotor speed $60 \mathrm{rpm}$ & 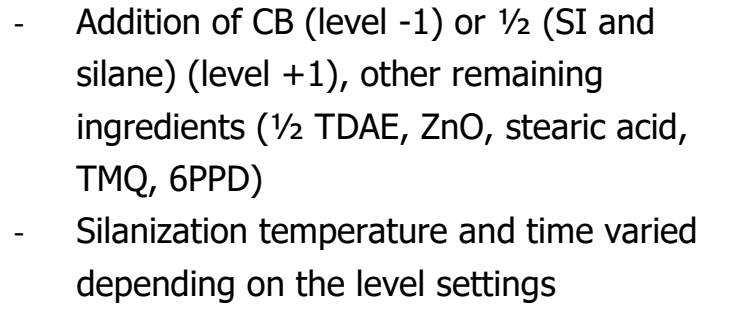 & $\begin{array}{c}\text { Varied } \\
\text { depending on } \\
\text { level settings }\end{array}$ \\
\hline Step 2: Internal mixer & Masterbatch & 1 \\
\hline $\begin{array}{l}\text { Mixer set temp. } 70^{\circ} \mathrm{C} \\
\text { Rotor speed } 50 \mathrm{rpm}\end{array}$ & - $\quad$ Addition of curatives (sulfur, CBS and DPG) & 2 \\
\hline
\end{tabular}

\subsubsection{TESTING OF COMPOUND AND VULCANIZATE PROPERTIES}

Mooney Viscosity (MV), Payne Effect (PE), Modulus 300\% (M300\%), Tensile Strength (TS), and tan $\delta$ at $100^{\circ} \mathrm{C}$ of the rubber compounds and vulcanizates were measured according to the methods described in Chapter 3. Other measurements are as follows:

Hardness shore $A$ - The vulcanizates were measured with a Zwick 3150 Shore A hardness tester according to ASTM D2240.

Apparent crosslink density - Various organic additives and impurities in vulcanizates were removed by extracting in toluene for 2 days and in acetone for another 2 days. After the extraction process, the samples were dried for 1 day at $60^{\circ} \mathrm{C}$ in a vacuum oven. After drying, the vulcanizates were cut into specific shapes and a weight of $60 \mathrm{mg}$. The samples were swollen in toluene at room temperature to an equilibrium swelling state and then removed from the solvent. The toluene on the surface of the sample was quickly blotted off with tissue paper. They were immediately weighed on an analytical balance and then dried in a vacuum oven. The volume fraction $\left(V_{r}\right)$ of rubber in the swollen gel was calculated by Equation 4.1, and the apparent crosslink density $\left(X_{c}\right)$ was calculated by using the Flory-Rehner theory [16] according to Equation 4.2: 


$$
V_{r}=\frac{m_{1} / \rho_{1}}{\left(m_{1} / \rho_{1}\right)+\left(m_{2} / \rho_{2}\right)}
$$

Equation 4.1

where $m_{1}$ and $m_{2}$ are the weight of polymer and weight of solvent in the swollen sample at equilibrium swelling. $\rho_{1}$ is the density of un-swollen rubber vulcanizates, and $\rho_{2}$ is the density of the solvent.

$$
X_{C}=\frac{\left(\ln \left(1-V_{r}\right)+V_{r}+\chi V_{r}^{2}\right)}{V_{2}\left(V_{r}^{1 / 3}-V_{r} / 2\right)}
$$

where $\chi$ is the polymer-solvent interaction parameter (0.36) [17], and $V_{2}$ is the molar volume of the solvent $\left(106.3 \mathrm{~cm}^{3} / \mathrm{mol}\right)$. No correction of the crosslink density was applied for the fillers contained in the compounds, as the influence of the different filler combinations on the polymer-solvent interaction parameter is not known. But as in each compound formulations, the amount of filler is not varied, the swelling data can be mutually compared to provide what will be called - apparent crosslink density.

\subsubsection{DOE METHOD}

The type of BR and filler, as well as the silanization temperature and time were varied following the experimental design as shown in Table 4.3.

Table 4.3 Experimental design for optimizing mixing.

\begin{tabular}{|c|l|c|c|c|}
\hline Factor & \multicolumn{1}{|c|}{ Parameters } & Level -1 & Level 0 & Level +1 \\
\hline Categoric & A: BR type & HC BR & & HC LCB BR \\
\hline Categoric & B: Filler type & CB/SI & & SI \\
\hline Numeric & C: Silanization temperature $\left({ }^{\circ} \mathrm{C}\right)$ & 130 & 140 & 150 \\
\hline Numeric & D: Silanization time (min) & 2 & 6 & 10 \\
\hline
\end{tabular}

A Resolution IV design with four factors ( 2 numerical and 2 categorical) and two levels $(-1$ and +1$)$ was applied. The number of experiments for Resolution IV design is $2^{4-1}$ and geometrically represented in a cube as shown in Figure 4.1. The cube is representative for two different types of BR. The three main axes refer to filler type, silanization temperature and silanization time. The center point is added for replication at each categorical factor. The total number of experiments is 16 runs. 


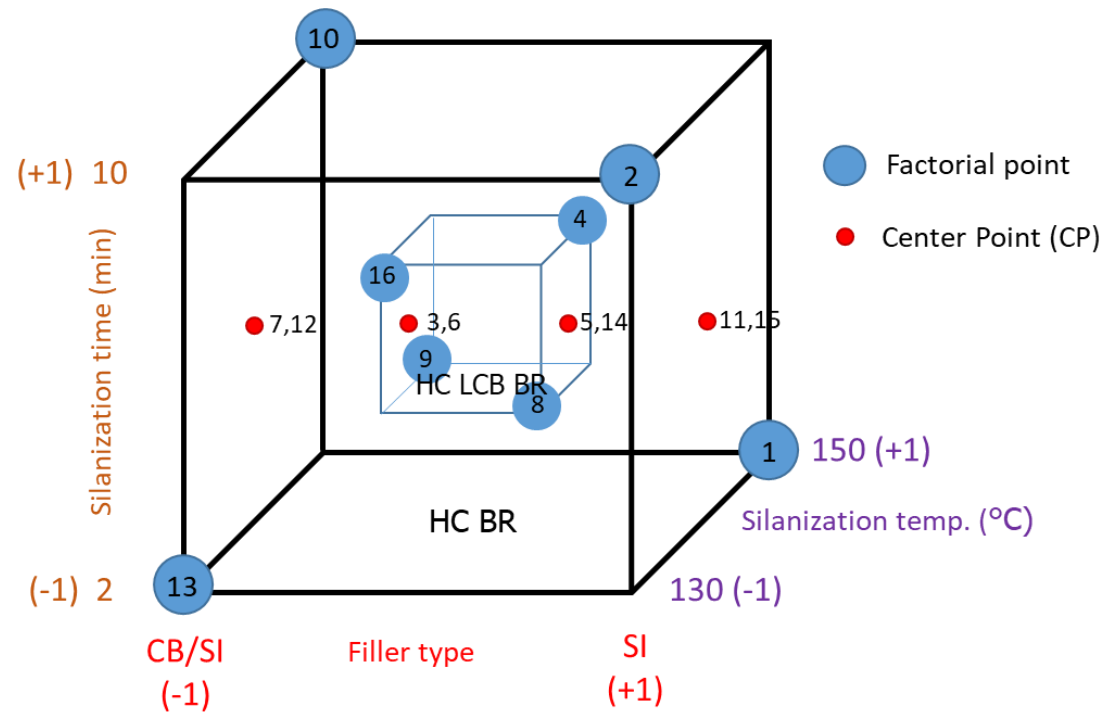

The cube represents a single type of $\mathrm{BR}$ ( $\mathrm{HC}$ and $\mathrm{HC}$ LCB)

DOE resolution IV

No. of numeric factor $=2$

No. of categoric factor $=2$

No. of levels $=2$

Center Point $=4 \times 2$ replication $=8$

No. of experiments $=2^{4-1}+8=16$ runs

Figure 4.1 Experimental design of Resolution IV with center points.

The effects of factors and the interaction between factors on rubber properties ( $Y$ ) were evaluated by Analysis of Variance (ANOVA) and then modeled by fitting a polynomial model to the data as described in Equation 4.3 [18].

$$
\begin{aligned}
Y= & \beta_{o}+\beta_{A} A+\beta_{B} B+\beta_{C} C+\beta_{D} D+\beta_{A B} A B+ \\
& \beta_{A C} A C+\beta_{A D} A D+\beta_{B C} B C+\beta_{B D} B D+\beta_{C D} C D+\varepsilon
\end{aligned}
$$

Equation 4.3

where $A, B, C$, and $D$ are independent factors; $\beta_{o}$ is the $Y$-intercept; $\beta_{A}, \beta_{B}, \beta_{C}, \beta_{D}$ are linear coefficients; $\beta_{A B}, \beta_{A C}, \beta_{A D}, \beta_{B C}, \beta_{B D}, \beta_{C D}$ are interaction regression coefficients; and $\varepsilon$ is the residual response variation not explained by the model. For DOE resolution IV, there will be confounding between two-factor interactions: $X_{A} X_{C}=X_{B} X_{D}$ and $X_{A} X_{D}=X_{B} X_{C}$.

Contour plots are used to visualize more in detail the effect of factors and/or interaction on responses.

\subsection{RESULTS AND DISCUSSION}

The coefficients of parameters obtained from ANOVA are shown in Table 4.4: parts 1 and 2. The silanization temperature and time are the most significant factors: $p$-value $<0.05$, written in blue, influencing $\mathrm{MV}, \mathrm{PE}$, and $\tan \delta$ at $100^{\circ} \mathrm{C}$. The effect of the investigated factors on all those mentioned properties shows a high correlation with R-squared above 0.9 except for PE. The type of filler and silanization temperature are the most significant factors on M300\%. The effect of factors on M300\% shows a correlation with R-squared of 0.86 . TS 
mainly depends on the type of BR and fillers used with R-squared of 0.84 . Apparent crosslink density and hardness Shore A are poorly modeled by the factors, as the R-squared values are below 0.8 .

Table 4.4 Coefficients of parameters (Part 1).

\begin{tabular}{|c|c|c|c|c|c|c|}
\hline \multirow[t]{3}{*}{ Responses } & & \multirow[b]{2}{*}{ Constant } & \multicolumn{4}{|c|}{ Variables } \\
\hline & & & $\begin{array}{l}\text { BR } \\
\text { type } \\
\text { A }\end{array}$ & $\begin{array}{l}\text { Filler } \\
\text { type } \\
\text { B }\end{array}$ & $\begin{array}{c}\text { Silanization } \\
\text { temperature } \\
\text { C }\end{array}$ & $\begin{array}{c}\text { Silanization } \\
\text { time } \\
\text { D }\end{array}$ \\
\hline & & $\boldsymbol{\beta}_{o}$ & $\boldsymbol{\beta}_{A}$ & $\boldsymbol{\beta}_{B}$ & $\beta_{C}$ & $\beta_{D}$ \\
\hline \multirow[t]{2}{*}{ MV (MU) } & & 89.68 & -2.18 & 0.61 & -3.66 & -5.86 \\
\hline & p-value & - & 0.002 & 0.23 & 0.0008 & $<0.0001$ \\
\hline \multirow[t]{2}{*}{$\mathrm{PE}(\mathrm{kPa})$} & & 281.06 & -5.24 & 12.74 & -23.59 & -24.39 \\
\hline & p-value & - & 0.22 & 0.01 & 0.0035 & 0.0029 \\
\hline \multirow{2}{*}{$\begin{array}{l}\text { Apparent crosslink } \\
\text { density }\left(\mathrm{mol} / \mathrm{cm}^{3}\right)\end{array}$} & & 2.81 & 0.05 & 0.02 & 0.05 & 0.05 \\
\hline & p-value & - & 0.09 & 0.50 & 0.17 & 0.16 \\
\hline \multirow[t]{2}{*}{$\tan \delta$ at $100^{\circ} \mathrm{C}$} & & 0.11 & -0.0011 & -0.0026 & -0.0065 & -0.0004 \\
\hline & p-value & - & 0.31 & 0.03 & 0.0005 & 0.002 \\
\hline \multirow[t]{2}{*}{$\mathrm{M} 300 \%(\mathrm{MPa})$} & & 7.83 & 0.24 & -1.08 & 0.66 & 0.35 \\
\hline & p-value & - & 0.24 & 0.0007 & 0.04 & 0.24 \\
\hline \multirow[t]{2}{*}{ TS (MPa) } & & 24.22 & 0.40 & -0.43 & -0.25 & -0.03 \\
\hline & p-value & - & 0.007 & 0.0045 & 0.14 & 0.85 \\
\hline \multirow[t]{2}{*}{ Hardness shore A } & & 61.84 & -0.15 & 0.0042 & -1.37 & -0.79 \\
\hline & p-value & - & 0.77 & 0.99 & 0.09 & 0.29 \\
\hline
\end{tabular}

Table 4.4 Coefficients of parameters (Part 2).

\begin{tabular}{|c|c|c|c|c|c|c|}
\hline \multirow[t]{3}{*}{ Responses } & & \multicolumn{4}{|c|}{ Variables } & \multirow[t]{3}{*}{ R-squared } \\
\hline & & AB & AC or BD & $A D$ or $B C$ & CD & \\
\hline & & $\beta_{A B}$ & $\beta_{A C}$ or $\beta_{B D}$ & $\beta_{A D}$ or $\beta_{B C}$ & $\beta_{C D}$ & \\
\hline \multirow[t]{2}{*}{ MV (MU) } & & 0.84 & -1.94 & 0.41 & -3.7 & \multirow[t]{2}{*}{0.96} \\
\hline & p-value & 0.24 & 0.02 & 0.55 & 0.05 & \\
\hline \multirow[t]{2}{*}{$\mathrm{PE}(\mathrm{kPa})$} & & -3.3 & -0.81 & -11.78 & -6.72 & \multirow[t]{2}{*}{0.89} \\
\hline & p-value & 0.565 & 0.886 & 0.0684 & 0.414 & \\
\hline \multirow{2}{*}{$\begin{array}{l}\text { Apparent crosslink } \\
\text { density }\left(\mathrm{mol} / \mathrm{cm}^{3}\right)\end{array}$} & & 0.02 & 0.02 & 0.02 & 0.08 & \multirow[t]{2}{*}{0.74} \\
\hline & p-value & 0.52 & 0.60 & 0.50 & 0.13 & \\
\hline \multirow[t]{2}{*}{$\tan \delta$ at $100^{\circ} \mathrm{C}$} & & -0.0035 & -0.0035 & -0.0055 & -0.0034 & \multirow[t]{2}{*}{0.93} \\
\hline & p-value & 0.79 & 0.04 & 0.005 & 0.13 & \\
\hline \multirow[t]{2}{*}{ M300\% (MPa) } & & 0.13 & 0.06 & 0.31 & 0.08 & \multirow[t]{2}{*}{0.86} \\
\hline & p-value & 0.65 & 0.83 & 0.28 & 0.84 & \\
\hline \multirow[t]{2}{*}{ TS (MPa) } & & 0.13 & -0.08 & -0.20 & -0.20 & \multirow[t]{2}{*}{0.84} \\
\hline & p-value & 0.42 & 0.61 & 0.22 & 0.38 & \\
\hline \multirow[t]{2}{*}{ Hardness shore A } & & -0.25 & -0.35 & -0.52 & 0.54 & \multirow[t]{2}{*}{0.48} \\
\hline & p-value & 0.72 & 0.62 & 0.48 & 0.60 & \\
\hline
\end{tabular}


MV of the compounds decreases as silanization temperature and time increase, see Figure 4.2. A higher degree of silanization leads to more hydrophobation of silanol groups on the SI surface by the silane, thus lower filler-filler interaction resulting in lower viscosity. HC BR reinforced either by $\mathrm{CB} / \mathrm{SI}$ or SI shows no significant difference in MV. The MV of HC BR compounds is independent of the silanization temperature at short silanization times below 6 mins. It can be seen from the mixing fingerprints as shown in Figure 4.3, that mixing $\mathrm{HC} B \mathrm{BR}-$ reinforced $\mathrm{SI}$ or $\mathrm{CB} / \mathrm{SI}$ at $130^{\circ} \mathrm{C}$ and $150^{\circ} \mathrm{C}$ for 2 mins results in a similar final torque, thus no difference in MV. Increasing silanization time to $10 \mathrm{mins}$ at $150^{\circ} \mathrm{C}$ requires a high energy input, thus more breakdown of the polymers, and results in reduction of the final torque, hence reduction in MV: see Figure 4.4 .

A: $B R$ type $=\mathrm{HC} B R$

B: Filler type $=\mathrm{CB} / \mathrm{SI}$

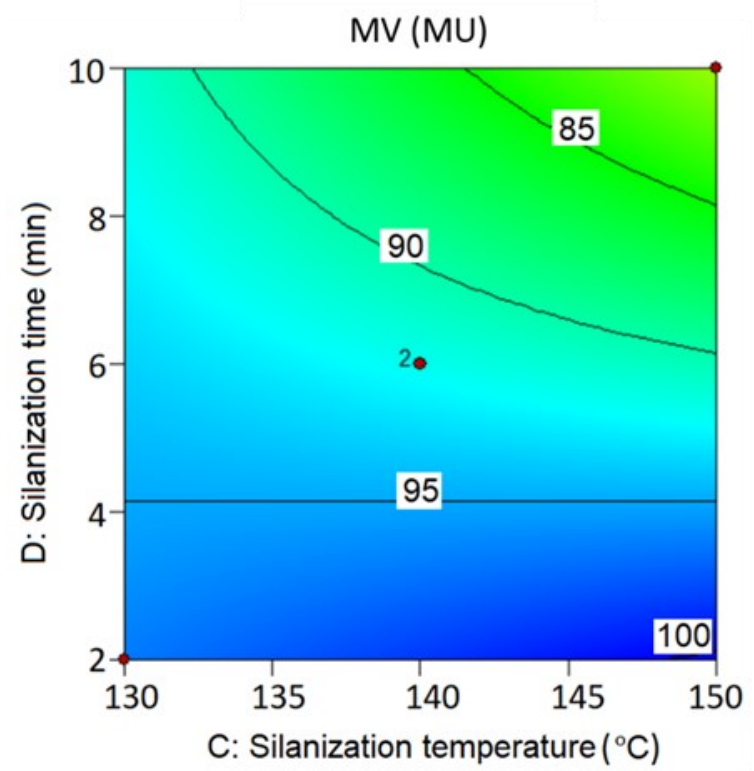

$A: B R$ type $=\mathrm{HC} B R$

B: Filler type $=\mathrm{SI}$

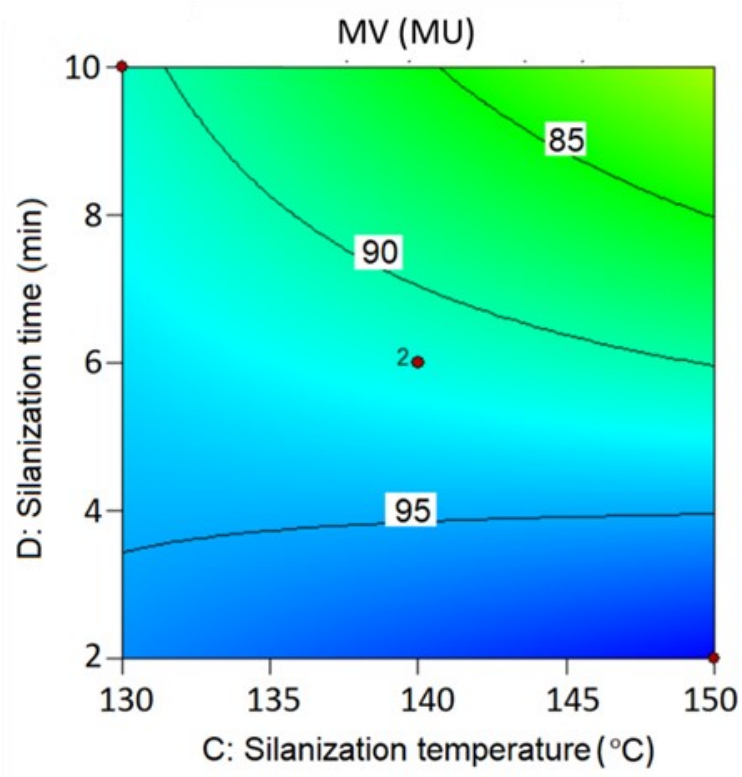

Figure 4.2 MV of HC BR compounds reinforced with $\mathrm{CB} / \mathrm{SI}$ (left) and SI (right) as function of silanization temperature and time. 


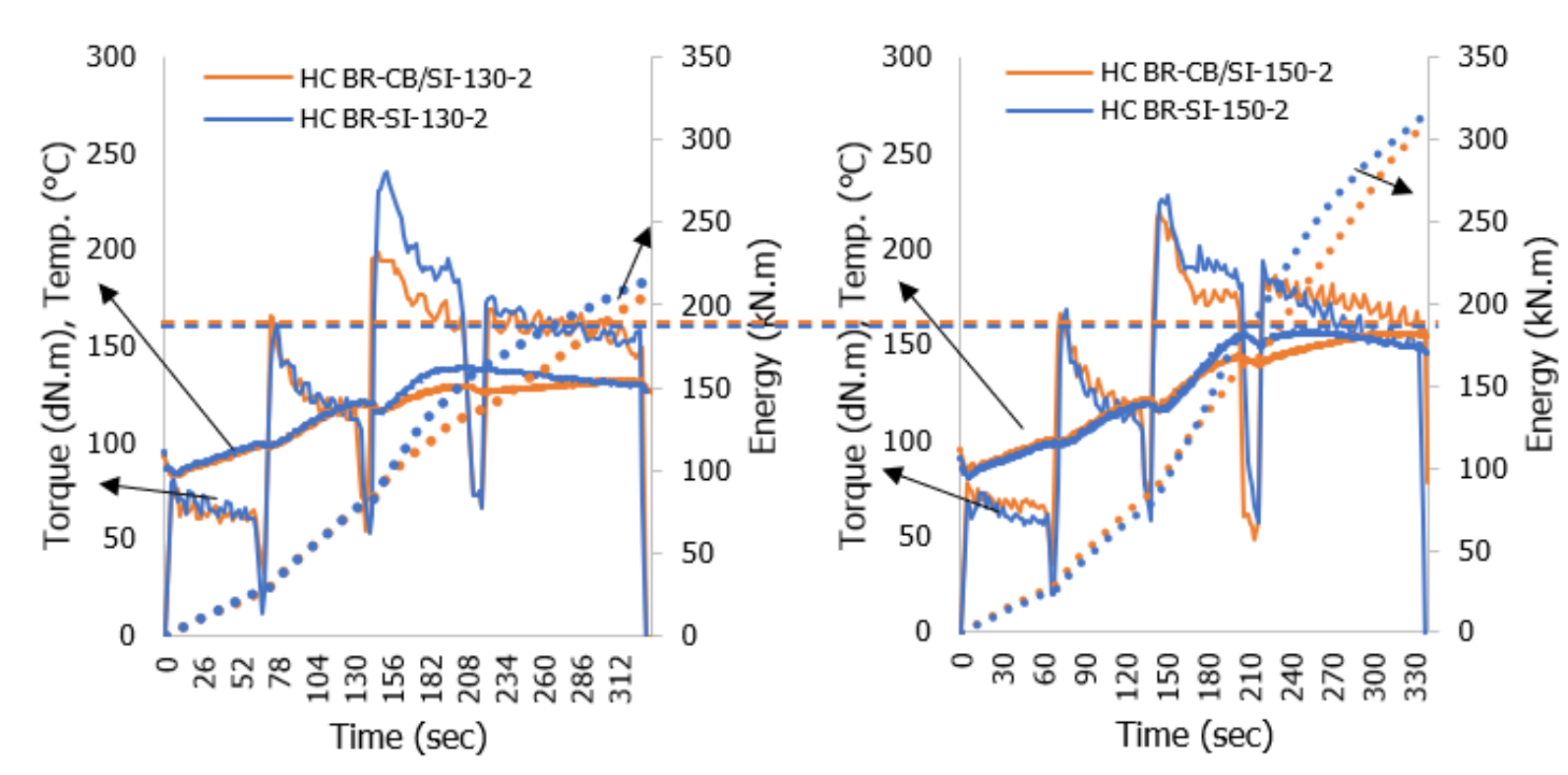

Figure 4.3 Mixing fingerprints of $\mathrm{CB} / \mathrm{SI}$ and SI reinforced $\mathrm{HC}$ BR compounds at $130^{\circ} \mathrm{C}$ (left) and $150^{\circ} \mathrm{C}$ (right) for 2 mins silanization time.

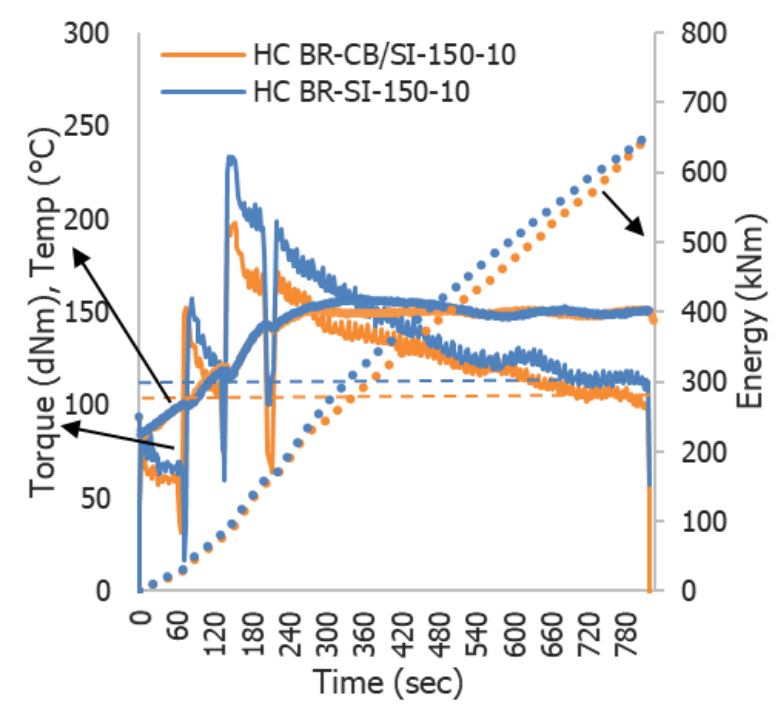

Figure 4.4 Mixing fingerprints of $\mathrm{CB} / \mathrm{SI}$ and $\mathrm{SI}$ reinforced $\mathrm{HC}$ BR compound at $150^{\circ} \mathrm{C}$ for 10 mins silanization time. 
In contrast, for $\mathrm{HC} \mathrm{LCB} B \mathrm{R}$, both silanization time and temperature significantly influence the MV: Figure 4.5. Branching of HC LCB BR improves the processability of this polymer relative to $\mathrm{HC} B$ R. Besides, silanization of the $\mathrm{CB} / \mathrm{SI}$ improves significantly as seen in the PE data: Figure 4.9 left. The better the silanization, the better the micro dispersion of the filler particles and the lower the final torque of CB/SI compounds obtained: Figure $4.6-4.7$.
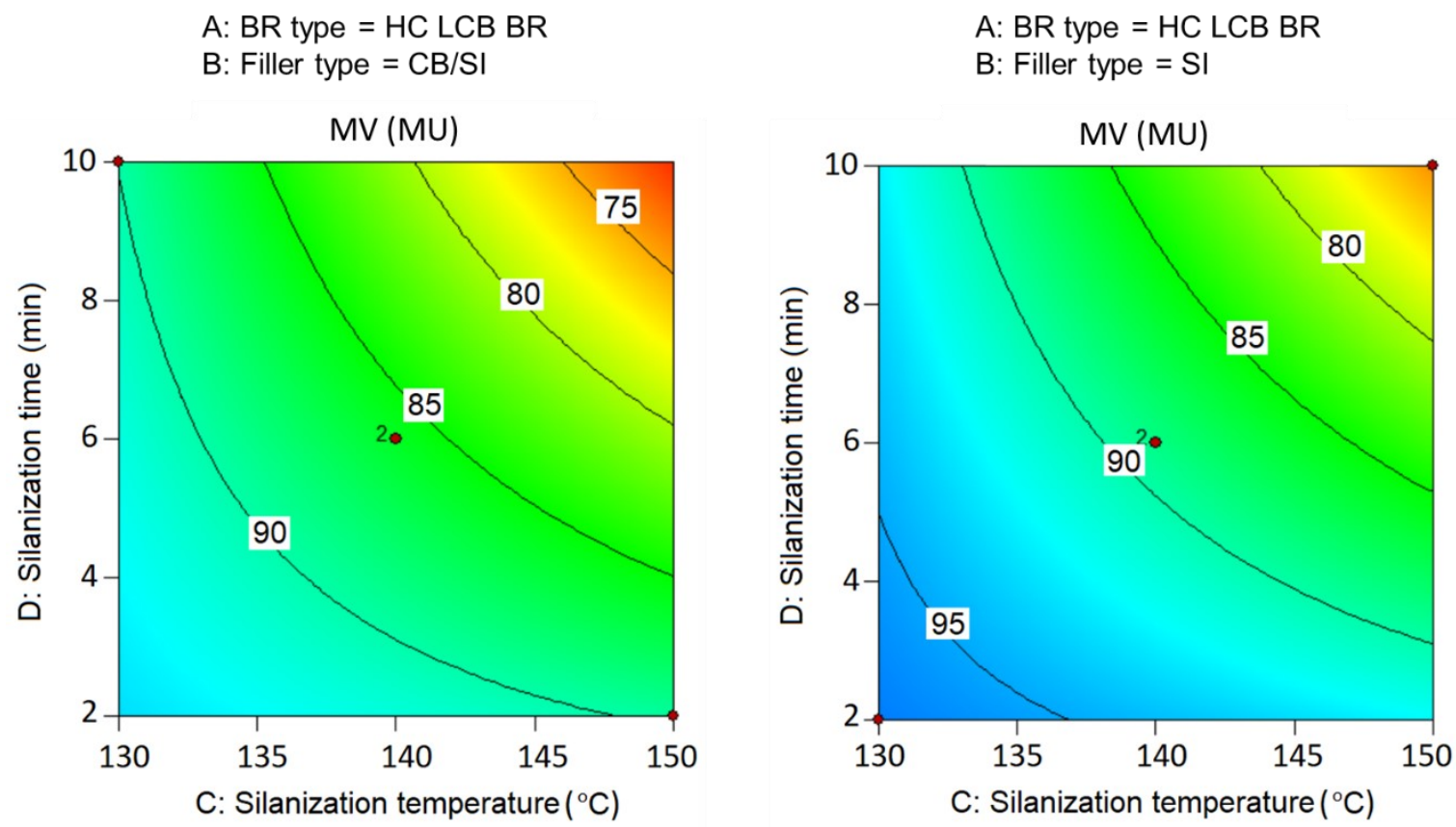

Figure 4.5 MV of HC LCB BR compounds reinforced with CB/SI (left) and SI (right) as function of silanization temperature and time.
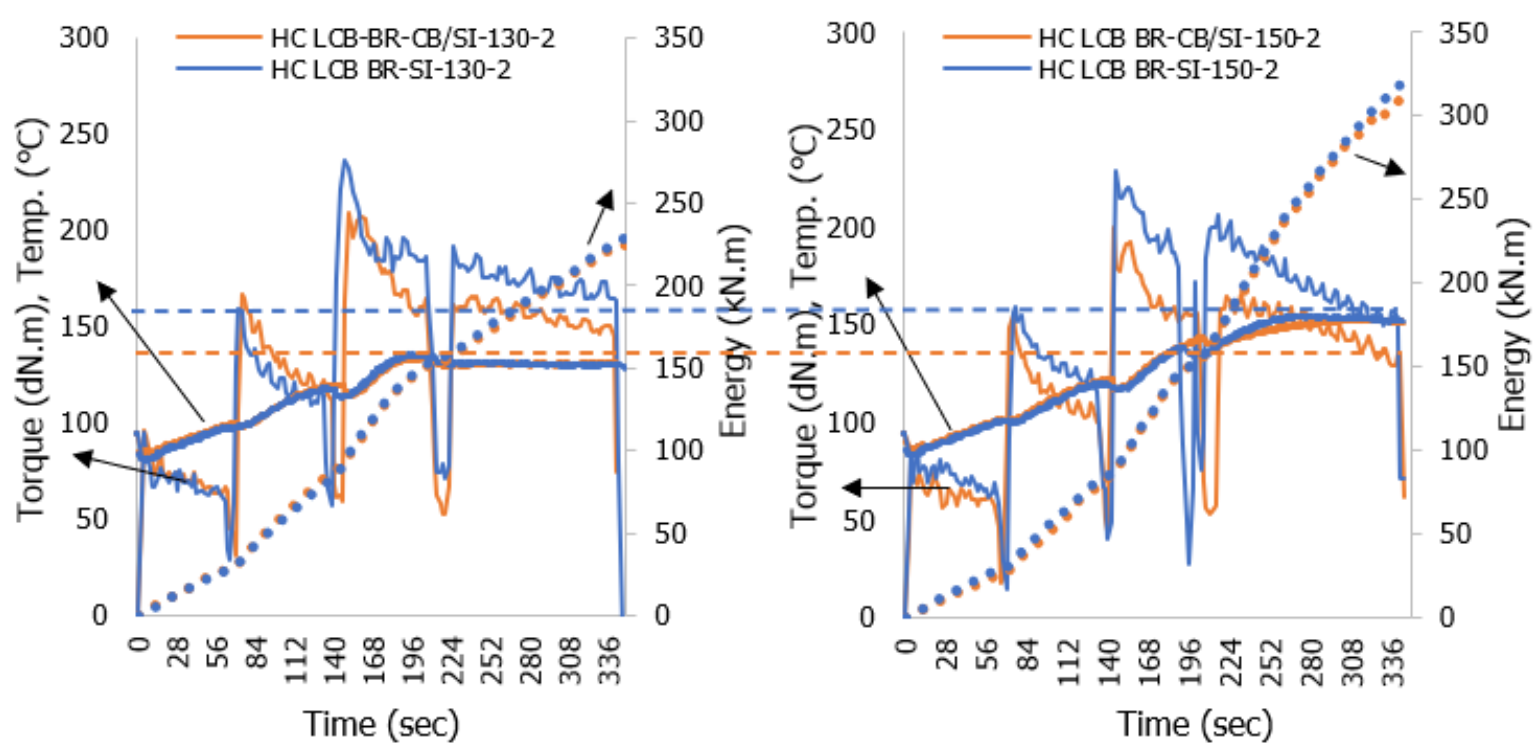

Figure 4.6 Mixing fingerprints of $\mathrm{CB} / \mathrm{SI}$ and SI reinforced $\mathrm{HC}$ LCB BR compounds at $130^{\circ} \mathrm{C}$ (left) and $150^{\circ} \mathrm{C}$ (right) for 2 mins. 


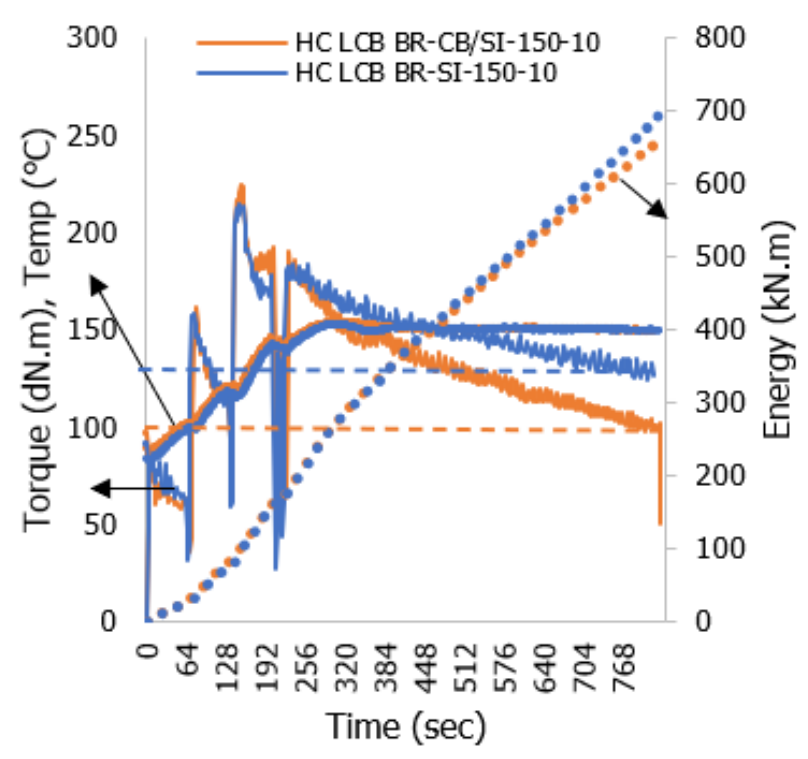

Figure 4.7 Mixing fingerprints of $\mathrm{CB} / \mathrm{SI}$ and $\mathrm{SI}$ reinforced $\mathrm{HC}$ LCB BR compounds at $150^{\circ} \mathrm{C}$ for 10 mins silanization time.

Figures 4.8 and 4.9 show the influence of temperature and silanization time on the PE: with increasing temperature and time, a lower PE is observed as the degree of silanization is increased. At higher silanization temperatures, the chain mobility increases, thus the polymers can easily penetrate into the cluster structure. The large filler clusters are successively broken to their ultimate size by shearing forces. Sufficient time of silanization is needed to ensure the hydrophobation of the SI, for the TESPT coupling agent to react with the silanol groups on the SI surface resulting in less filler-filler interaction. The interface between the matrix and the filler also increases and the filler particles are distributed homogenously in the rubber matrix. In line with the results of $M V, H C$ BR reinforced with $C B / S I$ and SI shows a lower degree of silanization, thus higher PE than HC LCB BR. The use of a hybrid CB/SI imparts lower filler-filler interaction compared to SI-filled in HC LCB BR: Figure 4.9.

Sattayanurak observed that the use of a low amount of CB up to $50 w t \%$ relative to the total filler in NR-filled compounds increases the PE slightly compared to that of the reference pure SI-filled compound [19]. It was stated that CB N134 favors filler network formation and thus increases the PE due to the small particle size and high specific surface area with narrow filler particle-particle distances. The type of $C B$ used in the present research is CB N234, which has a larger particle size and so a lower surface area than CB N134. Thus, CB N234 features a lower degree of filler network formation than CB N134. Combining CB N234 with SI decreases the filler network formation, hence lower PE compared to the use of SI alone. 
A: BR type = HC BR
B: Filler type $=\mathrm{CB} / \mathrm{SI}$

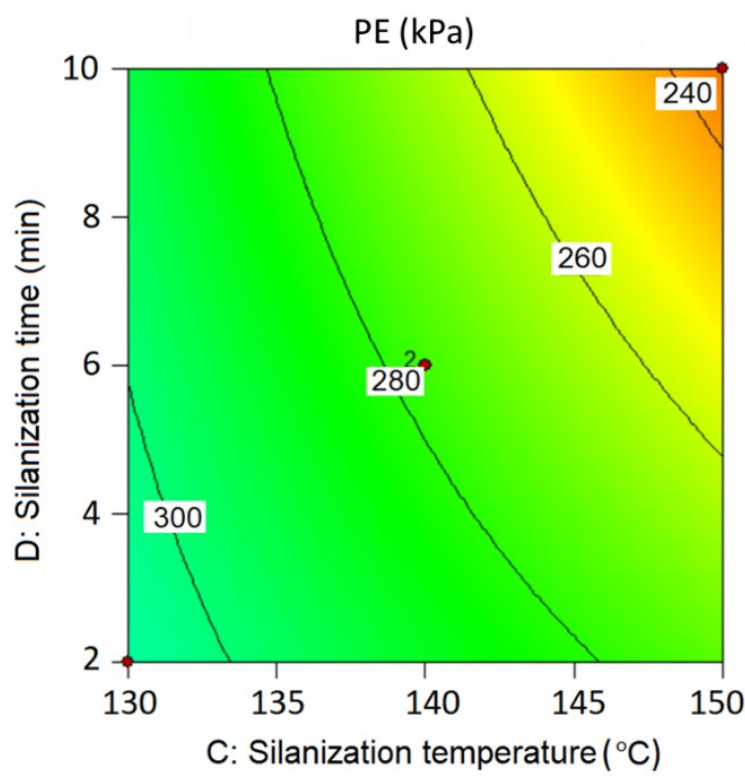

A: $B R$ type $=\mathrm{HC}$ BR

B: Filler type $=\mathrm{SI}$

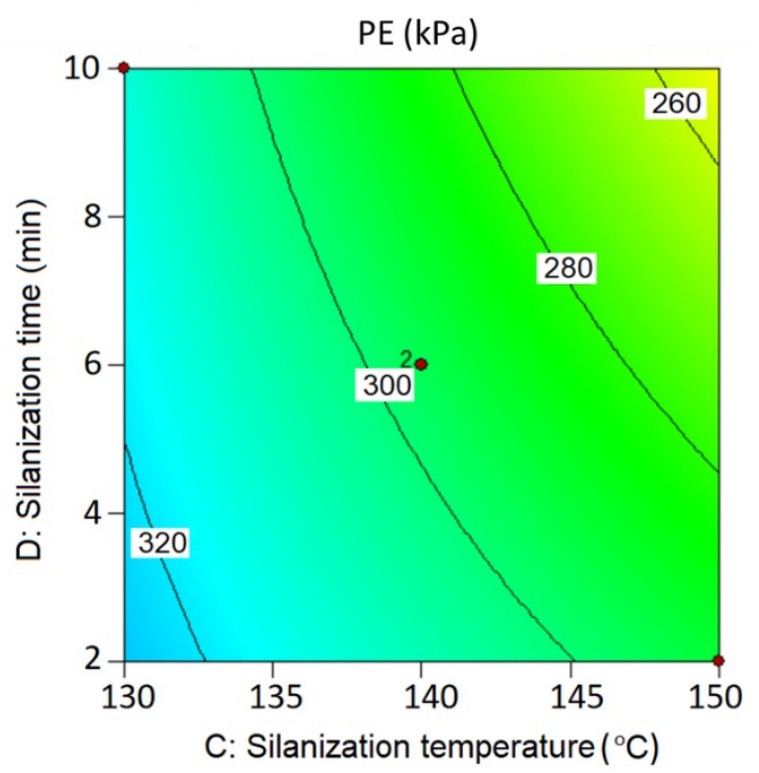

Figure 4.8 PE of HC BR compounds reinforced with CB/SI (left) and SI (right) as function of silanization temperature and time.
A: BR type $=$ HC LCB BR
A: BR type $=$ HC LCB BR
B: Filler type $=\mathrm{CB} / \mathrm{SI}$
B: Filler type $=\mathrm{SI}$
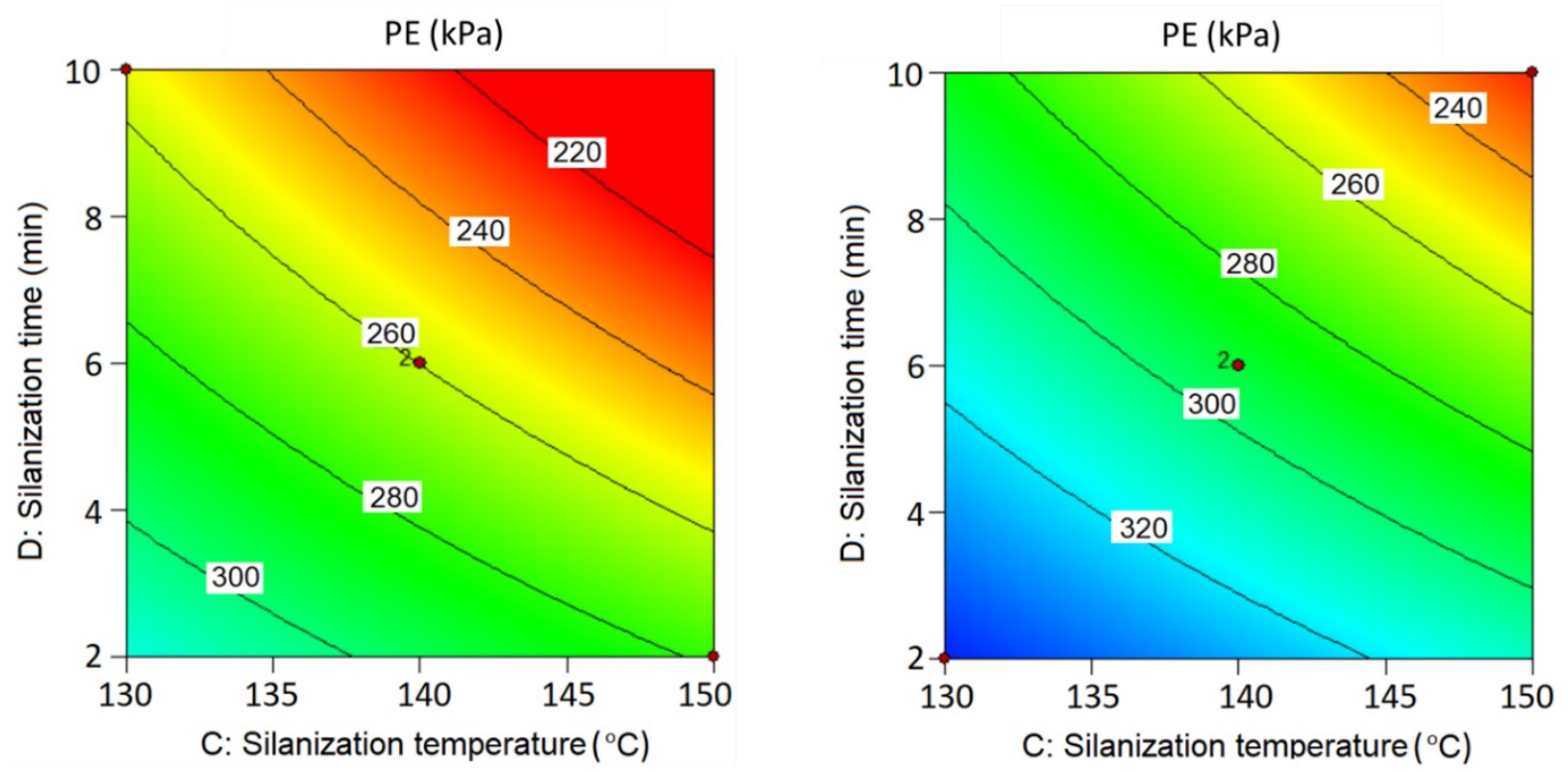

Figure 4.9 PE of HC LCB BR compounds reinforced with CB/SI (left) and SI (right) as function of silanization temperature and time. 
The apparent crosslink density indicates not only sulfur-crosslinks but also the contribution of filler-polymer coupling via the silane. HC BR filled-CB/SI and SI do not show a significant difference in the degree of silanization. This results in similar filler-rubber interaction and hence similar crosslink density: Figure 4.10. SI-filled HC LCB BR imparts higher crosslink density compared to CB/SI-filled HC LCB BR. This might be due to the higher covalent filler-rubber coupling in SI-filled rubber than in $\mathrm{CB} / \mathrm{SI}$ filled material. A high covalent fillerrubber coupling contributes to a high crosslink density: Figure 4.11. The higher silanization degree results in a higher crosslink density of HC LCB BR than HC BR.
A: $B R$ type $=\mathrm{HC} B R$
B: Filler type $=\mathrm{CB} / \mathrm{SI}$

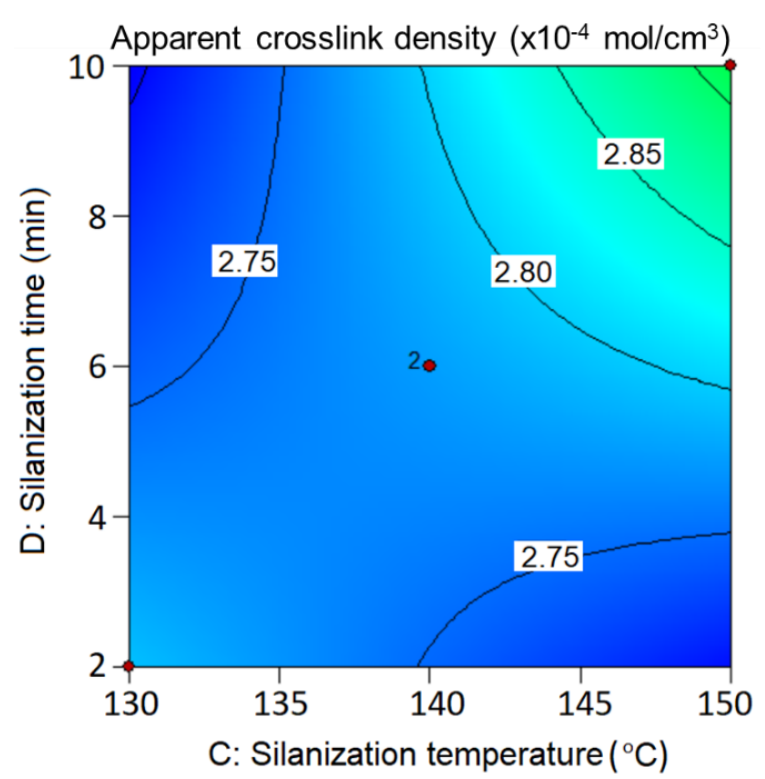

A: BR type $=\mathrm{HC}$ BR

B: Filler type $=$ SI

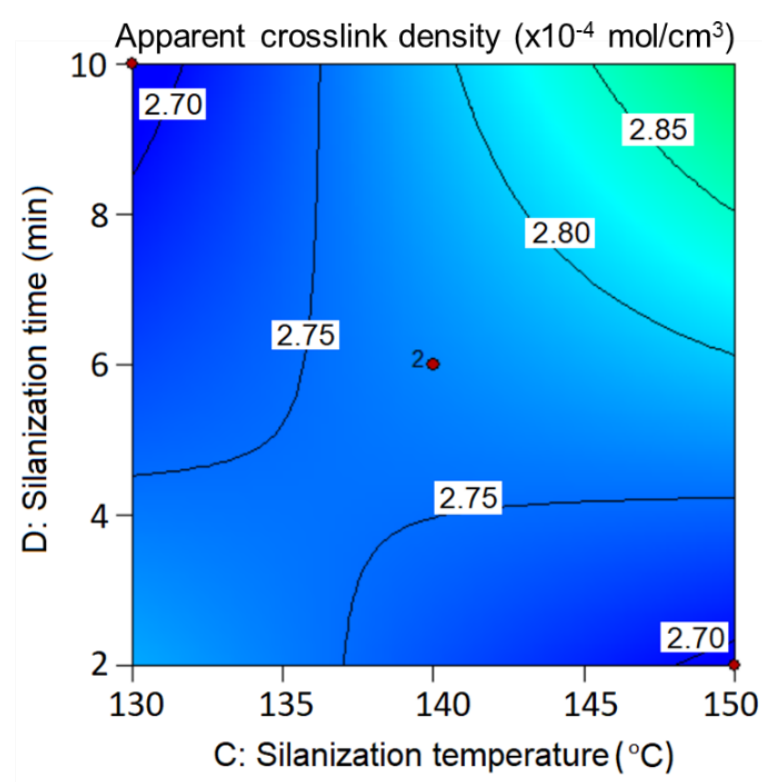

Figure 4.10 Apparent crosslink density of HC BR compounds reinforced with CB/SI (left) and SI (right) as function of silanization temperature and time. 
A: BR type $=$ HC LCB BR

B: Filler type $=\mathrm{CB} / \mathrm{SI}$

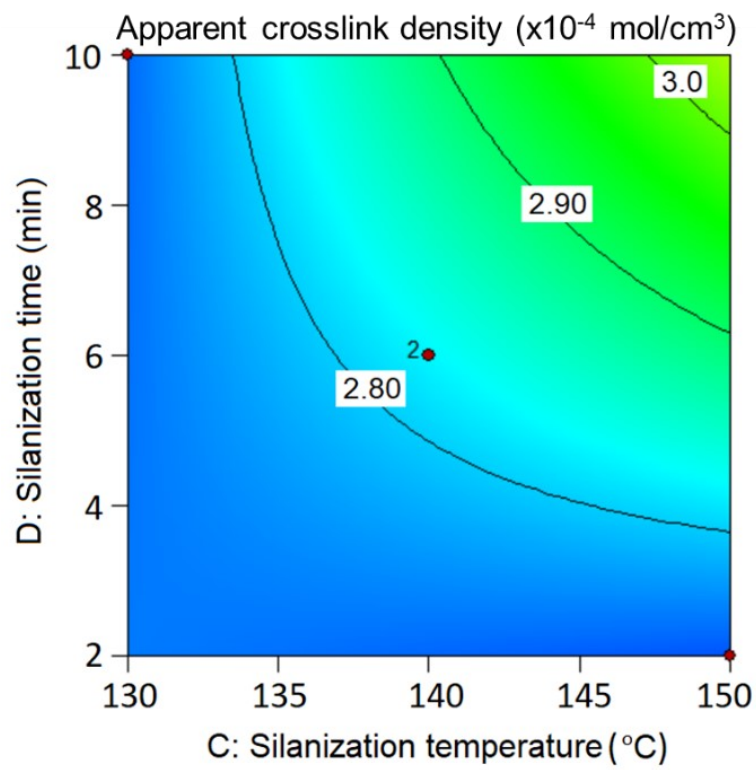

A: BR type $=$ HC LCB BR

B: Filler type $=\mathrm{SI}$

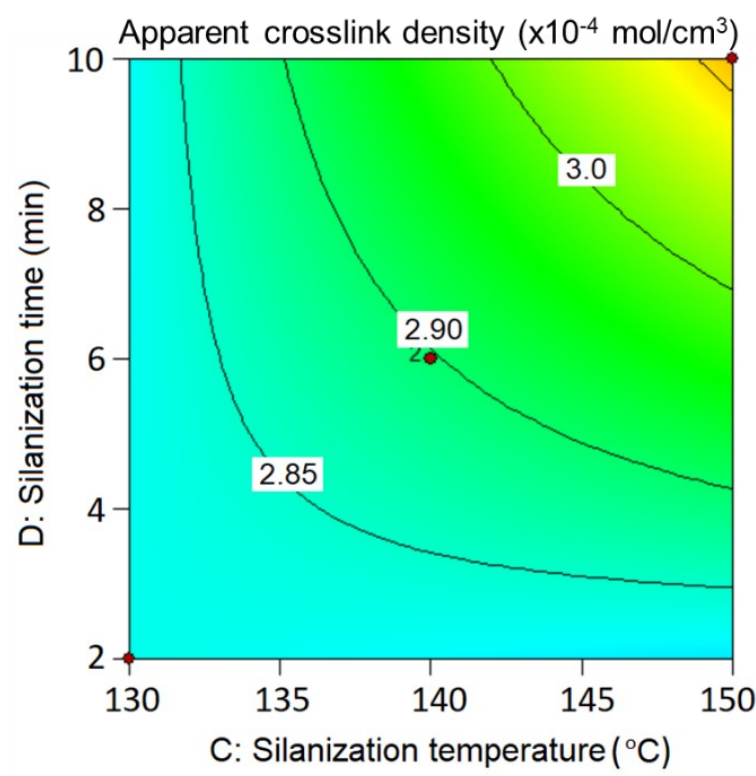

Figure 4.11 Apparent crosslink density of HC LCB BR compounds reinforced with CB/SI (left) and SI (right) as function of silanization temperature and time.

Tan $\delta$ at $100^{\circ} \mathrm{C}$ as a function of silanization temperature and time is shown in Figures 4.12 and 4.13 . Tan $\delta$ above $70^{\circ} \mathrm{C}$ can be used as an indication of heat build-up (HBU), for which a lower value indicates lower heat generation in the tire [20]. Tan $\delta$ is influenced by many factors such as crosslink density, filler-filler interaction, filler-polymer interaction, and type of polymer. HC BR shows that $\tan \delta$ is not influenced much by the silanization temperature at short silanization times: Figure 4.12. This is in line with the results of MV: Figure 4.2, and apparent crosslink density: Figure 4.10, which show no significant difference in those properties in HC BR reinforced either with CB/SI or SI. HC LCB BR reinforced with $\mathrm{CB} / \mathrm{SI}$ or SI show a significant difference in $\tan \delta$ as silanization temperature and time increase: Figure 4.13. The low final torque at the end of mixing, thus low MV: Figure 4.5 and 4.7, corresponds to a high degree of silanization. PE substantially decreases due to reduced fillerfiller interaction: Figure 4.9, and improved filler-rubber interaction, which contributes to high crosslink density: Figure 4.11. The branching in HC LCB BR also gives additional trapped entanglements. All those improved properties lead to a lower $\tan \delta$.

Comparing the two types of fillers, the SI-filler imparts lower tan $\delta$ than the CB/SIcombination. In pure SI-filled rubber, the extra network formations derived from silica-silanerubber coupling, which is stronger than the network formation in CB/SI-filled vulcanizates. In $\mathrm{CB} / \mathrm{SI}$-filled vulcanizates the network stems from the combination of covalent silica-rubber coupling via the silane and the physical CB-rubber interactions. These physical CB-rubber interactions of polymer chains adsorbed onto the surface of $C B$ particles consist of an immobilized polymer layer and the unrestricted bulk layer [21]. Filler-rubber interactions follow 
the order: chemically bound layer < immobilized layer < unrestricted bulk layer. Therefore, the SI-filled compounds impart lower tan $\delta / \mathrm{HBU}$ than CB/SI-filled vulcanizates.
A: BR type $=\mathrm{HC}$ BR
B: Filler type $=\mathrm{CB} / \mathrm{SI}$

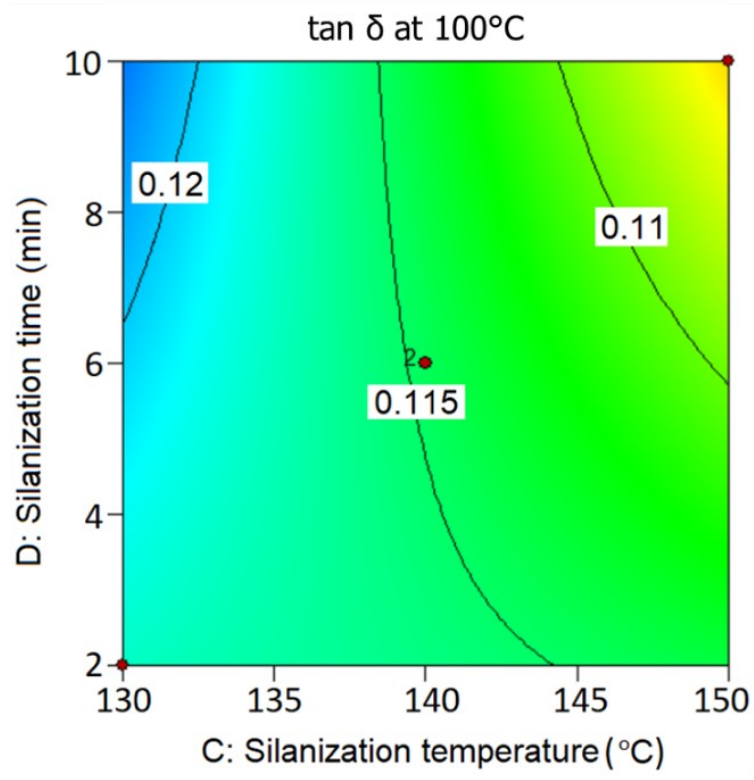

A: BR type $=\mathrm{HC}$ BR

B: Filler type $=\mathrm{SI}$

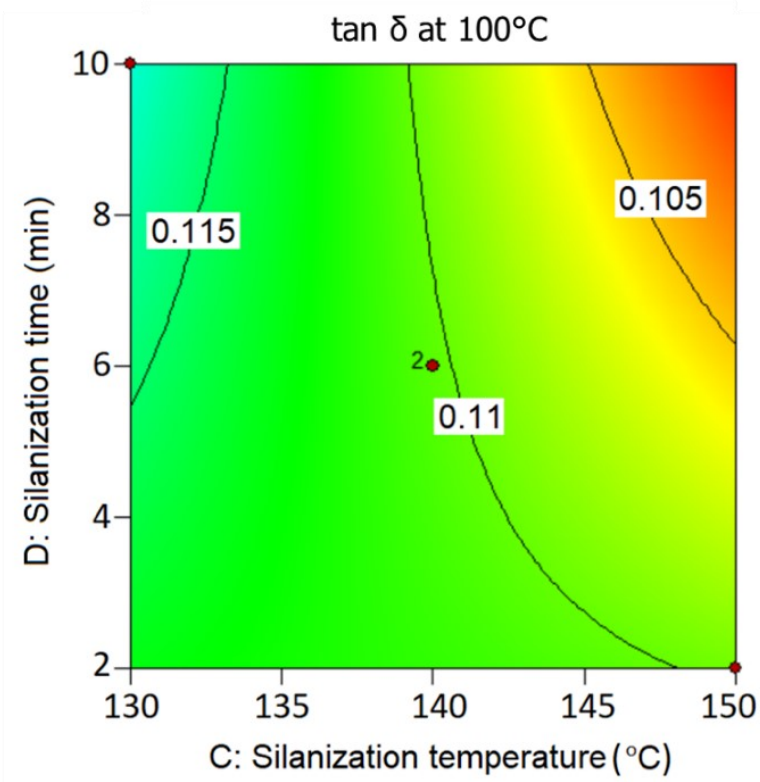

Figure 4.12 $\tan \delta$ of HC BR compounds reinforced with CB/SI (left) and SI (right) as function of silanization temperature and time.
A: BR type $=$ HC LCB BR
B: Filler type $=\mathrm{CB} / \mathrm{SI}$

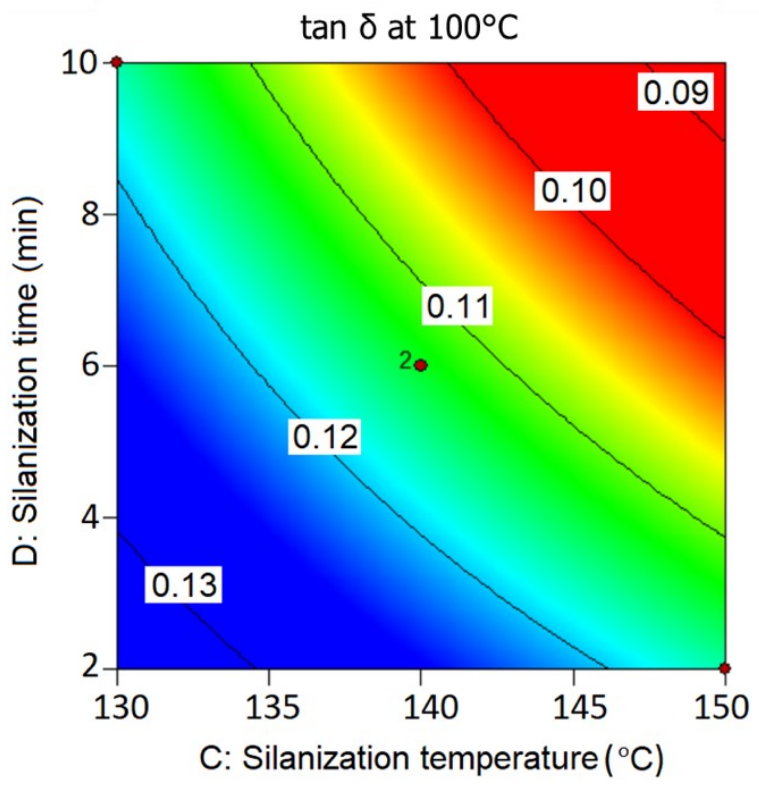

A: BR type $=\mathrm{HC}$ LCB BR

B: Filler type $=\mathrm{SI}$

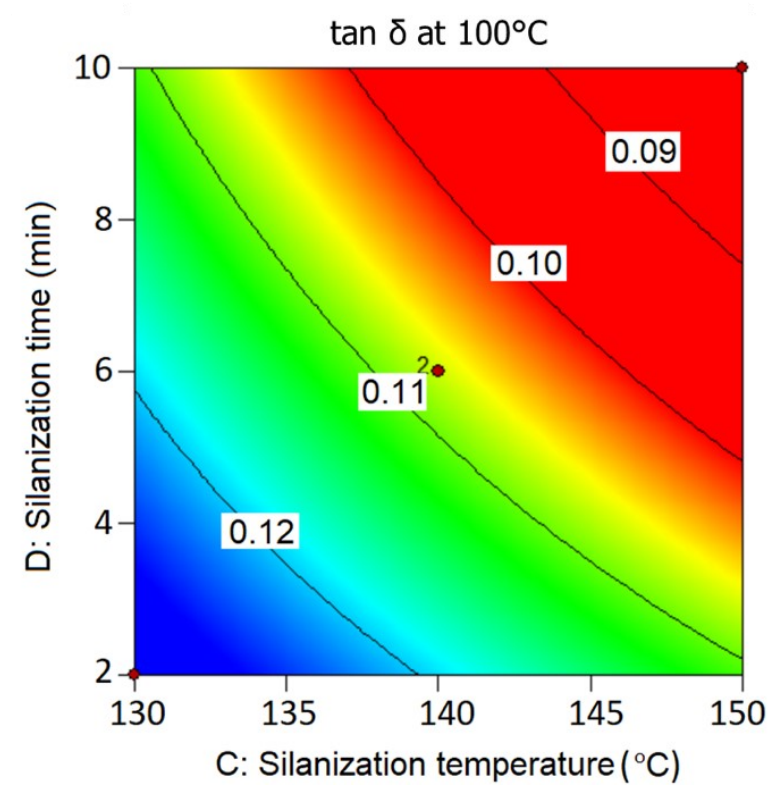

Figure 4.13 tan $\delta$ of HC LCB BR compounds reinforced with CB/SI (left) and SI (right) as function of silanization temperature and time. 
Figures 4.14 and 4.15 show the influence of silanization temperature and time on the $\mathrm{M} 300 \%$ of the rubber vulcanizates. M300\% of CB/SI- and SI-filled HC BR vulcanizates are relatively independent of silanization time: Figure 4.14. The high molecular weight of HC BR decreases its processability. MV does not decrease at short silanization times even when a high silanization temperature is employed: Figure 4.2. Increasing silanization time and temperature decrease MV but the values are still higher compared to HC LCB BR. The apparent crosslink density of $\mathrm{HC} B \mathrm{BR}$ is not significantly affected by silanization time and temperature: Figure 4.10. The use of HC LCB BR imparts better processability. As the silanization temperature and time increase, the degree of silanization increases. The low PE: Figure 4.9, and high apparent crosslink density values: Figure 4.11, observed as the silanization improves, lead to higher M300\%: Figure 4.15.
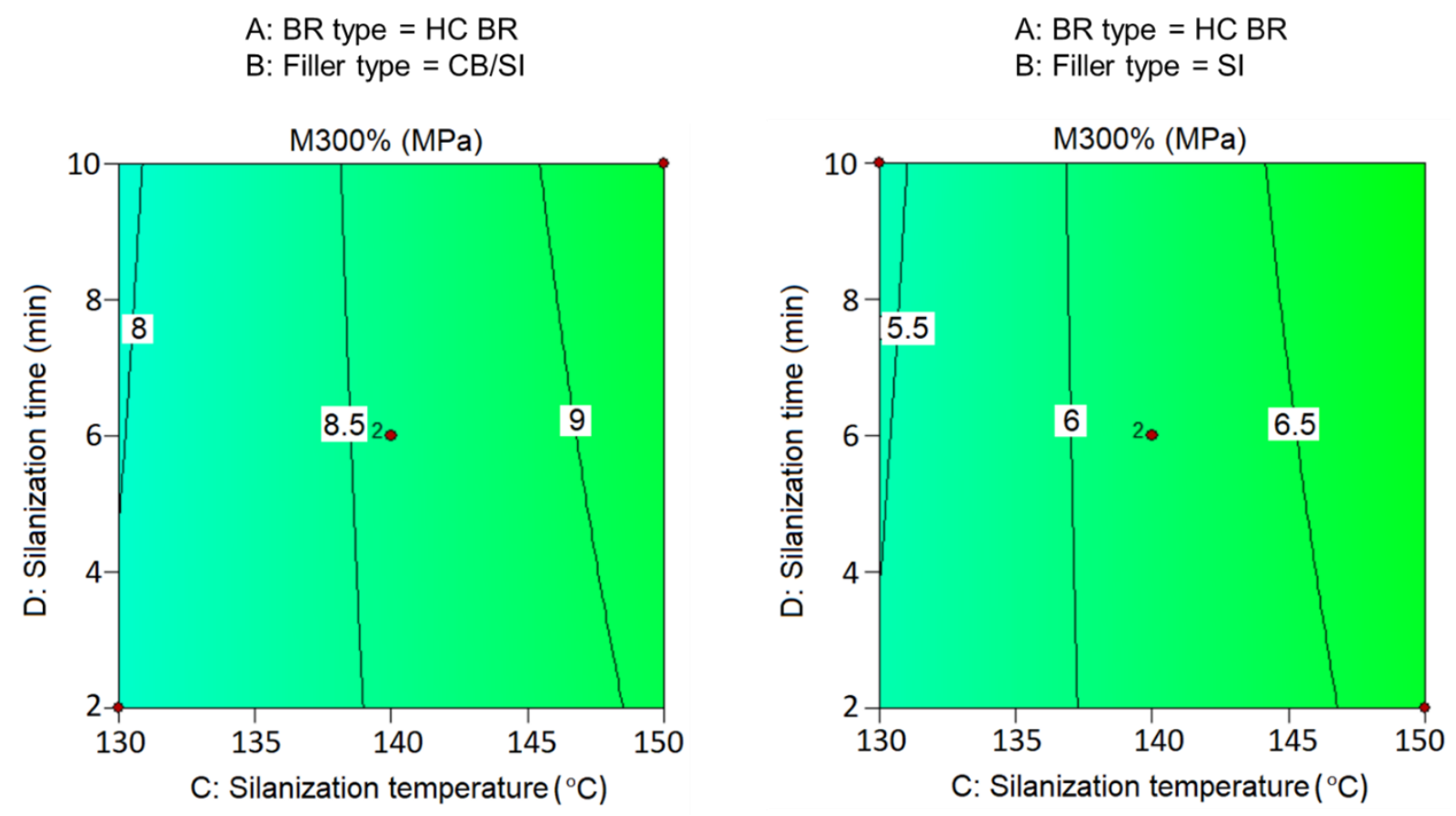

Figure 4.14 M300\% of HC BR compounds reinforced with $\mathrm{CB} / \mathrm{SI}$ (left) and SI (right) as function of silanization temperature and time. 

A: BR type $=$ HC LCB BR
$A:$ BR type $=$ HC LCB BR
B: Filler type $=\mathrm{CB} / \mathrm{SI}$
B: Filler type $=\mathrm{SI}$
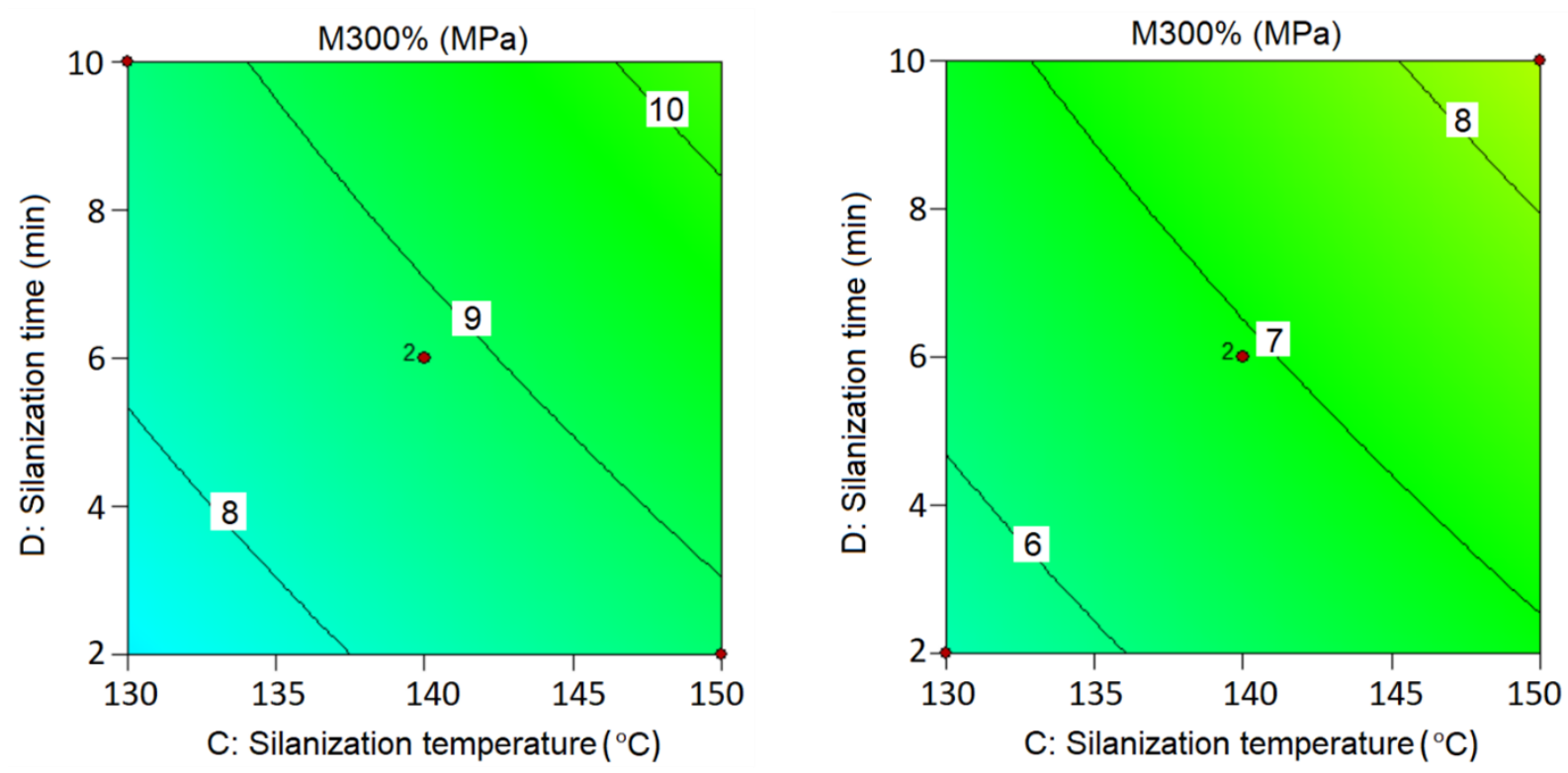

Figure 4.15 M300\% of HC LCB BR compounds reinforced with CB/SI (left) and SI (right) as function of silanization temperature and time.

The effect of silanization temperature and time on TS is shown in Figures 4.16 and 4.17. Within the range of silanization temperatures and times, the TS of the cured rubbers is relatively constant. HC LCB BR compounds show a slightly higher TS than HC BR-based compounds. The apparent crosslink density of HC LCB BR is higher than that of HC BR due to the high filler-rubber interactions and additional entanglements of the long-chain branched polymer which contribute to high crosslink density: Figure 4.11. CB/SI-filled vulcanizates show only slightly higher TS values compared to SI-filled vulcanizates due to slightly higher reinforcement: Figure 4.17. 
A: BR type $=\mathrm{HC}$ BR

B: Filler type $=\mathrm{CB} / \mathrm{SI}$

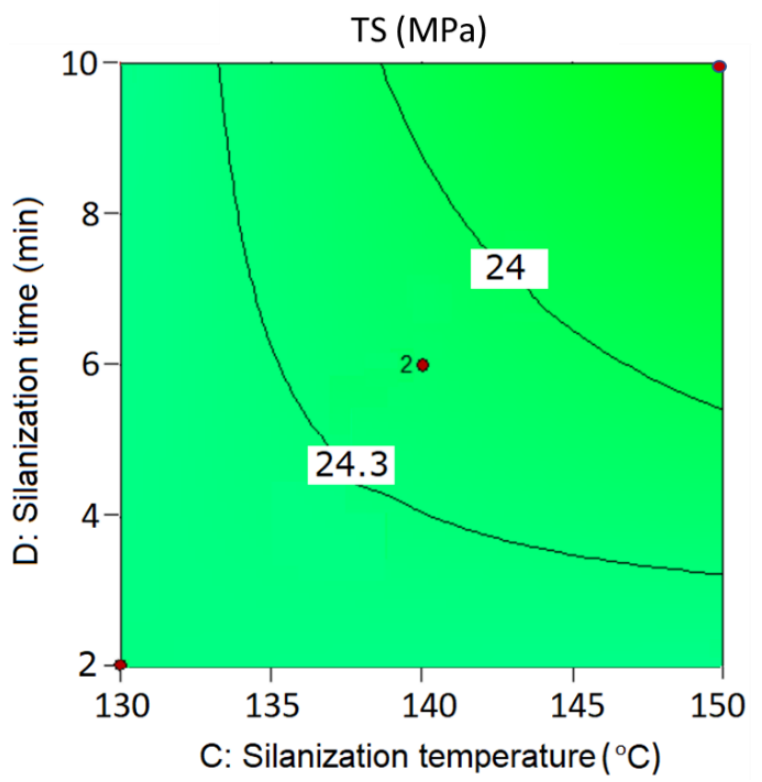

A: BR type $=\mathrm{HC} B R$

B: Filler type $=\mathrm{SI}$

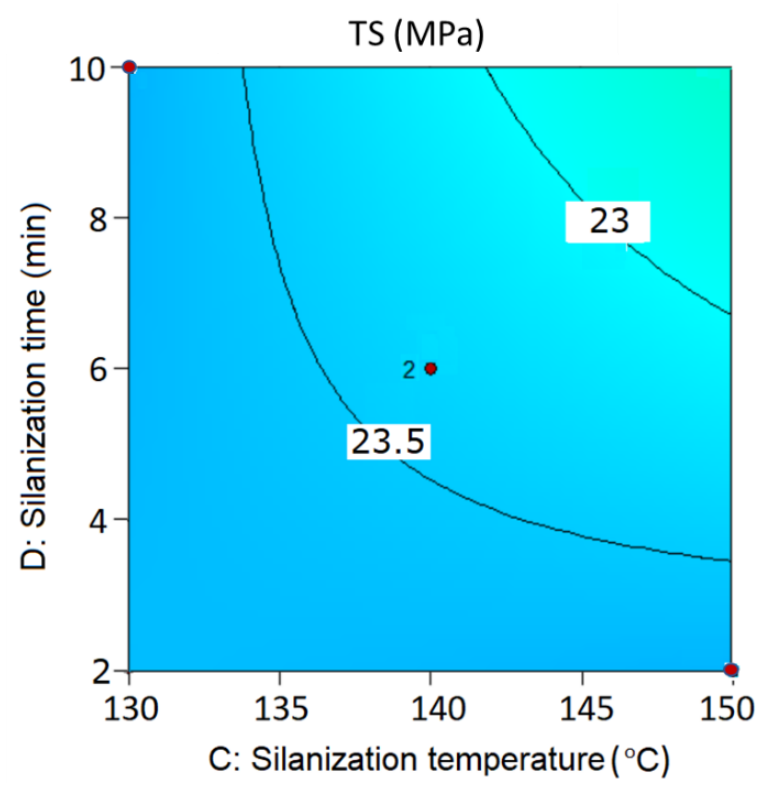

Figure 4.16 TS of HC BR compounds reinforced with $\mathrm{CB} / \mathrm{SI}$ (left) and SI (right) as function of silanization temperature and time.
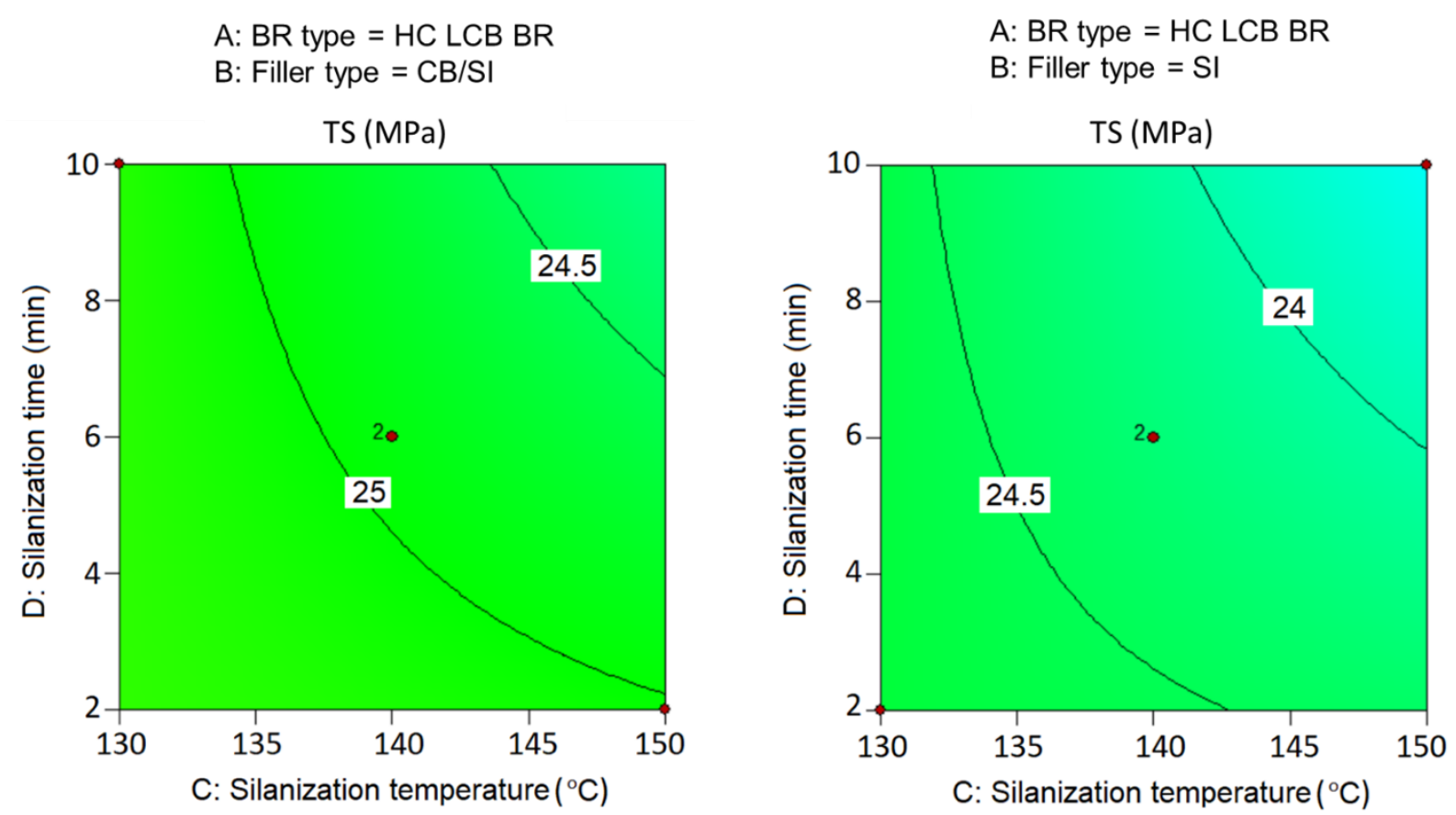

Figure 4.17 TS of HC LCB BR compounds reinforced with CB/SI (left) and SI (right) as function of silanization temperature and time. 
Figures 4.18 and 4.19 show the hardness of CB/SI- and SI-filled HC BR and HC LCB BR vulcanizates. The hardness of HC BR vulcanizates is clearly less dependent on silanization time and temperature compared to the HC LCB BR ones. It correlates well with the viscosity of the compounds. Due to the high linearity/high viscous polymer, HC BR is challenging to process, and a lower degree of silanization, hence higher PE, was achieved compared to HC LCB BR. Both characteristics make the MV of $\mathrm{HC}$ BR compounds less sensitive to silanization temperature and time: Figure 4.2. In HC LCB BR, branching improves processability. The PE decreases significantly as silanization temperature and time increase. A low MV of compounds was observed as the silanization degree increases, which leads to the low hardness of the vulcanizates. Overall the hardness is a property rather insensitive to intricate phenomena in the compound formulation, remotely related to the Young's modulus. Most conspicuous in the small difference in the values is the influence of the type of BR.

A: BR type $=\mathrm{HC}$ BR

B: Filler type $=\mathrm{CB} / \mathrm{SI}$

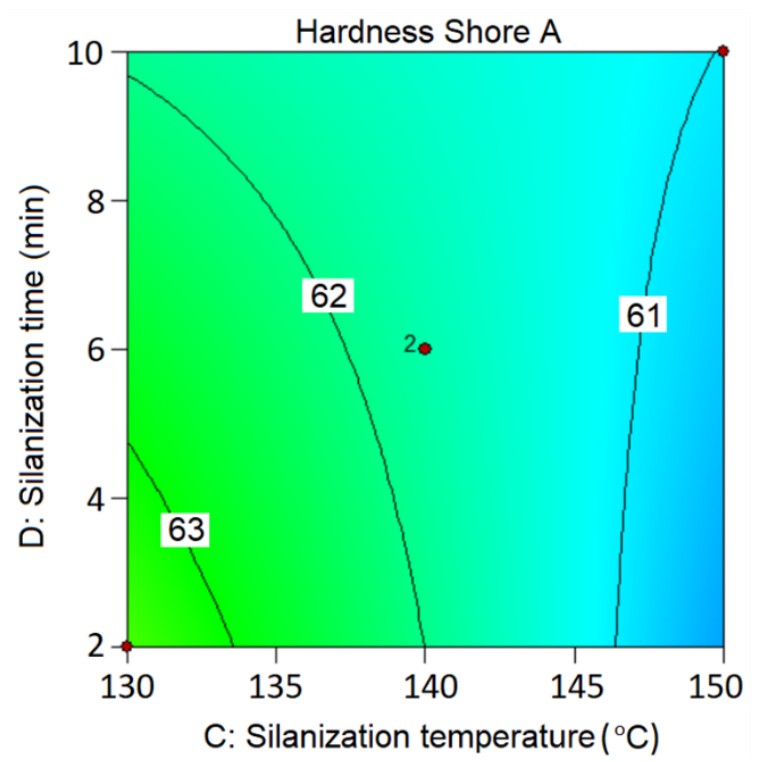

$A: B R$ type $=H C B R$

B: Filler type $=\mathrm{SI}$

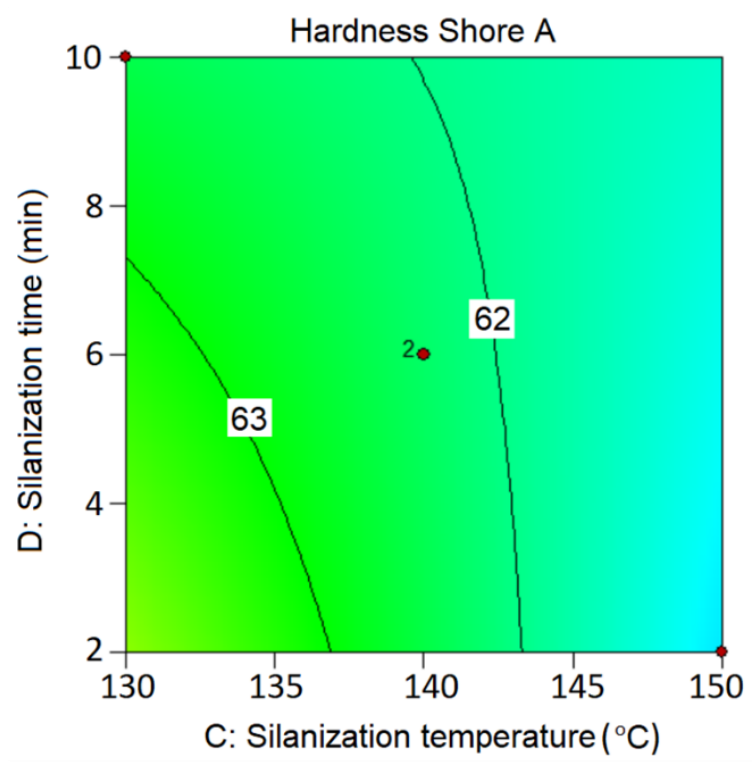

Figure 4.18 Hardness of $\mathrm{HC}$ BR compounds reinforced with $\mathrm{CB} / \mathrm{SI}$ (left) and SI (right) as function of silanization temperature and time. 
A: BR type $=$ HC LCB BR

B: Filler type $=\mathrm{CB} / \mathrm{SI}$

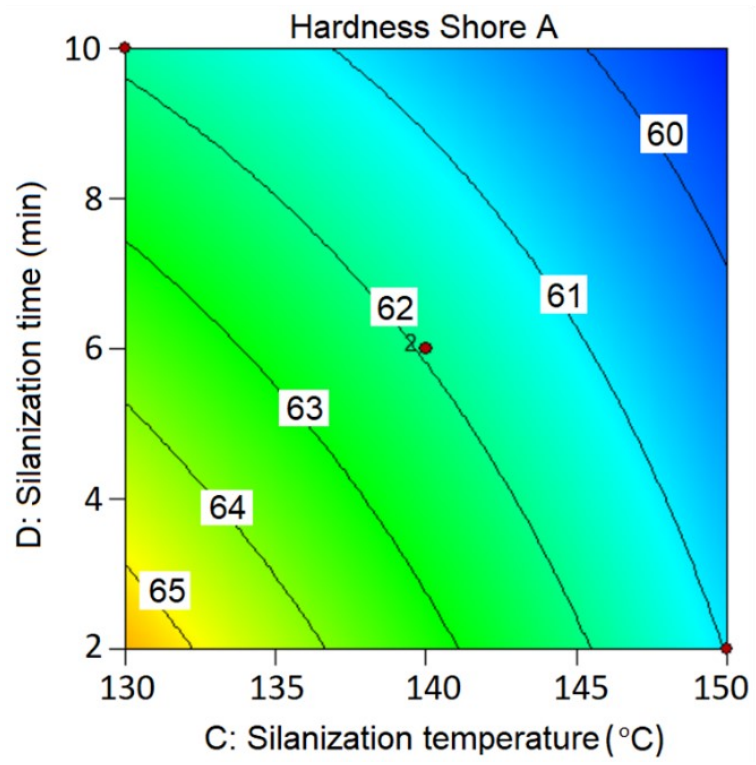

A: BR type $=$ HC LCB BR

B: Filler type $=$ SI

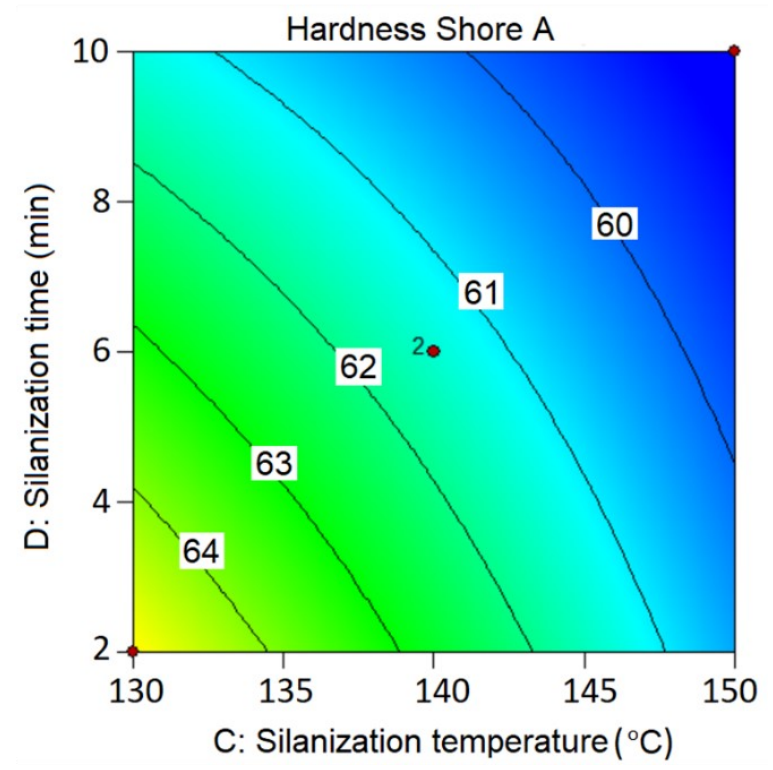

Figure 4.19 Hardness of HC LCB BR compounds reinforced with CB/SI (left) and SI (right) as function of silanization temperature and time.

\subsection{VALIDATION RUNS}

Validation runs were performed to assess the accuracy of the predicted properties from the model compared to the actual ones from the experimental run. The overlay plots are depicted in Figure 4.20. The silanization temperature and time can be set by following the yellow area of the overlay plot to achieve the target values. Both CB/SI- and SI-filled NR/HC LCB BR can be set at silanization temperatures of $140-155^{\circ} \mathrm{C}$ to achieve the target properties. In the case of silanization time, the SI-filled compounds need more time for mixing compared to $\mathrm{CB} / \mathrm{SI}$ compounds. For the confirmation runs, the silanization was set at $150^{\circ} \mathrm{C}$ and 7 mins for $\mathrm{CB} / \mathrm{SI}$ and $150^{\circ} \mathrm{C}$ and 9 mins for SI-filled to obtain a better balance between low Payne effect and low tan $\delta$, while maintaining TS and $\mathrm{M} 300 \%$. Table 4.5 shows the target values and the actual values of the desired properties. The output values from the confirmation run are close to the target values except for hardness. The target hardness in the range of 65 67. Therefore, adjustment of the current compound formulation of a hybrid CB/SI and SI should be made for the follow-up research in the next chapter to achieve the target hardness. Adjustment of the compound formulation can be made by increasing the filler, decreasing the oil content or adjusting the curatives. 

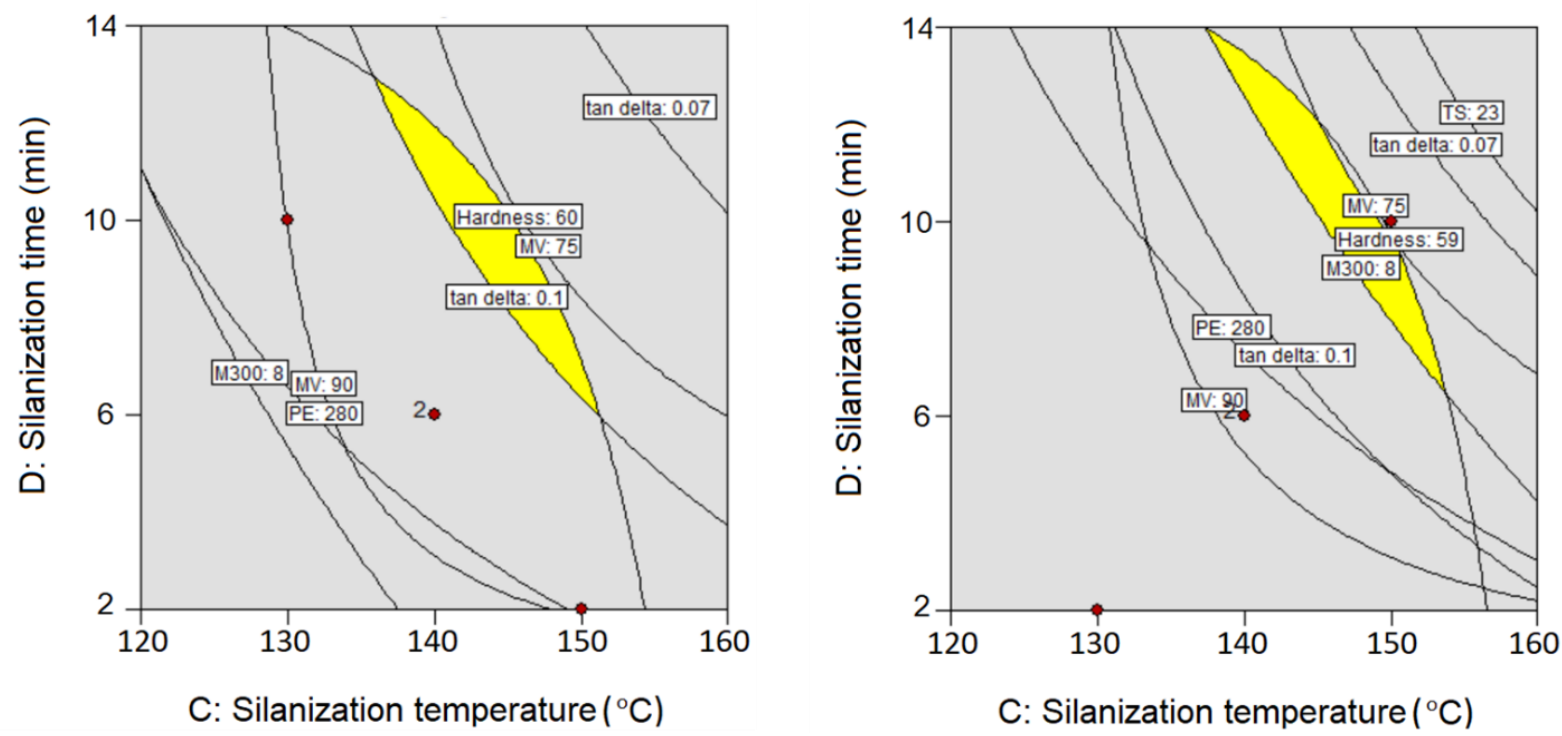

Figure 4.20 Overlay plot for CB/SI (left) and SI-filled (right) NR/HC LCB BR compounds.

Table 4.5 Target values and actual values of desired properties from the confirmation runs.

\begin{tabular}{|l|c|c|c|}
\hline \multicolumn{1}{|c|}{ Properties } & Target value & $\begin{array}{c}\text { A: HC LCB BR } \\
\text { B: CB/SI } \\
\mathbf{1 5 0 - 7}\end{array}$ & $\begin{array}{c}\text { A: HC LCB BR } \\
\text { B: SI } \\
\mathbf{1 5 0 - 9}\end{array}$ \\
\hline $\mathrm{MV}(\mathrm{MU})$ & $75-90$ & 74 & 75 \\
\hline $\mathrm{PE}(\mathrm{kPa})$ & $\max 280$ & 188 & 231 \\
\hline $\mathrm{TS}(\mathrm{MPa})$ & $\min 22[22]$ & 24 & 23 \\
\hline $\mathrm{M} 300 \%(\mathrm{MPa})$ & $8-16[22]$ & 9 & 8 \\
\hline $\tan \delta$ at $100^{\circ} \mathrm{C}$ & $0.07-0.17[23]$ & 0.094 & 0.08 \\
\hline Hardness Shore A & $65-67$ & 61 & 59 \\
\hline
\end{tabular}

\subsection{CONCLUSIONS}

The properties of $\mathrm{AC}$ tire treads containing SI alone or in combination with $\mathrm{CB}$ (CB/SI) show a strong dependence on the silanization temperature and time. High silanization temperatures and times enhance the silanization reaction, with the consequence of low fillerfiller interaction and high silica-silane-rubber coupling. HC LCB BR instead of HC BR improves the processability as evidenced by lower MV of the compounds. Furthermore, it shows lower $\mathrm{PE}$, tan $\delta$ at $100^{\circ} \mathrm{C}$, and slightly higher mechanical properties than the HC BR counterpart. $\mathrm{M} 300 \%$ and $\mathrm{TS}$ of $\mathrm{CB} / \mathrm{SI}$ vulcanizates are higher than the ones of the SI vulcanizates. However, the tan $\delta /$ heat-build-up of CB/SI vulcanizates are still higher compared to the ones for SI vulcanizates, resulting from a combination of chemical and physical filler-rubber interactions. A slight further improvement to achieve the target hardness of $65-67$ is needed. Both $\mathrm{CB} / \mathrm{SI}$ and SI formulations can be used instead of $\mathrm{CB}$ to decrease heat build-up of $\mathrm{AC}$ tire retreads, while still maintaining acceptable mechanical properties. 


\subsection{REFERENCES}

1. Rauline, R., Copolymer Rubber Composition with Silica Filler, Tires Having a Base Said Composition and Method of Preparing Same, to Compagnie Generale des Establissements Michelin, US5227425A (1993).

2. Lugisland, H.D. and Niedermeier, W., New Reinforcing Materials for Rising Tire Performance Demands, Rubber World, 228, 34 (2003).

3. Wagner, M.P., Reinforcing Silicas and Silicates, Rubber Chem. Technol., 49, 3, 703 (1976).

4. Hewitt, N., in Compounding Precipitated Silica in Elastomers, Chapter 2: Compounding Precipitated Silica in Natural Rubber, William Andrew Publishing: New York (2007).

5. Cruse, R.W., et al., Effect of Polysulfidic Silane Sulfur on Rolling Resistance, Rubber Plastics News, 26, 14 (1997).

6. Medalia, A.I., Filler Aggregates and Their Effect on Reinforcement, Rubber Chem. Technol., 47, 2, 411 (1974).

7. Wang, M.J., The Role of Filler Networking in Dynamic Properties of Filled Rubber, Rubber Chem. Technol., 72, 2, 430 (1999).

8. Kaewsakul, W., et al., Optimization of Mixing Condition for Silica-Reinforced Natural Rubber Tire Tread Compounds, Rubber Chem. Technol., 85, 2, 277 (2012).

9. Reuvekamp, L.A.E.M., et al., Effects of Mixing Conditions - Reaction of TESPT Silane Coupling Agent During Mixing with Silica Filler and Tire Rubber, Kautsch. Gummi Kunstst., 55, 41 (2002).

10. Wang, M.J., Effect of Polymer-Filler and Filler-Filler Interactions on Dynamic Properties of Filled Vulcanizates, Rubber Chem. Technol., 71, 3, 520 (1998).

11. Sae-oui, P., et al., Comparison of Reinforcing Efficiency between Si-69 and Si-264 in a Conventional Vulcanization System, Polym. Test., 23, 8, 871 (2004).

12. Wang, M.J., Effect of Filler-Elastomer Interaction on Tire Tread Performance Part II Effects on Wet Friction of Filled Vulcanizates, Kautsch. Gummi Kunstst., 91, 33 (2008).

13. Reuvekamp, L.A.E.M., et al., Effects of Time and Temperature on the Reaction of TESPT Silane Coupling Agent During Mixing with Silica Filler and Tire Rubber, Rubber Chem. Technol., 75, 2, 187 (2002).

14. Sengloyluan, K., et al., Silica-Reinforced Tire Tread Compounds Compatibilized by Using Epoxidized Natural Rubber, Eur. Polym. J., 51, 69 (2014).

15. Hayichelaeh, C., et al., Enhancing the Silanization Reaction of the Silica-Silane System by Different Amines in Model and Practical Silica-Filled Natural Rubber Compounds, Polym., 10, 6, 584 (2018).

16. George, S.C., et al., Effect of Degree of Crosslinking on Swelling and Mechanical Behavior of Conventionally Vulcanisate Styrene-Butadiene Rubber Membranes, Polym. Polym. Compos., 7, 343 (1999).

17. Allen, P.W. and Bristow, G.M., The Gel Phase in Natural Rubber, J. Appl. Polym. Sci., 3, 2, 603 (1963).

18. Eriksson, L., et al., Design of Experiments Principles and Applications, Umetrics AB: Sweden (2000).

19. Sattayanurak, S., et al., Silica-Reinforced Natural Rubber: Synergistic Effects by Addition of Small Amounts of Secondary Fillers to Silica-Reinforced Natural Rubber Tire Tread Compounds, Adv. Mater. Sci. Eng., 2019, Article ID 5891051 (2019).

20. Nordsiek, K.H., The "Integral Rubber" Concept - an Approach to an Ideal Tire Tread Rubber, Kautsch. Gummi Kunstst., 38, 178 (1985).

21. Wolff, S., Chemical Aspects of Rubber Reinforcement by Fillers, Rubber Chem. Technol., 69, 3, 325 (1996). 
22. Scriver, R.M. and Ross, W.A., Pneumatic Tire with Medium Vinyl Polybutadiene/ Polyisoprene Blend Tread, to The Goodyear Tire \& Rubber Company, US4192366A (1978).

23. Sandstrom, P.H., et al., Aircraft Tire, to The Goodyear Tire and Rubber Company, US7367369B2 (2008). 


\title{
THE EFFECT OF ZINC OXIDE AND DIPHENYL GUANIDINE ADDITION SEQUENCE ON PROCESSING, MECHANICAL AND DYNAMIC PROPERTIES
}

\begin{abstract}
The properties needed for aircraft tire treads/retreads are significantly different from the ones required for passenger car or truck tires, for which improvements mainly focus on a better balance of rolling, wet skid and wear resistance. Aircraft tires experience severe operation conditions during service: the temperature can reach above the critical temperature of polymers, thus accelerating tread wear. To reduce the peak temperatures of the tire tread during departure and landing, the material of the tread should have a low hysteresis. Furthermore, the tires need to be able to withstand high loads and impact during landing. Therefore, they also require outstanding strength properties.
\end{abstract}

This study focuses on the influence of the processing sequence of Zinc Oxide $(\mathrm{ZnO})$ and DiPhenyl Guanidine (DPG) during tread compound mixing on the properties mentioned above. The compound is based on a blend of Natural Rubber and Butadiene Rubber (NR/BR) reinforced with a hybrid Carbon Black/Silica (CB/SI) filler system. It is revealed that the $\mathrm{ZnO}$ addition sequence has a strong influence on the properties of the compounds and vulcanizates, while the DPG addition sequence influences only cure properties and filler-rubber interaction. The incorporation of $\mathrm{ZnO}$ in the first stage of mixing (Z1D1 and Z1D2) results in low Mooney Viscosity (MV), better SI dispersion, high reversion resistance and mechanical properties, but slow cure rate. When $\mathrm{ZnO}$ is omitted in the first stage and added in the last stage of mixing (Z2D1 and Z2D2), it results in high filler-polymer interaction, which is beneficial for high stress-strain properties. However, the latter compounds were prone to reversion under prolonged vulcanization or aging leading to a significant reduction of the Modulus at 300\% elongation (M300\%) and apparent crosslink density. The addition of DPG in the last stage of mixing (Z1D2 and Z2D2) decreases scorch time, optimum cure time and increases filler-rubber interaction. The addition of $\mathrm{ZnO}$ in the first stage of the mixing process and DPG in the last stage of mixing (Z1D2) results in a reduction of the hysteresis as measured by the tan $\delta$ of the vulcanizate at $100^{\circ} \mathrm{C}$ and $200^{\circ} \mathrm{C}$, which corresponds to the temperature on the surface of an aircraft tire tread during service. Considering all properties above, the Z1D2 addition sequence applied to a hybrid CB/SI-filled NR/BR blend is the most promising one for aircraft tire retreads. 


\subsection{INTRODUCTION}

The hysteresis of rubber, which results in energy dissipation and is thus responsible for Heat Build-Up (HBU), is an essential property of tires, especially Aircraft (AC) tires. A prominent example is the landing performance of an AC tire: During landing, the tire touches the ground with zero rotational speed under substantial load, thus creating massive friction between the tires and the ground. The combination of high speed and extreme load results in a severe temperature increase within the tires. The temperature in the contact patch of an AC tire can reach up to $300^{\circ} \mathrm{C}$ [1]. This temperature is high enough to degrade the tire material, which consists to a large portion of Natural Rubber (NR). High hysteresis can also have a negative impact on ultimate properties such as tread wear and failure. Another serious consequence is related to the chemical effects of temperature build-up on the properties of the final product: oxidation of polymer chains causing chain scission and a reduction of crosslink density resulting in softening in NR, or additional crosslink formation leading to hardening as seen in Butadiene Rubber (BR) and Styrene-Butadiene Rubber (SBR).

Several strategies are followed to minimize HBU and deterioration of properties of rubber articles which are subject to cyclic deformation. Concerning rubber mixing and compounding, the compound performance is not only determined by the right choice of the formulation components, but also by correct processing such as optimum parameter settings and addition sequence.

The polymer should be chosen to give low hysteresis at the temperature and frequency of operation [2]. AC tire treads are generally made of blends of NR and BR. The use of NR provides better mechanical strength such as superior tensile and tear properties, lower operating temperatures, reduced rolling resistance, excellent component-to-component adhesion, and good tire retreadability. A small portion of BR is added to improve the abrasion resistance.

Concerning the filler system, the attempts to minimize the hysteresis are:

- decreasing the filler loading;

- decreasing the surface area of fillers by using large particle size fillers; or

- in the case of using small particle size fillers, thus high surface area: increasing the dispersion of fillers by prolonged mixing or more efficient mixing techniques [3].

Carbon Black (CB), in particular High Abrasion Furnace (HAF), Intermediate Super Abrasion Furnace (ISAF) and Super Abrasion Furnace (SAF) types are commonly used in AC tire tread formulations to enhance abrasion resistance. Silica (SI) in combination with a coupling agent such as a silane has become a strong alternative to CB fillers in tires, especially in Passenger Car Tires (PCT). Several studies revealed that SI-silane provides a better balance in tire properties, in particular rolling resistance and wet grip, compared to $C B[4,5]$. However, in AC tire treads, SI-silane filler systems are used in combination with CB [6]. Generally, a CB- 
reinforced rubber has a higher modulus than a SI-reinforced one, while SI-silane provides a unique combination of tear strength, abrasion resistance, aging resistance and adhesion properties [7].

Up to now, SI cannot replace CB entirely in large tires such as truck and Off-The-Road (OTR) tires, for which reinforcement and abrasion resistance are essential properties. This is due to the fact that SI is less compatible with the polymers used for the treads of these tires, especially when NR is the primary polymer in the formulation. The non-rubber components of $\mathrm{NR}$, in particular proteins, are reported to be the origin of the outstanding properties of NR. However, it has been demonstrated that the proteins contained in NR compete with the coupling agents for reaction with the SI during mixing, so disturb its reinforcement effect and consequently affect the final properties of the vulcanizate [8]. Besides, SI is more difficult to disperse and can reduce the effectiveness of some components of the vulcanization system, resulting in reduced reinforcement and poorer performance compared to the CB counterpart [9]. The use of SI with a high surface area can improve treadwear properties. However, a higher surface area means a higher number of silanol groups on the SI surface, which leads to an increase of filler-filler interaction. This increase as reflected in a higher so-called Payne Effect (PE), leads to a higher hysteresis loss. Additionally, it results in a higher degree of adsorption of accelerators [10], influencing the curing efficiency.

The effect of ZnO and DPG in SI-filled compounds was the subject of investigations of several researchers [11-15]. ZnO can interact with the SI surface, resulting in a reduction of the reaction efficiency between SI and silane: the silanol groups on the SI surface are acidic of nature, therefore they can react with an alkali such as $\mathrm{ZnO}$ [11]. Studies showed that a higher PE value was observed in SI-filled SSBR or SSBR/BR compounds when ZnO is introduced in the first mixing stage $[11,14]$. DPG is known as a secondary accelerator, which is generally used in combination with sulfenamide types as primary accelerators such as $\mathrm{N}$ Cyclohexyl-2-Benzothiazole Sulfenamide (CBS) in SI-filled compounds. DPG is required to accelerate the silanization reaction, when this type of amine is added to a SI-silane compound [16]. Considering the points discussed above, the present study aims at elucidating the influence of the addition sequence of $\mathrm{ZnO}$ and DPG in CB/SI-filled NR/BR blends on the compound and vulcanizate properties of AC tire retreads. 


\subsection{EXPERIMENTAL}

\subsubsection{MATERIALS}

The ingredients used in the present study were described in Chapter 4. The compound formulations are shown in Table 5.1. The filler system used in this research was a hybrid of CB and SI. The compound formulation is the same as described in Chapter 4, with the difference that in this study only HC LCB BR was used, and that the total filler amount was increased from 55 to 70 parts per hundred rubber (phr) in order to obtain a comparable hardness to the one of the CB-filled vulcanizates. The amount of TESPT and DPG was calculated based on the CTAB specific surface area of the SI type as suggested by Guy et al. [17]. The addition sequence of ZnO (Z) and DPG (D) was divided into a first stage (1) and second stage (2) of mixing.

Table 5.1 Compound formulations.

\begin{tabular}{|c|c|c|c|c|c|}
\hline Mixing & Ingredients & Z1D1 & Z1D2 & Z2D1 & Z2D2 \\
\hline $1^{\text {st }}$ stage & NR & \multicolumn{4}{|c|}{70} \\
\hline & HC LCB BR & \multicolumn{4}{|c|}{30} \\
\hline & CB & \multicolumn{4}{|c|}{35} \\
\hline & SI & \multicolumn{4}{|c|}{35} \\
\hline & TESPT & \multicolumn{4}{|c|}{3.2} \\
\hline & $\mathrm{ZnO}$ & 5 & 5 & 0 & 0 \\
\hline & Stearic acid & \multicolumn{4}{|c|}{3} \\
\hline & 6PPD & \multicolumn{4}{|c|}{2} \\
\hline & TMQ & \multicolumn{4}{|c|}{1} \\
\hline & TDAE oil & \multicolumn{4}{|c|}{7.5} \\
\hline & DPG & 0.7 & 0 & 0.7 & 0 \\
\hline $2^{\text {nd }}$ stage & Sulfur & \multicolumn{4}{|c|}{1.5} \\
\hline & CBS & \multicolumn{4}{|c|}{1.5} \\
\hline & DPG & 0 & 0.7 & 0 & 0.7 \\
\hline & $\mathrm{ZnO}$ & 0 & 0 & 5 & 5 \\
\hline
\end{tabular}

Amount of TESPT and DPG were calculated according to the following equations:

TESPT $(\mathrm{phr})=0.00053 \times \mathrm{Q} \times \mathrm{A}$ and DPG $(\mathrm{phr})=0.00012 \times \mathrm{Q} \times \mathrm{A}$

where $Q$ is the amount of silica (phr) and $A$ is the CTAB surface area of the silica $\left(171 \mathrm{~m}^{2} / \mathrm{g}\right)$

\subsubsection{COMPOUND PREPARATION}

Two-stage mixing was performed as shown in Table 5.2. NR was initially masticated to have a Mooney Viscosity (MV) close to the viscosity of BR. The masticated NR and BR were mixed for 1 minute (min). Then SI, silane, half of the Treated Distillate Aromatic Extract (TDAE) oil with or without DPG depending on the settings were added and mixed for $1 \mathrm{~min}$. After that, $\mathrm{CB}$ and other remaining ingredients with or without $\mathrm{ZnO}$ were added, and the rotor speed was adjusted in order to reach the targeted temperature for silanization within 1 min. The temperature was maintained at $150^{\circ} \mathrm{C}$ for about 7 mins to complete the silanization 
reaction. The ram was opened for about 1 min after 3 mins of silanization to release the ethanol produced during the silanization reaction. The compounds were discharged, sheeted out on a two-roll mill and kept overnight prior to incorporation of sulfur, CBS with or without ZnO and DPG in an internal mixer at a set temperature of $70^{\circ} \mathrm{C}$ and initial rotor speed of 50 revolutions per minute (rpm). After the masterbatch was mixed for $1 \mathrm{~min}$, the rotor speed was decreased to $30 \mathrm{rpm}$ before curatives were added and mixed for 2 mins.

Table 5.2 Two-step mixing procedure.

\begin{tabular}{llc}
\hline & Mixing procedure & Time (mins) \\
\hline $\begin{array}{l}\text { Stage 1: Internal } \\
\text { mixer }\end{array}$ & Mixing of masticated NR and BR & 1 \\
Initial mixer set temp. & Addition of silica, silane, 1/2 TDAE oil, & 1 \\
$100^{\circ} \mathrm{C}$ & with/without DPG & \\
Initial rotor speed 60 & Addition of CB and other remaining ingredients & 1 \\
rpm & with/without ZnO and adjustment of rotor speed & \\
& till reaching the silanization temperature of $150^{\circ} \mathrm{C}$ & \\
& - & Silanization reaction (ram sweep after 3 min \\
\hline Stage 2: Internal & silanization) & 7 \\
mixer & Masterbatch & 1 \\
Mixer set temp. $70^{\circ} \mathrm{C}$ & - & Addition of curatives (sulfur and CBS) with/without \\
Rotor speed $50 \mathrm{rpm}$ & DPG, ZnO & 2 \\
\hline
\end{tabular}

\subsubsection{TESTING OF COMPOUNDS AND VULCANIZATES}

Payne Effect (PE) and stress-strain properties of the compounds were measured according to the methods described in Chapter 3. While apparent crosslink density was measured using the method described in Chapter 4. Additionally, the following measurement methods were used:

Mooney Viscosity (MV) - The compounds were tested for their MV by using a Mooney Viscometer 2000VS (Alpha Technologies, USA) at $125^{\circ} \mathrm{C}$ with a large rotor at a shear rate of $2 \mathrm{rpm}$ for about 4 mins with $1 \mathrm{~min}$ of pre-heating. MV was measured at $125^{\circ} \mathrm{C}$ instead of $100^{\circ} \mathrm{C}$ to decrease the initial MV of compounds which cannot be measured due to the limitation of the machine. The initial MV decreases as the temperature of testing increases [18]. In terms of the final MV, the effect of temperature on the MV becomes small at higher shear rates (above $1 \mathrm{rpm}$ ) as shown in Figure 5.1. Therefore, it can be concluded that the differences in final $\mathrm{MV}$ at $100^{\circ} \mathrm{C}$ and $125^{\circ} \mathrm{C}$ at $2 \mathrm{rpm}$ of the compounds in this study will not be very large. 


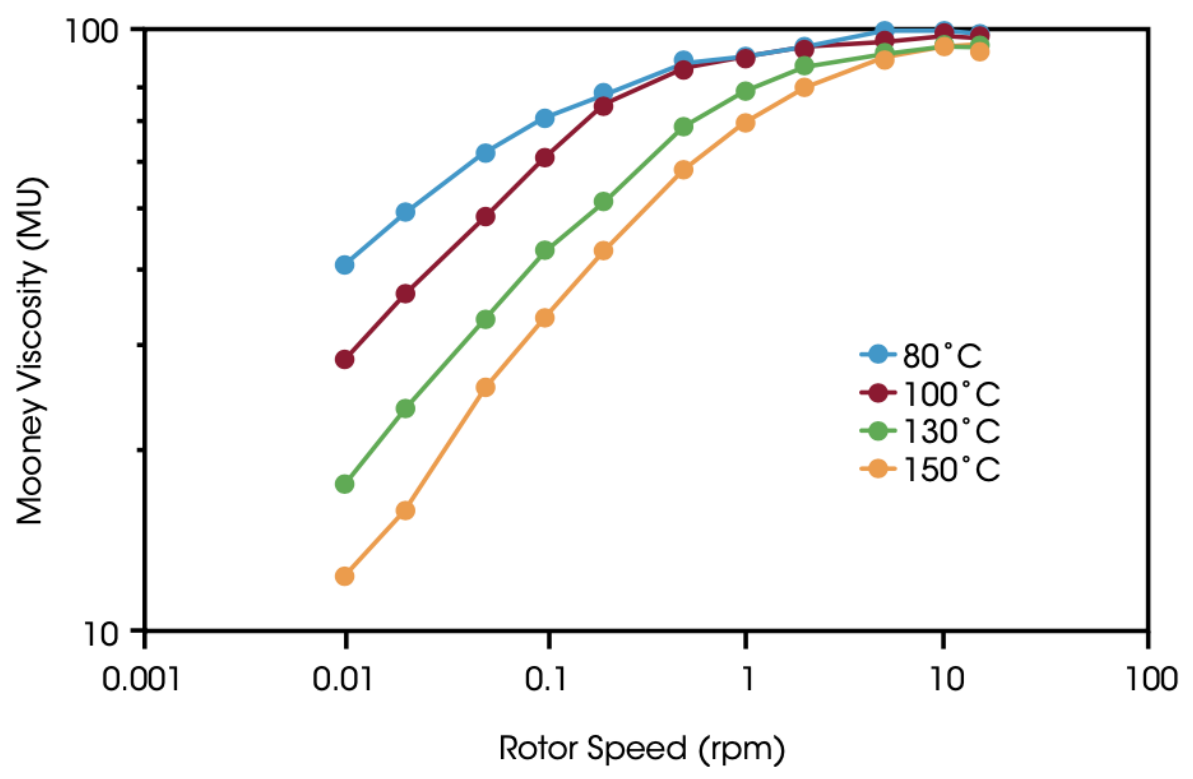

Figure 5.1 The effect of shear rate and temperature on the final MV [19].

Cure behavior - Scorch time ( $\left(\mathrm{ts}_{2}\right)$ and optimum cure time $\left(\mathrm{t}_{90}\right)$ were tested using a Rubber Process Analyzer (RPA 2000) at $150^{\circ} \mathrm{C}$, with a frequency of $1.67 \mathrm{~Hz}$ and $6.98 \%$ strain. The Cure Rate Index (CRI) was calculated according to Equation 5.1 and reversion (\%) was calculated according to Equation 5.2:

$$
\begin{gathered}
C R I=\frac{100}{t_{90}-t s_{2}} \\
\text { Reversion }(\%)=\left(\frac{S_{\text {max }}-S_{\text {final }}}{S_{\max }}\right) \times 100
\end{gathered}
$$

where $S_{\max }=$ Rheometer maximum torque;

$S_{\text {final }}=$ Rheometer cure torque at final (measurement) time.

Bound rubber content - The uncured rubber compound (without curatives), approximately 0.2 grams, was cut and put into a metal cage and immersed in toluene at room temperature. The toluene was renewed every day. After three days, the sample was removed from the toluene and dried at $100^{\circ} \mathrm{C}$ for 24 hours. The bound rubber was calculated according to Equation 5.3:

$$
\text { Bound rubber content }=\frac{m_{r}-m_{f}}{m_{p}} \times 100 \%
$$

where $m_{r}$ is the dry weight of samples after toluene treatment under normal conditions, $m_{f}$ is the weight of the filler in the sample and $m_{p}$ is the weight of the rubber in the specimen.

Hysteresis - The hysteresis was measured for both, uncured compounds and vulcanizates. The hysteresis of uncured compounds was measured at $100^{\circ} \mathrm{C}$ in a frequency sweep of $0.5-$ $33.33 \mathrm{Hertz}(\mathrm{Hz})$ and a fixed strain of $10 \%$. The hysteresis measurements for the vulcanizates were performed after curing the compounds first to their $\left(t_{90}+2\right)$ mins. at $150^{\circ} \mathrm{C}$ in the RPA. 
After curing in situ, the temperature was decreased or increased depending on the range of interest $\left(100^{\circ} \mathrm{C}\right.$ or $\left.200^{\circ} \mathrm{C}\right)$. The hysteresis was then measured using the same parameters as used for the uncured compounds.

Scanning Electron Microscopy - Energy Dispersive X-ray spectroscopy (SEM-EDX) -Vulcanized samples were extracted by acetone for 24 hours to remove non-rubber ingredients. The samples were then cut into small pieces. The cross-sectional surface was covered with a thin layer of gold to avoid electrostatic charging during the examination. SEM-EDX images were taken by a JEOL-JSM-T20. The particle size distribution of the SEM-EDX images was calculated using Image] software. The detailed procedure is explained elsewhere [20].

\subsection{RESULTS AND DISCUSSION}

Figure 5.2 shows the MV of the CB/SI-filled NR/BR compounds with different addition sequences. Compounds containing ZnO from the masterbatch stage (Z1D1 and Z1D2) show a lower MV compared to compounds with ZnO added in the last stage of mixing (Z2D1 and $\mathrm{Z2D2}$ ). Zinc stearate, which forms in a reaction of $\mathrm{ZnO}$ and stearic acid, can influence the mastication process when a high portion of NR is used. Zinc stearate can act as a peptizer, which is effective as a viscosity reducer in NR, especially when $C B$ is also present in the rubber compound [21]. The compounds are filled with CB and SI, and zinc stearate can interact with the silanol groups of the SI. This reaction competes with the function of $\mathrm{ZnO}$ as an activator for the accelerators. The mechanism here involves zinc stearate, which can react with silanol groups as shown in Figure 5.3 [22] and cover the SI surface due to its long hydrocarbon side chains, this way reducing the SI network formation and resulting in a lower viscosity. Figure 5.4 depicts the possible interaction mechanism of zinc stearate during silanization reactions [23]. 


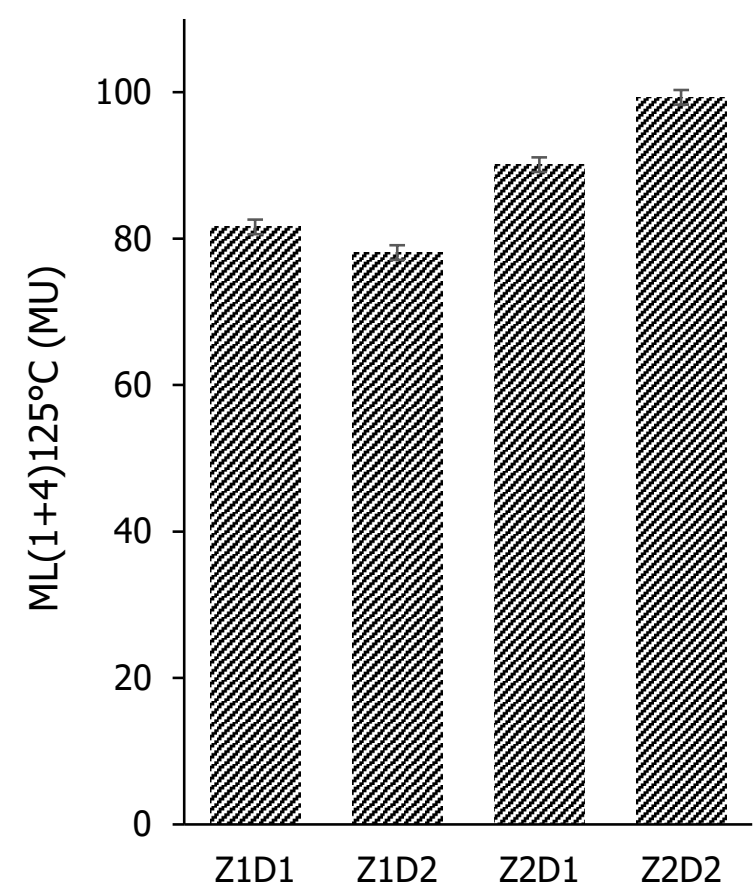

Figure 5.2 MV of rubber compounds with different addition sequences.

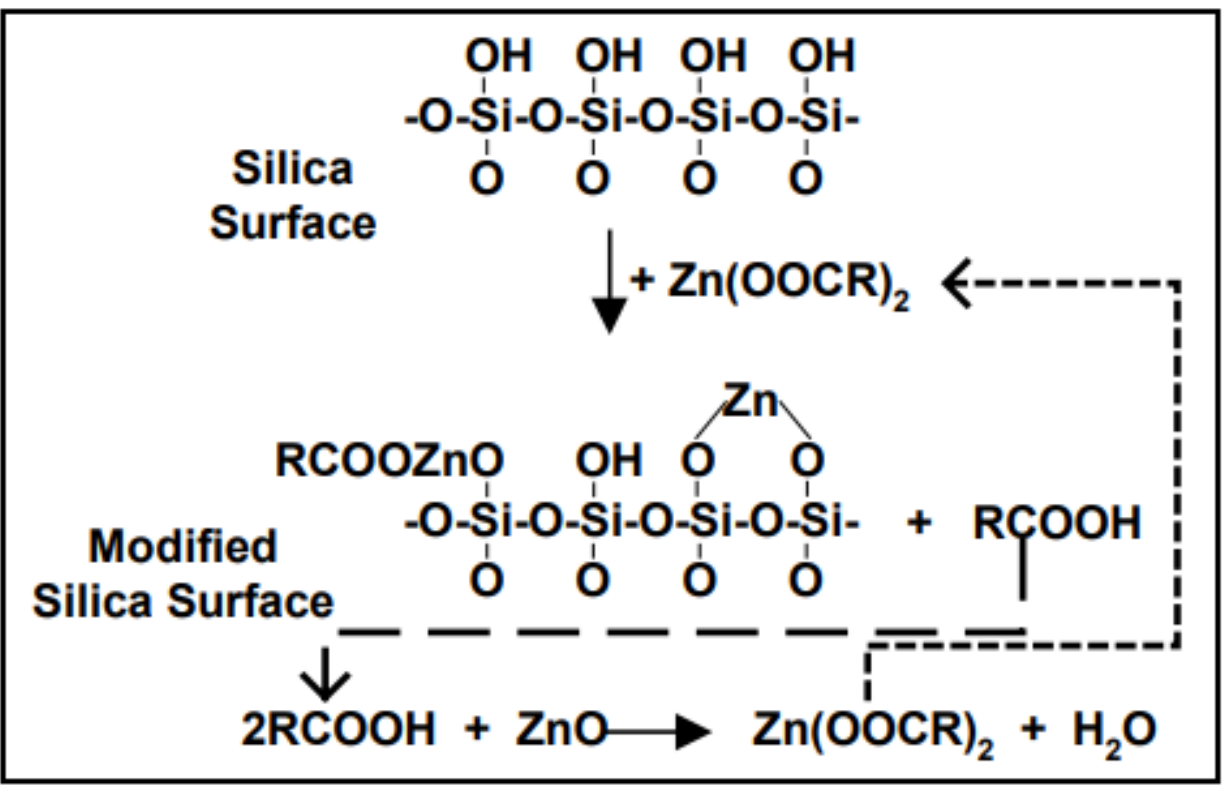

Figure 5.3 Reaction of zinc stearate with SI [22]. 


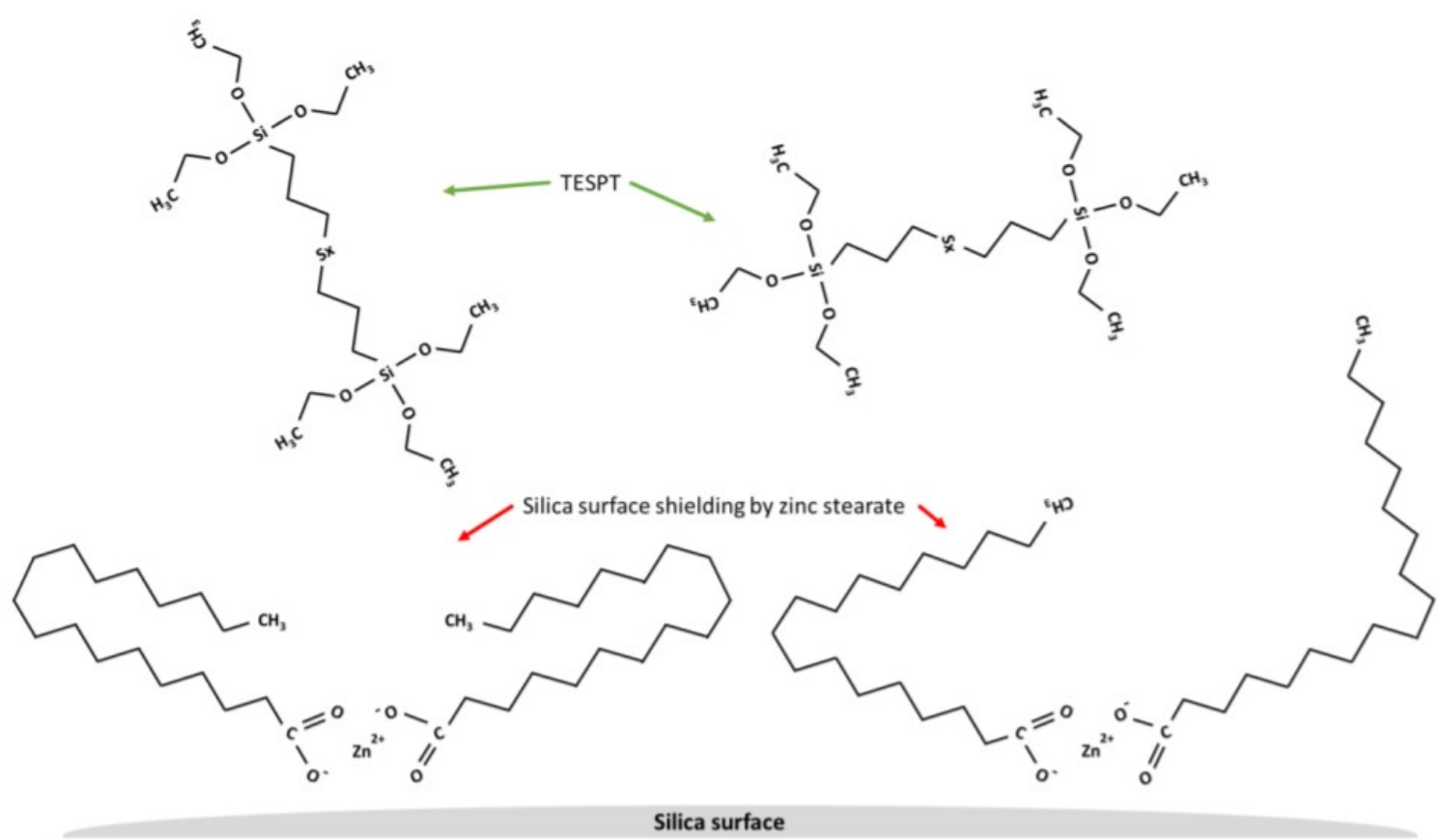

Figure 5.4 Possible mechanism of shielding the SI surface by zinc stearate and blocking it for silane [23].

Table 5.3 shows the curing characteristics of the various compounds with different $\mathrm{ZnO}$ and DPG addition sequences. $\mathrm{ZnO}$ is an inorganic compound which functions as an activator to speed up the vulcanization process. However, $\mathrm{ZnO}$ is difficult to disperse in the rubber matrix, therefore stearic acid is added to solubilize the zinc and set zinc ions free to form complexes with accelerators [24]. Addition of $\mathrm{ZnO}$ in the first stage of mixing (Z1D1 and Z1D2) allows better solubilization of the oxide by stearic acid to form zinc stearate. Zinc stearate provides accelerator activation through the formation of zinc-accelerator complexes. As explained earlier, zinc stearate also interacts with SI silanols, and this reaction competes with the role of zinc stearate as activator and leads to a reduction of the cure rate [25].

Table 5.3 Curing characteristics of compounds.

\begin{tabular}{|l|r|r|r|r|}
\hline \multicolumn{1}{|c|}{ Characteristics } & \multicolumn{1}{c|}{ Z1D1 } & \multicolumn{1}{c|}{ Z1D2 } & \multicolumn{1}{c|}{ Z2D1 } & \multicolumn{1}{c|}{ Z2D2 } \\
\hline Scorch time, ts2 $(\mathrm{min})$ & 5.5 & 4.3 & 3.2 & 2.6 \\
\hline Cure time, $\mathrm{t}_{90}(\mathrm{~min})$ & 14.0 & 11.4 & 8.6 & 7.7 \\
\hline Cure rate index, CRI $\left(\mathrm{min}^{-1}\right)$ & 12.2 & 14.1 & 18.5 & 19.6 \\
\hline $\mathrm{S}_{\min }$ (dN.m) & 3.2 & 3.3 & 3.6 & 3.8 \\
\hline $\mathrm{S}_{\max }(\mathrm{dN} . \mathrm{m})$ & 16.9 & 17.5 & 17.9 & 18.6 \\
\hline Cure torque difference, $\mathrm{S}_{\max }-\mathrm{S}_{\min }(\mathrm{dN} . \mathrm{m})$ & 13.7 & 14.2 & 14.3 & 14.6 \\
\hline Reversion $(\%)$ & 4.4 & 4.6 & 12.1 & 12.5 \\
\hline
\end{tabular}

The DPG addition sequence slightly influences the curing characteristics, in which addition of DPG in the first stage of mixing (Z1D1 and Z2D1) decreases the cure rate. Many studies revealed that besides DPG acting as a secondary accelerator of the vulcanization reaction $[12,26]$, it can reduce the polarity of SI by being adsorbed onto the SI surface [27]. 
DPG is also capable of accelerating the silanization reaction [26]. A slower cure rate was observed when DPG was added in an early mixing stage of a SI-filled compound. Lim et al. [28] reported that the slower vulcanization rate is induced by the adsorption of DPG onto the SI surface.

Figure 5.5 shows that less reversion is occurring when $\mathrm{ZnO}$ is added in the first stage of mixing (Z1D1 and Z1D2). The presence of $\mathrm{ZnO}$ in the first mixing stage leads to a considerable decrease of the cure rate, which relates to the formation of a zinc-acceleratorsulfur coordination complex, resulting in scorch time ( $\left.\mathrm{ts}_{2}\right)$ delay and formation of a more stable crosslink structure. The complex may also have a thermo-stabilizing effect that can prevent the destruction processes in the elastomer main chain or the crosslinked network already occurring at the cure temperature [29].

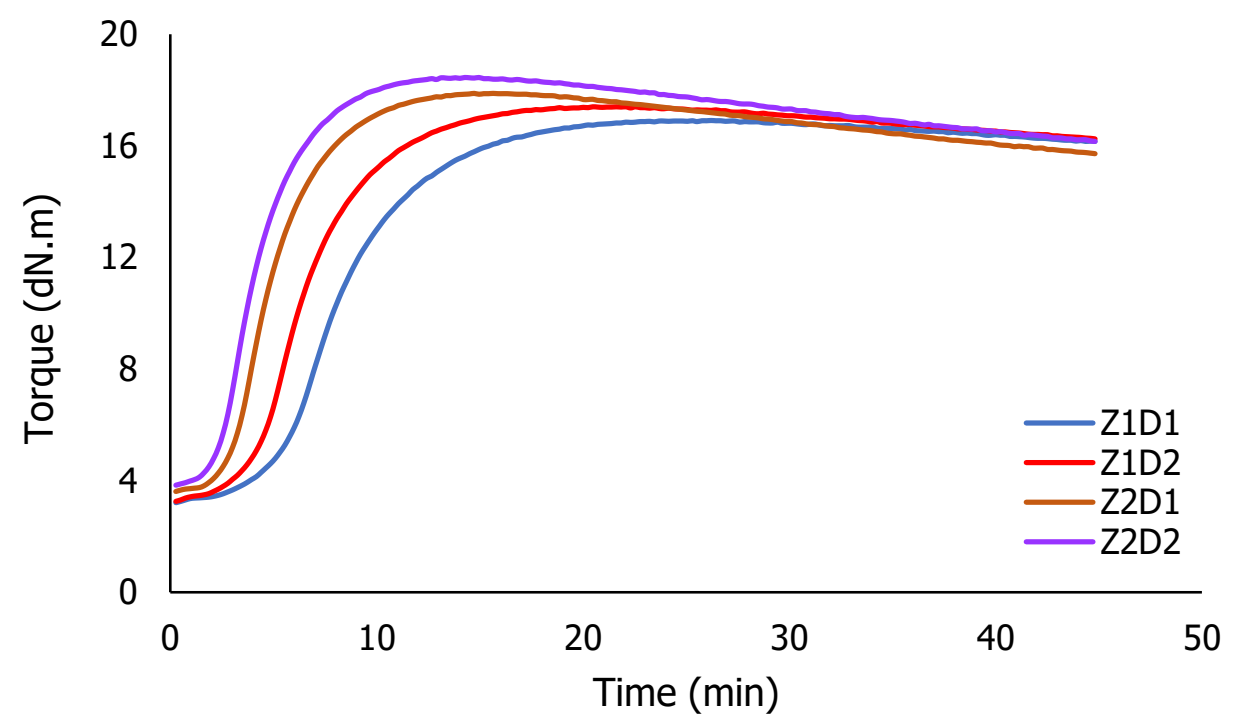

Figure 5.5 Curing curves of rubber compounds with different addition sequences.

Figure 5.6 shows the PE with different $\mathrm{ZnO}$ and DPG addition sequences for the yet unvulcanized compounds. The storage modulus $\mathrm{G}^{\prime}$ depends on the addition sequence of $\mathrm{ZnO}$ in these hybrid CB/SI-filled rubber compounds. The $\mathrm{G}^{\prime}$ of compounds, in which $\mathrm{ZnO}$ is added at the earlier stage of mixing (Z1D1 and Z1D2), is much lower in comparison to compounds with $\mathrm{ZnO}$ added in the final stage of mixing (Z2D1 and Z2D2) for the same reason as described above: $\mathrm{ZnO}$ can react with stearic acid to produce soluble zinc stearate, which interacts with SI silanol moieties. Zinc stearate can have a positive effect on lowering the filler-filler interaction due to its long aliphatic chains (17 $\mathrm{CH}_{2}$ - groups), thus improving SI dispersion and resulting in lower viscosity [25]. 

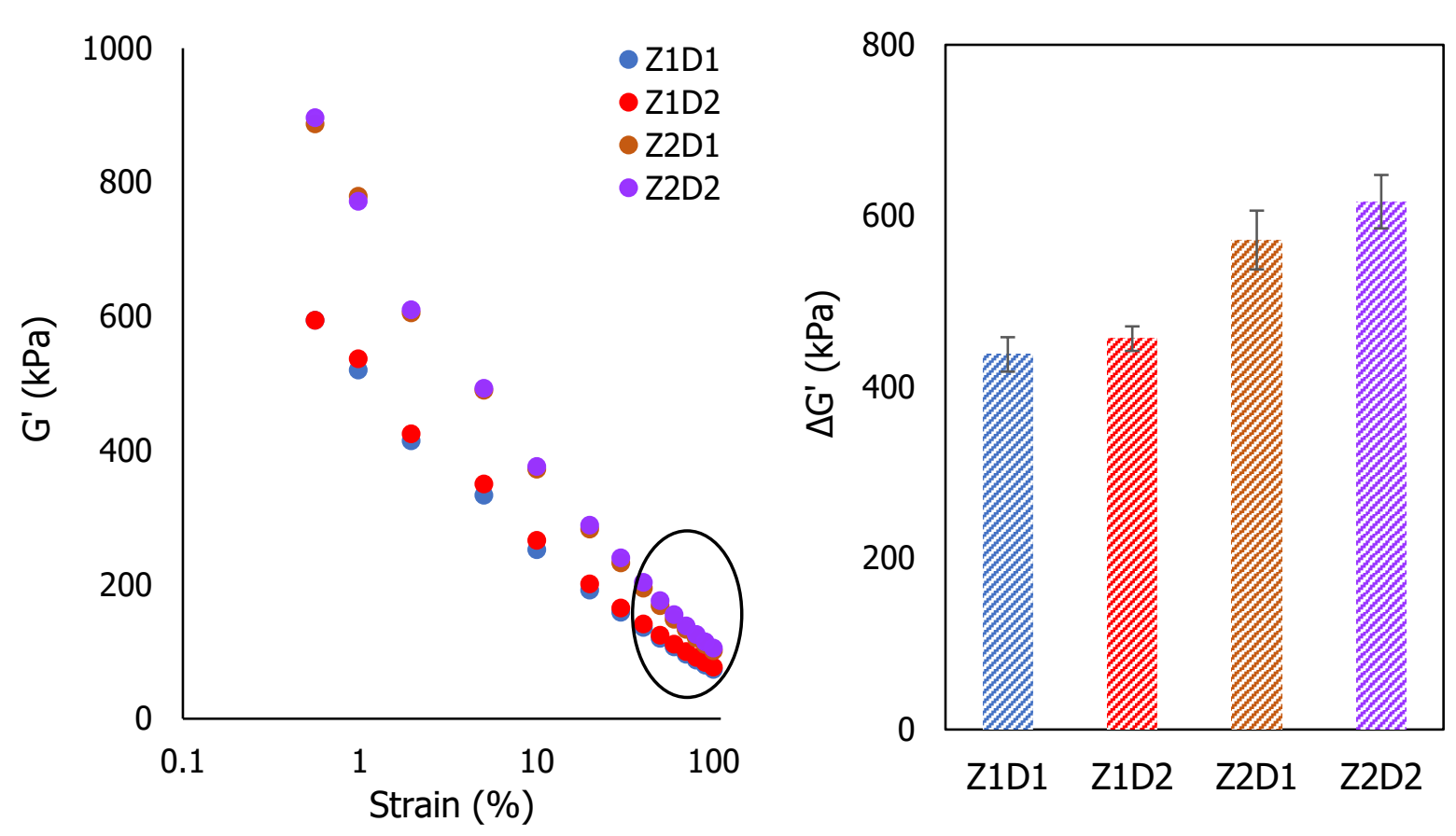

Figure 5.6 Storage modulus versus strain (left) and PE (right) of rubber compounds.

The $P E$, the difference of $G^{\prime}$ at low and at high strain $\left(\Delta G^{\prime}\right)$, indicates how well the filler disperses in the rubber matrix on microscale. A high PE indicates strong filler-filler interaction, and consequently a low degree of dispersion. Compounds with $\mathrm{ZnO}$ added in the last stage of mixing (Z2D1 and Z2D2) show high $\mathrm{G}^{\prime}$ values at low strain, which indicates high filler-filler interaction, and also slightly higher $\mathrm{G}^{\prime}$ at high strain. $\mathrm{G}^{\prime}$ at high strain can be correlated with filler-polymer interaction. Figure 5.7 shows a typical example of the complex shear modulus of filled rubber versus dynamic shear deformation. There are four contribution parameters to the complex shear modulus: the hydrodynamic effect (filler type and loading), the polymer network (rubber type, vulcanization system), the polymer-filler interaction (filler and rubber type) and the filler-filler interaction. Only the filler-filler interaction is strain dependent. However, the trend of the PE in this study is different from results found by other researchers. Reuvekamp et al. [11] found that the presence of $\mathrm{ZnO}$ increases the risk of pre-scorch in silica-filled SSBR/BR compounds due to its catalytic effect on sulfur release from the coupling agent bis-(TriEthoxySilylPropyl)Tetrasulfide (TESPT). An increase of $\mathrm{G}^{\prime}(100 \%)$ for the compound with $\mathrm{ZnO}$ added in an early mixing stage was observed, when the dump temperature exceeded $150^{\circ} \mathrm{C}$. Jin [23] also reported the negative effect of ZnO in SI-filled SSBR/BR compounds, in which an increment of the PE value was observed with increasing $\mathrm{ZnO}$ concentration in the masterbatch (MB) stage until the $\mathrm{ZnO}$ concentration reached 1.5 phr. 


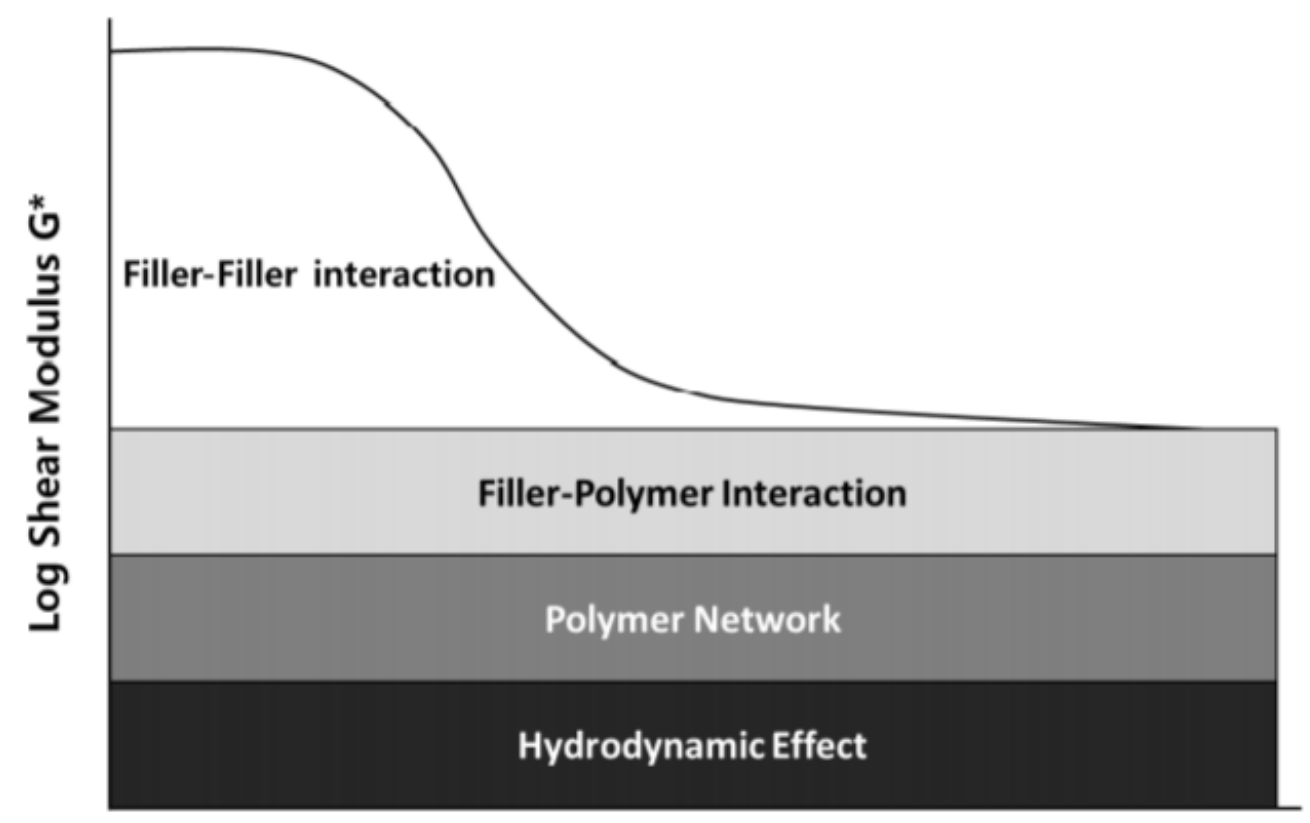

\section{Log Shear Deformation}

Figure 5.7 Contributions to the shear modulus for a typical rubber compound [3].

The effect of DPG addition sequence on the PE is small in the CB/SI-filled compounds. This might be caused by a sufficient silanization time of 7 mins, during which a complete silanization reaction has been reached. Therefore, the effect of DPG as silanization booster cannot be seen anymore.

Next to the DPG addition sequence, silanization was performed for 3 resp. 7 mins to prove that DPG is acting as a silanization booster. Figure 5.8(a) shows that at short silanization times, thus when the silanization reaction is not complete, the addition of DPG together with SI in the first stage of mixing (Z1D1) can indeed promote the silanization reaction resulting in lower filler-filler interaction compared to the addition of DPG in the final step (Z1D2). However, when the silanization was complete, both compounds show the same PE regardless of the DPG addition, as shown in Figure 5.8(b). 
(a)

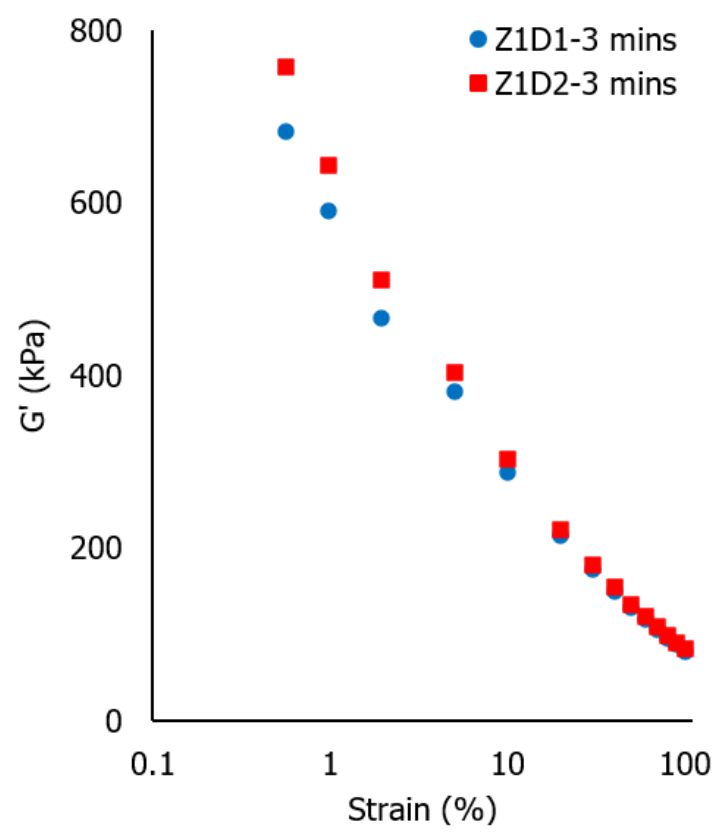

(b)

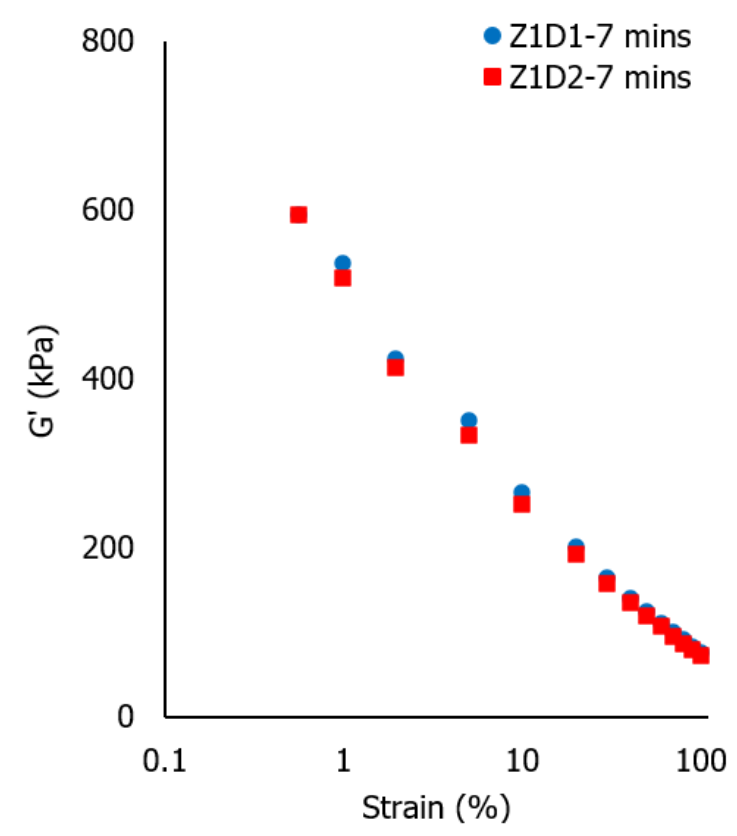

Figure 5.8 Payne effect of compounds with different silanization times: 3 mins (a); 7 mins (b).

Bound rubber measurements were performed as further indication of polymer-filler interaction next to $\mathrm{G}^{\prime}$ at high strain. The addition of $\mathrm{ZnO}$ in the final stage of mixing increases filler-polymer interaction, as depicted in Figure 5.9(a). On the one hand, when $\mathrm{ZnO}$ is added to the masterbatch, zinc stearate can lower the filler-filler interaction due to its long hydrocarbon chains. On the other hand, zinc stearate can block the access of silane molecules, thus interfering with the silane bonding to the silica surface during silanization and thus cause a lower amount of bound rubber. By adding $\mathrm{ZnO}$ in the final stage, the silanization efficiency increases. The interaction between alkoxy groups of TESPT and silanol groups on the silica surface during the mixing process reduces hydrophilicity of the silica surface and thus improves rubber-filler interaction [30]. Besides, the addition of DPG in the first mixing stage decreases bound rubber: the reaction sites on the SI surface are shielded by DPG, and in this way DPG blocks the access for the silane, the same as in the case of zinc stearate. This finding is contrary to the outcome of several other studies that amines, including DPG, are believed to promote the silanization when added in the masterbatch resulting in a decrease in fillerfiller interaction and an increase in bound rubber content $[15,31]$. The effect of DPG as a silanization booster might not apply to the full for all rubber formulations and mixing conditions. We proof in the present study that adding DPG in the first stage of mixing of a $\mathrm{NR} / \mathrm{BR}$ blend at sufficient silanization time results in lower filler-rubber interaction than adding DPG in the last stage of mixing.

To show the contrast between the unvulcanized and the vulcanized states of the various compounds, Figure 5.9 compares the bound rubber before vulcanization and the apparent crosslink density after. Figure 5.9(b) shows the apparent crosslink density of the vulcanizates cured at $150^{\circ} \mathrm{C}$ and subsequently aged at $100^{\circ} \mathrm{C}$ for $10 \mathrm{mins}$, and the same 
vulcanizates aged at $200^{\circ} \mathrm{C}$ for 10 mins in order to mimic the surface temperature variation of AC tire treads during service. There is a tentative relation between the apparent crosslink density after vulcanization and the bound rubber before in Figure 5.9(a), though the effect is much larger in the unvulcanized state. For the first condition, the vulcanizates show only a minimal increase in apparent crosslink densities. The 10 mins. aging at $100^{\circ} \mathrm{C}$ will not expected to cause a noticeable change in apparent crosslink density, as the compounds were vulcanized at $150^{\circ} \mathrm{C}$. However, for the second condition: aging for 10 mins. at $200^{\circ} \mathrm{C}$, the Z1D1 and Z1D2 rubbers show a higher apparent crosslink density compared to the Z2D1 and Z2D2 ones. The addition of $\mathrm{ZnO}$ in the first stage of mixing therefore improves the thermal stability of the network [29] as explained in the vulcanization part.

(a)

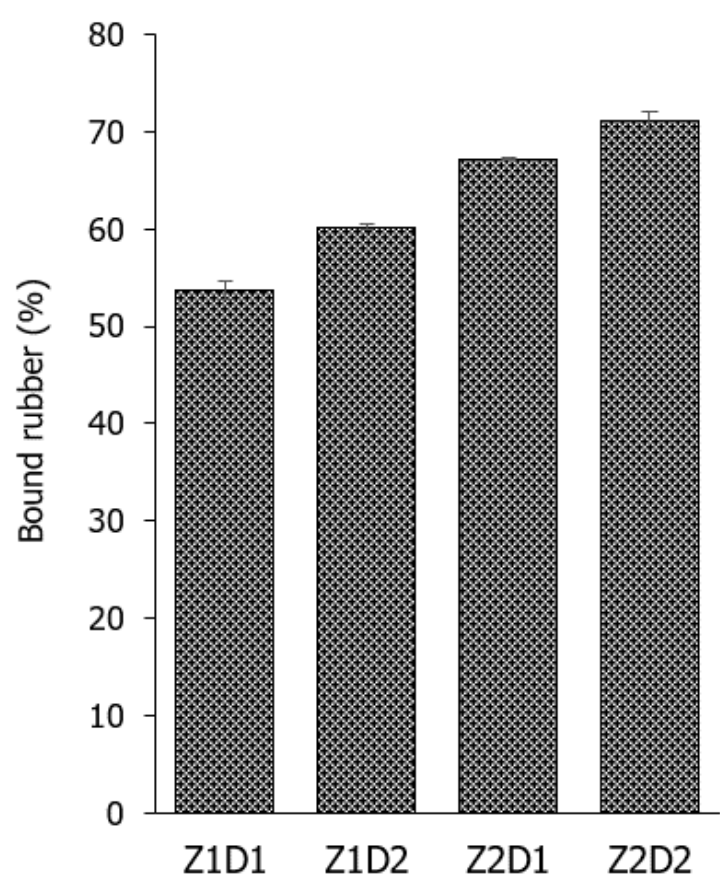

(b)
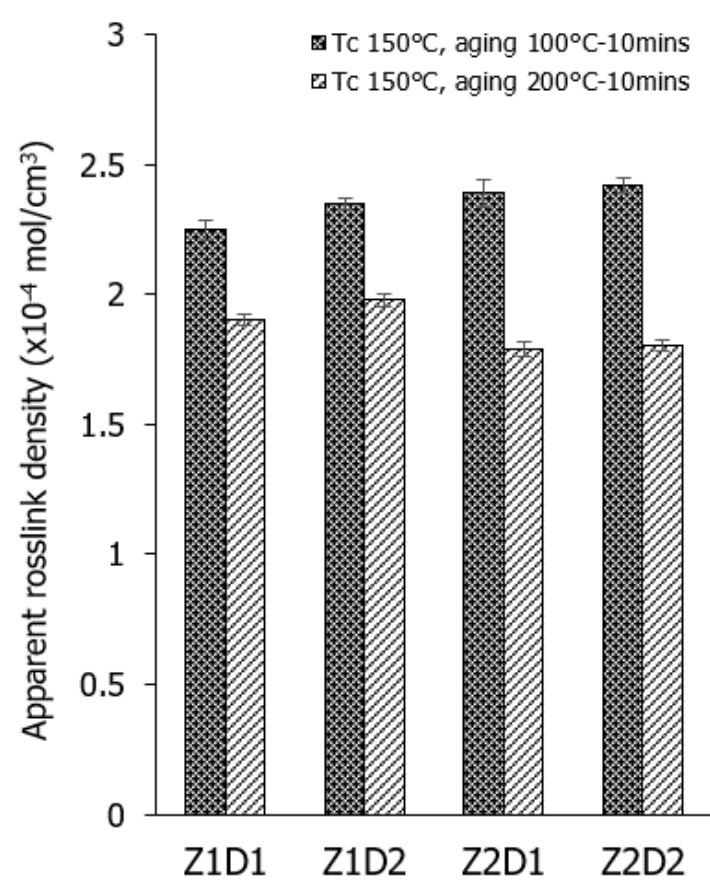

Figure 5.9 Bound rubber content of compounds (a); apparent crosslink density of vulcanizates (b) with different addition sequences (Tc: curing temperature).

Figure 5.10 shows the tensile strength and $\mathrm{M} 300 \%$ of the vulcanizates investigated. The ZnO and DPG addition sequence has almost no effect on tensile strength. However, the $\mathrm{ZnO}$ and DPG addition sequence does affect M300\%: Compounds containing a high bound rubber content before vulcanization show slightly higher M300\% values compared to compounds with lower contents. Bound rubber is an immobilized polymer layer derived from the polymer chains adsorbed onto the filler surface, which cannot be removed easily. Other contributions of the polymer to reinforcement are entanglements and sulfur crosslinks formed during vulcanization. The addition of ZnO and DPG in the last stage of mixing (Z2D2) results in the highest $\mathrm{M} 300 \%$ compared to the other addition sequences, in accordance also with the slight increase in apparent crosslink density for $100^{\circ} \mathrm{C}$ aging as seen in Figure $5.9(\mathrm{~b})$. 


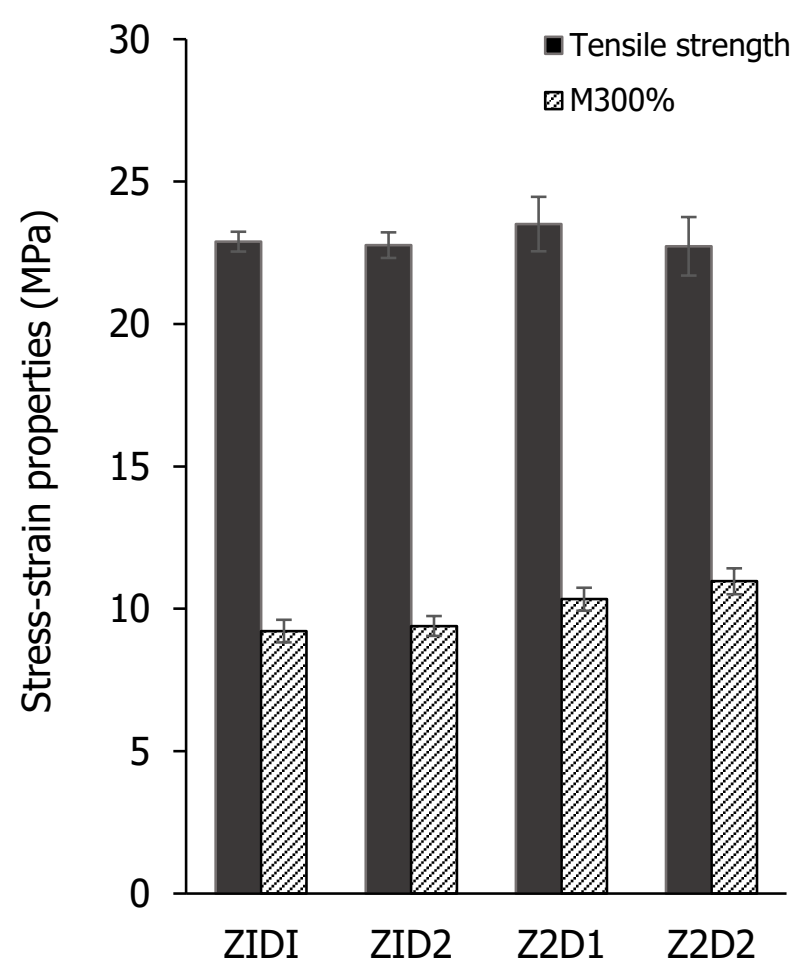

Figure 5.10 Stress-strain properties of vulcanizates with different addition sequences.

Figure 5.11 shows the storage $\mathrm{G}^{\prime}$ and loss moduli $\mathrm{G}^{\prime \prime}$ as well as the phase angle $\tan \delta$ of the still unvulcanized rubber compounds in a frequency sweep from 0.1 till $33.33 \mathrm{~Hz}$ and at $10 \%$ fixed strain. As frequency increases, $G^{\prime}$ and $G^{\prime \prime}$ of the compounds increase. This increase in moduli with frequency is the common behavior, where the materials move away from the rubber plateau into the transition region towards the glassy state. Addition of ZnO and DPG in the last stage of mixing (Z2D2) results in considerably higher $\mathrm{G}^{\prime}$ values compared to other addition sequences due to higher filler-filler interactions: Figure 5.6, and filler-rubber interactions: Figure 5.9(a). In the uncured rubbers, crosslink density is not a factor yet. As $\tan \delta$, taken as an indication for hysteresis, is the ratio of $G^{\prime \prime}$ to $G^{\prime}$, the final value depends on both moduli. Low frequencies allow sufficient time for molecular segmental rearrangements of the polymers, while at high frequencies only a short period for the rubber molecules to rearrange is available. High filler-rubber interaction decreases the mobility of the chains. The Z2D1 and Z2D2 compounds contain a high bound rubber content, reducing the chain mobility and thus molecular friction, leading to less hysteresis and subsequent heat generation. Compounds with less bound rubber (Z1D1 and Z1D2) show a steeper increase in tan $\delta$ towards low frequencies than high bound rubber compounds (Z2D1 and Z2D2), which in the ultimate case of all rubber immobilized would have resulted in a horizontal curve. 

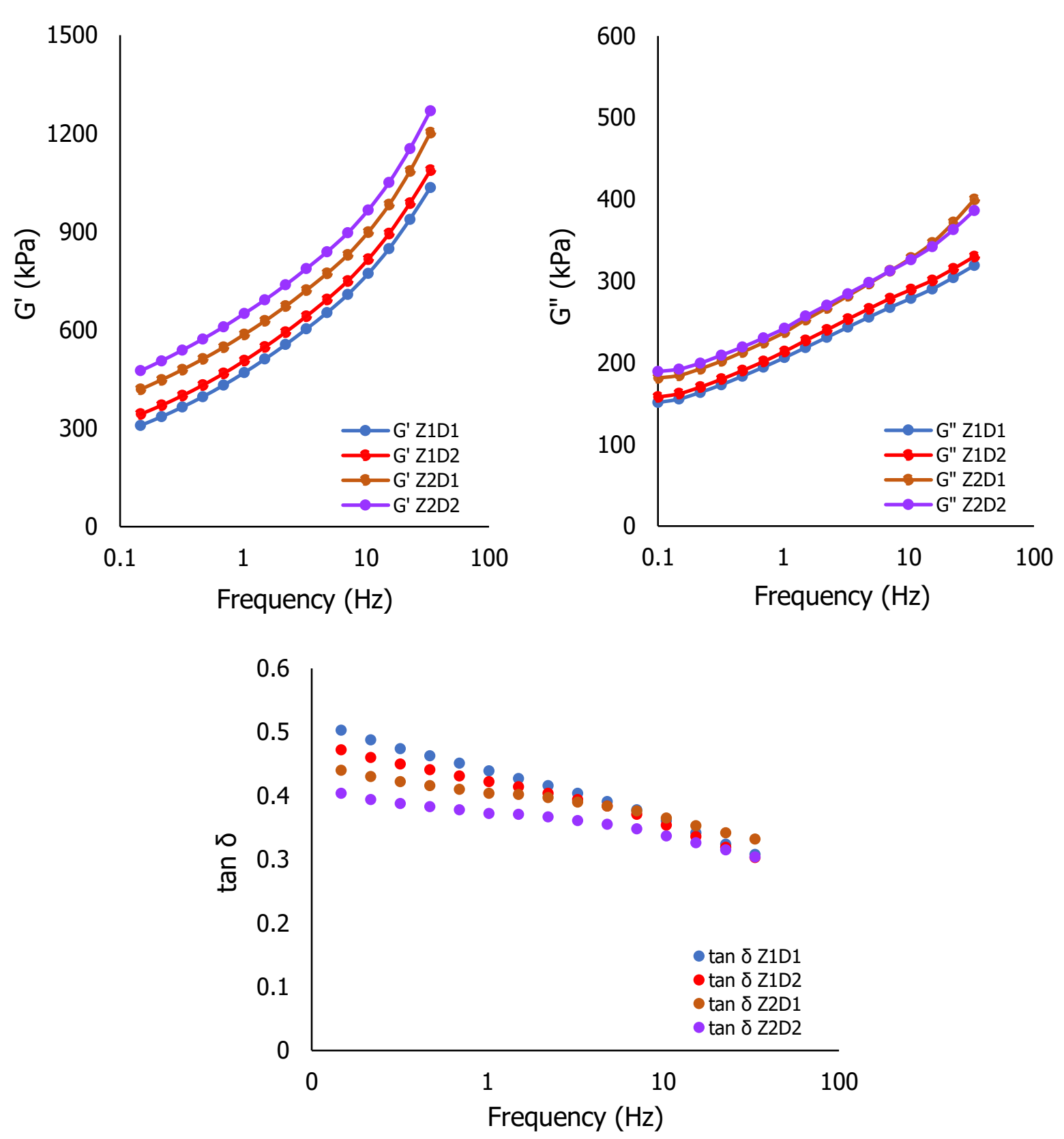

Figure 5.11 G', G" and tan $\delta$ in a frequency sweep at $10 \%$ fixed strain for the uncured rubbers measured at $100^{\circ} \mathrm{C}$.

Figure 5.12 shows the viscoelastic $\left(G^{\prime}, G^{\prime \prime}, \tan \delta\right)$ properties for the vulcanizates cured at $150^{\circ} \mathrm{C}$ and measured at $100^{\circ} \mathrm{C}$ (left) and $200^{\circ} \mathrm{C}$ (right). (Note: This is different from the 10 mins. aging at $100^{\circ} \mathrm{C}$ and $200^{\circ} \mathrm{C}$ employed for the crosslink density measurements). The curvature of the tan $\delta$ curves is opposite of what was seen in the previous Figure 5.11, because now the crosslink density plays the major role with an effect of the filler-filler interaction left as well, but the polymer-filler interaction merged into the crosslink network. Z2D2 shows a slightly higher $\tan \delta$ compared to the other addition sequences. This is due to the fact that Z2D2 shows the highest crosslink density: Figure 5.9(b), and also high filler-filler interaction: Figure 5.6. The other addition sequences show similar tan $\delta$ values at $100^{\circ} \mathrm{C}$ due to balanced high crosslink density: Figure 5.9(b) and low filler-filler interaction: Figure 5.6. When the 
hysteresis is measured at $200^{\circ} \mathrm{C}$, which implicitly corresponds to a little after-cure, the tan $\delta$ of Z1D2 improves more than for the other addition sequences. Similarly, Z1D2 showed the highest crosslink density when cured at $150^{\circ} \mathrm{C}$ and aged at $200^{\circ} \mathrm{C}$ : Figure 5.9 (b). A high crosslink density decreases the dangling chain ends and entrapped entanglements. The presence of three-dimensional networks prevents the chains from slippage. These combinations result in the lowest tan $\delta / \mathrm{HBU}$ of $\mathrm{Z1D} 2$ at $200^{\circ} \mathrm{C}$. Derived from these observations, Table 5.4 shows the various contributions of the different addition sequences on the various factors influencing tan $\delta$.
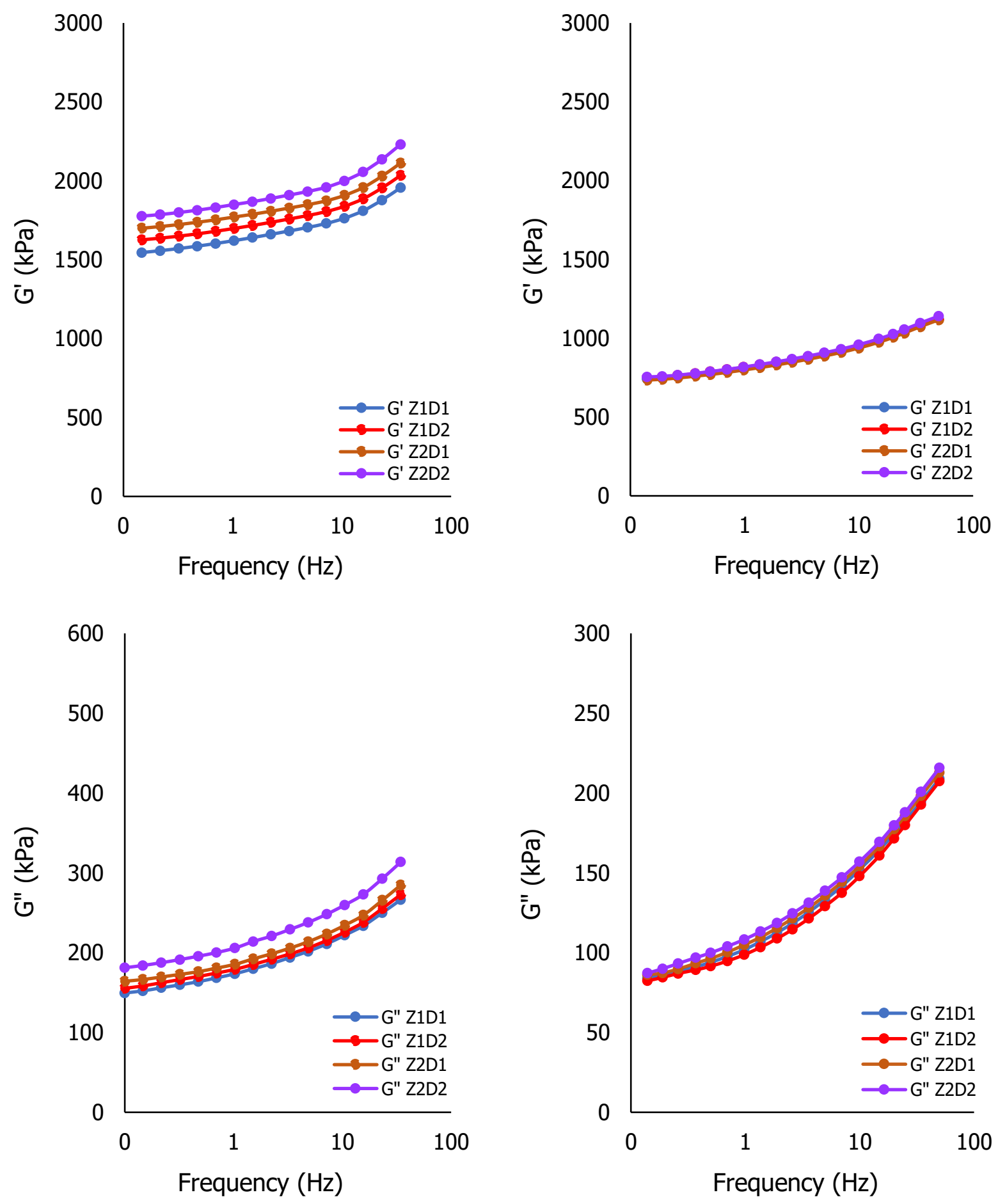

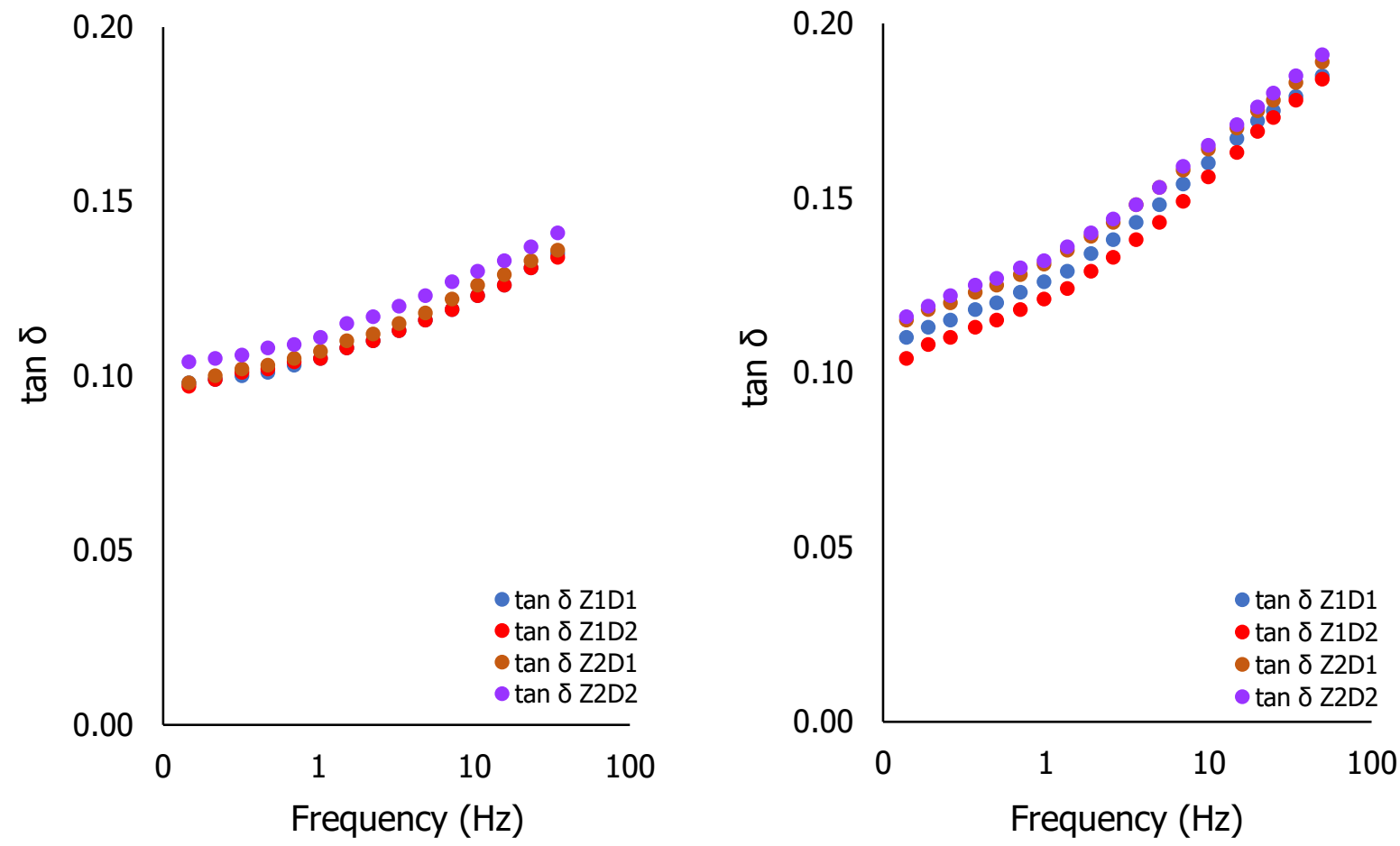

Figure 5.12 Viscoelastic properties for vulcanizates cured at $150^{\circ} \mathrm{C}$ and hysteresis measured at $100^{\circ} \mathrm{C}$ (left) and at $200^{\circ} \mathrm{C}$ (right).

Table 5.4 Summary of the network contributions influencing tan $\delta$.

\begin{tabular}{|l|c|c|c|c|}
\hline \multicolumn{1}{|c|}{$\begin{array}{c}\text { Network } \\
\text { contributions }\end{array}$} & Z1D1 & Z1D2 & Z2D1 & Z2D2 \\
\hline Filler-filler interaction (PE) & ++++ & +++ & ++ & + \\
\hline $\begin{array}{l}\text { Filler-polymer interaction } \\
\text { (Bound rubber) }\end{array}$ & + & ++ & +++ & ++++ \\
\hline $\begin{array}{l}\text { Apparent crosslink density } \\
\text { @150C (filler-polymer and } \\
\text { polymer-polymer) }\end{array}$ & +++ & +++ & ++++ & ++++ \\
\hline $\begin{array}{l}\text { Apparent crosslink density } \\
\text { @200ㄷ (filler-polymer and } \\
\text { polymer-polymer) }\end{array}$ & +++ & ++++ & ++ & ++ \\
\hline
\end{tabular}

\section{Note:}

Ranking according to the four compounding sequences

++++ best, + worst 
SEM-EDX pictures of SI in the polymer matrices are shown in Figure 5.13, representing the dispersion on macroscale. In this picture, SI clusters are clearly smaller in compounds to which ZnO is added in the first stage of mixing (Z1D1 and Z1D2) compared to the size of SI clusters in compounds when $\mathrm{ZnO}$ is added in the last stage of mixing (Z2D1 and Z2D2). Almost $50 \%$ of the SI clusters are below $2 \mu \mathrm{m}$ in Z1D1 and Z1D2. The SI cluster sizes of Z2D1 and Z2D2 are more heterogenous than those of Z1D1 and Z1D2, with only $30 \%$ of them below 2 $\mu \mathrm{m}$ : Figure 5.14.

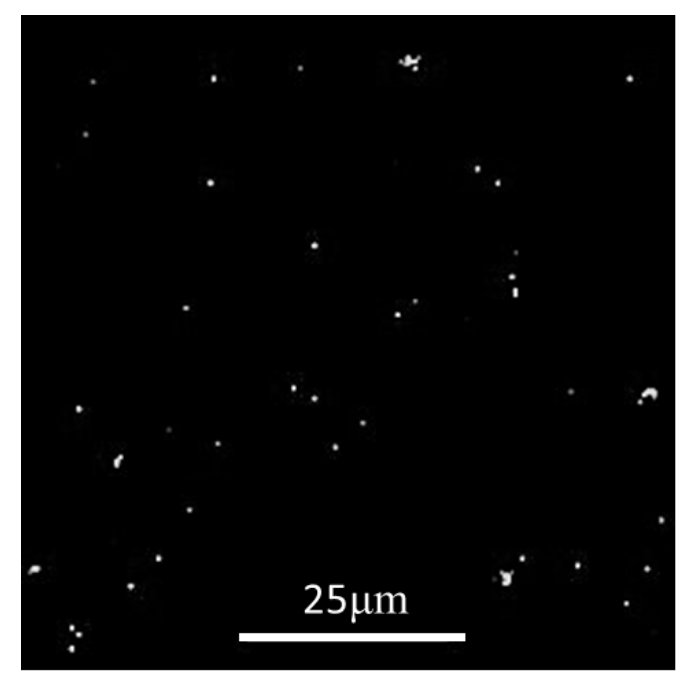

Z1D1

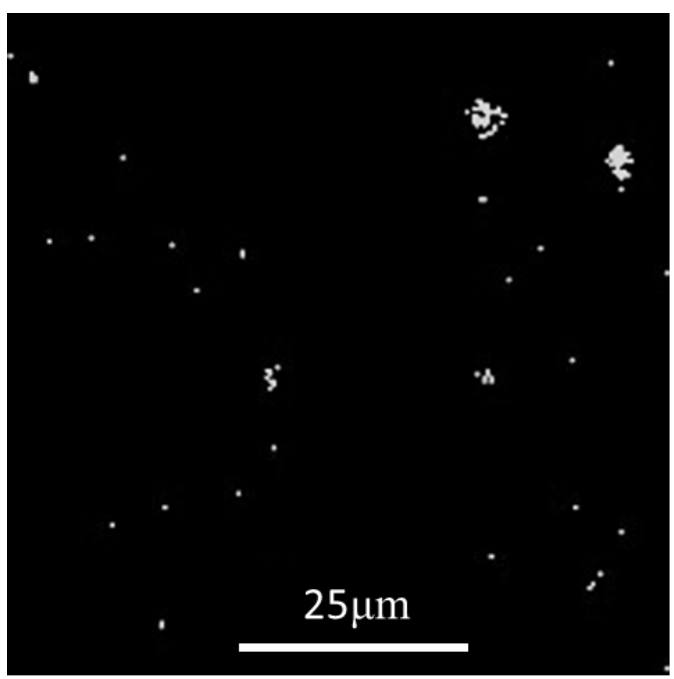

Z2D1

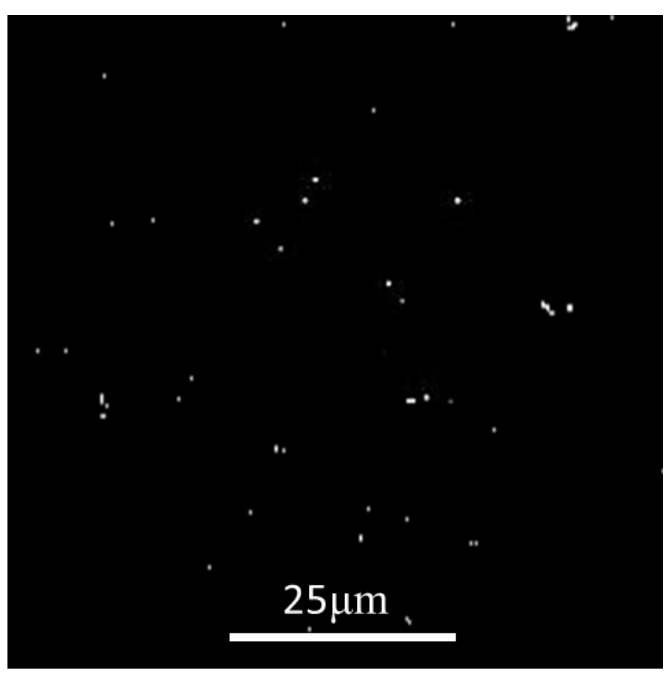

Z1D2

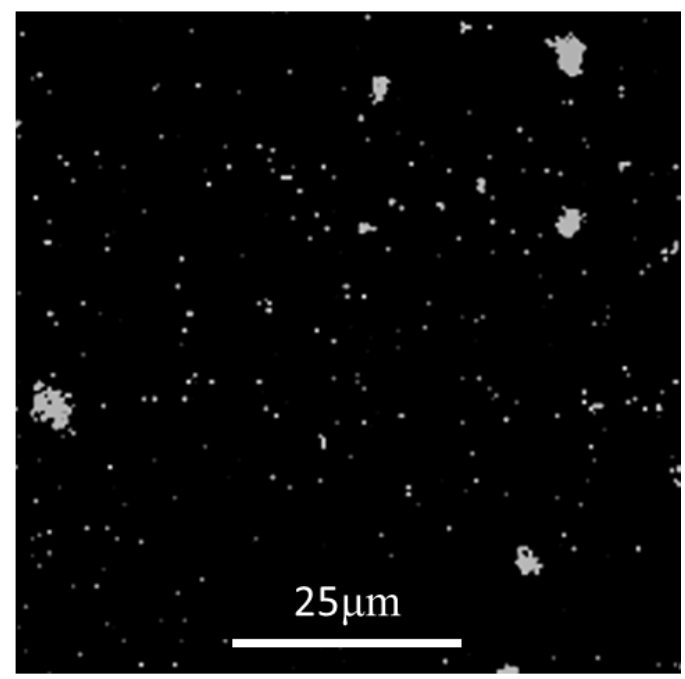

Z2D2

Figure 5.13 SEM-EDX images for SI clusters in the polymer matrix. 

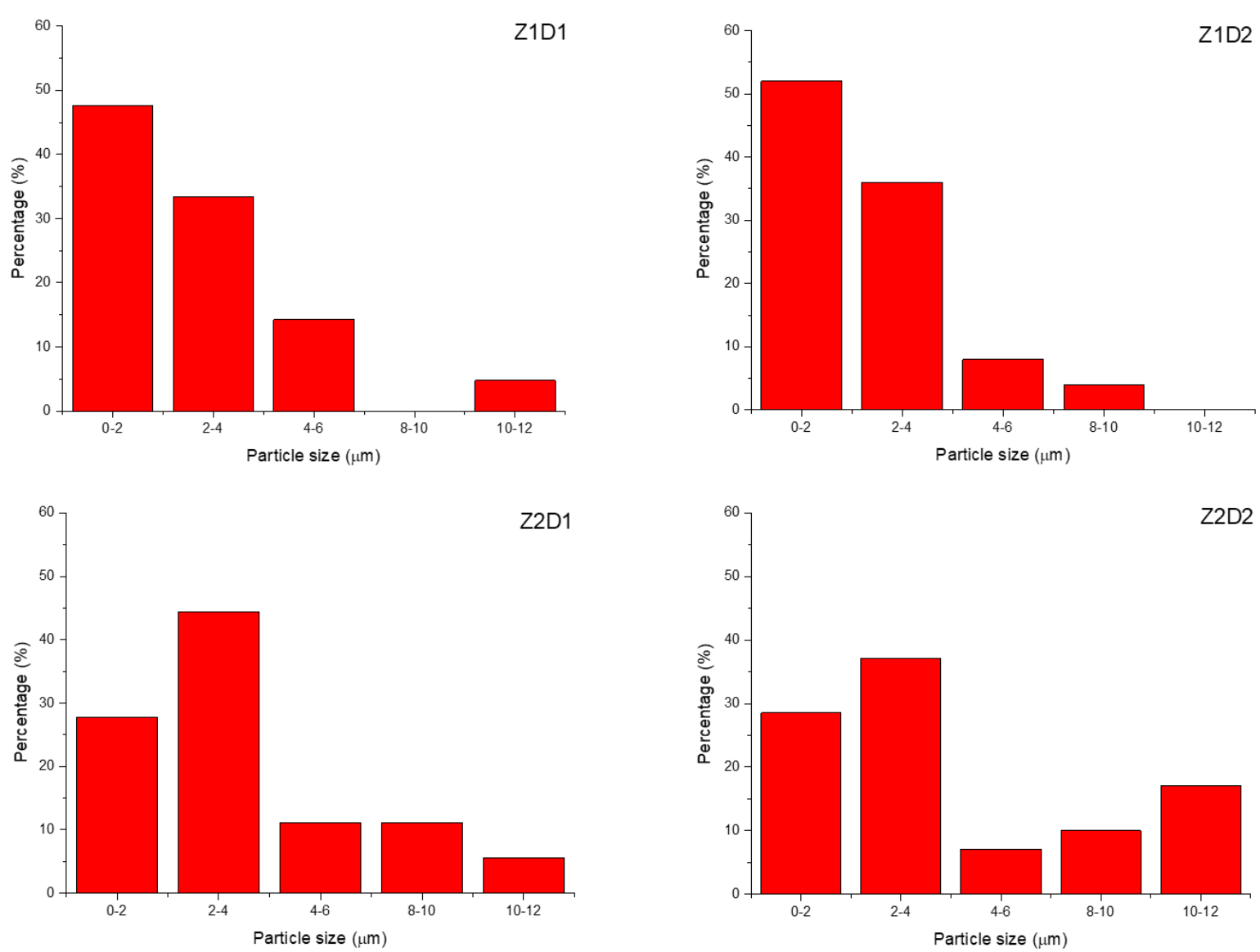

Figure 5.14 Size distribution of SI clusters in the polymer matrix. 
Figure 5.15 shows the zinc dispersion in the polymer matrix from the SEM-EDX analysis. It is expected that zinc reacts with stearic acid to form zinc stearate when added in the first stage of mixing, resulting in better solubility of zinc and thus better dispersion in the polymer matrix. However, from Figure 5.15 and later confirmed by the size distribution in Figure 5.16 it is clear that different addition sequences of ZnO and DPG do not influence the dispersion of zinc compounds in the polymer matrix. Approximately $90 \%$ of the zinc clusters are smaller than or equal to $4 \mu \mathrm{m}$, which corresponds to the typical average particle size of Red-Seal ZnO.

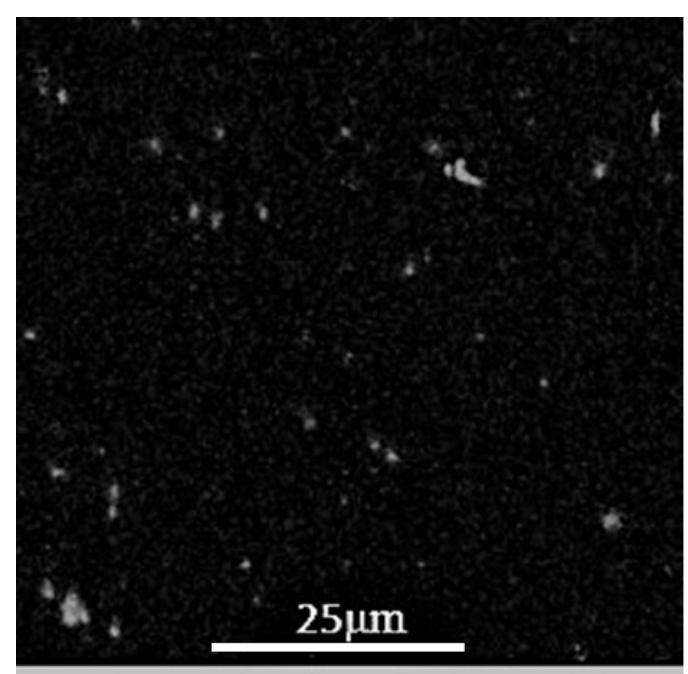

Z1D1

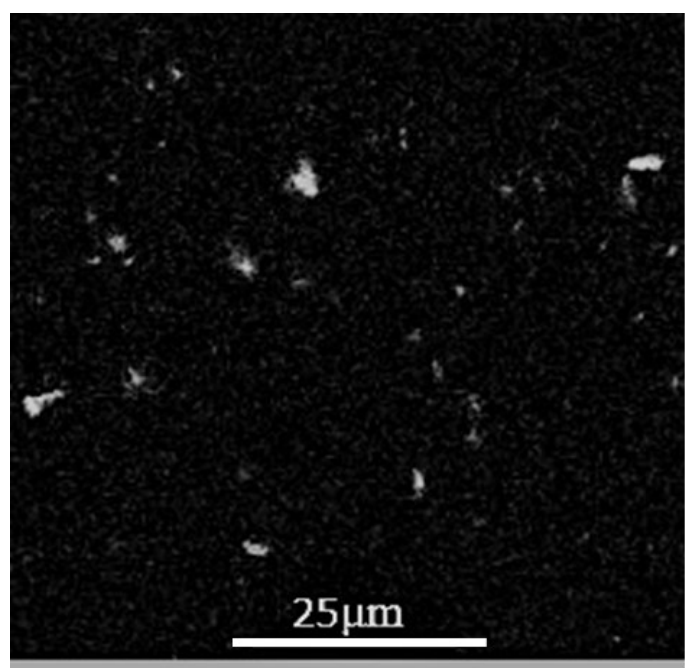

Z2D1

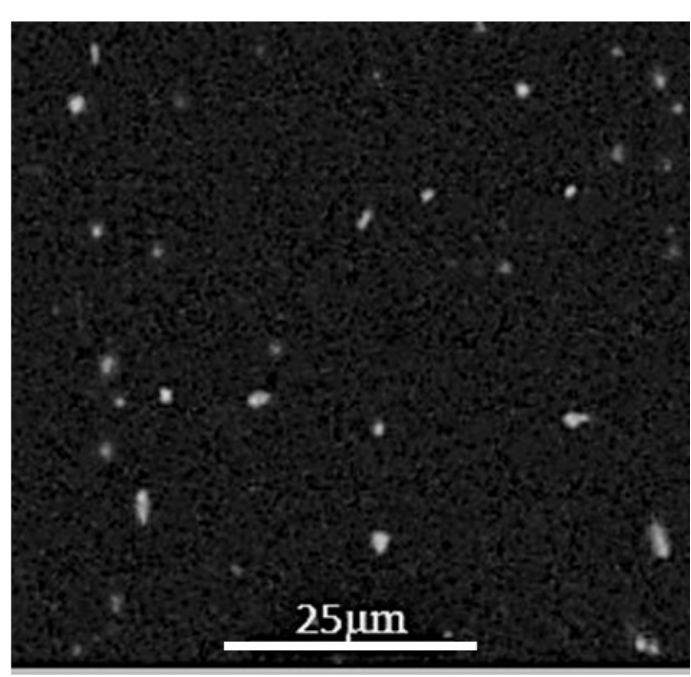

Z1D2

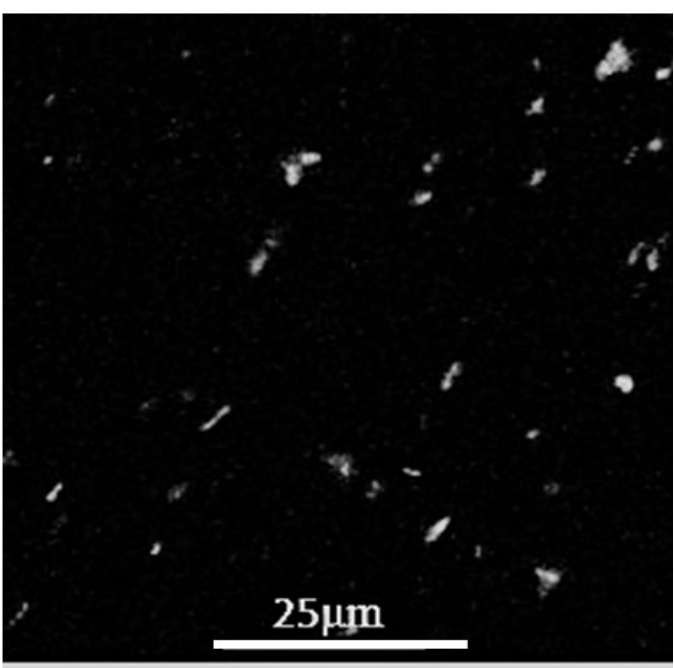

Z2D2

Figure 5.15 SEM-EDX images for zinc dispersion in the polymer matrix. 

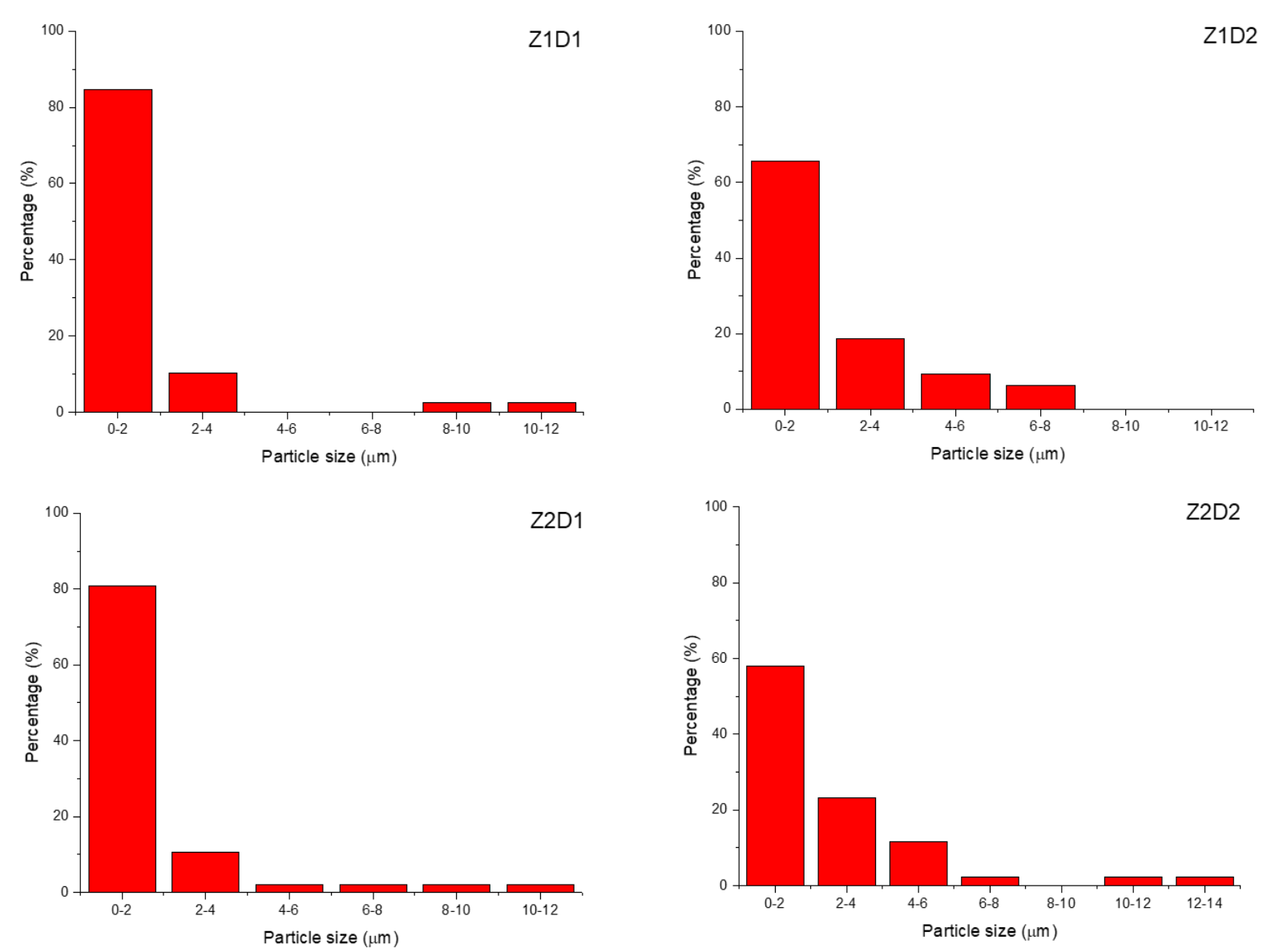

Figure 5.16 Particle size distribution of zinc clusters in the polymer matrix. 


\subsection{CONCLUSIONS}

Hybrid CB/SI-filled NR/BR compounds were investigated with focus on the effect of the $\mathrm{ZnO}$ and DPG addition sequence on the material properties with specific interest on hysteresis/ $\tan \delta$. Addition of ZnO in the first stage of mixing (Z1D1 and Z1D2) decreases the MV and results in lower filler-filler interaction (Payne Effect) and smaller SI clusters in the compound matrix as measured by SEM/EDX. The cure rate of the compounds decreased compared to compounds in which $\mathrm{ZnO}$ was added in the final stage of mixing, but compounds with $\mathrm{ZnO}$ added in the masterbatch are more resistant to thermal degradation, as expressed in a low reversion seen in the cure curves. Compounds with $\mathrm{ZnO}$ added in the last stage of mixing (Z2D1 and Z2D2) show a high bound rubber content as a result of a higher silanization efficiency. High filler-polymer interaction of Z2D1 and Z2D2 vulcanizates improves M300\%. However, due to reversion, the vulcanizates experience a significant reduction of crosslink density, and consequently higher tan $\delta /$ hysteresis at a temperature of $200^{\circ} \mathrm{C}$. Compounds containing DPG in the last stage of mixing (Z1D2 and Z2D2) impart a higher cure rate and filler-rubber interaction compared to compounds with DPG added in the first stage of mixing (Z1D1 and Z2D1). In the case of dynamic properties, most notably the hysteresis, the addition of $\mathrm{ZnO}$ in the first stage of mixing and DPG in the last stage of mixing (Z1D2) results in a low tan $\delta$ at $100^{\circ} \mathrm{C}$ and $200^{\circ} \mathrm{C}$. Considering all properties discussed above, the Z1D2 addition sequence shows a better balance of high stress-strain properties and low hysteresis in a hybrid $\mathrm{CB} / \mathrm{SI}$-filled NR/BR blend, which is beneficial for $\mathrm{AC}$ tire retreads.

\subsection{REFERENCES}

1. Alroqi, A.A., et al., Aircraft Tyre Temperature at Touchdown With Wheel Prerotation, J. Aircraft, 54, 3, 926 (2017).

2. Medalia, A.I., Heat Generation in Elastomer Compounds: Causes and Effects, Rubber Chem. Technol., 64, 3, 481 (1991).

3. Wang, M.J., Effect of Polymer-Filler and Filler-Filler Interactions on Dynamic Properties of Filled Vulcanizates, Rubber Chem. Technol., 71, 3, 520 (1998).

4. Lugisland, H.D. and Niedermeier, W., New Reinforcing Materials for Rising Tire Performance Demands, Rubber World, 228, 34 (2003).

5. Schwaiger, B. and Blume, A., Silica/Silane - $A$ Winning Reinforcement Formula, Rubber World, 222, 32 (2000).

6. Sandstrom, P.H., et al., Aircraft Tire, to The Goodyear Tire and Rubber Company, US7367369B2 (2008).

7. Hashim, A.S., et al., The Effect of Bis-(3-Triethoxysilylpropyl) Tetrasulfide on Silica Reinforcement of Styrene-Butadiene Rubber, Rubber Chem. Technol., 71, 2, 289 (1998).

8. Sarkawi, S.S., et al., The Influence of Non-Rubber Constituents on Performance of Silica Reinforced Natural Rubber Compounds, Eur. Polym. J., 49, 3199 (2013).

9. Chakraborty, S., et al., Precipitated Silica in Tires, Rubber World, 248, 37 (2013).

10. Meon, W., et al., in Rubber Compounding: Chemistry and Applications, Chapter 7: Silica and Silanes, 2nd ed., Rogers, B., Ed., Marcel Decker: New York (2004).

11. Reuvekamp, L.A.E.M., et al., Effect of Zinc Oxide on the Reaction of TESPT Silane Coupling Agent with Silica and Rubber, Rubber Chem. Technol., 77, 34, 34 (2004). 
12. Mihara, S., Reactive Processing of Silica-Reinforced Tire Rubber: New Insight into the Time and Temperature Dependence of Silica Rubber Interaction, PhD thesis, Elastomer Technology and Engineering, University of Twente, The Netherlands (2009).

13. Kim, I.J., et al., Effect of Nano Zinc Oxide on the Cure Characteristics and Mechanical Properties of the Silica-Filled Natural Rubber/Butadiene Rubber Compounds, J. Appl. Polym. Sci., 117, 3, 1535 (2010).

14. Blume, A., et al., Functionalized SBRs in Silica-Reinforced Tire Tread Compounds: Interactions with Filler and Zinc Oxide, No. 26, in 190th ACS Technical Meeting Pittsburgh, PA (2016).

15. Jin, J., et al., On the Various Roles of 1,3-Dipheny/ Guanidine in Silica/Silane Reinforced SBR/BR Blends, Polym. Test., 93, 106858 (2021).

16. Penot, C., Rubber Composition for a Tire Comprising a Reinforcing Inorganic Filler and an (Inorganic Filler/Elastomer) Coupling System, to Michelin Recherche et Technique S.A, US6951897B2 (2005).

17. Guy, L., et al., New Insights in the Dynamic Properties of Precipitated Silica Filled Rubber Using a New High Surface Silica, Kautsch. Gummi Kunstst., 62, 383 (2009).

18. Bristow, G.M., The Mooney Viscosity of Raw Natural Rubber, J. Nat. Rubb. Res., 5, 3, 182 (1990).

19. TA Instruments, $M V$ one, Available online: https://www.tainstruments. com/products/rubber-testing/mooney-viscometer/ (accessed on 20 July 2020).

20. Particle Analysis Using ImageJ, Available online: http://www.nuance.northwestern. edu/docs/epic-pdf/ ParticleAnalysisUsingImage].pdf (accessed on 4 December 2020).

21. Wolers, M.E. et al., Further Developments on Metal Soaps as Processing Promoter for The Rubber Industry, Available online: https://static1.squarespace.com/static/ developmentsonmetalsoaps.pdf (accessed on 5 September 2019).

22. Hewitt, N., in Compounding Precipitated Silica in Elastomers, Chapter 1: Silica as a Reinforcing Agent, William Andrew Publishing: New York (2007).

23. Jin, J., Influence of Compounding and Mixing on Filler Dispersion and Curing Behavior of Silica Compounds, PhD thesis, Elastomer Technology and Engineering, University of Twente, The Netherlands (2020).

24. Kresja, M.R. and Koenig, J.L., in Elastomer Technology Handbook, The Nature of Sulfur Vulcanization, CRC Press: New Jersey (1993).

25. Hewitt, N., in Compounding Precipitated Silica in Elastomers, Chapter 2: Compounding Precipitated Silica in Natural Rubber, William Andrew Publishing: New York (2007).

26. Mihara, S., et al., Rubber Composition, to Yokohama Rubber Co. Ltd., US7923493B2 (2011).

27. Zaborski, M. and Donnet, J.B., Activity of Fillers in Elastomer Networks of Different Structure, Macromol. Symp., 194, 1, 87 (2003).

28. Lim, S.H., et al., Effect of 1,3-Diphenyl-guanidine (DPG) Mixing Step on the Properties of SSBR-silica Compounds, Elastomers Compos., 51, 2, 81 (2016).

29. Todorova, N., et al., Zinc Resinate's Influence on the Properties of Silica Filled Composites Based on Natural Rubber, J. Chem. Technol. Metall., 49, 3, 213 (2014).

30. Pattanawanidchai, S., et al., Cure Retardation of Peroxide-Cured Silica Filled Natural Rubber Influenced by Organosilane, Polym. Eng. Sci., 59, 1, 42 (2019).

31. Kaewsakul, W., et al., Optimization of Rubber Formulation for Silica-Reinforced Natural Rubber Compounds, Rubber Chem. Technol., 86, 2, 313 (2013). 


\title{
THE INFLUENCE OF DIFFERENT TYPES OF BUTADIENE RUBBER ON PROCESSING, MECHANICAL AND DYNAMIC PROPERTIES OF AIRCRAFT TIRE RETREADS
}

\begin{abstract}
The polymer selection plays a crucial role in the performance of rubber products, also for aircraft tire treads. Heat generation and high temperatures in aircraft tire treads have detrimental effects on most properties: it decreases the final performance and accelerates tread wear due to thermo-mechanical degradation, which shortens the service life of the treads. Butadiene Rubber (BR) is commonly added as minor component to Natural Rubber (NR) in aircraft tire treads to increase their longevity. In the present study, the influence of various types of $B R$ is investigated: High-Cis BR (HC BR), High-Cis Long-Chain Branched BR (HC LCB BR), Low-Cis star-branched BR (LC BR), and High-Vinyl BR (HV BR), blended with $N R$, in a hybrid Carbon Black/Silica (CB/SI) filled compound on the properties of aircraft tire retreads. Comparing the four types of BR, HC LCB BR shows improvements in processability, filler-rubber interaction, as well as the lowest tan $\delta$ values at $100^{\circ} \mathrm{C}$ and at low frequencies due to long-chain branching. However, at an average service temperature of aircraft tire treads of around $200^{\circ} \mathrm{C}$, the use of the NR/HV BR blend shows the best performance in terms of $\tan \delta$ compared to the other BR types. Highly crosslinked networks are responsible for low Heat Build-Up (HBU). Therefore, the use of HV BR in the blends with NR in CB/SI-filled vulcanizates provides low heat generation materials and can act as a potential polymer in a blend with NR suitable for aircraft tire retreads.
\end{abstract}




\subsection{INTRODUCTION}

High temperature generation within the tread of aircraft tires is one of the vital concerns because it relates to the service life of the tire. Wear increases with tread temperature, and rises rapidly when the temperature passes $80^{\circ} \mathrm{C}$, depending on the tread compound formulation [1]. Temperature build-up in a tire is determined by the hysteresis loss during deformation of the tire. The use of low hysteresis rubber can minimize tire temperature build-up without sacrificing other desirable properties.

Primarily Natural Rubber (NR) is used in compounds for aircraft tires because of its relatively low heat generation under dynamic conditions. Butadiene Rubber (BR) is commonly added in smaller quantities in order to increase the longevity of aircraft tire treads. Commonly the types of BR used in the tire industry are characterized by a very low glass transition temperature $(\mathrm{Tg})$ in the region of -75 to $-100^{\circ} \mathrm{C}$. High-Cis BR grades have a cis-content of more than $95 \mathrm{wt} \%$, which is beneficial for wear and cut growth resistance. Cut growth resistance is vital for reducing tear propagation or cracking during operation. The highest ciscontent of about $99 \%$ results in the most linear chain structure, producing a polymer with the best tensile properties and low hysteresis, thus low Heat Build-Up (HBU) [2].

Developing tread formulations for an optimum balance between traction, hysteresis and abrasion is important. The introduction of vinyl units into polybutadiene alters its glass transition temperature and physical properties significantly. A higher vinyl content increases the $\mathrm{Tg}$ by creating a more rigid molecular chain structure [2]. Polybutadiene having a vinylcontent of 10 to $30 \mathrm{wt} \%$ has a $\mathrm{Tg}$ between -70 and $-85^{\circ} \mathrm{C}$ and exhibits low wear and rolling resistance but poor wet traction. The high-vinyl polybutadiene grades with a vinyl content of 80 to $95 \mathrm{wt} \%$ and a $\mathrm{Tg}$ of -10 to $-30^{\circ} \mathrm{C}$ provide excellent traction but poor wear resistance. Research has shown that the optimum balance between traction, wear and rolling resistance can be obtained using polybutadiene with a vinyl content of $70 \mathrm{wt} \%$ [3]. Figure 6.1 depicts the effect of polymer microstructure of BR on the physical properties, in particular as the result of the amount of 1,2-polybutadiene configurations, as the counterpart of cis- and transconfigurations, together adding up to $100 \%$. The higher the qualitative ranking in Figure 6.1, the better, except for wear resistance. 


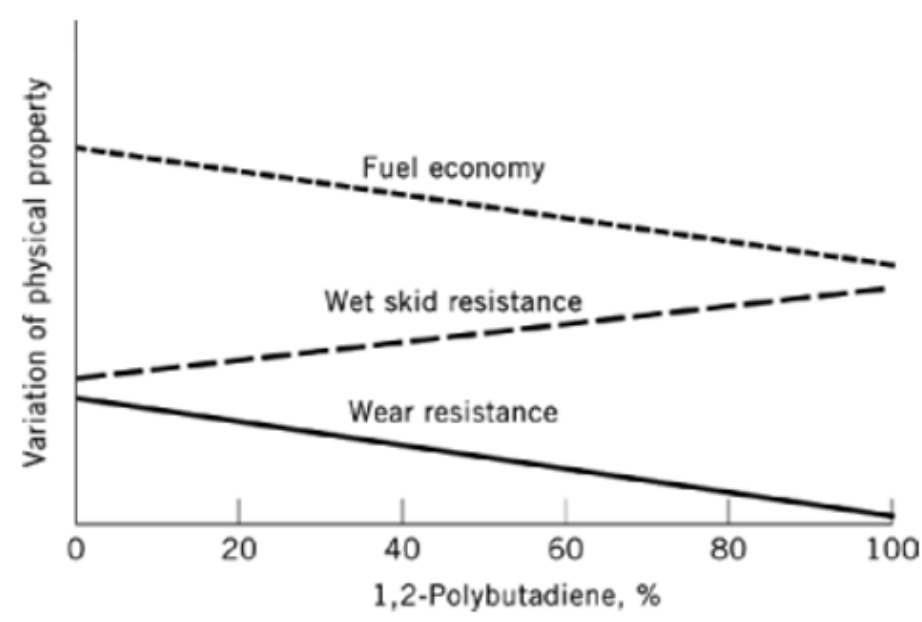

Figure 6.1 Effect of the 1,2-polybutadiene level on physical properties related to tires [3].

The properties of vulcanizates are strongly affected by the polymer choice. The polymer architecture determines the performance of tires in terms of wear, traction, and rolling resistance. Therefore, proper selection of the polymers to be blended and the composition is crucial for the best compromise in compound properties. Table 6.1 shows that polymer architecture plays a key role in the viscoelastic properties of any tire elastomer as related to the overall tire performance. Certain polymer features such as weight average molecular weight (Mw) and molecular weight distribution (MWD) may be related to rolling resistance and processability. Similarly, tacticity displays a great effect on wear, rolling resistance, traction, and processability. Monomer composition and co-monomer sequence are stated to be related to wear, traction and rolling resistance. The degree of branching also affects traction, rolling resistance and processability [4].

Table 6.1 The effect of polymer architecture on the tire performance [4].

\begin{tabular}{|c|c|c|c|c|c|}
\hline & $\begin{array}{l}M W \text { and } \\
M W D\end{array}$ & Tactioity & $\begin{array}{c}\text { Monomer } \\
\text { composition }\end{array}$ & $\begin{array}{l}\text { Sequence } \\
\text { distribution }\end{array}$ & Branching \\
\hline Wear & & & & & \\
\hline Traction & & & & & \\
\hline $\begin{array}{l}\text { Rolling } \\
\text { resistance }\end{array}$ & |WII & & UI & & |W|| \\
\hline Processability & & 8 & & & \\
\hline
\end{tabular}




\subsection{EXPERIMENTAL}

\subsubsection{MATERIALS}

For the present study, four types of BR were selected on basis of approximately the same viscosity as masticated NR, but grossly differing in molecular architectures and cis/transvs. 1,2-vinyl butadiene configurations. High-Cis essentially linear BR (HC BR), High-Cis LongChain Branched BR (HC LCB BR), Low-Cis star branched BR (LC BR) and High-Vinyl BR (HV$\mathrm{BR})$ are investigated in order to characterize their effect on processability, mechanical and dynamic properties such as tan $\delta$ (hysteresis) in hybrid CB/SI-filled NR/BR compounds. All four samples were produced with proprietary polymerization technology of the respective suppliers, which precludes an all-encompassing understanding of all intricacies of the products, other than shown hereunder in Table 6.2. Other compounding ingredients are as described in Chapter 5. Buna CB 22 and Buna Nd 22 EZ are produced with a Neodymium (Nd) catalyst. Buna CB 60 and Europrene BR HV80 are produced by Lithium-based anionic polymerization.

Table 6.2 BRs used and properties as delivered by the supplier.

\begin{tabular}{|l|c|c|c|c|}
\hline \multicolumn{1}{|c|}{ Properties } & HC BR & HC LCB BR & LC BR & HV BR \\
\hline Trade name & BUNA CB 22 & $\begin{array}{c}\text { BUNA } \\
\text { Nd 22 EZ }\end{array}$ & BUNA CB60 & $\begin{array}{c}\text { EUROPRENE } \\
\text { BR HV80 }\end{array}$ \\
\hline Company & \multicolumn{3}{|c|}{ ARLANXEO, Germany } & VERSALIS ENI \\
\hline Catalyst & Neodymium & Neodymium & Lithium & Lithium \\
\hline Cis content, wt\% & $>96$ & $>96$ & 38 & - \\
\hline Vinyl content, wt\% & - & - & 11 & 77 \\
\hline MV (ML(1+4) $100^{\circ} \mathrm{C}, \mathrm{MU}$ & 63 & 63 & 60 & 70 \\
\hline $\begin{array}{l}\text { Glass transition temperature, } \\
{ }^{\circ} \mathrm{C}\end{array}$ & - & - & - & -31 \\
\hline
\end{tabular}

\subsubsection{COMPOUND PREPARATION}

The formulation used for this study is presented in Table 6.3, expressed in parts per hundred parts of rubber (phr). The compounds were prepared following a two-step mixing procedure as described in Chapter 5 with Zinc Oxide $(\mathrm{ZnO})$ added in the first stage of mixing and DiPhenyl Guanidine (DPG) added in the second stage of mixing (Z1D2). 
Table 6.3 Compound formulations.

\begin{tabular}{|c|c|}
\hline Ingredients & phr \\
\hline NR & 70 \\
\hline BR & 30 \\
\hline CB & 35 \\
\hline SI & 20 \\
\hline TESPT & 1.8 \\
\hline Stearic acid & 3 \\
\hline 6PPD & 2 \\
\hline TMQ & 1 \\
\hline ZnO & 5 \\
\hline Sulfur & 1.5 \\
\hline CBS & 1.5 \\
\hline DPG & 0.4 \\
\hline
\end{tabular}

Amount of TESPT and DPG were calculated according to the following equations:

TESPT (phr) $=0.00053 \times \mathrm{Q} \times \mathrm{A}$ and DPG $(\mathrm{phr})=0.00012 \times \mathrm{Q} \times \mathrm{A}$

where $Q$ is the amount of silica (phr) and $A$ is the CTAB surface area of the silica $\left(171 \mathrm{~m}^{2} / \mathrm{g}\right)$

\subsubsection{TESTING OF RAW RUBBERS}

Relative molecular weight determination - Gel Permeation Chromatography (GPC) was performed to analyze the weight average molecular weight (Mw), number average molecular weight (Mn), and Poly Dispersity Index (PDI) of the different types of BR used in this study. $10 \mathrm{mg}$ of a sample and $5 \mathrm{mg}$ of standard polystyrene were dissolved in $20 \mathrm{ml}$ of TetraHydroFuran (THF) to obtain a sample solution. A Tosoh HLC-8320GPC was used, THF comprising $5 \mathrm{mmol} / \mathrm{l}$ of triethylamine was used as eluent, and $10 \mu \mathrm{l}$ of the sample solution was injected to obtain a chromatogram by using a Refractive Index (RI) detector. The column oven temperature was $40^{\circ} \mathrm{C}$, and the THF flow rate was $0.35 \mathrm{ml} / \mathrm{min}$ [5].

Branching Index - A measurement of the degree of branching was determined by Large Amplitude Oscillation Strain (LAOS) in a Rubber Process Analyzer (RPA) from TA Instruments at $160^{\circ} \mathrm{C}$ in a strain sweep in the range of $0.1-1300 \%$ strain at a fixed frequency of $0.5 \mathrm{~Hz}$ $[6]$.

\subsubsection{TESTING OF COMPOUND AND VULCANIZATE PROPERTIES}

Mooney Viscosity (MV), Payne Effect (PE), cure characteristics, bound rubber content, apparent crosslink density, stress-strain properties and tan $\delta$ at $100^{\circ} \mathrm{C}$ of the compounds or $\tan \delta$ at $100^{\circ} \mathrm{C}$ and $200^{\circ} \mathrm{C}$ in a frequency sweep of vulcanized rubber with different types of $\mathrm{BR}$ and filled with a hybrid CB/SI filler, were measured. The methods and equipment used were the same as described in Chapters 3 and 5. 
Tan $\delta$ in temperature sweep - Samples were cut from vulcanized rubber sheets of $2 \mathrm{~mm}$ thickness. Measurements were performed using a Dynamic Mechanical Analyzer (DMA) GABO in two segmented conditions. The first condition employed was a temperature sweep in tension mode between $-120^{\circ} \mathrm{C}$ and $40^{\circ} \mathrm{C}$ with $1^{\circ} \mathrm{C} / \mathrm{min}$ rate at a dynamic strain of $0.1 \%$, static strain of $1 \%$, and a frequency of $10 \mathrm{~Hz}$. The second condition was a temperature sweep from -40 to $120^{\circ} \mathrm{C}$ where the dynamic and static strain were set at $3 \%$. The temperature increase rate, frequency and deformation mode were the same as described above. The glass transition temperature $(\mathrm{Tg})$ of the compounds was taken as the temperature of the peak of the loss modulus $\left(\mathrm{E}^{\prime \prime}\right)$ curve and of the $\tan \delta$ curve. Tan $\delta$ at $-30^{\circ} \mathrm{C}$ and $\tan \delta$ at $5^{\circ} \mathrm{C}$ were chosen as indicators of ICe Traction (ICT) and Wet Skid Resistance (WSR) of tire treads, respectively, while $\tan \delta$ at $100^{\circ} \mathrm{C}$ was used as indicator for hysteresis/Heat Build-Up (HBU).

\subsection{RESULTS AND DISCUSSION}

\subsubsection{Mw, Mn, PDI AND BRANCHING INDEX}

The BRs used were first characterized for their weight- and number-average molecular weights, Mw and Mn, respectively their PDI $=\mathrm{Mw} / \mathrm{Mn}$, by GPC. Table 6.4 shows the values of $\mathrm{Mw}, \mathrm{Mn}$ and PDI of the different types of BR. It is to be noted that the calculated molecular weights of the BRs are relative to the known molecular weights of essentially linear narrow molecular weight polystyrene samples as a standard reference. The branching index of BRs was determined by the LAOS method. Figure 6.3 shows the strain rate plotted against the stress for one cycle of deformation of the different types of BR. The values of branching are depicted in Table 6.5: for rubber analysis, a negative (-) branching index value means that the polymer is mostly linear. The higher the branching index, the more branching the polymer has [7].

HC BR and HC LCB BR were both made with Neodymium catalysis. For HC BR this catalysis results in a "normal molecular weight distribution": Figure 6.2 , with a $\mathrm{Mw} / \mathrm{Mn} \approx 2.0$ as given in Table 6.4. However, the molecules are not perfectly linear because of some sidereactions of the catalyst. There is some LCB taking place, which results in a positive branching index of 0.62. Similarly, for HC LCB BR, this LCB is extra promoted during polymerization, which increases the PDI to 2.2 and raises the branching index to a higher value of 1.2 (for the same MV). HV BR was produced with butyl-Lithium living polymerization which gives essentially linear molecules without branches and with all the same molecular weight. This would result in theoretical PDI's of essentially 1.0, while from GPC measurement the result is 1.9 , which means it was not quite as good as theoretically predicted. The secondary loop as shown in Figure 6.3 for HV BR indicates that this polymer has least branching compared to the other types of BR. The branching index from LAOS is -1.7 , which means that no branching is detected. It is important to note that the molecular weight and PDI of LC BR was not properly defined by GPC. This is because of the star-branched molecular architecture of LC BR. All four-armed polymers have the same molecular weight, equal to 4 times the molecular weight of the individual arms. Some stars may have missed one arm, and others may have 
only 2. This may have caused the broader PDI than 1.0. This star structure results in a lower hydrodynamic radius than the linear structure for the same molecular weight, by higher compaction of the molecular coils in solution. The GPC commonly used for molecular weight characterization separates the molecules based on hydrodynamic volume. Therefore, the GPC underestimates the real molecular weight and PDI of LC BR relative to the essentially linear polystyrene calibration samples. It is expected that LC BR has a higher number of branching index even than HC LCB BR. However, the branching index of LC BR is only 0.4 . This value measured on the star-branched LC BR cannot directly be compared with the ones measured for the regular branched polymers because of its special architecture. Therefore, LAOS also has a problem to signify the branching index for this BR grade.

Table 6.4 Mw, Mn and PDI of different types of butadiene rubber.

\begin{tabular}{|c|c|c|c|}
\hline BR type & Mw $\times 10^{5}(\mathrm{~g} / \mathrm{mol})$ & Mn $\times 10^{5}(\mathrm{~g} / \mathrm{mol})$ & PDI $=M w / M n$ \\
\hline HC BR & 6.0 & 2.7 & 2.0 \\
\hline HC LCB BR & 5.3 & 2.4 & 2.2 \\
\hline LC BR & 3.1 & 1.9 & 1.6 \\
\hline HV BR & 5.7 & 3.0 & 1.9 \\
\hline
\end{tabular}

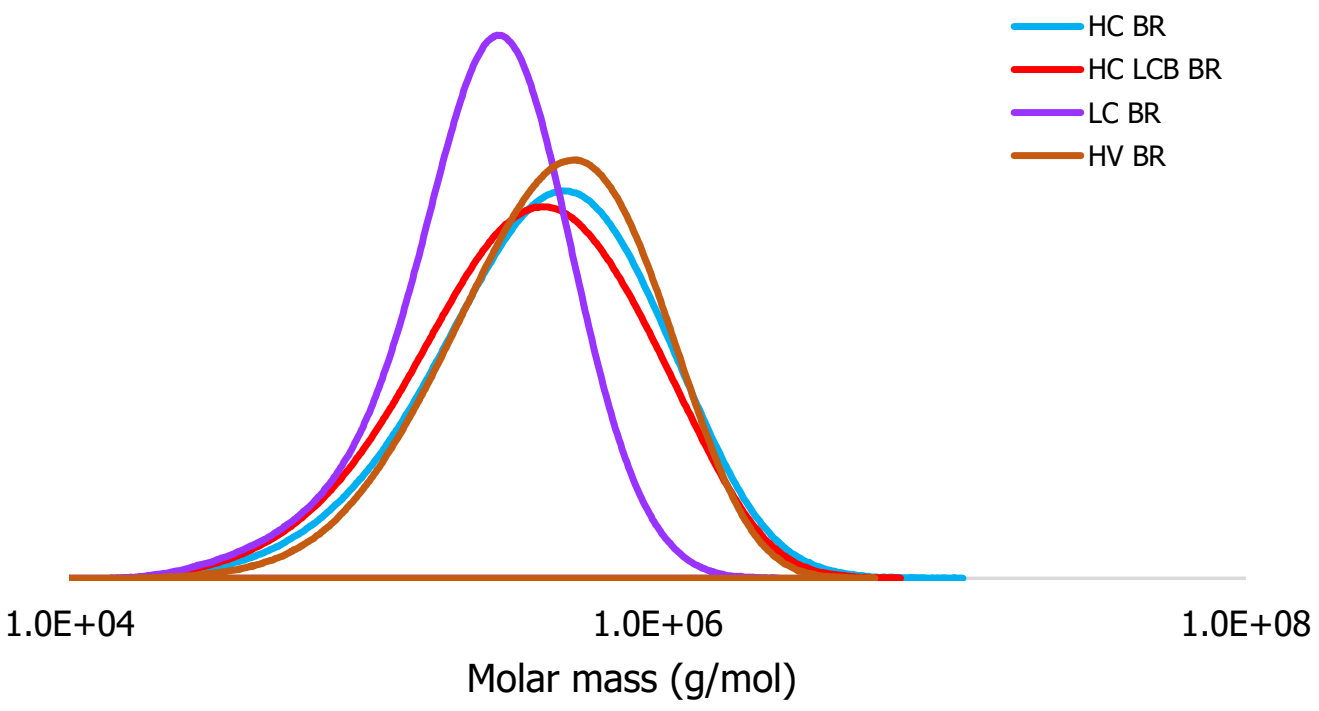

Figure 6.2 Molecular weight distribution of different types of BR. 


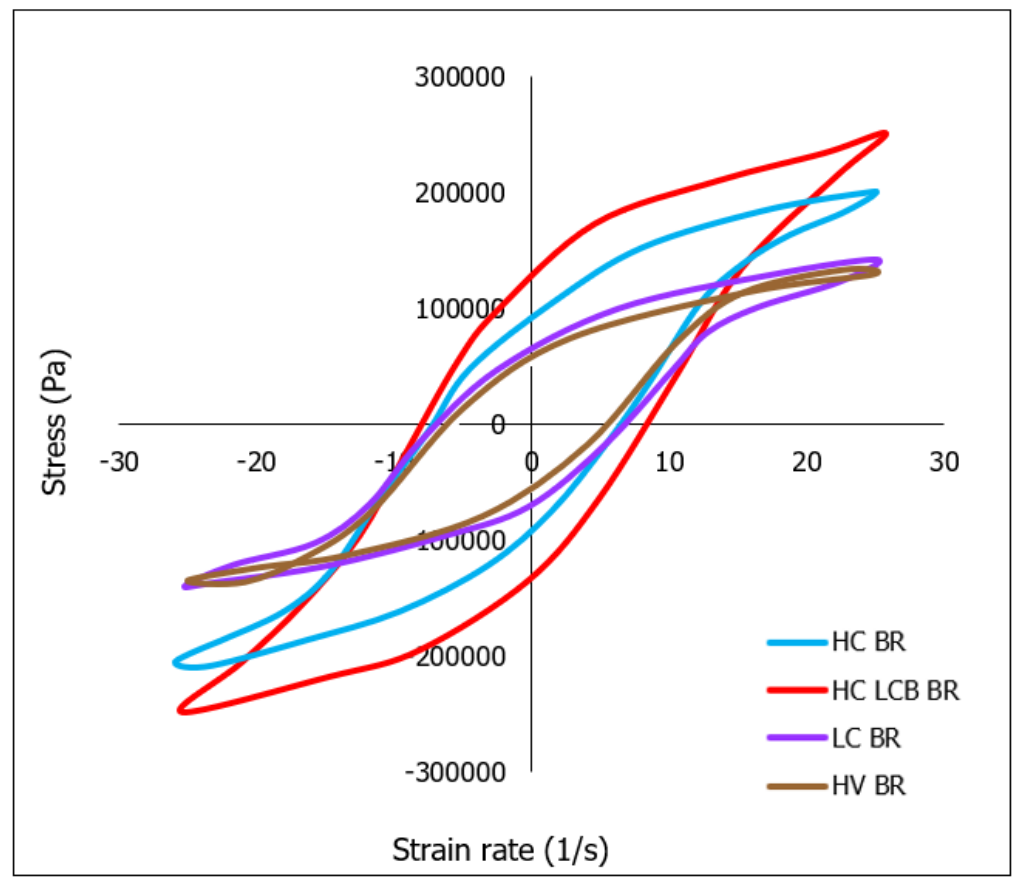

Figure 6.3 Strain rate versus stress of different types of BR.

Table 6.5 Branching of BRs.

\begin{tabular}{|c|c|c|c|}
\hline \multicolumn{4}{|c|}{ Branching index } \\
\hline HC BR & HC LCB BR & LC BR & HV BR \\
\hline 0.62 & 1.2 & 0.4 & -1.7 \\
\hline
\end{tabular}

\subsubsection{GLASS TRANSITION TEMPERATURE (Tg) OF THE RUBBERS}

The glass transition temperature $(\mathrm{Tg})$ of the polymers used in this study was measured with DMA. The Tg was calculated using two different methods: as the peak of the loss modulus $\left(\mathrm{E}^{\prime \prime}\right)$ signal $(\mathrm{TI})$, and as the peak of the tan $\delta$ signal (Tt). Commonly the first occurs several degrees lower in temperature than the second [8]. Figure 6.4 shows $E^{\prime \prime}$ and $\tan \delta$ as functions of temperature. The measured Tgs are summarized in Table 6.6. TI relates to the physical property changes attributed to transitions in materials that are associated with different localized or medium-to-long-range cooperative motions of molecular segments. Tt relates to the midpoint between the glassy and rubbery states of a polymer [9]. The Tgs of the HC BR and HC LCB BR are the lowest among the BRs: the double bonds in the cis-configuration reduce the energy barrier for the rotation of adjacent $\mathrm{C}-\mathrm{C}$ bonds compared to those in the trans-structure, which reduces the glass transition temperature [10]. The Tg of HV BR is the highest compared to the other BRs, which is attributed to the vinyl groups restricting the segmental movements and decreasing the flexibility of the molecular chains [11]. The structure of NR is comparable to that of cis-BR. Both materials are unsaturated hydrocarbons. In the case of NR, the double bonds are activated by the presence of a methyl group, while in the polybutadiene molecule, it lacks this side group making it less reactive. Furthermore, 
since the methyl side group tends to stiffen the polymer chain of $N R$, the $\mathrm{Tg}$ of $\mathrm{NR}$ is consequently higher than that of cis-BR [12].

Table 6.6 Measured glass transition temperatures.

\begin{tabular}{|l|c|c|}
\hline \multicolumn{1}{|c|}{ Rubber } & $\begin{array}{c}\text { Loss modulus (E") peak } \\
\mathbf{T l}\left({ }^{\circ} \mathbf{C}\right)\end{array}$ & $\begin{array}{c}\text { Tan } \mathbf{~ p e a k ~} \\
\mathbf{T t}\left({ }^{\circ} \mathbf{C}\right)\end{array}$ \\
\hline HC BR & -102 & -96 \\
\hline HC LCB BR & -101 & -95 \\
\hline LC BR & -95 & -87 \\
\hline HV BR & -36 & -31 \\
\hline NR & -70 & -65 \\
\hline
\end{tabular}
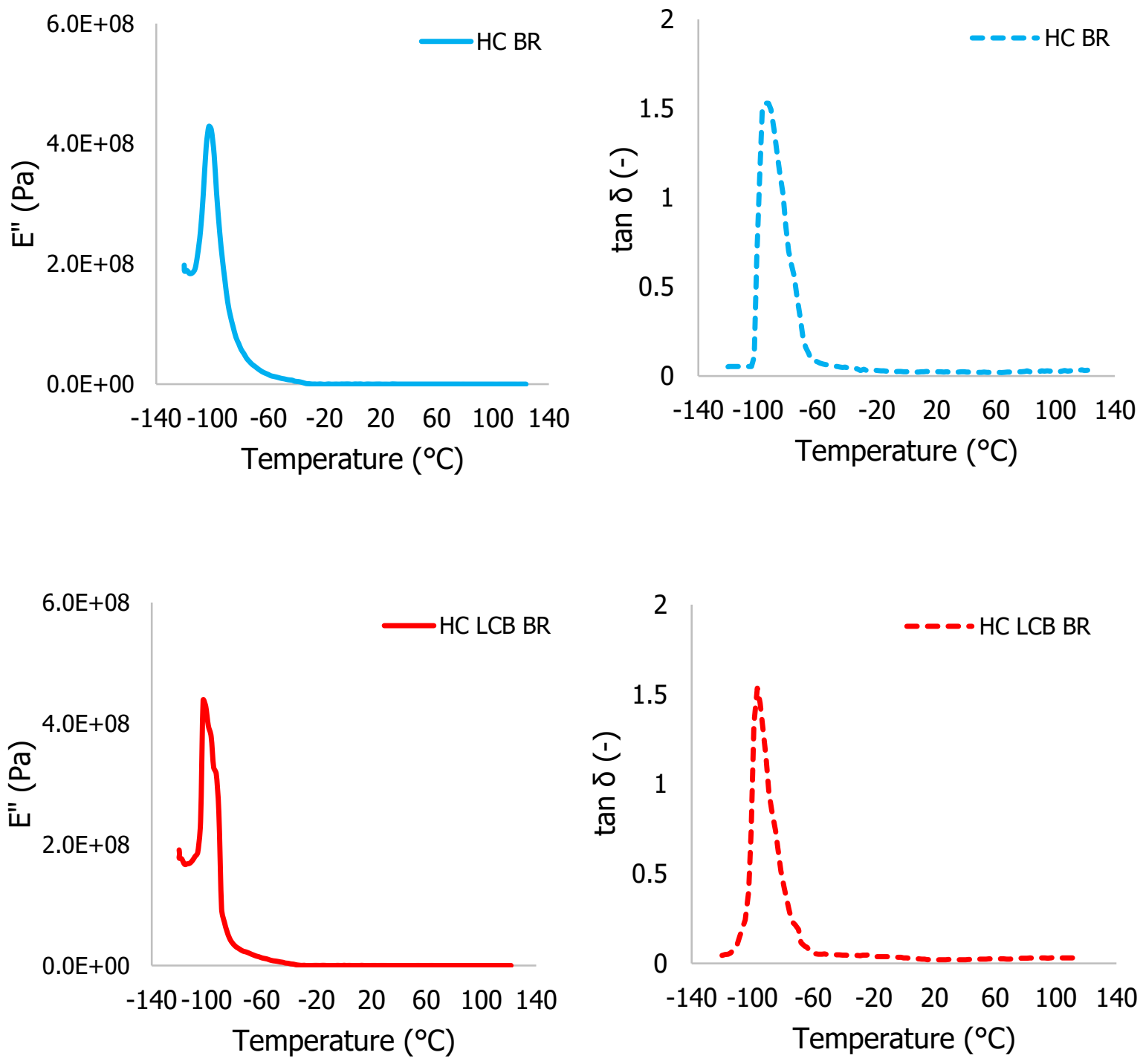

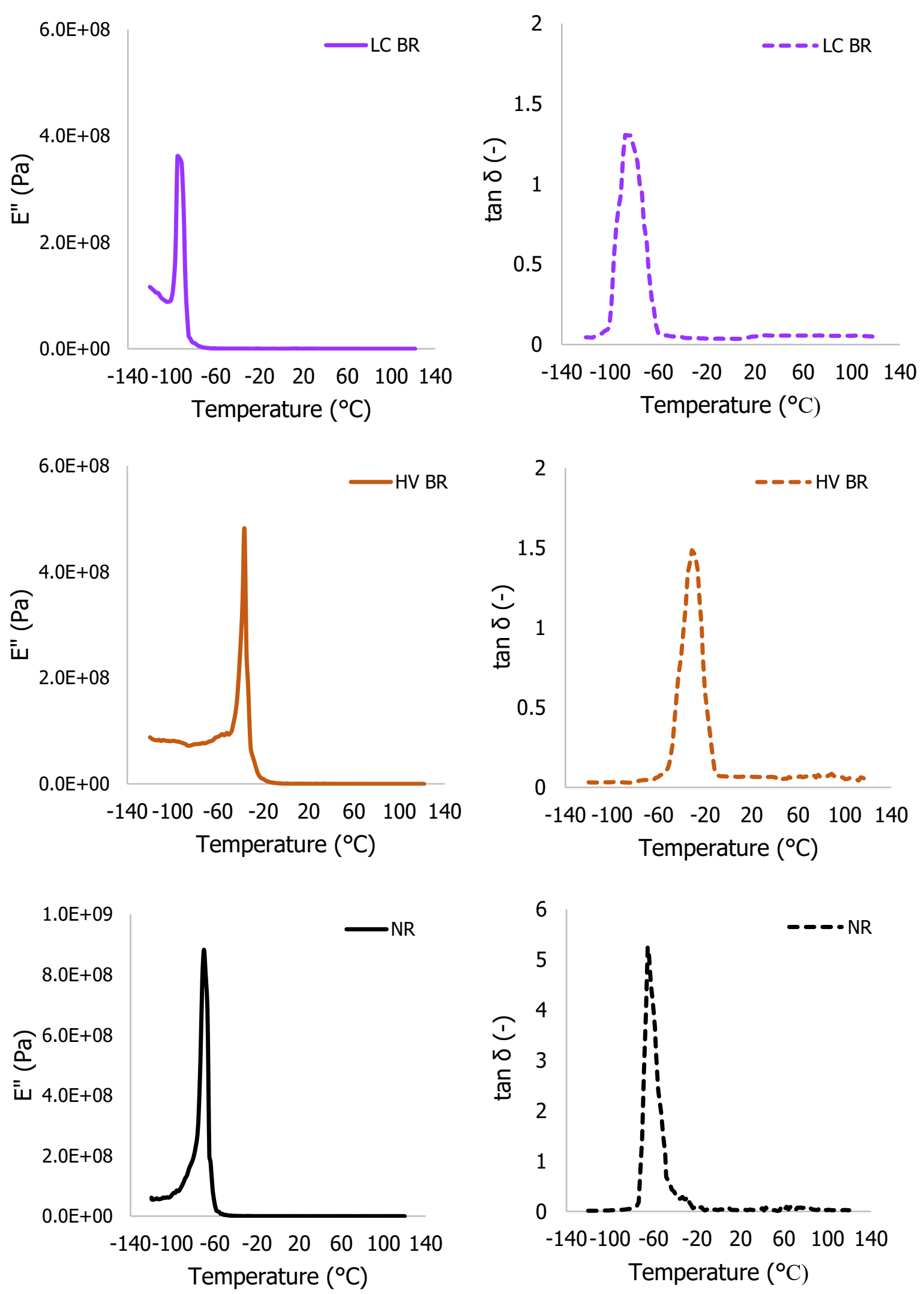

Figure 6.4 Loss modulus $\left(E^{\prime \prime}\right)$ and $\tan \delta$ of the rubbers measured in a temperature sweep. 


\subsubsection{DYNAMIC MECHANICAL PROPERTIES OF SINGLE RUBBERS AND THE BLEND (NR/BR)}

\subsubsection{UNVULCANIZED UNFILLED SINGLE RUBBERS}

Figure 6.5 shows the storage modulus $\left(\mathrm{G}^{\prime}\right)$, loss modulus $\left(\mathrm{G}^{\prime \prime}\right)$ and $\tan \delta$ of the single elastomers in the frequency range of $0.1-33 \mathrm{~Hz}$. Figure $6.5(\mathrm{a})$ shows that a crossover of the $\mathrm{G}^{\prime}$ and $\mathrm{G}^{\prime \prime}$ curves can be observed for the high molecular weight, high vinyl linear polymer HV BR at about $0.3 \mathrm{~Hz}$. HC BR and NR are high molecular weight polymers with a slight amount of branching, and for those the $\mathrm{G}^{\prime}$ and $\mathrm{G}^{\prime \prime}$ meet but do not cross-over yet at a frequency of $0.1 \mathrm{~Hz}$. In Figure 6.5(b) showing the two-branched BR, the crossover point of $\mathrm{G}^{\prime}$ and $\mathrm{G}^{\prime \prime}$ is shifted to even lower frequencies, out of the measurement range [13]. The crossover point shifts towards a lower frequency as molecular weight and branching increases [14-17]. Therefore, within the frequency range of the measurement, the $\mathrm{G}^{\prime}$ and $\mathrm{G}^{\prime \prime}$ of HC LCB BR and LC BR run more or less parallel. This concurs with the work of Winter [18, 19]. Both $\mathrm{G}^{\prime}$ and G" of LC BR increase linearly as the frequency increases. Apparently, the star-branching of this latter BR is most pronounced, so that the cross-over point is situated very far left to lower frequencies.

Tan $\delta$ is the ratio of $G^{\prime \prime}$ over $G^{\prime}$. Figure 6.5(c) shows tan $\delta$ as a function of frequency for all types of BR. Generally speaking, for linear polymers, viscous behavior prevails over elastic at low frequencies, corresponding to a phase angle $\delta$ aiming for $90^{\circ}$, so that tan $\delta$ goes to a high value. For heavily branched polymers the entanglements of the branches restrict flow, which usually demonstrates itself as "elastic" behavior, corresponding to a low phase angle $\delta$, so a low tan $\delta$ [20]. It should be noted though, that the actual molecular weight and the PDI's of the pertinent polymers also play a role herein. All these characteristic features of the polymers are to some extent interrelated. This is clearly visible in Figure 6.5(c). NR and HV BR show the typical behavior of non-entangled, non-branched polymers; HV BR even more so than NR. HC BR has a higher tan $\delta$ at higher frequencies but levels off at lower frequencies at a lower $\tan \delta$ value; the same and even more so the HC LCB BR. This clearly points at a higher molecular weight combined with some long-chain branching and/or a somewhat broader PDI, as demonstrated in Table 6.4. LC BR shows a nearly horizontal behavior of the $\tan \delta$, very little dependence of tan $\delta$ on frequency, typical for a heavily branched polymer. The branches entangle and cause a strong elastic response in the still liquid, non-vulcanized state. 
(a)

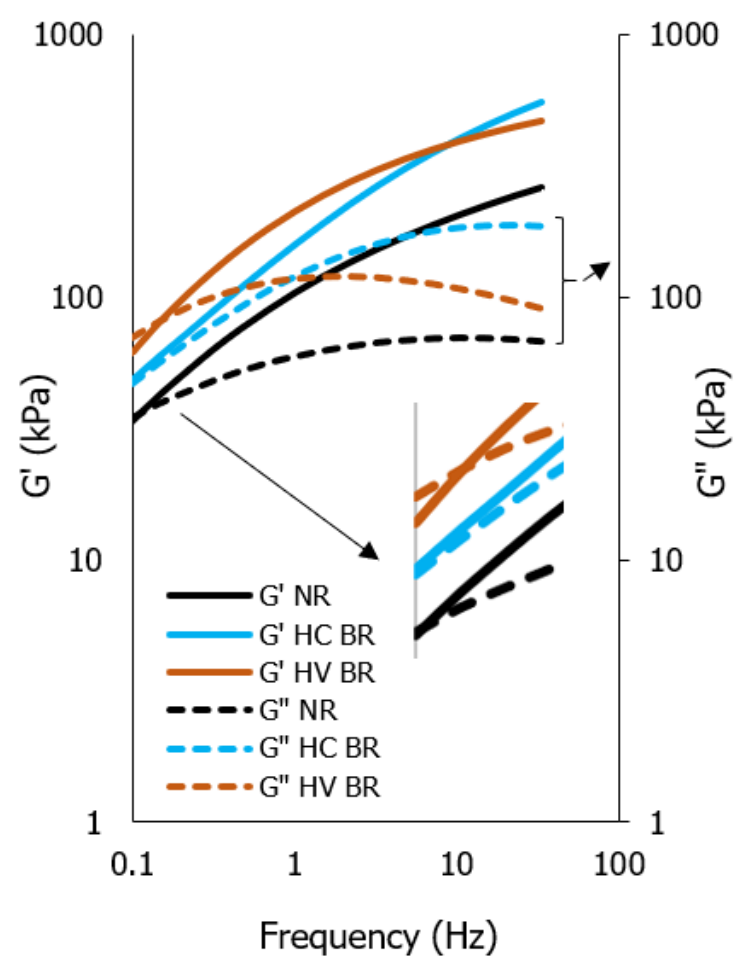

(b)

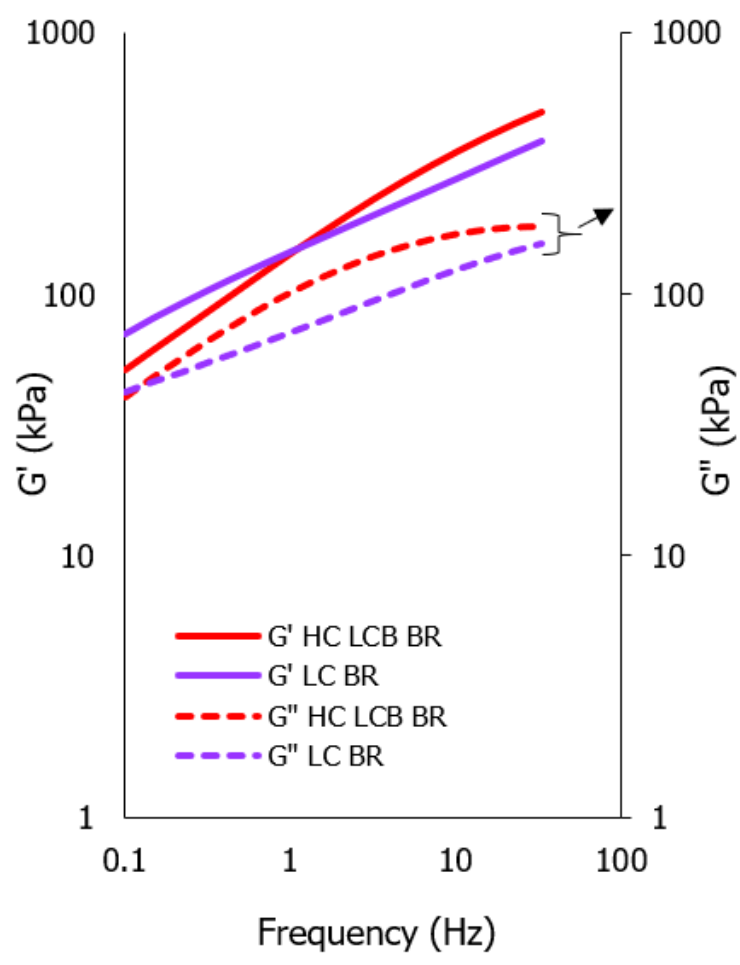

(c)

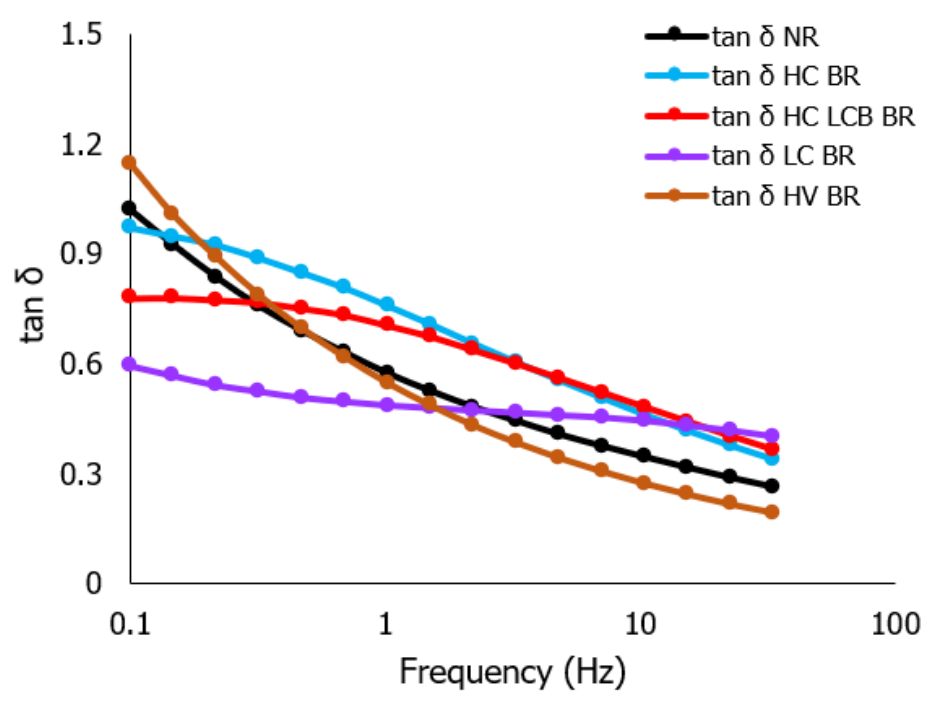

Figure 6.5 G' and G" of uncured unfilled-single rubbers: NR, HC BR, HV BR (a); HC LCB BR, LC BR (b); and $\tan \delta$ of uncured unfilled-single rubbers (c) measured at $100^{\circ} \mathrm{C}$. 


\subsubsection{UNFILLED-NR/BR BLENDS}

Figure 6.6 shows the viscoelastic properties of the uncured blends of NR with different types of BR. In the blends with NR, all types of BR still show similar viscoelastic behavior trends as measured for the pure polymers, only the magnitudes of the properties become smaller as NR is the major component of the blends.

(a)

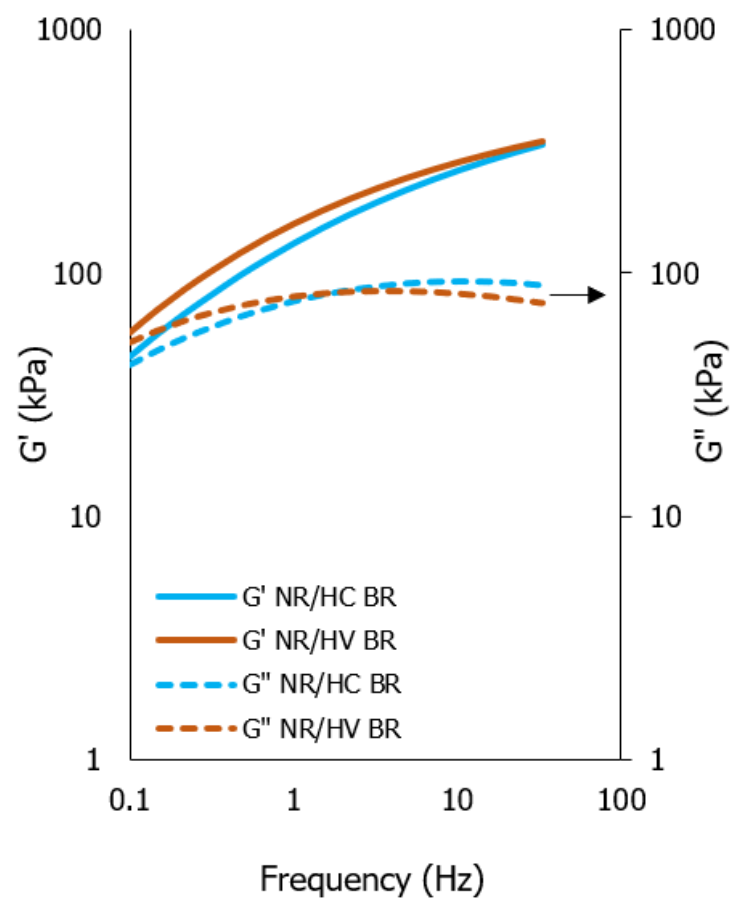

(b)

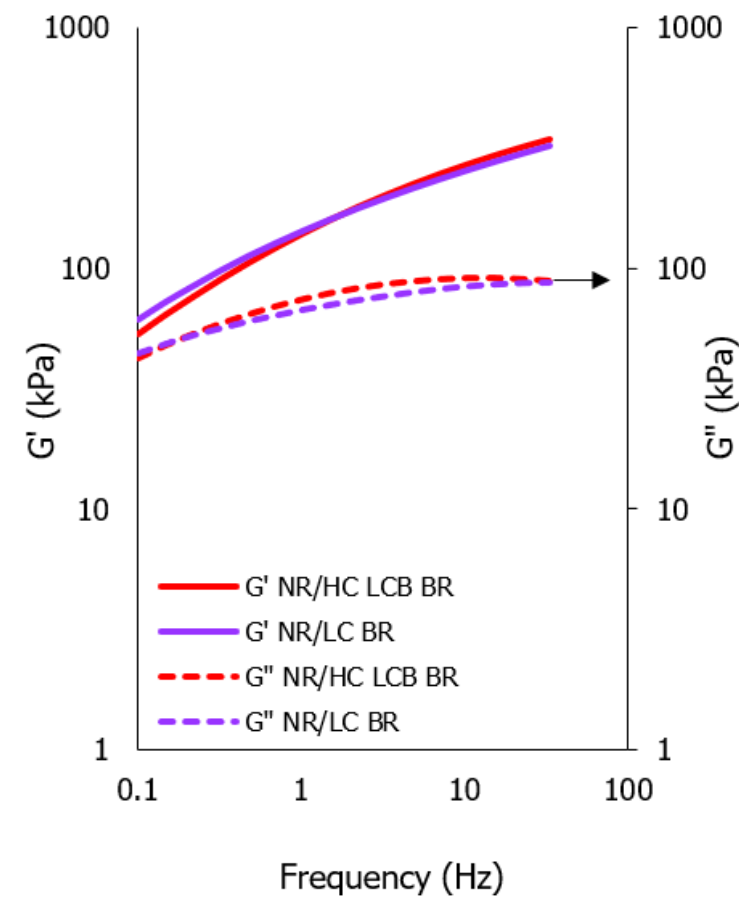

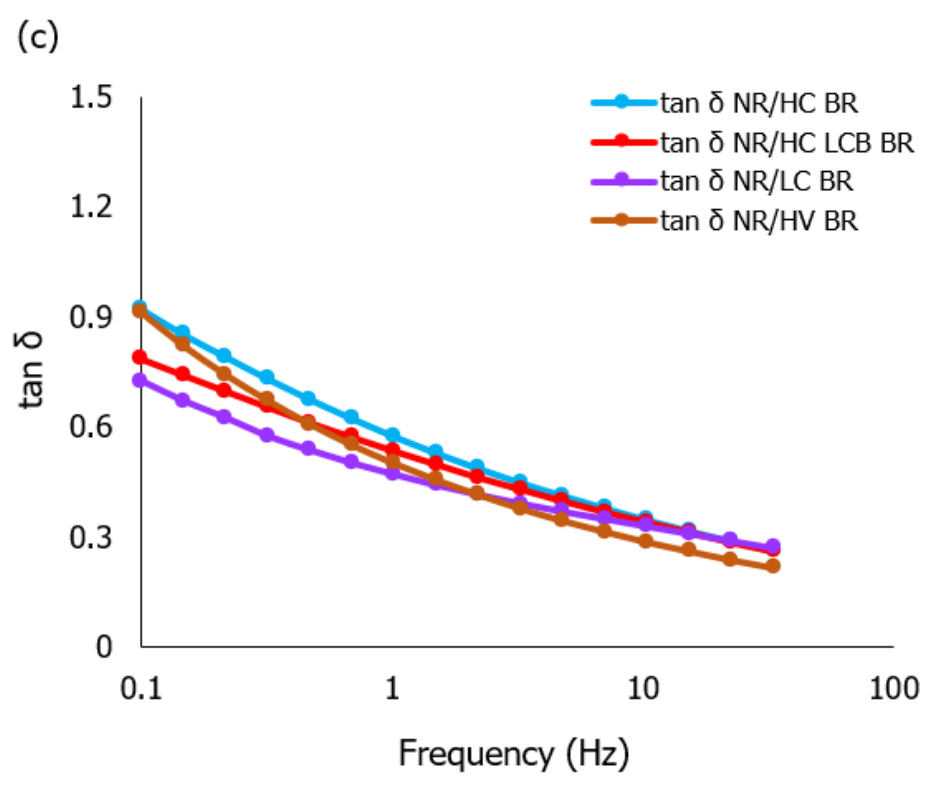

Figure 6.6 G' and G" of: NR/HC BR, NR/HV BR (a); NR/HC LCB BR, NR/LC BR (b); and tan $\delta$ of uncured unfilled-NR/BR blends (c) measured at $100^{\circ} \mathrm{C}$. 


\subsubsection{PROPERTIES OF CB/SI-FILLED NR/BR COMPOUNDS AND VULCANIZATES \\ 6.3.4.1 VISCOSITIES}

The MV of the compounds before vulcanization, consisting of a blend of NR with the different types of BR are shown in Figure 6.7. The MV of the compounds not only depends on the macro- and micro-structure of the polymers: molecular weight, PDI and branching, but also on the silanization efficiency of the SI-silane filler system in the different types of polymers. NR/LC BR shows the lowest MV among the other types of BR due to the fact that the NR unravels or dilutes the branches of this grade and thus enhances flow. For the same reason is the MV of NR/HC LCB BR lower than of NR/HC BR and NR/HV BR. The viscosities of the compounds are overall a little high due to the use of SI in their compound formulations. However, all compounds are still processable and can be compared on equal footing.

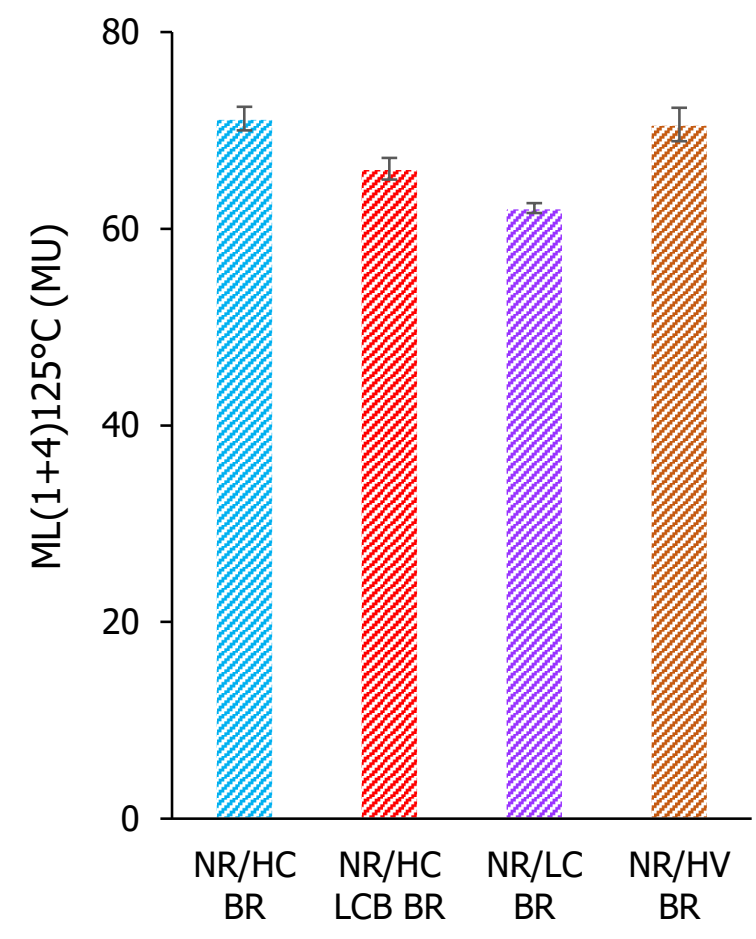

Figure 6.7 MV of CB/SI-filled NR/BR compounds.

Figure 6.8 shows the PE of the still unvulcanized compounds containing NR blends with the different types of BR. Branching improves the processability of HC LCB BR, as it enhances elastic over viscous behavior during mixing. This should result in less remaining filler-filler interaction and as a consequence better filler dispersion. HC LCB BR indeed shows the lowest $P E$ as an indication for remaining filler-filler interaction: Figure 6.8. The NR/HV BR blend shows the highest PE: This might be due to a low silanization efficiency between SI and silane in this high 1,2-vinyl containing elastomer, as cis-1,4 units are more reactive than trans-1,4 and 1,2vinyl units. 

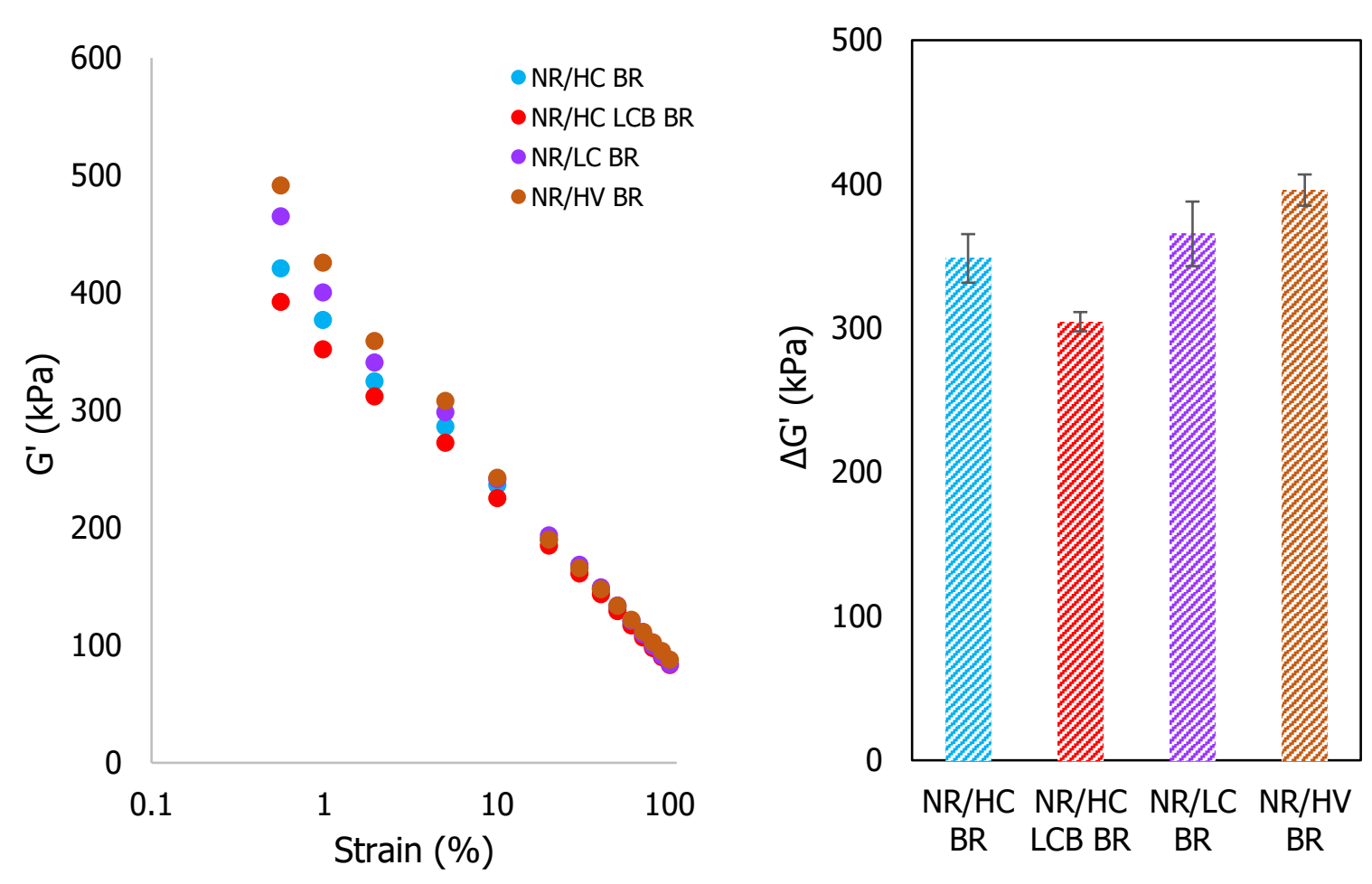

Figure 6.8 PE of CB/SI-filled NR/BR compounds.

Figure 6.9 shows the effect of BR types on filler-polymer interaction (as opposed to filler-filler interaction) measured as bound rubber. In compounds containing SI, the use of a silane coupling agent is essential to achieve a high SI dispersion resulting from reduced fillerfiller interaction, and a good reinforcing effect by overcoming the low compatibility between rubber and SI. NR/HC BR and NR/HC LCB BR show a higher bound rubber content, thus better interaction with the fillers CB and SI compared to NR/HV BR. The coupling agent TESPT apparently has a higher reactivity towards a polymer having a higher content of cis-1,4moieties than having 1,2-vinyl-moieties. NR/LC BR has the lowest bound rubber because LC BR has a high percentage of trans-1,4 moieties: The trans-1,4-unit has a lower reactivity than the cis-1,4-unit. The reason for this is that the trans-1,4 unit is thermodynamically more stable [21]. This finding is also in line with a model study from Sato, who found that a model olefin (cis-3-hexene) with cis-structure has higher reactivity with TESPT than the one with a vinyl structure (3-methyl-1-pentene) [22]. Another possible explanation is that the star-branched architecture of LC BR creates more steric hindrance for the polymer to attach to the SI surface for silanization. The results of bound rubber are in line with the results of the PE. 


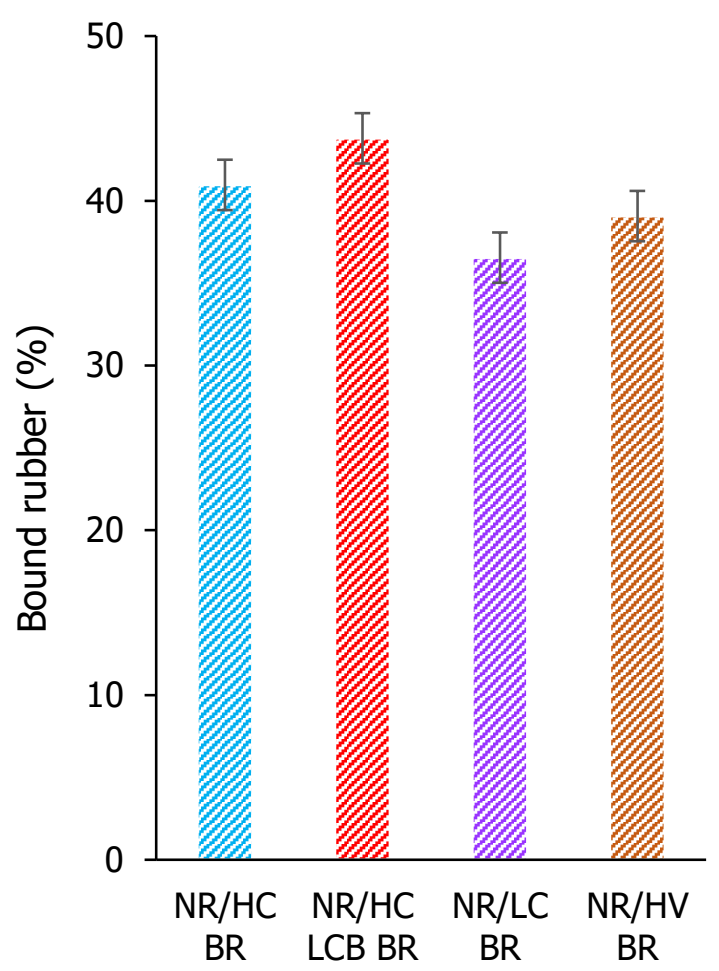

Figure 6.9 Bound rubber content of CB/SI-filled NR/BR compounds.

Figure 6.10 shows the vulcanization curves and Table 6.7 shows the cure characteristics of the compounds with different types of BR. The different types of BR do not show clear differences in scorch times $\left(\mathrm{ts}_{2}\right)$. With the content of 1,2-vinyl-units in the structure of BR increasing, the optimum vulcanization time ( $\left.t_{90}\right)$ increases: HV BR with a vinyl-content of $77 \mathrm{wt} \%$, compared to LC BR with $11 \mathrm{wt} \%$, has a slightly longer optimum cure time $\left(\mathrm{t}_{90}\right)$. Compared to the high-cis BR counterparts, which by definition have a low vinyl content, the former two require a significantly longer vulcanization time. This indicates preferential participation of the 1,4-cis-units in the reaction with sulfur-containing systems, thus resulting in a faster vulcanization of high-cis rubber compared to high 1,2-vinyl rubber. All types of BR show the same torque difference at the end of their vulcanization period.

Table 6.7 Curing characteristics of compounds.

\begin{tabular}{|l|r|r|r|r|}
\hline \multicolumn{1}{|c|}{ Characteristics } & NR/HC BR & NR/HC LCB BR & NR/LC BR & NR/HV BR \\
\hline Scorch time, $\mathrm{ts}_{2}(\mathrm{~min})$ & 3.2 & 3.2 & 3.6 & 3.5 \\
\hline Cure time, $\mathrm{t}_{90}(\mathrm{~min})$ & 7.3 & 7.1 & 8.6 & 11.2 \\
\hline Cure rate index, CRI $\left(\mathrm{min}^{-1}\right)$ & 24.4 & 25.6 & 20.0 & 13.0 \\
\hline $\mathrm{S}_{\min }(\mathrm{dN} . \mathrm{m})$ & 2.8 & 2.6 & 2.6 & 2.6 \\
\hline $\mathrm{S}_{\max }(\mathrm{dN} . \mathrm{m})$ & 18.0 & 17.9 & 17.2 & 17.6 \\
\hline $\mathrm{S}_{\max }-\mathrm{S}_{\min }(\mathrm{dNm})$ & 15.2 & 15.3 & 14.6 & 15.0 \\
\hline
\end{tabular}




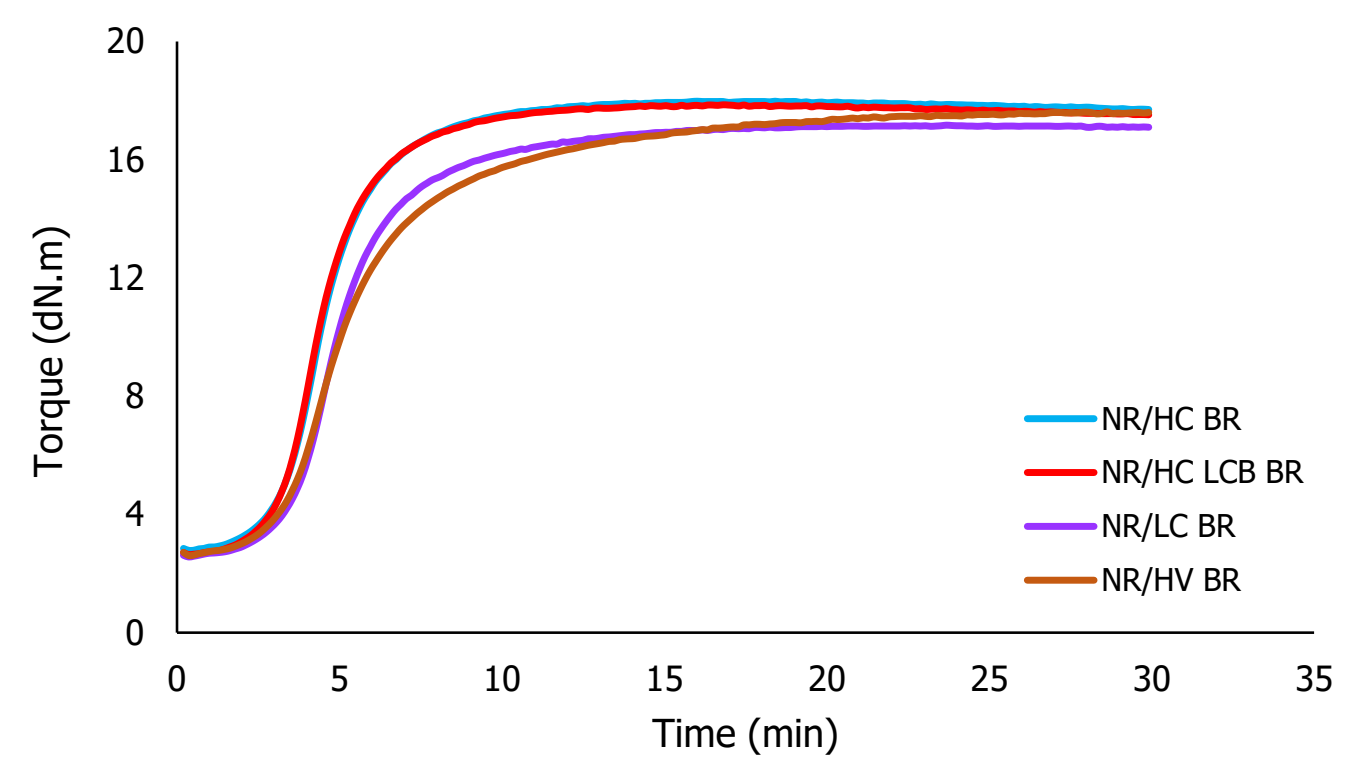

Figure 6.10 Vulcanization curves of $\mathrm{CB} / \mathrm{SI}$-filled NR/BR compounds at $150^{\circ} \mathrm{C}$.

Figure 6.11 depicts the apparent crosslink densities of the blends after vulcanization. Due to the preferential reaction of sulfur with the cis-1,4-units of $B R$ and high filler-rubber interaction, the blends of NR with the high-cis BRs (NR/HC BR and NR/HC LCB BR) show a higher apparent crosslink density compared to the other blends (NR/LC BR and NR/HV BR).

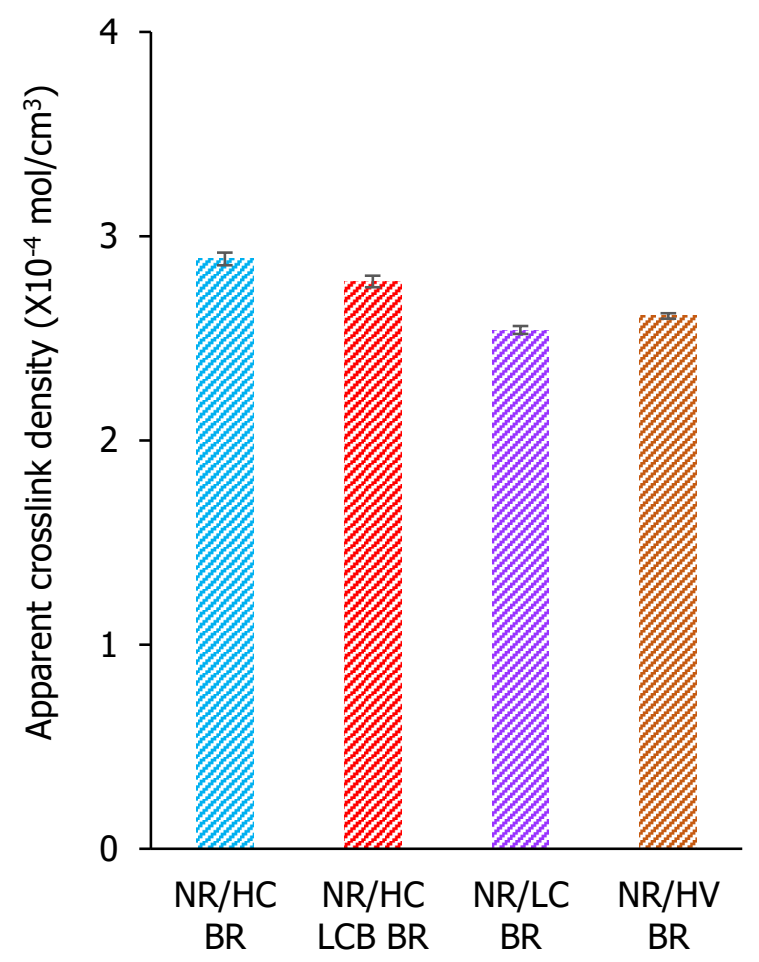

Figure 6.11 Apparent crosslink density of $\mathrm{CB} / \mathrm{SI}$-filled NR/BR vulcanizates cured at $150^{\circ} \mathrm{C}$. 


\subsubsection{MECHANICAL PROPERTIES}

The stress-strain properties of vulcanizates containing different types of BR are shown in Figure 6.12. The properties show small differences. The tensile strength, $\mathrm{M} 300 \%$, and elongation at break (EAB) of the vulcanized blends with high-cis BRs are slightly higher due to the slightly higher filler-polymer interactions: Figure 6.9 and apparent crosslink density: Figure 6.11.
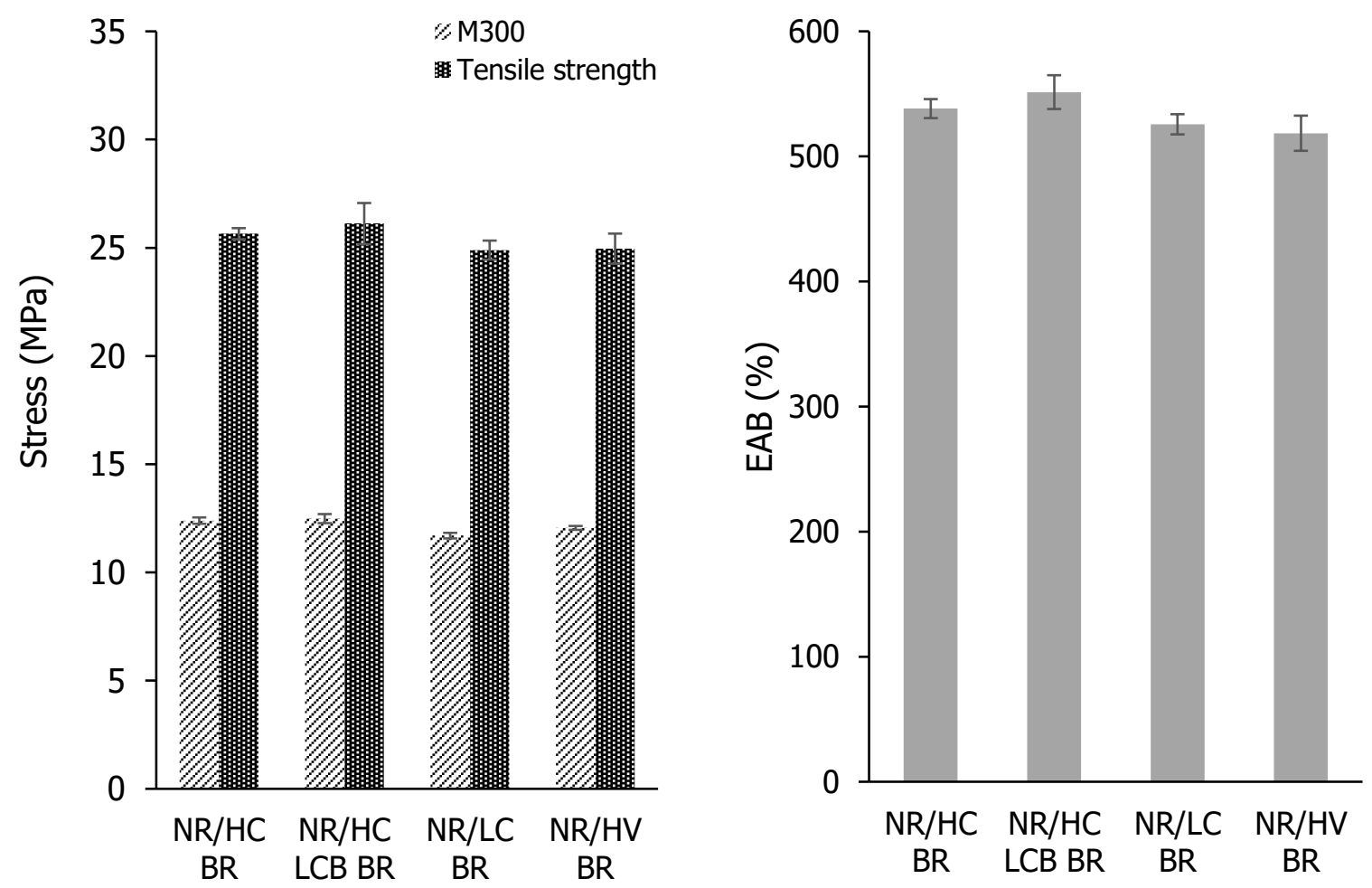

Figure 6.12 Mechanical properties of CB/SI-filled NR/BR vulcanizates.

\subsubsection{VISCOELASTIC PROPERTIES OF CB/SI-FILLED NR/BR BLENDS 6.3.4.3.1 CB/SI-FILLED NR/BR COMPOUNDS}

Figure 6.13 shows the $\mathrm{G}^{\prime}, \mathrm{G}^{\prime \prime}$, and tan $\delta$ of $\mathrm{CB} / \mathrm{SI}$-filled uncured NR/BR compounds measured at $100^{\circ} \mathrm{C}$. The addition of filler reduces the $\mathrm{G}^{\prime}$ differences between the types of $B R$. The $G^{\prime \prime}$ of NR/HV BR is higher at low frequencies, but becomes lower as the frequency increases compared to the other blends: $\tan \delta$ of a filled-NR/HV BR compound shows a similar behavior as its unfilled counterpart. 
(a)

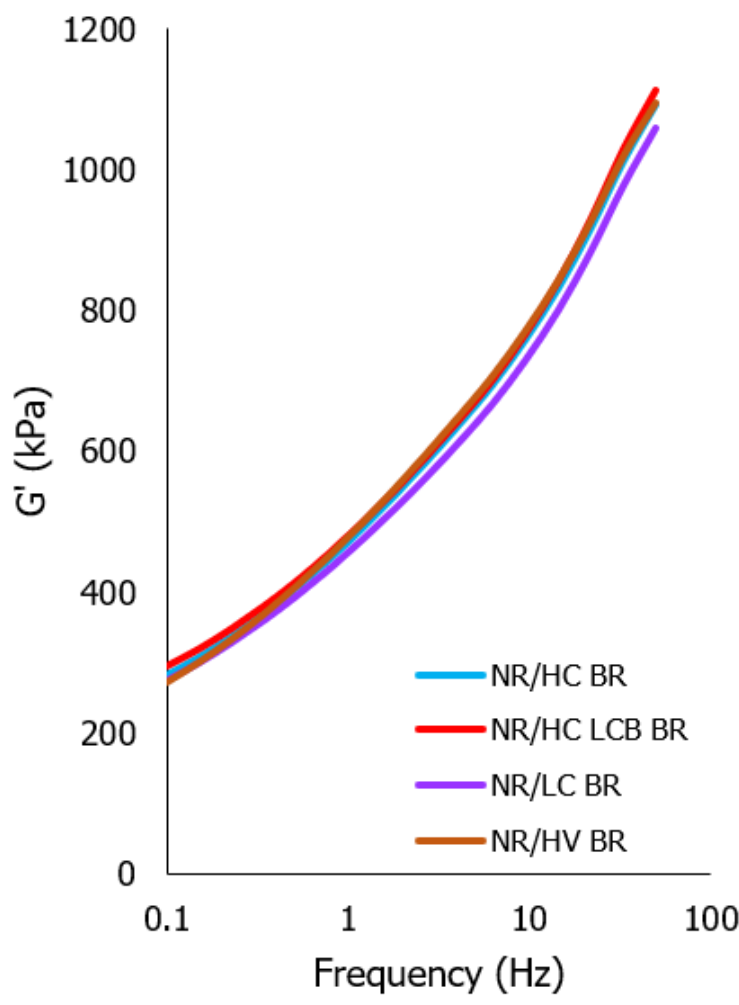

(b)

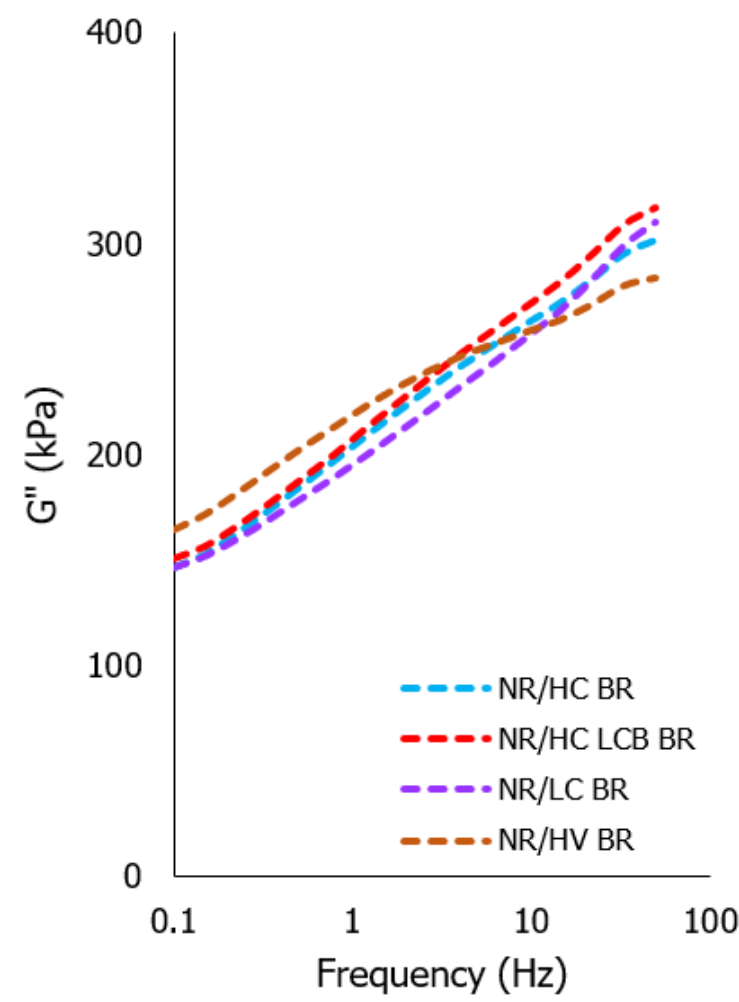

(c)

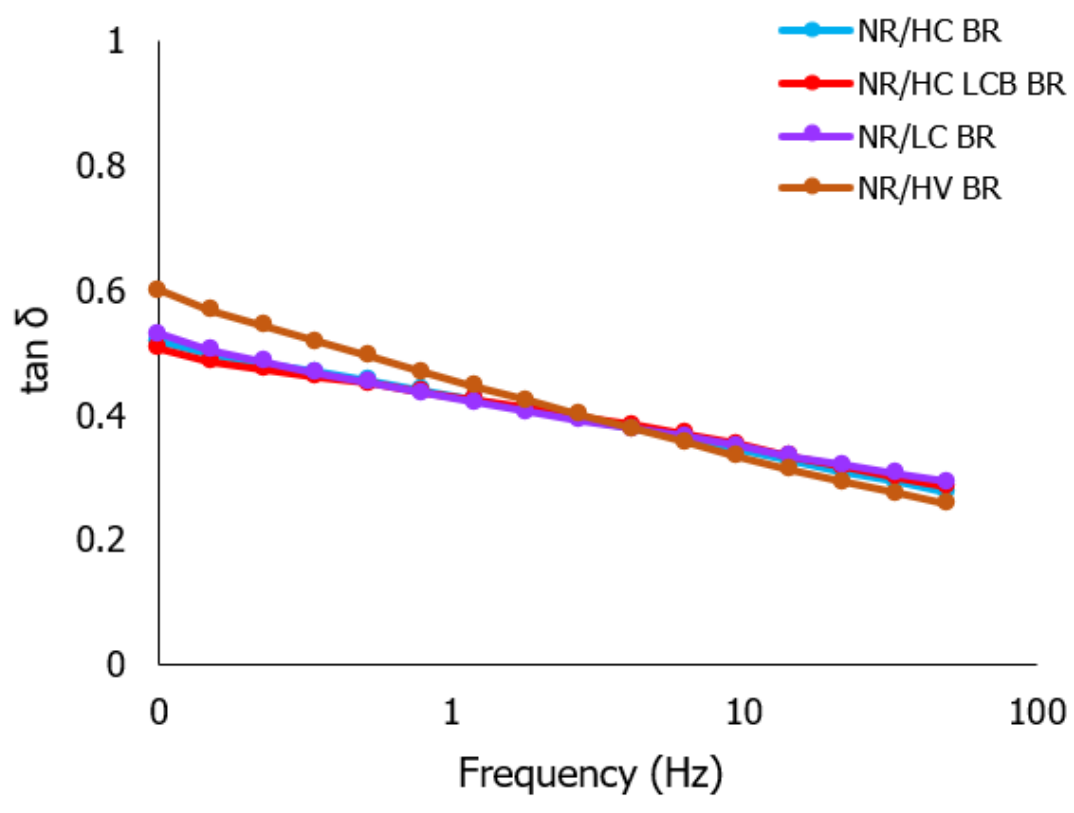

Figure 6.13 G' (a); G" (b); and tan $\delta(c)$ of CB/SI-filled NR/BR compounds measured at $100^{\circ} \mathrm{C}$. 


\subsection{CB/SI-FILLED NR/BR VULCANIZATES}

Figure 6.14 (left) depicts $G^{\prime}, G^{\prime \prime}$ and tan $\delta$ of CB/SI-filled NR/BR vulcanizates (cured at $150^{\circ} \mathrm{C}$ ) measured at $100^{\circ} \mathrm{C}$. The NR/HV BR vulcanizate shows a significantly lower $\mathrm{G}^{\prime}$ and higher $G^{\prime \prime}$ as frequency increases compared to the other blends. High filler-filler interaction, low filler-rubber interaction, and more so low apparent crosslink density are responsible for high $G^{\prime \prime}$ and $\tan \delta$. NR/HC BR and NR/HC LCB BR show lower G" hence a low tan $\delta$. NR/HC LCB BR shows just a slightly lower tan $\delta$ at low frequency than NR/HC BR due to the branching.

Figure 6.14 (right) shows the viscoelastic properties of CB/SI-filled NR/BR vulcanizates (cured at $150^{\circ} \mathrm{C}$ ) measured at $200^{\circ} \mathrm{C}$ to mimic the high temperatures generated in aircraft tire treads during landing. The $\mathrm{G}^{\prime}$ is the highest, while the $\mathrm{G}^{\prime \prime}$ of NR/HV BR is the lowest among these blends. At a temperature of $200^{\circ} \mathrm{C}$, the degradation of HV BR is dominated by recrosslinking of radicals. 1,2-vinyl units undergo more rapid re-crosslinking than the cis-1,4 and trans-1,4 units, which reflect in better reversion resistance: Figure 6.15, and higher apparent crosslink density: Figure 6.16 , than other BR types. The high crosslink density lowers the G" and $\tan \delta$ of $\mathrm{NR} / \mathrm{HV} \mathrm{BR}$ at $200^{\circ} \mathrm{C}$.
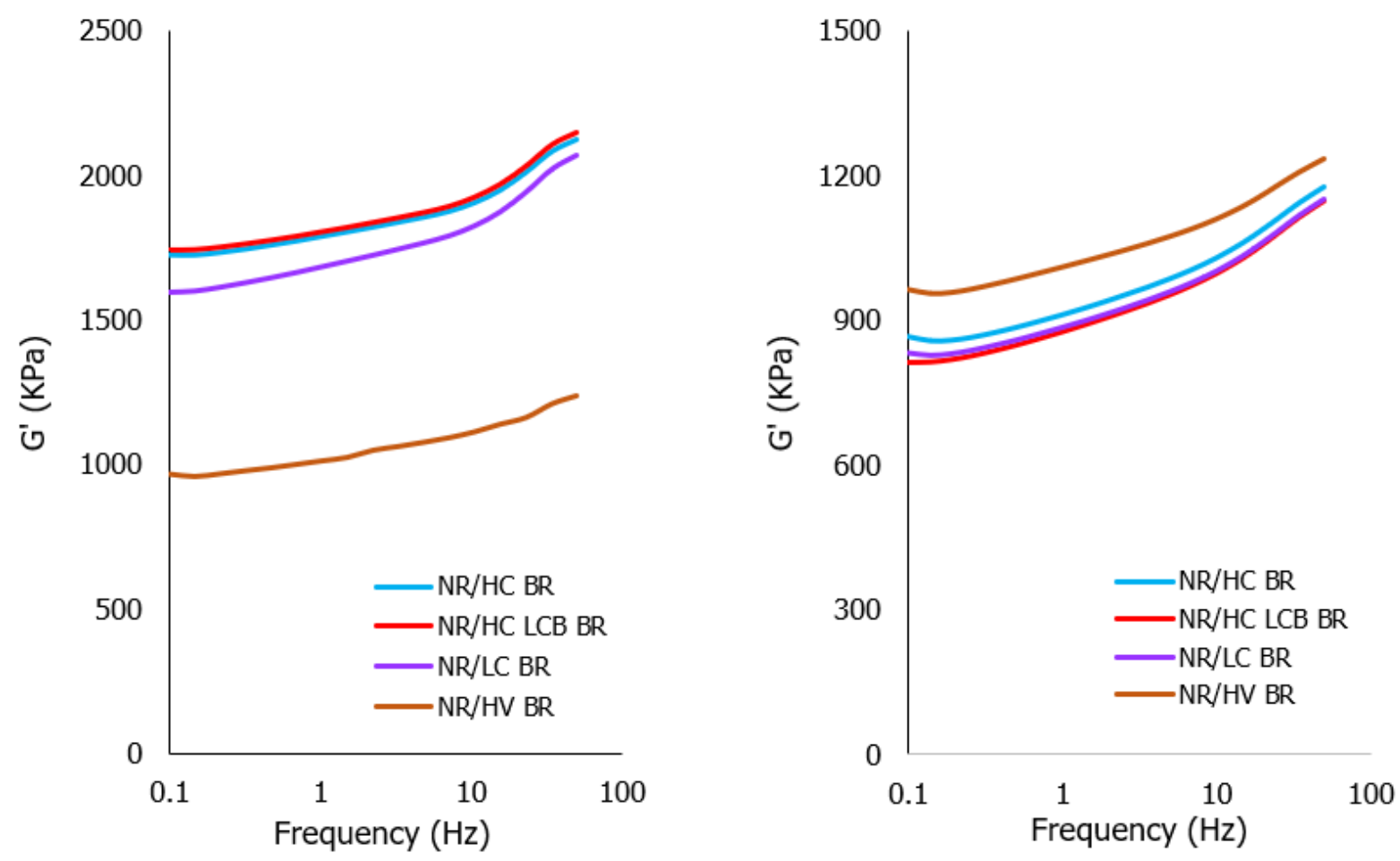

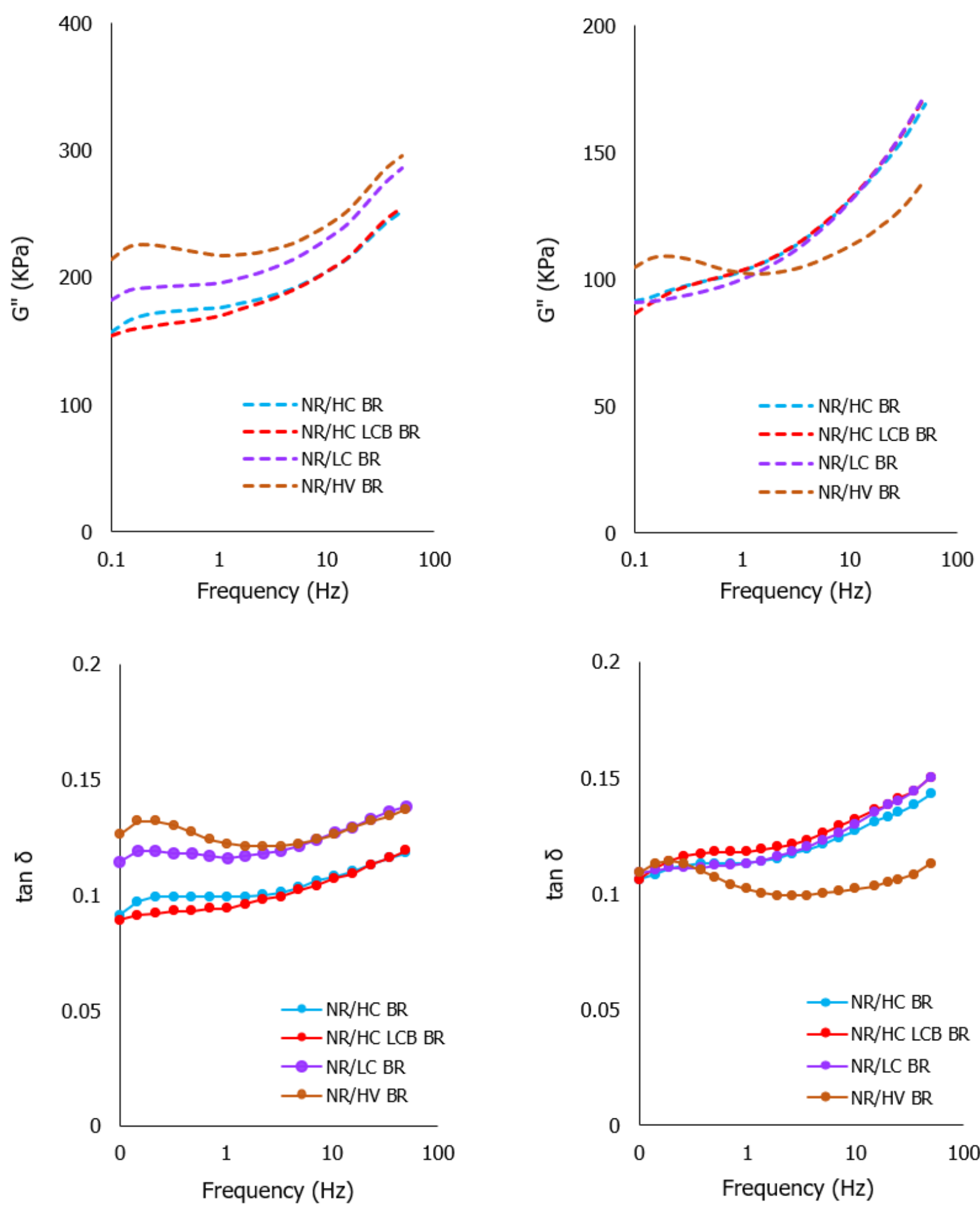

Figure 6.14 Dynamic properties ( $\mathrm{G}^{\prime}, \mathrm{G}^{\prime \prime}, \tan \delta$ ) of $\mathrm{CB} / \mathrm{SI}$-filled NR/BR vulcanizates (cured in situ at $150^{\circ} \mathrm{C}$ ) measured at: $100^{\circ} \mathrm{C}$ (left); $200^{\circ} \mathrm{C}$ (right). 


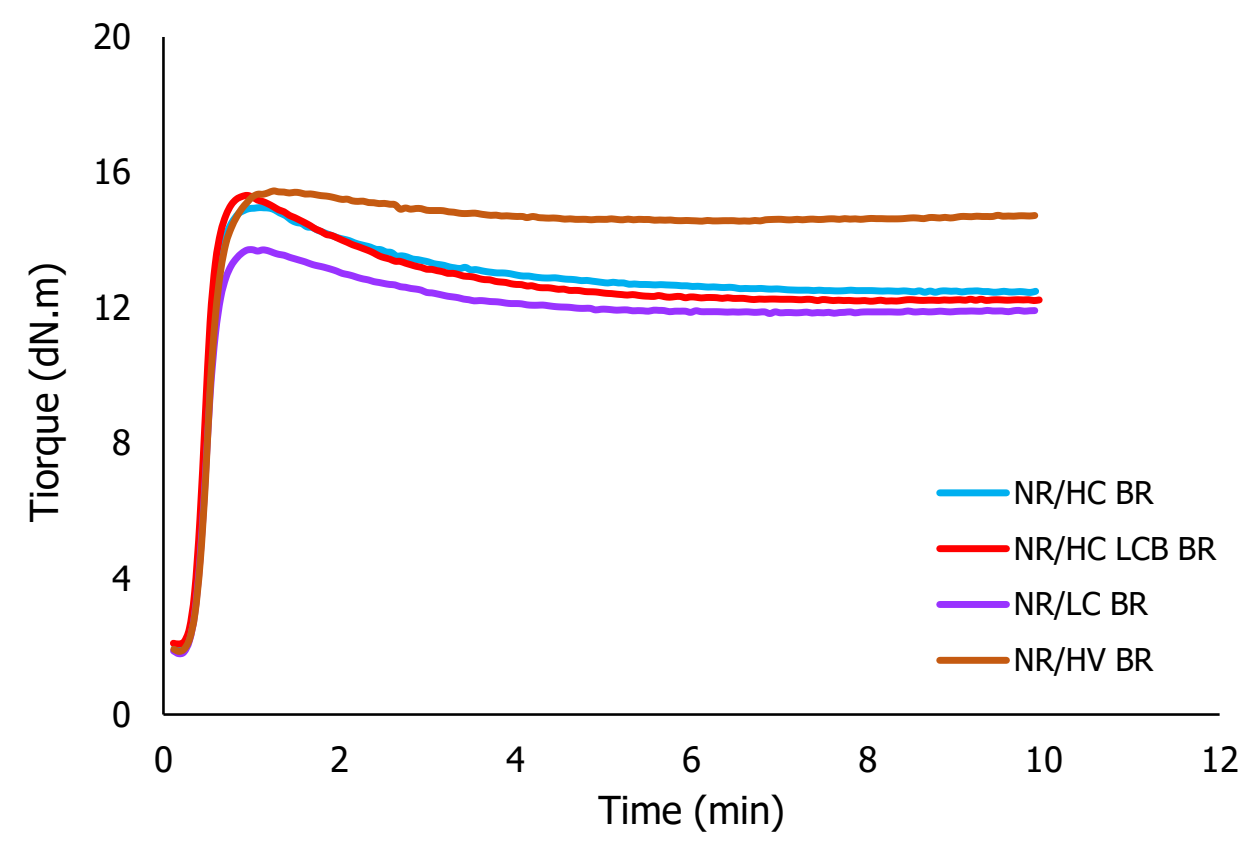

Figure 6.15 Cure curves of $\mathrm{CB} / \mathrm{SI}$ filled-NR/BR compounds at $200^{\circ} \mathrm{C}$.

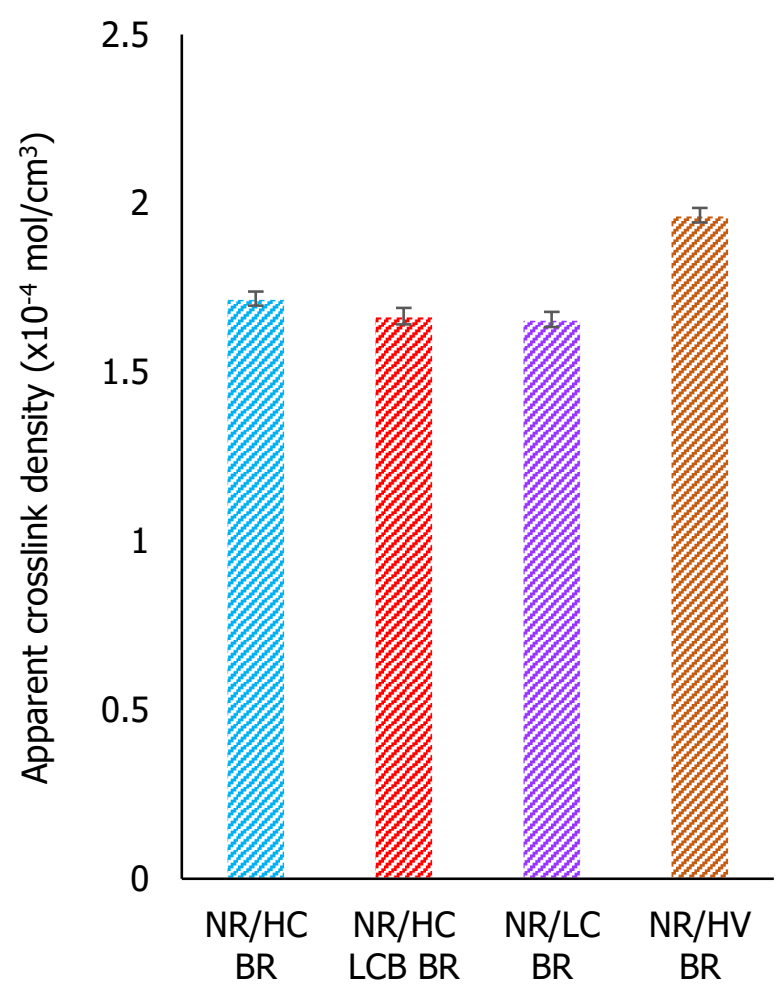

Figure 6.16 Apparent crosslink density of CB/SI-filled NR/BR vulcanizates at $200^{\circ} \mathrm{C}$.

Figure 6.17 shows tan $\delta$ as a function of temperature measured by a DMA for the $\mathrm{CB} / \mathrm{SI}$-filled NR/BR vulcanizates. All blends except NR/HV BR show a small shoulder and $\tan \delta$ peak more or at less the same temperature around $-90^{\circ} \mathrm{C}$. The small shoulders correspond to the $\mathrm{Tg}$ of the cis- and trans-configurations in the minor portions of BR (30 phr) [23]. The large $\tan \delta$ peaks correspond to the $\mathrm{Tg}$ of NR (70 phr): Table 6.8. For the NR/HV BR blend there is only one peak visible, which indicates that these two polymers are miscible. The $\mathrm{Tg}$ of NR is 
$-65^{\circ} \mathrm{C}$ and $\mathrm{HV}$ BR is $-31^{\circ} \mathrm{C}$. Using the Fox equation: see Equation 2.4 , Chapter 2 , the theoretical $\mathrm{Tg}$ blend is $-49^{\circ} \mathrm{C}$, while based on the DMA measurement, the $\mathrm{Tg}$ is approximate $-44^{\circ} \mathrm{C}$. A compatible blend would have a single $\mathrm{Tg}$ lying somewhere in between the $\mathrm{Tg}(\mathrm{s})$ of the two constituent polymers [24].

Table 6.9 shows that NR/HV BR has the highest tan $\delta$ peak temperature, but still in the sub-zero region, indicative for best ICT and WSR of tire treads made thereof. At a temperature of $100^{\circ} \mathrm{C}$, the tan $\delta$ of $\mathrm{NR} / \mathrm{HV}$ BR is still slightly higher which indicates a little higher $\mathrm{HBU}$ compared to the other types of BR.

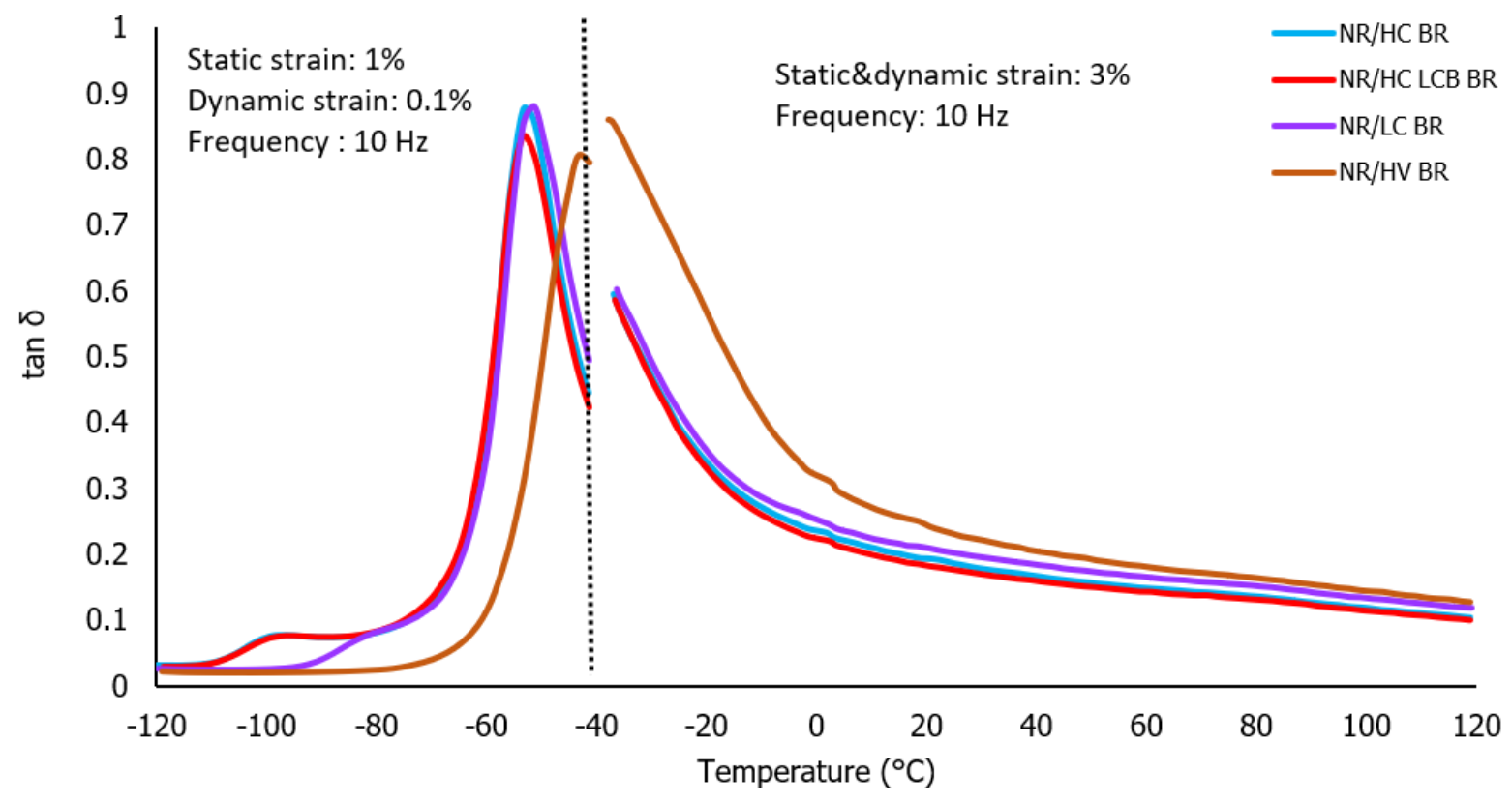

Figure 6.17 Tan $\delta$ of CB/SI-filled NR/BR vulcanizates in a temperature sweep measured by DMA.

Table 6.8 $\mathrm{Tg}$ of CB/SI-filled NR blends with different types of BR.

\begin{tabular}{|l|c|c|}
\hline \multicolumn{1}{|c|}{ Rubber } & $\begin{array}{c}\text { tan } \mathbf{\delta} \text { of small shoulder BR } \\
\left({ }^{\circ} \mathbf{C}\right)\end{array}$ & $\begin{array}{c}\text { Tan } \mathbf{~} \text { peak } \\
\text { NR }\left({ }^{\circ} \mathbf{C}\right)\end{array}$ \\
\hline NR/HC BR & -96 & -53 \\
\hline NR/HC LCB BR & -96 & -53 \\
\hline NR/LC BR & -82 & -51 \\
\hline NR/HV BR & \multicolumn{2}{|c|}{-44} \\
\hline
\end{tabular}


Table 6.9 Loss tangent at different temperatures of CB/SI-filled NR/BR vulcanizates.

\begin{tabular}{|l|c|c|c|}
\hline \multicolumn{1}{|c|}{ Blend } & $\begin{array}{c}\text { Ice grip } \\
\tan \mathbf{\delta}-\mathbf{3 0}^{\circ} \mathbf{C}\end{array}$ & $\begin{array}{c}\text { Wet skid } \\
\tan \mathbf{\delta} \mathbf{5}^{\circ} \mathbf{C}\end{array}$ & $\begin{array}{c}\text { Heat build-up } \\
\tan \mathbf{\delta} \mathbf{1 0 0} \mathbf{C}\end{array}$ \\
\hline NR/HC BR & 0.49 & 0.22 & 0.12 \\
\hline NR/HC LCB BR & 0.48 & 0.21 & 0.11 \\
\hline NR/LC BR & 0.51 & 0.24 & 0.13 \\
\hline NR/HV BR & 0.76 & 0.29 & 0.14 \\
\hline
\end{tabular}

\subsection{CONCLUSIONS}

Four different types of BR as single polymers and in blends with NR were studied concerning their influence on processing, mechanical and dynamic properties. In their nature, HC BR and HC LCB BR show a slight difference in $G^{\prime \prime}$, hence low tan $\delta$ at low frequencies due to branching in the HC LCB BR. LC BR having a star-branched architecture shows no difference in $\tan \delta$ in a frequency sweep due to no difference in $\mathrm{G}^{\prime}$ as well as $\mathrm{G}^{\prime \prime}$ as the frequency increases, typical for strongly branched polymers. An essentially linear HV BR in its nature shows a high $\tan \delta$ at low frequency and low $\tan \delta$ at high frequency, signaling a prevalence of viscous behavior over elastic. In the unfilled blends with NR, the BRs still inherit the viscoelastic behavior of their pure elastomers, only that the magnitudes become lower than for the pure rubber because of the dilution effect.

When fillers are introduced into the blends, not only the nature of the polymers, but also the interaction between the fillers and the polymers influence the final properties. NR/HC $B R$ and NR/HC LCB BR reinforced with CB/SI show a fast optimum cure time ( $\left.t_{90}\right)$, high reinforcement as well as high apparent crosslink density, and low tan $\delta$ at $100^{\circ} \mathrm{C}$. Cis- 1,4 units have the highest reactivity towards the silane coupling agent, leading to lower filler-filler interaction, and correspondingly higher filler-rubber interactions compared to trans-1,4 and 1,2-vinyl units. However, at a temperature of $200^{\circ} \mathrm{C}$, which can be reached at the surface of AC tire treads during landing, NR/HV BR shows the lowest tan $\delta$. It can be explained by $a$ higher reversion resistance which leads to a higher crosslink density of NR/HV BR at the service temperature compared to the other types of BR. This evidence reveals the potential use of HV BR blends with NR for AC tire retread applications, since it provides a low tan $\delta$ at $200^{\circ} \mathrm{C}$, signaling a low HBU. 


\subsection{REFERENCES}

1. Schilling, B. and Barnes, J.R., Introductory Review of Wear and Friction, in Conference on "Friction and Wear in Tyres", Waltham Abbey, UK (1968).

2. Polybutadiene - Properties, Applications, Processing and Types of Polybutadiene (BR), Available online: https://www.azom.com/article.aspx?ArticleID=1719 (accessed on 11 June 2018).

3. Halasa, A.F. and Massie, J.M., in Kirk Othmer Encyclopedia of Chemical Technology, Polybutadiene, John Wiley \& Sons (2000).

4. Halasa, A.F., Preparation and Characterization of Solution SIBR via Anionic Polymerization, Rubber Chem. Technol., 70, 3, 295 (1997).

5. Yuichi, K. and Junichi, Y., Modified Butadiene Polymer, Method for Producing the Same, Rubber Composition and Tire, to Asahi Kasei Chemicals Corp, JP2013245248A (2013).

6. Rubber Process Analyzer: Bridging the Gap Between Polymer and Compound Rheological Properties and True Material Processing on the Shop Floor, Available online: http://www.tainstruments.com/wp-content/uploads/TA-Instruments-CUICARpresentation-201609-RPA-Compound-Properties.pdf (accessed on 15 June 2019).

7. Using the Large Amplitude Oscillatory Shear (LAOS) Method to Characterize Polymer Long Chain Branching, Available online: https://www.tainstruments.com/pdf/ literature/RT006.pdf (accessed on 21 Feb. 2021).

8. Glass Transition by DMA, Available online: http://www.campoly.com/files/ 6114/2850/4047/035_Glass_Transition_by_DMA_ADMIN-0243_v2.0.pdf (accessed on 6 March 2019).

9. Measurement of the Glass Transition Temperature Using Dynamic Mechanical Analysis, Available online: http://www.tainstruments.com/pdf/literature/TS64.pdf (accessed on 7 March 2019).

10. Steric Arrangement in Cis and Trans Configuration, Available online: http://polymerdatabase.com/polymer\%20physics/Cis-Trans.html\#: :text=Steric \%20Arrangement\%20in\%20Cis\%20and\%20Trans\%20Configuration\&text=These $\% 2$ 0two\%20isomers\%20are\%20called,of\%20the\%20central\%20double\%20bond (accessed on 7 March 2019).

11. Hua, J., et al., Effect of Vinyl and Phenyl Group Content on the Physical and Dynamic Mechanical Properties of HVBR and SSBR, Appl. Polym. Sci, 135, 12, 1 (2017).

12. Brydson, J.A., in Plastic Materials, Chapter 11: Aliphatic Polyolefins other than Polyethylene, and Diene Rubbers, 7th ed., Elsevier Ltd (1999).

13. Kaszas, G., Effect of Branching on the Rheological Properties of Butyl Elastomer, Kautsch. Gummi Kunstst., 56, 32 (2003).

14. Roovers, J., Linear Viscoelastic Properties of Polybutadiene: A Comparison With Molecular Theories, Polym. Journal, 18, 2, 153 (1986).

15. Rahalkar, R.R. and Tang, H., Prediction of Zero-Shear Viscosity of Linear Polybutadienes from the Crossover Point Using Doi-Edwards Theory, Rubber Chem. Technol., 61, 5, 812 (1988).

16. Lobos, Z.J. and Tang, H., Rheological Determination of Molecular Weight and Molecular-Weight Distribution for Commercial-Type Butyl Elastomers, Rubber Chem. Technol., 62, 4, 623 (1989).

17. Kaszas, G., Processability Characteristics of Linear and Branched Butyl Rubber, Kautsch. Gummi Kunstst., 55, 438 (2002).

18. Winter, H.H. and Chambon, F., Analysis of Linear Viscoelasticity of a Crosslinking Polymer at the Gel Point, J. Rheology, 30, 2, 367 (1986).

19. Chambon, F. and Winter, H.H., Linear Viscoelasticity at the Gel Point of a Crosslinking PDMS with Imbalanced Stoichiometry, J. Rheology, 31, 8, 683 (1987). 
20. Booij, H.C., Long-Chain Branching and Viscoelasticity of Ethylene-Propylene-Diene Elastomers, Kautsch. Gummi Kunstst., 44, 128 (1991).

21. Versloot, P., et al., Sulfur Vulcanization of Simple Model Olefins, Part V: Double Bond Isomerization during Accelerated Sulfur Vulcanization as Studied by Model Olefins, Rubber Chem. Technol., 70, 1, 106 (1997).

22. Sato, M., Reinforcing Mechanisms of Silica/ Sulfide-silane vs. Mercapto-silane Filled Tire Tread Compound, PhD thesis, Elastomer Technology and Engineering, University of Twente, The Netherlands (2018).

23. Chiu, H.T., et al., A Study of Rheological Behavior and Compatibility of NR/BR Blends, Polym. Plast. Technol., 45, 7, 845 (2007).

24. Corish, P.J., Fundamental Studies of Rubber Blends, Rubber Chem. Technol., 40, 2, 324 (1967). 


\title{
INCORPORATION OF RESINS FOR IMPROVING THE PROPERTIES OF AIRCRAFT TIRE RETREADS*
}

\begin{abstract}
This study focuses on the use of oligomeric resins in order to benefit from their effect on improving the performance of aircraft tire retreads. The aim was to enhance the tackiness for the retreading process and their final performance in terms of superior stress-strain properties and low heat generation in order to decrease treadwear; thus increasing the tire's service life, and in terms of traction or skid resistance to improve safety during landing of an aircraft. Two types of resins are investigated: a terpene phenol and an aromatic hydrocarbon C9 resin, added to compounds with different filler systems: Carbon Black (CB), hybrid Carbon Black/Silica (CB/SI), and pure Silica (SI). The rubber compounds and vulcanizates are compared to their controls for each filler system.
\end{abstract}

The use of resins improves processing independent of the filler system, with a slight improvement of tensile strength, Modulus at 300\% (M300\%) and Elongation at Break (EAB). The incorporation of resins improves the tackiness for the compounds with all filler systems, which is beneficial for the retreading process. A significant improvement in Ice Traction (ICT) and Wet Skid Resistance (WSR) with a trade-off in Heat Build-Up (HBU) is observed in CBand $\mathrm{CB} / \mathrm{SI}$-reinforced compounds when resins are added. Terpene phenol and aromatic hydrocarbon resin show comparable ICT, while the aromatic hydrocarbon C9 resin gives a better WSR performance than the terpene phenol in all compounds. However, a slight improvement in $\mathrm{HBU}$ with the use of both resins is only observed in the SI-filled system.

The present exploratory study into the addition of resins demonstrates the potential to significantly improve the overall performance or aircraft tire retreads, justifying more indepth investigations into this possibility in real tires. 


\subsection{INTRODUCTION}

Aircraft (AC) tires are used in different stages; these can be divided into taxiing, takeoff, and landing. During taxiing, the speed is relatively low, and therefore the tire temperature increases only slightly. During takeoff and landing, the temperature in the tread increases considerably due to high-speed friction between tire and runway [1]. However, the landing phase is the most burdensome and therefore defines the design specifications of the tire [2]. At the first touch between the tire and the runway, the tire has no rotational speed. Therefore, the tire heats up instantaneously, generates smoke from degraded rubber, and blackens the runway [3].

For AC tire/retreaded tire manufacturing, the demand is to increase service life without many changes in the existing formulation and processing. From a compounding point of view, the selection of polymers, fillers, and other additives is crucial to address the Heat Build-Up (HBU) problem in AC tire treads and minimize trade-offs. Additives are generally used at relatively low levels to fine-tune the tread performance.

Resins are used in the rubber industry as processing aids, tackifiers, curing agents, and reinforcing agents [4]. In the past, resins were used to lower viscosity, enhance tackiness and green strength of uncured compounds as well as to improve mechanical properties of the vulcanizates. Tack is the ability of two materials to resist separation after bringing the surfaces into contact for a short time under light pressure [5]. In order for a rubber compound to exhibit high tack, three conditions must be fulfilled:

1) Intimate molecular contact between the two surfaces,

2) Interdiffusion of polymeric chains across the interface,

3) The bond must be capable of resisting high stress before rupture [6].

In order to increase the contact area, the material must perform viscous flow. However, increasing contact area and interdiffusion are not enough to achieve high tack. The third condition must also be met, which requires sufficient green strength. Green strength is the ability of rubber compounds to resist deformation and fracture before vulcanization. The contact and interdiffusion might be achieved using a process oil, but it is inferior to cohesive strength and hence produces little tack. In contrast, hard brittle solids such as resins, have high cohesive strengths. Only polymeric materials above their glass transition temperature $(\mathrm{Tg})$ can exhibit good tack because they provide a proper balance between molecular mobility needed to achieve bond formation and cohesive strength to resist rupture. Resins fulfill these requirements and are therefore known as tackifiers.

Today, resins are used in tire manufacturing, especially Passenger Car Tires (PCT), to enhance the viscoelastic properties. The use of resins in Silica (SI)-filled PCT results in an improvement in traction, handling, treadwear, and rolling resistance. It is crucial to understand 
how the different types of resins affect the viscoelastic properties of the rubbers in order to tailor the tire properties.

Table 7.1 shows the types of resin used in the rubber industry. Reactive resins, for example resole-phenol-formaldehyde resins, react with unsaturated bonds in the polymer chains, improving heat and moisture resistance, but reducing flexibility. When a non-reactive resin is compatible with rubber, the polymer entanglement density decreases, which results in improved processability and decrease of the modulus of vulcanizates [7]. A softer rubber compound provides better surface contact with the substrate and increases tackiness.

A compatible and non-reactive hydrocarbon resin increases the $\mathrm{Tg}$ of a compound compared to the neat rubber [8]. The higher $\mathrm{Tg}$ of the compound raises the $\tan \delta$ value at $0^{\circ} \mathrm{C}$ by more viscoelastic damping and thus improves the wet traction characteristics of tire treads built on basis of these compounds. Tan $\delta$ measured between $35-75^{\circ} \mathrm{C}$ is indicative of rolling resistance of tire treads: the higher, the more rolling loss, and this may slightly increase. At a temperature exceeding $100^{\circ} \mathrm{C}$, the tan $\delta$ of a resin-containing rubber is lower than the one of the control rubber without resin, which indicates low HBU: Figure 7.1. If the resin is partially compatible or if the loading of resin exceeds its miscibility level in the rubber compound, then a second peak from the resin is seen in the tan $\delta$ curve [7].

Table 7.1 Types of resin used in the rubber industry [7].

\begin{tabular}{|l|l|l|}
\hline \multicolumn{2}{|c|}{ Reactive resins } & \multirow{2}{*}{ Non-reactive resins } \\
\cline { 1 - 2 } \multicolumn{1}{|c|}{ Curing resins } & \multicolumn{1}{|c|}{ Reinforcing resins } & \\
\hline Phenol-formaldehyde & Phenol-formaldehyde & Phenol-formaldehyde \\
\hline Resole type & High styrene & Hydrocarbon resins \\
\hline & Methylene donors & Terpene derivatives \\
\hline & Resorcinol (formaldehyde) & Coumarone indene \\
\hline & Polybutadiene & Rosin derivatives \\
\hline & Styrene-acrylonitrile & Tall oil derivatives \\
\hline & Polyvinyl chloride & Phenol-acetylene condensation \\
\hline & & \\
\hline
\end{tabular}




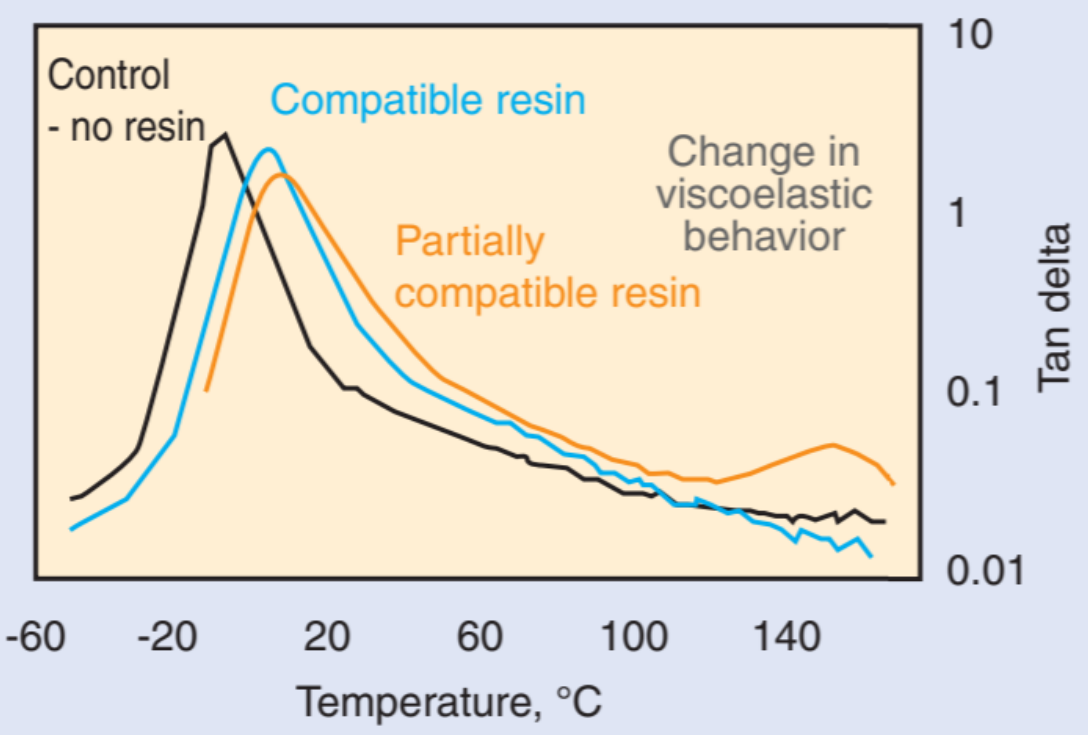

Figure 7.1 Effect of compatible vs. partially compatible resins on viscoelastic properties [7].

When designing rubber compounds with the use of resins, the properties of resins give valuable information about their suitability. The properties include:

- Softening point which is indicative of viscosity and controlled by the average molecular weight of the oligomeric material

- Glass transition temperature $(\mathrm{Tg})$

- Thermal stability

- Viscosity

- Solubility which depends on the resin type

- Average molecular weight

- Molecular weight distribution

- Compatibility which can be defined as having only one glass transition temperature. Compatibility depends on the resin type, molecular weight and its distribution, resin structure, and configuration. More details of the properties above are given in Chapter 2.

It is challenging to manipulate the performance balance of traction, treadwear, and rolling resistance of tires. These three properties are commonly referred to as the magic triangle for improving passenger car/truck tire performance. In AC tires, the properties of interest are low heat generation in the tread since this tire part is prone to temperature increase due to the extreme conditions. High temperatures are detrimental to tire properties: It can decrease the strength and accelerate treadwear. Therefore, it is crucial to develop a compound formulation with low hysteresis while maintaining other required properties. This chapter will explore how the use of resins helps to enhance the processing, tackiness and final properties of AC tire retreads. 


\subsection{EXPERIMENTAL}

\subsubsection{MATERIALS}

The elastomers used in this study were Ribbed Smoked Sheet (RSS-1) from Weber \& Schaer GmbH \& Co. KG, Germany, and High-Cis Long-Chain Branched Butadiene Rubber (HC LCB BR) from ARLANXEO, Germany. The polymers as well as all other rubber ingredients are described in Chapter 3. The resins employed were SYLVATRAXXTM products from Kraton Polymers Corp.: SYLVATRAXX 6720 is a Terpene Phenol (TP) resin, SYLVATRAXX 4401 is an aromatic hydrocarbon C9 resin (C9). The characteristic properties are given in Table 7.2. The structure of the resins is depicted in Figure 7.2. The properties of the Treated Distillate Aromatic Extract (TDAE) oil are given in Table 7.3. Table 7.4 shows the solubility parameters of polymers and resins used in this study.

Table 7.2 Resins used in this research $[9,10]$.

\begin{tabular}{|l|c|c|}
\hline \multicolumn{1}{|c|}{ Properties } & TP & C9 \\
\hline Main designation & Terpene phenol & Aromatic hydrocarbon \\
\hline Glass transition temperature, $\operatorname{Tg}\left({ }^{\circ} \mathrm{C}\right)$ & 68 & 39 \\
\hline Softening point $\left({ }^{\circ} \mathrm{C}\right)$ & $113-123$ & $82-88$ \\
\hline Density $\left(\mathrm{g} / \mathrm{cm}^{3}\right)$ & 1.03 & 1.06 \\
\hline Viscosity at $150^{\circ} \mathrm{C}(\mathrm{mPa} . \mathrm{s})$ & 3400 & 650 \\
\hline
\end{tabular}

(a)

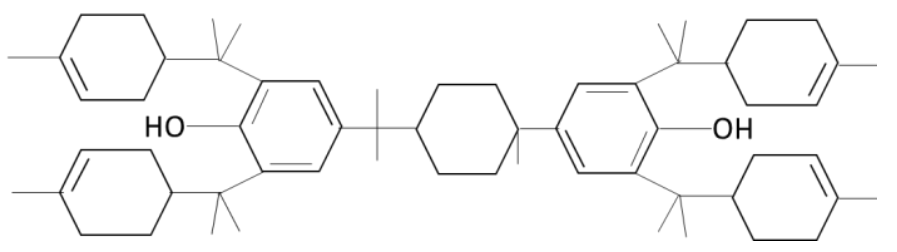

(b)<smiles>Cc1ccc(CCC(c2ccccc2)C(Cc2ccccc2)c2ccccc2C)cc1</smiles>

Figure 7.2 Structure of terpene phenol [11] (a); aromatic C9 resin [12] (b). 
Table 7.3 Properties of TDAE [13].

\begin{tabular}{|l|c|c|}
\hline \multicolumn{1}{|c|}{ Properties } & Standard test method & TDAE \\
\hline Color & ASTM D156 & $8.0 \mathrm{D}$ \\
\hline Density at $15^{\circ} \mathrm{C}\left(\mathrm{g} / \mathrm{cm}^{3}\right)$ & ASTM D1298 & 0.95 \\
\hline Density at $20^{\circ} \mathrm{C}\left(\mathrm{g} / \mathrm{cm}^{3}\right)$ & ASTM D1298 & 0.947 \\
\hline Kinematic viscosity at $40^{\circ} \mathrm{C}\left(\mathrm{mm}^{2} / \mathrm{s}\right)$ & ASTM D445 & 410 \\
\hline Kinematic viscosity at $100^{\circ} \mathrm{C}\left(\mathrm{mm}^{2} / \mathrm{s}\right)$ & ASTM D445 & 18.8 \\
\hline Sulfur (wt\%) & ISO 14596 & 0.8 \\
\hline Aniline point $\left({ }^{\circ} \mathrm{C}\right)$ & ASTM D611 & 68 \\
\hline Glass transition temp, $\mathrm{Tg}\left({ }^{\circ} \mathrm{C}\right)$ & IP346 & -48 \\
\hline
\end{tabular}

Table 7.4 Solubility parameters $(\delta)$ of polymers and resins.

\begin{tabular}{|c|c|c|c|}
\hline & $\begin{array}{c}\delta \\
(\mathrm{MPa})^{1 / 2}\end{array}$ & $\begin{array}{c}\delta^{*} \\
(\mathrm{MPa})^{1 / 2}\end{array}$ & $\begin{array}{c}\left|\delta *_{N R / B R}-\delta *_{\text {resin or oil }}\right| \\
(\mathrm{MPa})^{1 / 2}\end{array}$ \\
\hline Natural rubber (NR) & $16.3-17[14]$ & $17.8[15]$ & - \\
\hline Butadiene rubber (BR) & $16-17[14]$ & $17.7[15]$ & - \\
\hline NR/BR 70/30 & - & $17.7[15]$ & - \\
\hline Terpene Phenol (TP) & $16-23[15]$ & $20.2^{\mathrm{a}}[15]$ & 2.4 \\
\hline Aromatic hydrocarbon C9 (C9) & $18[16]$ & $19.4[15]$ & 1.6 \\
\hline TDAE & - & $17.2[13]$ & 0.5 \\
\hline
\end{tabular}

*: calculation of the Hildebrand parameter from group contributions of the molar vaporization energy $(\mathrm{U})$ and molar volume $(\mathrm{V})$ at $25^{\circ} \mathrm{C}$ from Table 2.12 , Chapter 2.

a: two molecules of terpene and one molecule of phenol are assumed. 
An example of the theoretical Hildebrand parameter $\delta^{*}$ of terpene phenol calculated from group contributions is shown in Table 7.5:

Table 7.5 Calculated solubility parameters $\left(\delta^{*}\right)^{a}$ of terpene phenol resin from group contributions.

\begin{tabular}{|c|c|c|c|c|c|}
\hline Group contributions & Number & $\begin{array}{c}\Delta U \\
(\mathrm{~kJ} / \mathrm{mol})\end{array}$ & $\begin{array}{l}\text { Total } \Delta U \\
(\mathrm{~kJ} / \mathrm{mol})\end{array}$ & $\begin{array}{c}V \\
\left(\mathrm{~cm}^{3} / \mathrm{mol}\right)\end{array}$ & $\begin{array}{c}\text { Total V } \\
\left(\mathrm{cm}^{3} / \mathrm{mol}\right)\end{array}$ \\
\hline$-\mathrm{CH}_{3}$ & 15 & 4.7 & 70.7 & 33.5 & 502.5 \\
\hline$-\mathrm{CH}_{2-}^{-}$ & 15 & 4.9 & 74.1 & 16.1 & 241.5 \\
\hline$=\mathrm{CH}-$ & 8 & 4.3 & 34.5 & 13.5 & 108.0 \\
\hline$>\mathrm{CH}-$ & 5 & 3.4 & 17.2 & -1.0 & -5.0 \\
\hline$>\mathrm{C}<$ & 6 & 1.5 & 8.8 & -19.2 & -115.2 \\
\hline$=\mathrm{C}<$ & 12 & 4.3 & 51.7 & -5.5 & -66.0 \\
\hline$-\mathrm{OH}$ & 1 & 29.8 & 29.8 & 10.0 & 10.0 \\
\hline Conjugated $=$ & 10 & 1.7 & 16.7 & -2.2 & -22.0 \\
\hline \multirow[t]{2}{*}{6 membered rings } & 7 & 1.1 & 7.4 & 16.0 & 112.0 \\
\hline & & & 310.8 & & 765.8 \\
\hline \multicolumn{5}{|c|}{$\delta *$ terpene phenol } & $20.2^{a}$ \\
\hline
\end{tabular}

a: two molecules of terpene and one molecule of phenol are assumed. 


\subsubsection{COMPOUND PREPARATION}

The compound formulations are shown in Table 7.6. The filler systems used in this research are Carbon Black (CB), a hybrid system of Carbon Black and Silica (CB/SI) and pure Silica (SI). All control compounds were formulated to obtain a comparable hardness. The control (C) compounds contain TDAE oil in the CB-filled, but no TDAE oil in the CB/SI- and SIfilled systems. TP are compounds with Terpene Phenol resin, and C9 indicates addition of the aromatic hydrocarbon C9 resin. A standard carcass formulation [17] was used as countersurface for green tack measurements.

Table 7.6 Compound formulations.

\begin{tabular}{|c|c|c|c|c|c|c|c|}
\hline \multirow[t]{2}{*}{ Ingredients } & \multirow[t]{2}{*}{ Carcass } & \multicolumn{2}{|c|}{ CB } & \multicolumn{2}{|c|}{ CB/SI } & \multicolumn{2}{|c|}{ SI } \\
\hline & & $\mathbf{C}$ & TP/C9 & C & TP/C9 & $\mathbf{C}$ & TP/C9 \\
\hline NR (RSS\#1) & 100 & \multicolumn{6}{|c|}{70} \\
\hline BR (HC LCB BR) & 0 & \multicolumn{6}{|c|}{30} \\
\hline CB (N234) & 25 & \multicolumn{2}{|c|}{55} & \multicolumn{2}{|c|}{35} & \multicolumn{2}{|c|}{0} \\
\hline $\begin{array}{c}\text { SI (ULTRASIL } \\
7005)\end{array}$ & 0 & \multicolumn{2}{|c|}{0} & \multicolumn{2}{|c|}{20} & \multicolumn{2}{|c|}{55} \\
\hline TESPT & 0 & \multicolumn{2}{|c|}{0} & \multicolumn{2}{|c|}{1.7} & \multicolumn{2}{|c|}{4.8} \\
\hline $\mathrm{ZnO}$ & 5 & \multicolumn{6}{|c|}{5} \\
\hline Stearic acid & 1 & \multicolumn{6}{|c|}{3} \\
\hline 6PPD & 1 & \multicolumn{6}{|c|}{2} \\
\hline TMQ & 1 & \multicolumn{6}{|c|}{1} \\
\hline Resin & 0 & 0 & 7.5 & 0 & 7.5 & 0 & 7.5 \\
\hline TDAE & 4 & 7.5 & 0 & 0 & 0 & 0 & 0 \\
\hline Sulfur & 2.5 & \multicolumn{6}{|c|}{1.5} \\
\hline CBS & 0.7 & \multicolumn{2}{|c|}{1.5} & \multicolumn{2}{|c|}{1.5} & \multicolumn{2}{|c|}{2} \\
\hline DPG & 0 & \multicolumn{2}{|c|}{0} & \multicolumn{2}{|c|}{0.4} & \multicolumn{2}{|c|}{1.1} \\
\hline
\end{tabular}

Amount of TESPT and DPG were calculated according to the following equations:

TESPT (phr) $=0.00053 \times \mathrm{Q} \times \mathrm{A}$ and DPG $(\mathrm{phr})=0.00012 \times \mathrm{Q} \times \mathrm{A}$

where $Q$ is the amount of silica (phr) and $A$ is the CTAB surface area of the silica $\left(171 \mathrm{~m}^{2} / \mathrm{g}\right)$

Mixing of the CB-filled compounds was performed using an internal mixer (Brabender Plasticorder 350s) with a mixer temperature initially set at $50^{\circ} \mathrm{C}$, a rotor speed of 130 revolutions per minute (rpm), and a fill factor of $70 \%$. NR was initially masticated prior to the addition of BR. The masticated NR and BR were blended for 1 minute (min). Then half of the $\mathrm{CB}$ and TDAE oil were added and mixed for $1 \mathrm{~min}$. After $1 \mathrm{~min}$, the other half of CB and TDAE oil were added and mixed for another 6 mins. Finally, all other ingredients: ZnO, stearic acid, 6PPD, and TMQ, were added and mixed for 2.5 mins. The compounds were dumped, sheeted out on a two-roll mill, and kept overnight before the incorporation of sulfur and CBS in the same internal mixer at a set temperature of $70^{\circ} \mathrm{C}$ and initial rotor speed of $50 \mathrm{rpm}$. For this, the masterbatch was mixed for $1 \mathrm{~min}$, the rotor speed was decreased to $30 \mathrm{rpm}$ before 
curatives were added, and the compound was mixed for another 2 mins. The detailed procedure is described in Chapter 3.

For CB/SI- and SI-filled compounds, the mixer temperature and rotor speed were set at $100^{\circ} \mathrm{C}$ and $60 \mathrm{rpm}$. The masticated NR and BR were blended. In CB/SI, silica and silane were added first and mixed for $1 \mathrm{~min}$. At the second addition, the CB was added with other rubber ingredients except for curatives. In SI-filled compounds, half silica and silane were added after mixing the rubber and the other half silica-silane and remaining ingredients except curatives at the second addition. The rotor speed was then adjusted/decreased to reach the temperature for silanization of $150^{\circ} \mathrm{C}$. The temperature of silanization was maintained for 7 mins and 9 mins for the CB/SI- and the Si-filled compounds, respectively. After 3 mins of silanization, the ram was opened for about $1 \mathrm{~min}$ to release ethanol produced in the silanization reaction. Then the compounds were dumped. The second stage of admixing the curatives was done according to the same procedure as the CB-filled compounds.

\subsubsection{TESTING OF COMPOUND AND VULCANIZATE PROPERTIES}

Mooney Viscosity (MV), Payne Effect (PE), apparent crosslink density, and stress-strain properties after vulcanization were measured as described in Chapter 3. Cure behavior was measured using the procedure as explained in Chapter 5, and dynamic mechanical properties: $\tan \delta$, using a DMA were performed according to the method described in Chapter 6.

The tackiness of compounds with/without resin in different filler systems was tested using a universal tensile testing machine Zwick Z10. Tack measurements were performed using a custom-made device, and the procedure was adopted based on the work of Mikrut [18]. Pieces of rubber with dimensions of $20 \times 20 \times 2 \mathrm{~mm}$ were used as test samples. The sample and the counter sample (carcass compound) were pressed against orifice disks to generate a convex contact surface: Fig. 7.3(a). The sample was brought into contact with the counter surface with a pre-load of $10 \mathrm{~N}$ for 10 seconds prior to the test: Figure 7.3(b), and then separated with a speed of $500 \mathrm{~mm} / \mathrm{sec}$ : Figure 7.3(c). The separation force versus separation distance were recorded. For each sample, five tack measurements were done, and the average was taken as the final result. The contact area was calculated from the radius of curvature. The measurements were performed at room temperature. 
(a)

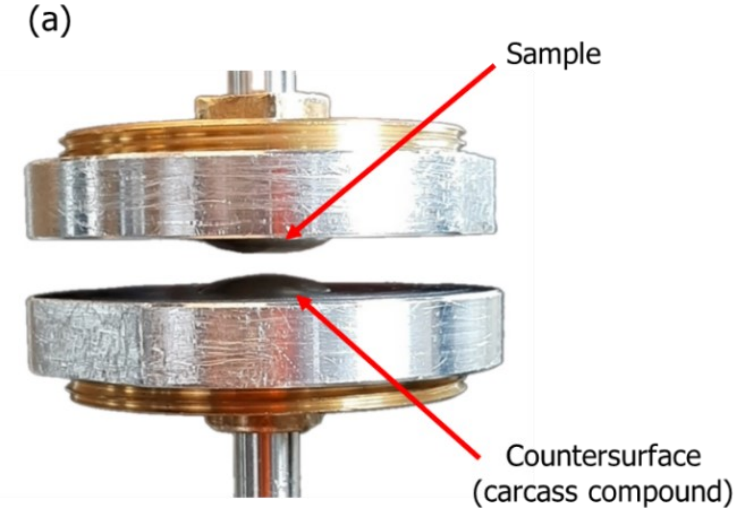

(b)

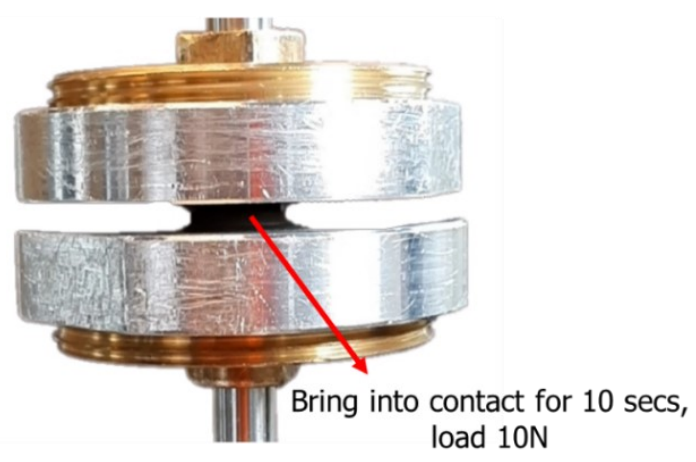

(c)

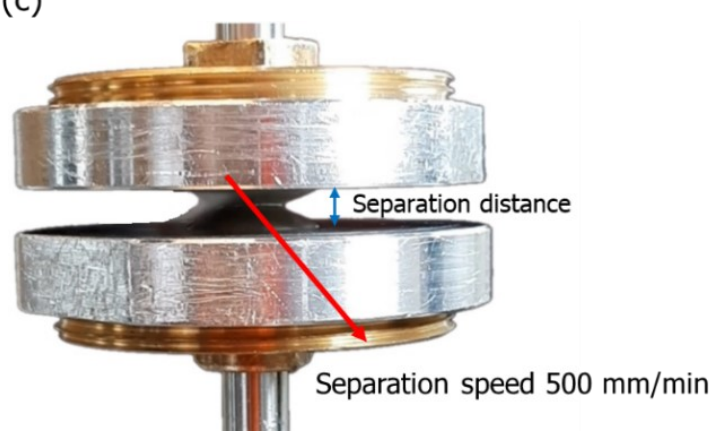

Figure 7.3 Tack measurement.

\subsection{RESULTS AND DISCUSSION}

\subsubsection{MIXING PERFORMANCE}

Figure 7.4 shows the mixing profiles of the compounds with resin in comparison to the respective controls for the materials with different filler systems. The torque curves of the resin compounds show no significant difference relative to the control in the CB system. The replacement of an equivalent amount of oil by resin in the CB-filled compounds, combined with the high temperature above the softening point of the resin generated during mixing, results in similar end torques. In the $\mathrm{CB} / \mathrm{SI}$ - and SI-systems, the addition of resins imparts lower mixing torque than in the control. The temperature of silanization for both, the CB/SIand SI-filled compound, was maintained at $150^{\circ} \mathrm{C}$, well above the softening points of the resins. Thus, the resins easily penetrate into the rubber matrix, decrease the intermolecular forces and facilitate filler incorporation and distribution into the rubber matrix. 

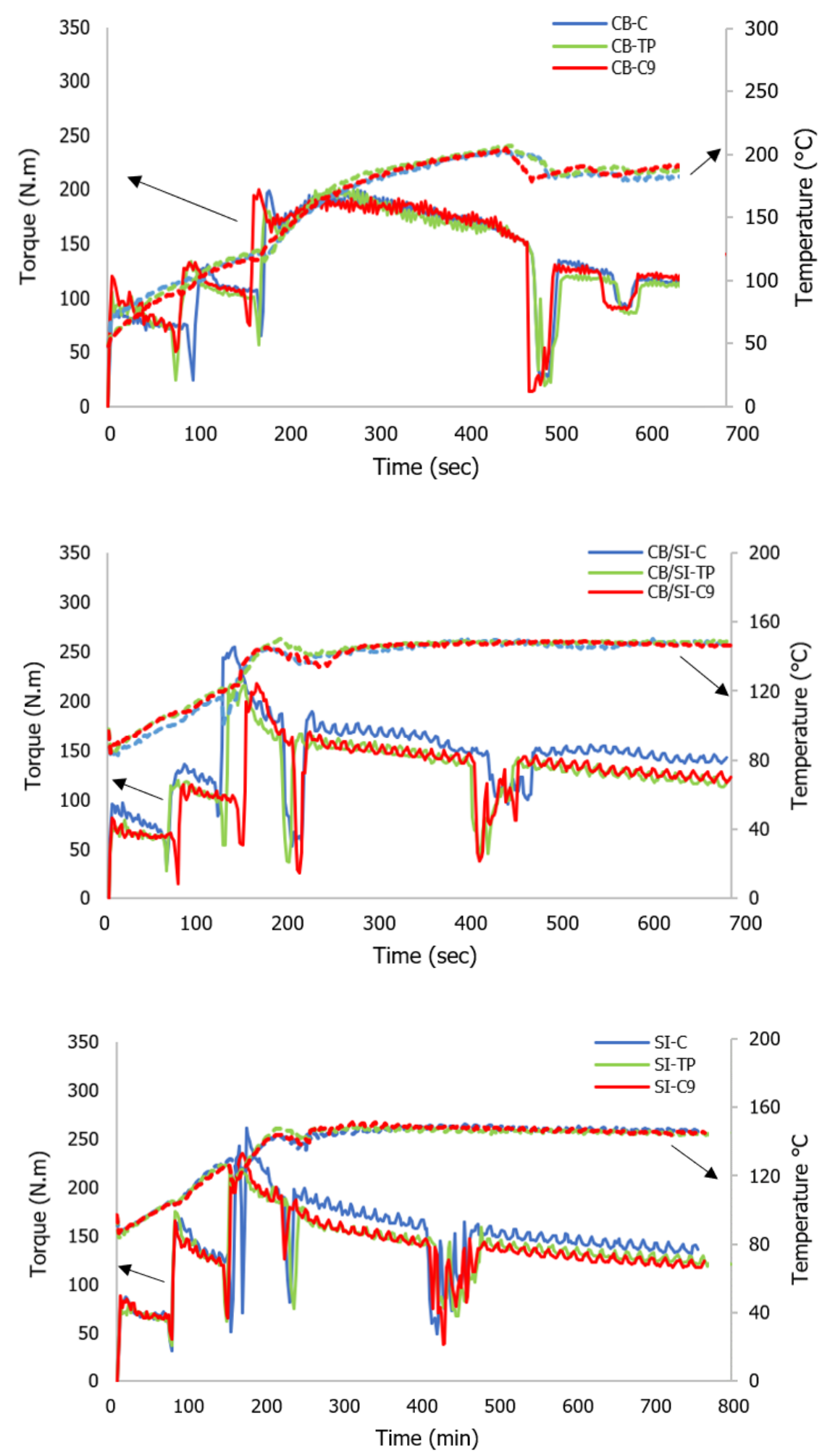

Figure 7.4 Mixing curves of compounds containing resins in comparison to the controls with different filler systems. 


\subsubsection{COMPOUND PROPERTIES}

The addition of resins slightly decreases the MV of the CB/SI- and SI-filled compounds, as shown in Figure 7.5. All compounds were mixed above the softening points of the resins, so they were blended as viscous liquids into the compounds. The amount of resin is equal to the amount of oil in the CB-filled compound, hence no significant difference in MV is observed depending on the addition of oil or resin. In CB/SI- and SI-filled compounds, the controls contain no oil, therefore they impart high MV. The silanization temperature of CB/SI- and SI materials was maintained at $150^{\circ} \mathrm{C}$, and at this temperature the resins were in liquid, viscous form. Therefore, they could easily penetrate between the polymer chains. The presence of low molecular weight molecules like resins pushes the polymer chains apart and reduces the intermolecular force between rubber molecules, which increases the free volume and facilitates better filler dispersion, decreasing the MV. The results of MV are in line with the results of the mixing curves: lower end torques for lower MV.

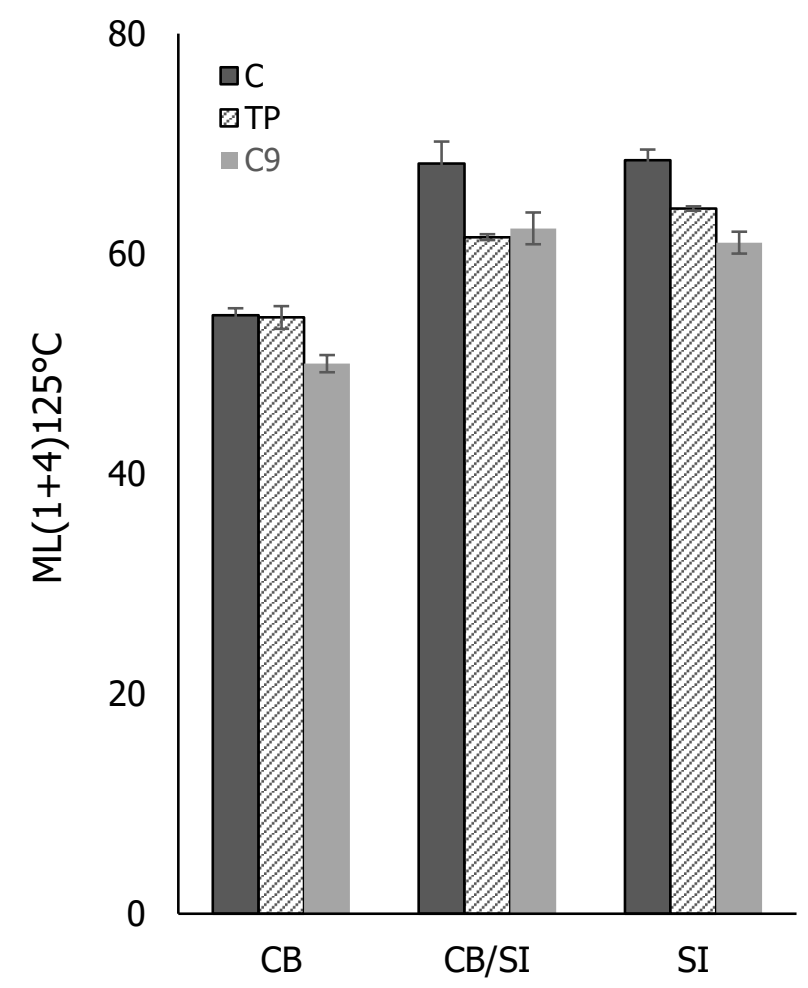

Figure 7.5 MV of compounds containing resins and different filler systems in comparison to the controls. 
To characterize the tack properties of the compound surface, it was brought into contact with the countersurface, a carcass compound: Figure 7.3. The curves of force versus separation distance for all compounds with the different filler systems are depicted in Figure 7.6. The tack of the compounds containing resins in comparison with resin-free controls is shown in Figure 7.7(a) as the maximum force needed for separation, and the separation distance is given in Figure 7.7(b). Independent of the filler systems, the use of resins TP and C9 increases the force needed for separation. The incorporation of the higher molecular weight resins instead of oil increases the cohesive strength. $C B-C$ shows a higher separation distance than CB-TP and CB-C9. This may be because both, CB-C and the carcass compound, contain $C B$ and oil. The surface energies of these two materials will not differ much, thus readily promoting contact and inter-diffusion when brought into contact. The separation distance increases because these compounds are more sticky; however, the force needed for separation is low due to poor cohesive strength of the compound due to the oil. The separation distance of compounds containing resins in both, the CB/SI- and SI-filled systems, is the same as their respective controls. This is most probably due to the fact that all compounds containing silica with or without resins have to overcome the surface energy difference with the carcass material containing CB and oil. In order for the contact area to increase, for interdiffusion and for bonding between the two surfaces to take place, the material must overcome this surface energy barrier. Compounds which have different compositions might need more time, higher pressure or temperature to overcome the surface energy difference. 

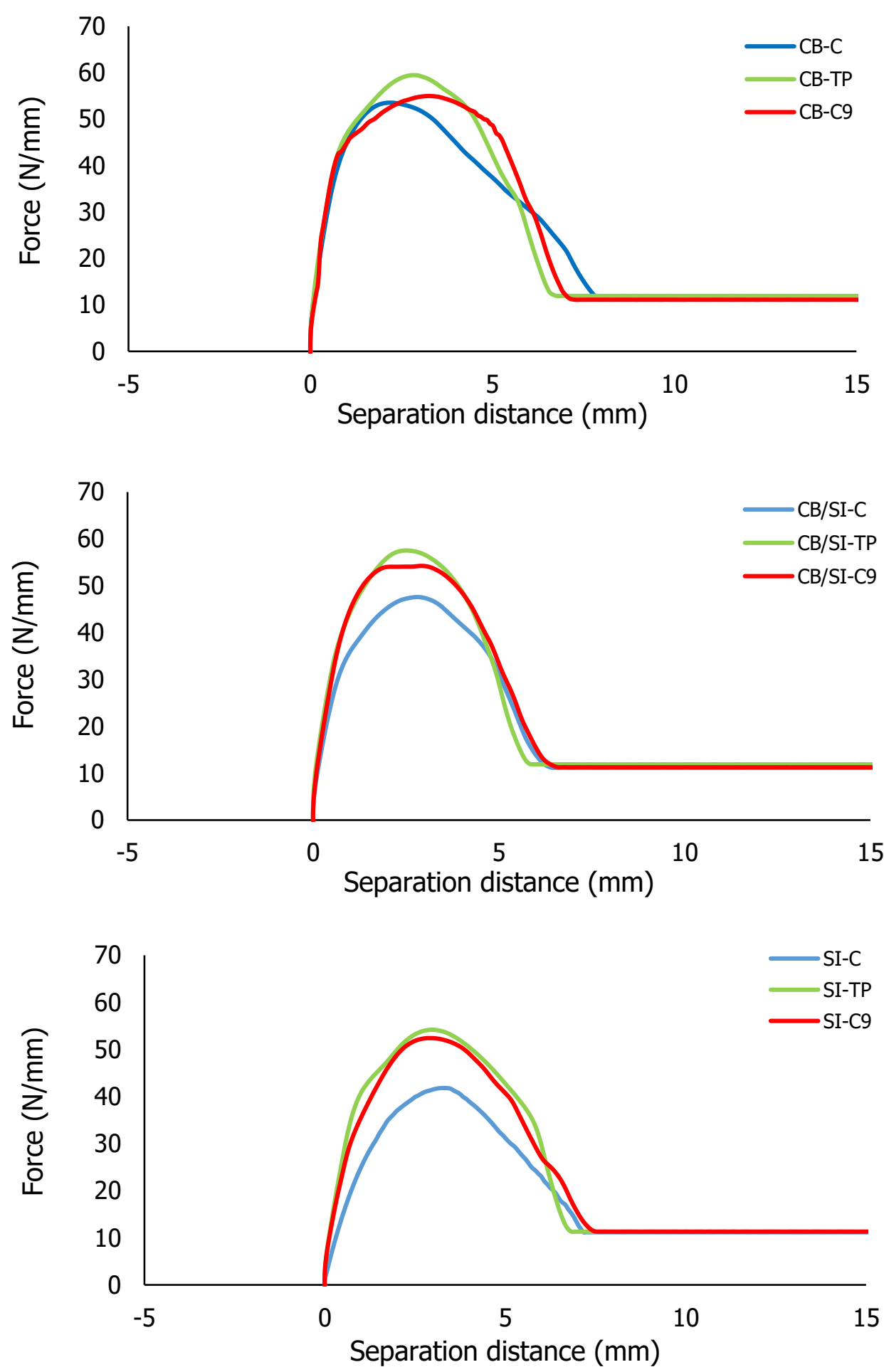

Figure 7.6 Force versus separation distance of compounds with/without resins for different filler systems. 
(a)

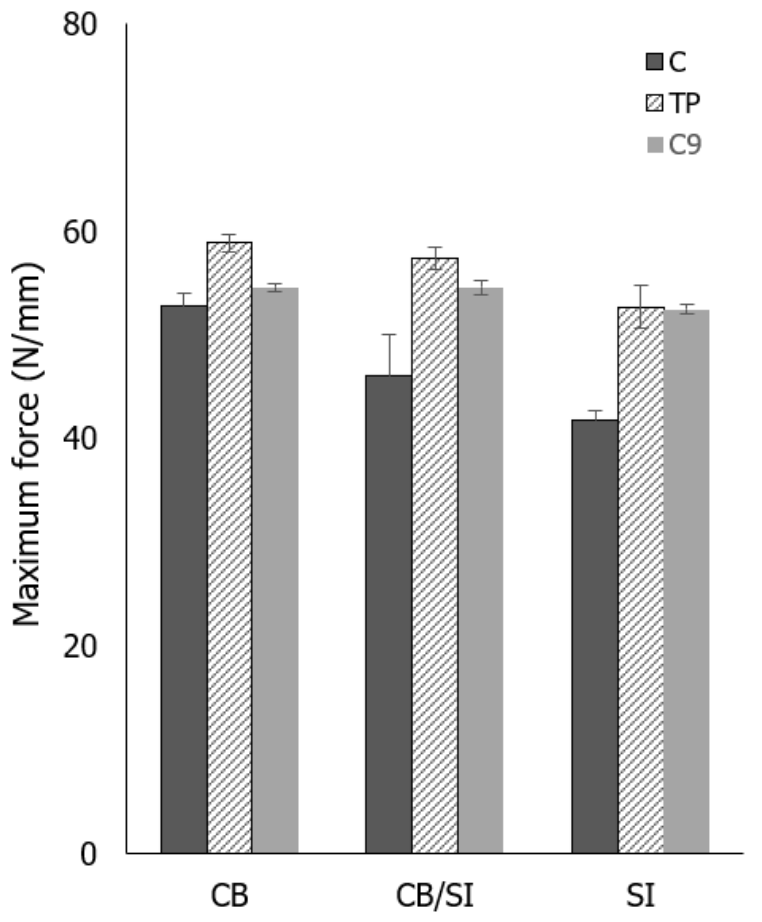

(b)

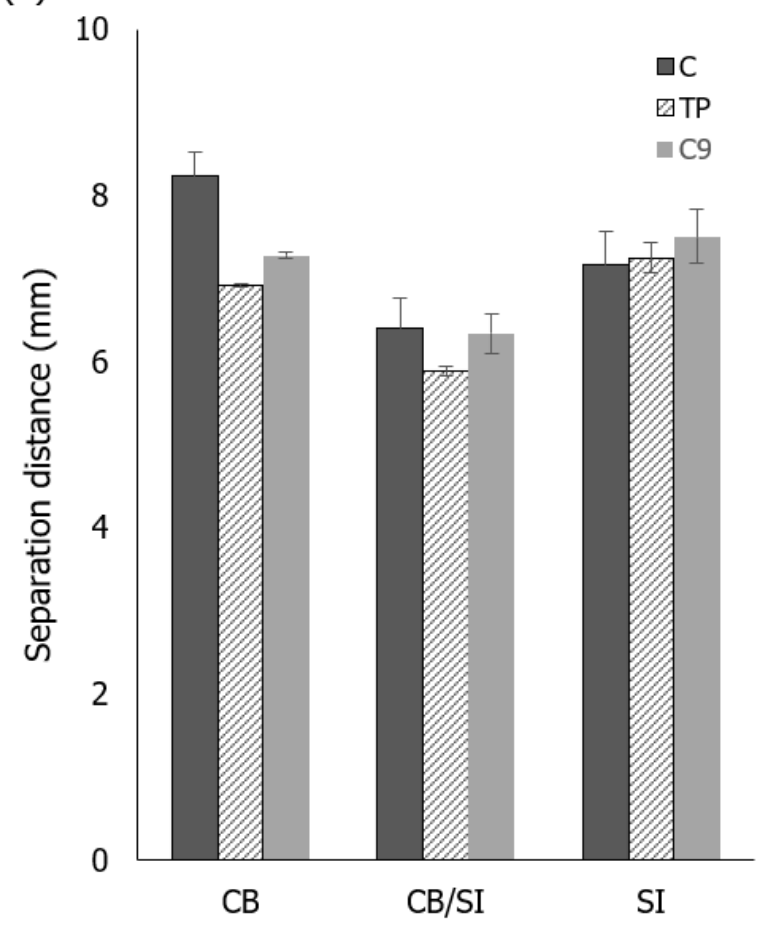

Figure 7.7 Tack measured as maximum forces (a) and separation distances (b) of compounds containing resins and different filler systems in comparison to the controls.

\subsubsection{VULCANIZATION CHARACTERISTICS}

Figure 7.8 shows the cure curves of the compounds containing resins in comparison with their controls for the CB-, CB/SI-, and SI-filled materials. Compared to their controls, the $\mathrm{C} 9$ and TP resin compounds show a minor influence on scorch time $\left(\mathrm{ts}_{2}\right)$ and optimum cure time ( $\left.t_{90}\right)$ for all filler systems: see Table 7.7. Compared to the controls, the use of C9 and TP decreases the rheometer minimum torque $S_{\text {min }}$ in vulcanizates containing silica: CB/SI and SI. The rheometer minimum torque $S_{\min }$ bears a relation to the mixing torque at the end of the mixing process and the MV, as can be seen by comparison with the data presented in Figure 7.5.

The maximum rheometer torque $S_{\max }$ or better even the torque difference $S_{\max }-S_{\min }$ is often quoted as a measure for crosslink density. However, this is not quite right as the intrinsic viscoelastic rigidity of the compounds, determined by filler-filler and preferred filler-polymer interactions also contribute to the $S_{\max }$. So, the lower the $S_{\min }$ to start with, the lower the $S_{\max }$ at equal crosslink density. The contributions of crosslink density and intrinsic viscoelastic rigidity cannot be separated in these curves. The $S_{\max }-S_{\min }$ generally increases in the series of $\mathrm{CB}<\mathrm{CB} / \mathrm{SI}<\mathrm{SI}$, irrespective of whether the controls are compared or the TP or C9 variants. Furthermore, the TP and C9 compounds generally show a reduced $S_{\max }-S_{\min }$ versus their controls. These rankings do qualitatively agree with those of the MV as presented in Figure 7.5. It is a clear indication that the differences are not necessarily a sign of reduced crosslink density but, like for the MV, the result of stronger filler-polymer bonding and a larger free volume due to the addition of resins. See also next paragraph: crosslink densities. 

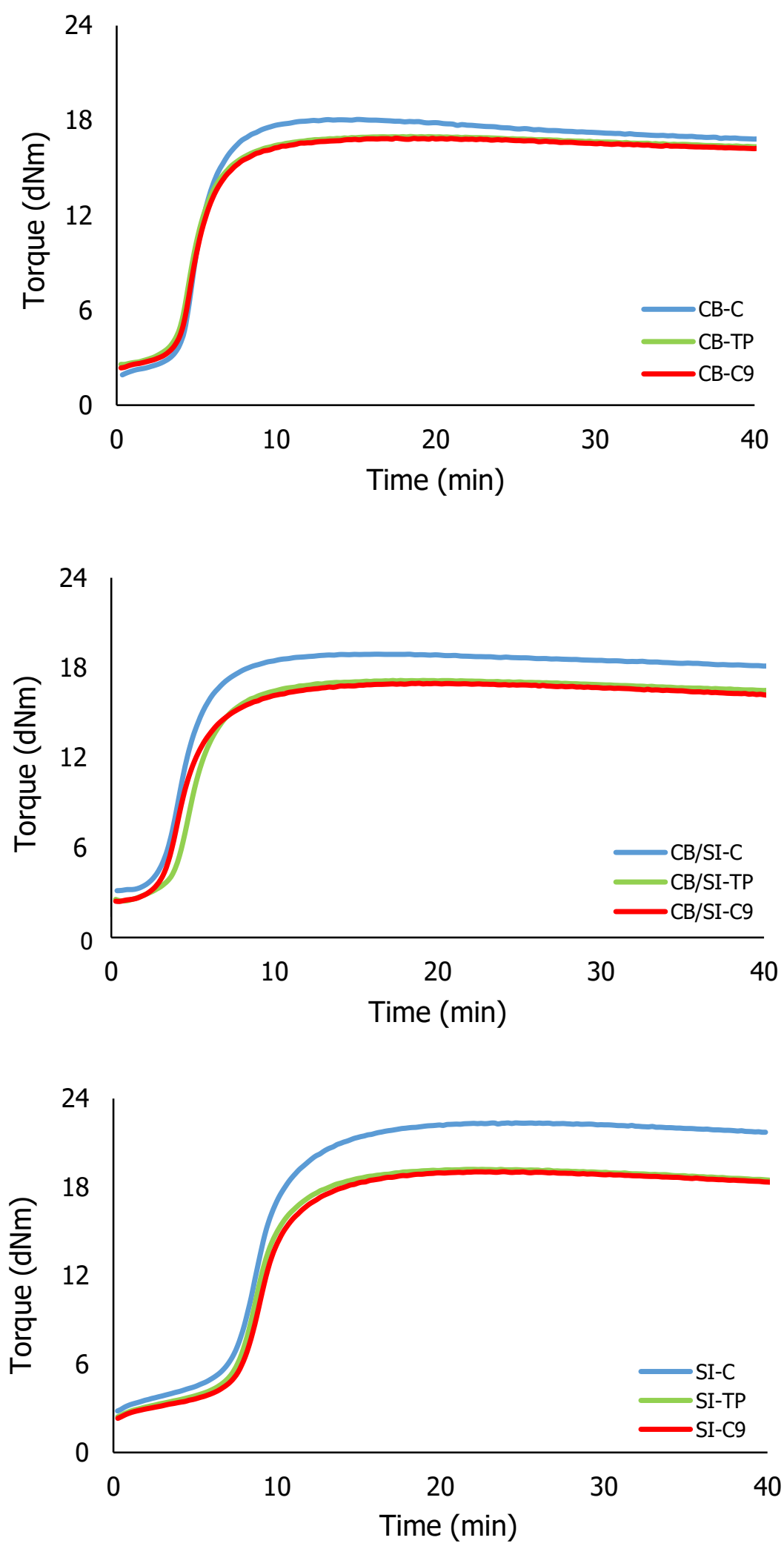

Figure 7.8 Cure curves of compounds containing resins and different filler systems in comparison with the respective controls. 
Table 7.7 Cure characteristics of all compounds.

\begin{tabular}{|c|c|c|c|c|c|c|c|c|c|}
\hline \multirow[t]{2}{*}{ Characteristics/Properties } & \multicolumn{3}{|c|}{ CB } & \multicolumn{3}{|c|}{ CB/SI } & \multicolumn{3}{|c|}{ SI } \\
\hline & C & TP & C9 & C & TP & C9 & C & TP & C9 \\
\hline Scorch time, ts2 (min) & 4.1 & 3.9 & 3.8 & 3.2 & 3.9 & 3.3 & 5.7 & 6.3 & 6.6 \\
\hline Optimum cure time, tgo $_{90}(\mathrm{~min})$ & 7.5 & 7.8 & 7.8 & 7.9 & 8.2 & 8.3 & 12.8 & 12.3 & 12.7 \\
\hline Cure rate index $\left(\mathrm{min}^{-1}\right)$ & 29.3 & 25.6 & 25.0 & 21.3 & 23.2 & 20.0 & 14.1 & 16.7 & 16.4 \\
\hline $\mathrm{S}_{\min }(\mathrm{dN} \cdot \mathrm{m})$ & 2.7 & 2.6 & 2.4 & 3.1 & 2.4 & 2.4 & 3.2 & 2.4 & 2.3 \\
\hline $\mathrm{S}_{\max }(\mathrm{dN} \cdot \mathrm{m})$ & 18.1 & 17.0 & 16.9 & 18.9 & 17.2 & 17.0 & 22.4 & 19.2 & 19.0 \\
\hline $\mathrm{S}_{\max }-\mathrm{S}_{\min }(\mathrm{dN} \cdot \mathrm{m})$ & 15.4 & 14.4 & 14.5 & 15.8 & 14.8 & 14.6 & 19.2 & 16.8 & 16.7 \\
\hline
\end{tabular}

The effect of resins on the apparent crosslink density is shown in Figure 7.9 as derived from swelling experiments. It is the resultant from the contribution of sulfur polymer-polymer crosslinks and from filler-rubber interaction. There is a slight increasing trend in going from $\mathrm{CB}$ towards SI, most likely because of the stronger chemical filler-rubber coupling for the latter, in comparison with the physical interaction in the CB case. The replacement of CB by silica and the addition of resins does not result in large crosslink density differences for all systems. The use of resins does neither negatively interfere with the network formation during vulcanization nor with the silanization reaction for systems containing CB/SI and SI; it even has a small positive effect.

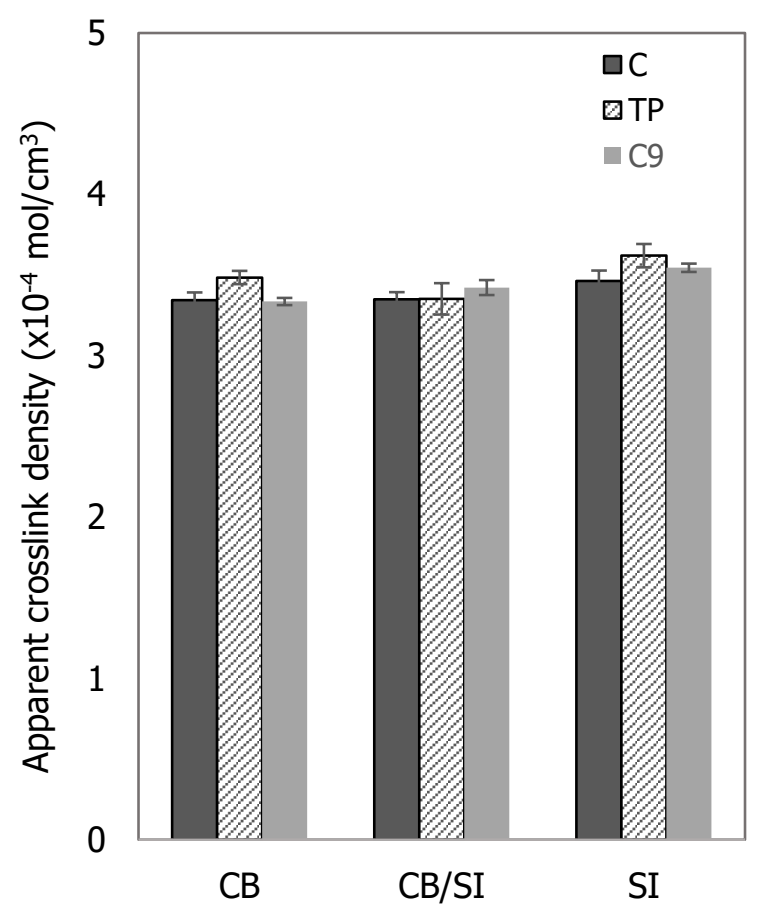

Figure 7.9 Apparent crosslink density of vulcanizates containing resins and different filler systems compared to the controls. 


\subsubsection{DYNAMIC PROPERTIES AFTER VULCANIZATION}

Figure 7.10 shows the PE as an indicator for the micro-dispersion of the fillers, in which lower values indicate better micro-dispersion. The viscosities of TP and C9 at $150^{\circ} \mathrm{C}$ are 3400 and $650 \mathrm{MPa} . \mathrm{s}$ respectively $[9,10]$; the viscosity of TDAE oil at $100^{\circ} \mathrm{C}$ is $17.86 \mathrm{MPa} . \mathrm{s}$ [13]. Despite a higher viscosity of the resins compared to oil, they impart a similar PE in the CB system. The dispersion of $\mathrm{CB}$ in the polymer matrix is relatively easy due to the less developed filler-filler network of $\mathrm{CB}$ and the high compatibility of $\mathrm{CB}$ with the non-polar polymers. Therefore, replacing an equivalent amount of TDAE oil with resins in CB-filled compounds results in nearly the same PE as the CB-control. The addition of TP and C9 does not negatively interfere with the silanization and even shows a slight improvement of silanization. A slight decrease in PE is observed in CB/SI- and SI-filled systems by the addition of resins from their respective controls.

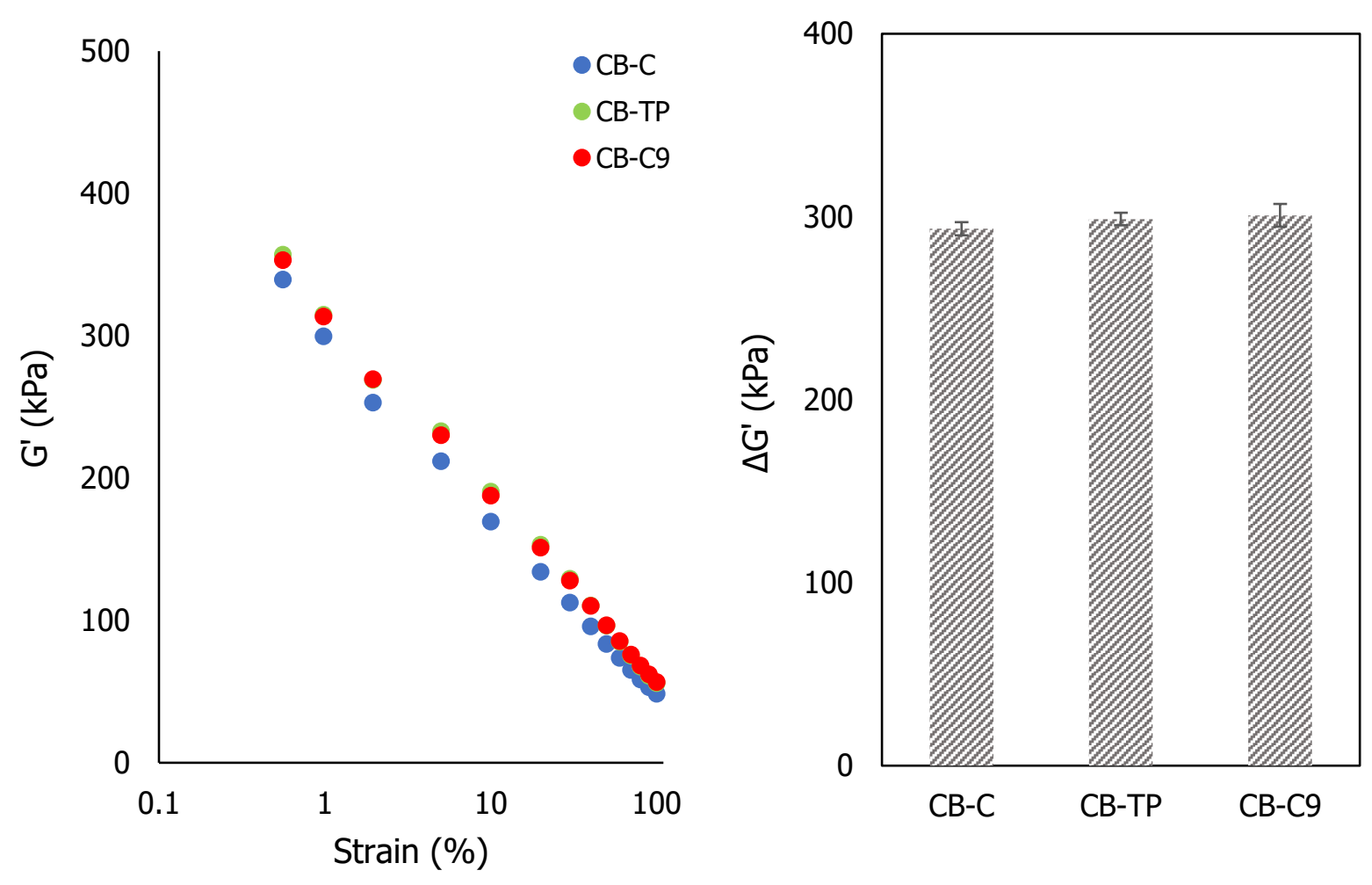



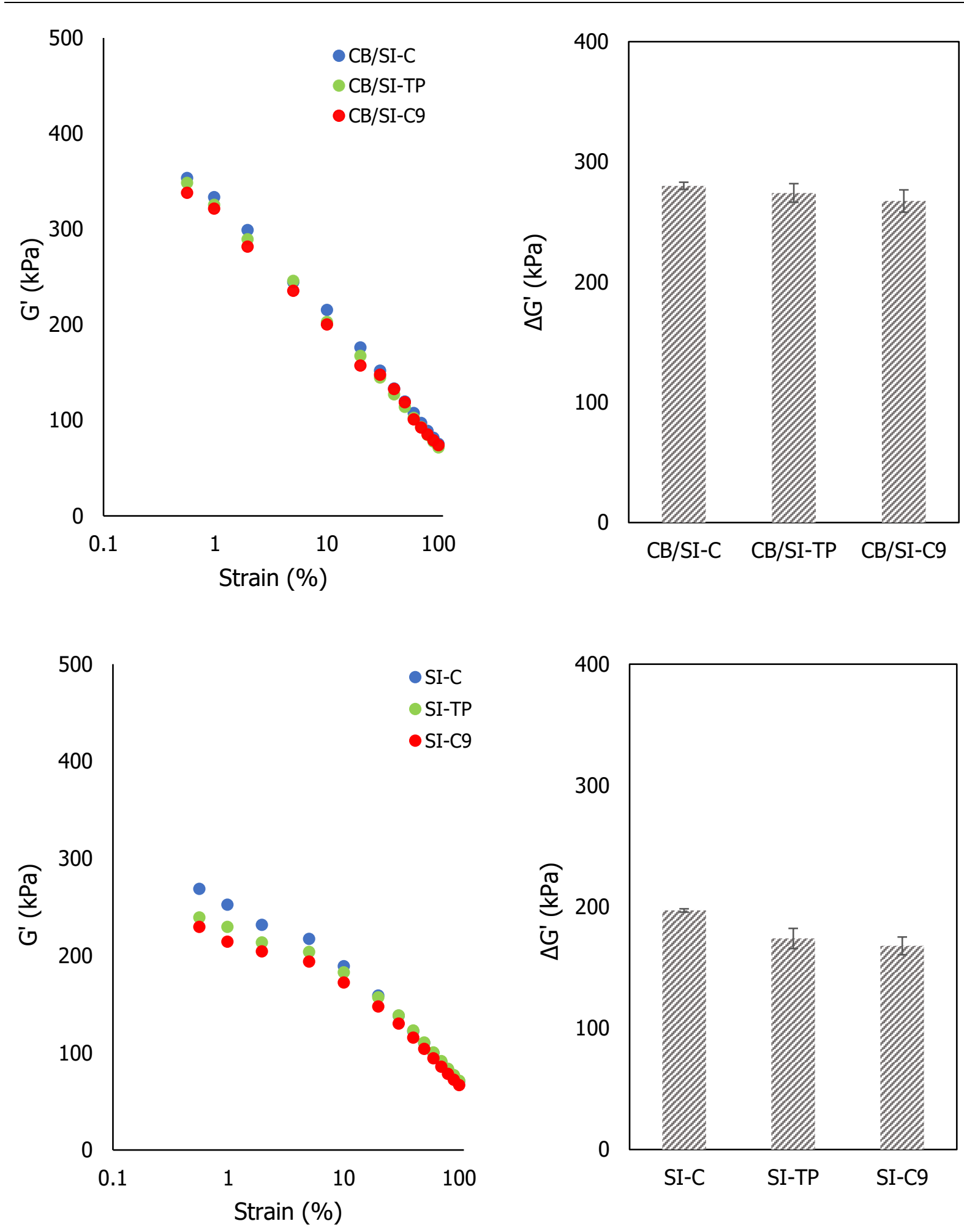

Figure 7.10 PE of compounds containing resins and different filler systems in comparison with the controls. 
Figure 7.11 depicts the viscoelastic damping, $\tan \delta$ values, as a function of temperature for the vulcanizates containing resins in comparison to their controls. The $\mathrm{Tg}$ corresponds to the temperature, at which a peak in tan $\delta$ is observed. Compatible resins and rubbers will shift or broaden the tan $\delta$ peak region. In the case that resin and rubber are incompatible, two separate Tg-peaks are commonly visible in the tan $\delta$ curve as a function of temperature [19], located at their original positions, at least if both are present in sufficient quantities. As can be seen from Table 7.8 and Figure 7.11, the use of resins shifts the $\tan \delta$ peak of the vulcanizates slightly to a higher temperature compared to the controls. This is clearly due to the addition of resins with high $\mathrm{Tg}$ and softening point, the more for TP than for C9. As the Tg's of the NR-phase as well as of the BR-phase shift with the addition of the resins: Table 7.8, it may be taken as an indication that the resins have no particular preference for either of the two phases. However, due to the lower amount of BR versus NR in the formulation, the shift in Tg of BR is very difficult to discern, so the BR-data in Table 7.8 need to be taken with some reserve.

Table 7.8 Measured glass transition temperatures.

\begin{tabular}{|l|c|c|}
\hline \multicolumn{1}{|c|}{ Rubber } & Tg BR $\left({ }^{\circ} \mathbf{C}\right)$ & Tg NR $\left({ }^{\circ} \mathbf{C}\right)$ \\
\hline CB-C & -97 & -53 \\
\hline CB-TP & -92 & -49 \\
\hline CB-C9 & -94 & -51 \\
\hline CB/SI-C & -97 & -53 \\
\hline CB/SI-TP & -93 & -49 \\
\hline CB/SI-C9 & -94 & -51 \\
\hline SI-C & -97 & -51 \\
\hline SI-TP & -93 & -49 \\
\hline SI-C9 & -94 & -50 \\
\hline
\end{tabular}

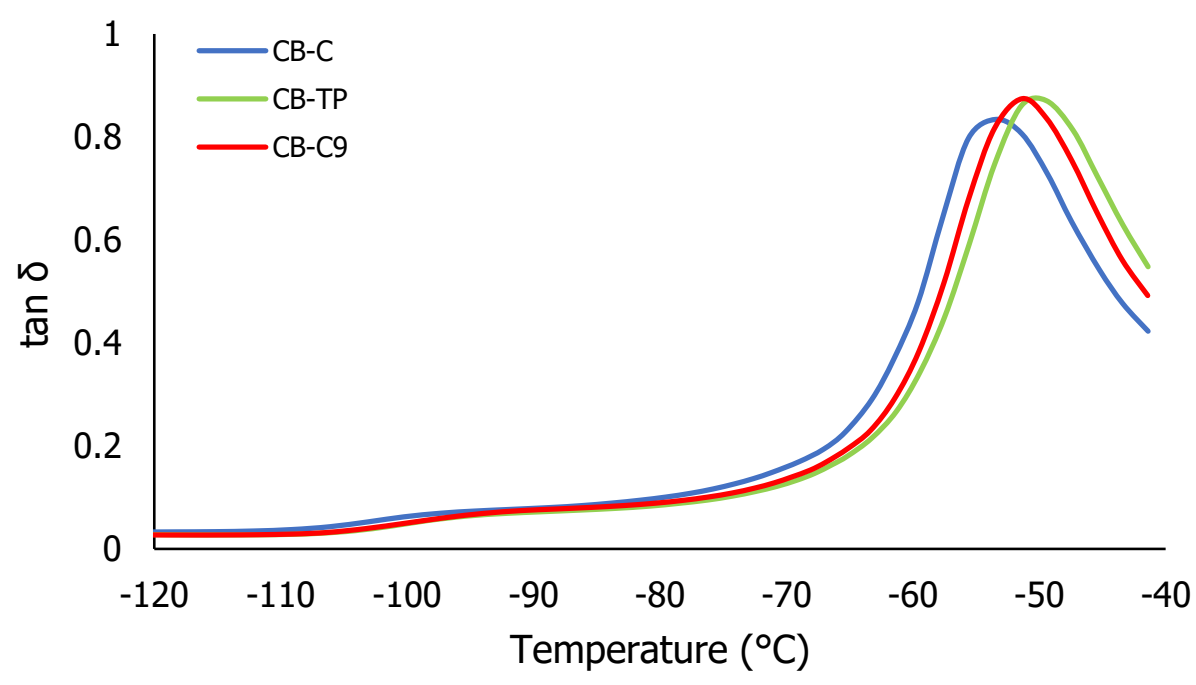



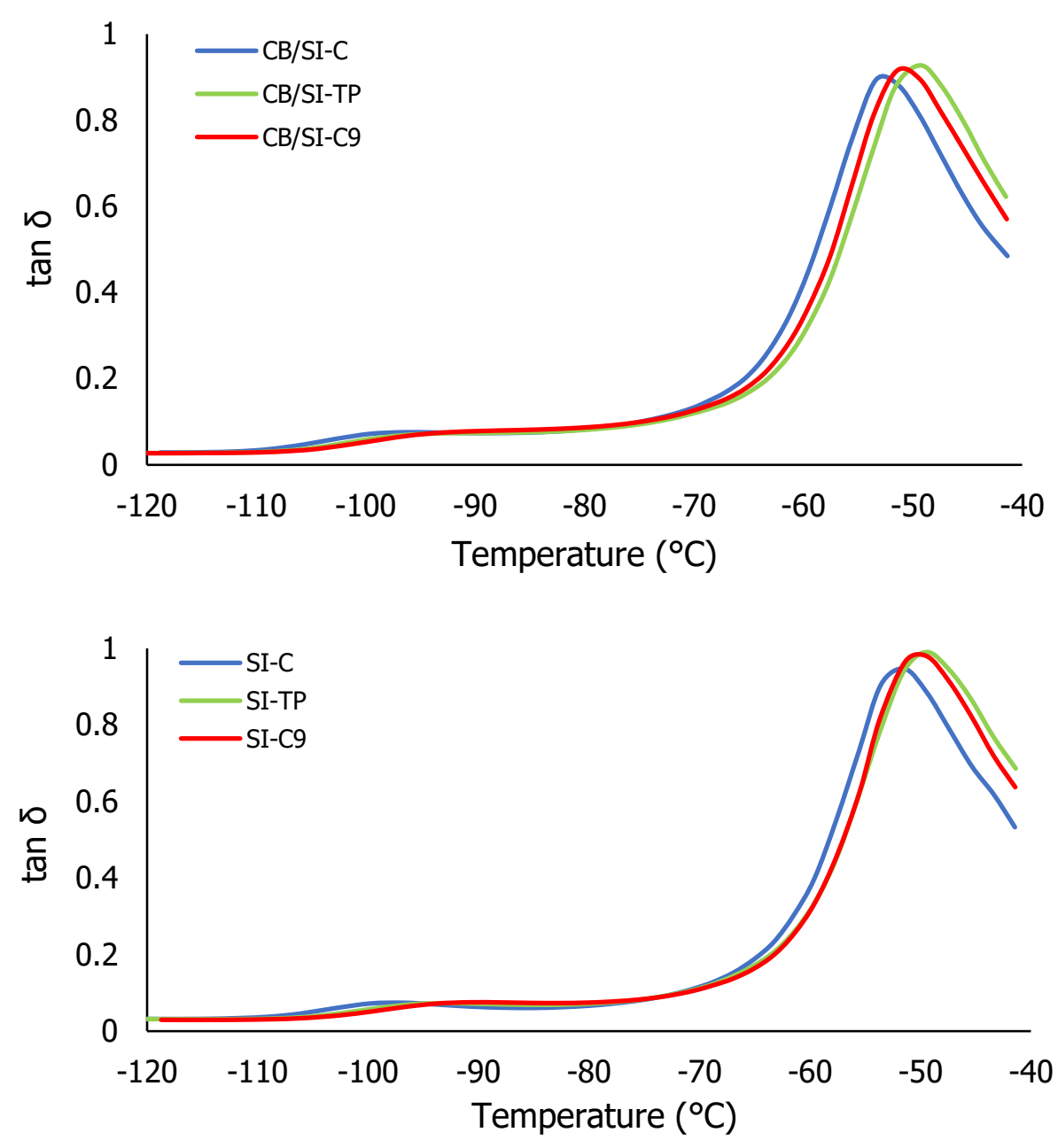

Figure 7.11 Tan $\delta$ measured in a temperature sweep from -120 to $-40^{\circ} \mathrm{C}$ for all vulcanizates.

Figure 7.12 shows $\tan \delta$ in a temperature sweep from -40 to $40^{\circ} \mathrm{C}$. For the interpretation of these data, the well-known formalism of Nordsiek to simulate whole tire tread performance in laboratory-scale dynamic testing is used. The temperature region of -35 to $0^{\circ} \mathrm{C}$ can be employed as indicator for Ice Traction (ICT), and tan $\delta$ in the region of 0 to $20^{\circ} \mathrm{C}$ is indicative for wet traction or Wet Skid Resistance (WSR) of a tire tread based on such a compound [20]. Figures 7.13(a) and (b) summarize the tan $\delta$ values at $-30^{\circ} \mathrm{C}$ for ICT and $5^{\circ} \mathrm{C}$ for WSR. The addition of resins, independent of the filler system, raises the tan $\delta$ and so improves the ICT performance as well as WSR compared to the respective control vulcanizates. At $-30^{\circ} \mathrm{C}$, the use of TP resin results in only a slightly higher ICT than for C9 in all filler systems. This is related to the shift of the tan $\delta$ peak as a consequence of using resins with a high $\mathrm{Tg}$ and molecular weight. At $5^{\circ} \mathrm{C}$, the $\mathrm{C} 9$ resin provides a higher WSR than TP and the respective controls in all filler systems. This seemingly contradictory observation is visible in the cross-over of the tan $\delta$ curves for TP and $C 9$ around $-20^{\circ} \mathrm{C}$, as seen for all three filler systems in Figure 7.12. It relates to the structure of $\mathrm{C}$, which contains methyl groups on the aromatic rings from vinyltoluene and along the polymer chain from $\alpha$-methylstyrene groups, providing more flexibility for rotation and movement than the bulky configuration of TP: see 
Figure 7.2. Thus the mobility of the chains increases more for C9 than for TP at raising temperature, leading to relatively higher viscoelastic losses.
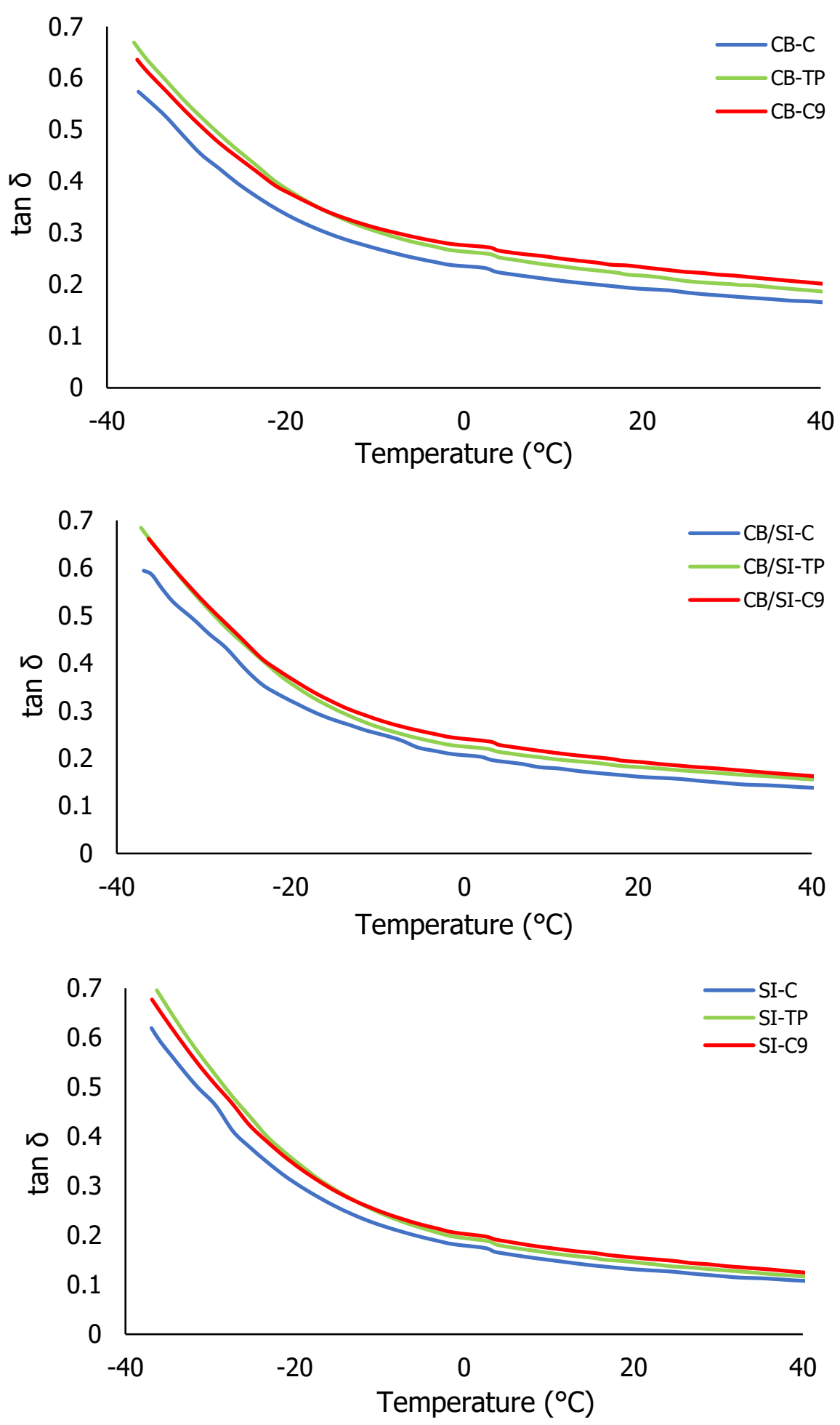

Figure 7.12 Tan $\delta$ in a temperature sweep from -40 to $40^{\circ} \mathrm{C}$ for all vulcanizates. 
(a)

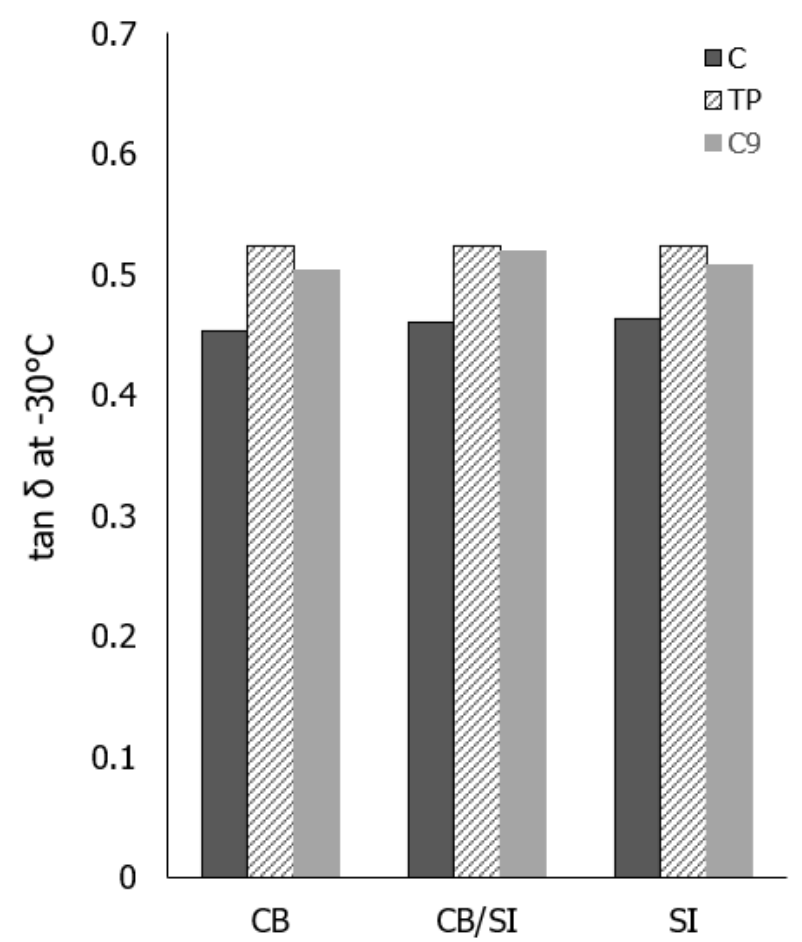

(b)

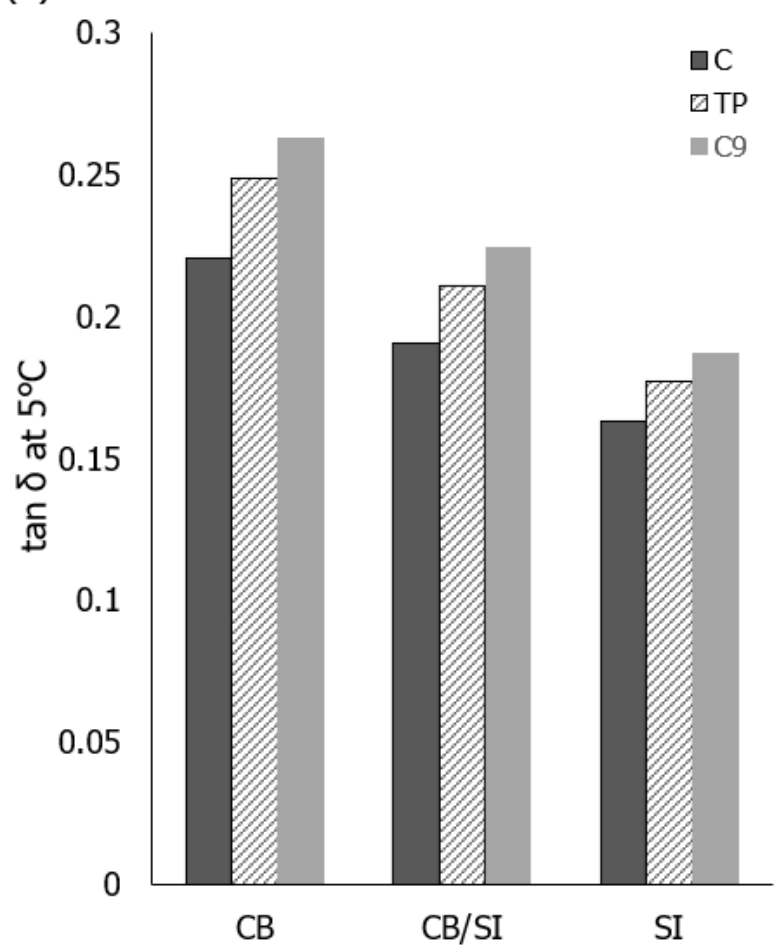

Figure 7.13 Tan $\delta$ values of the resin-containing rubbers at $-30^{\circ} \mathrm{C}(\mathrm{a})$ and $5^{\circ} \mathrm{C}(\mathrm{b})$ in comparison with the respective controls.

Figure 7.14 depicts the tan $\delta$ values at $100^{\circ} \mathrm{C}$ as indicator for $\mathrm{HBU}$. It is clearly visible that the $\tan \delta$ values decrease substantially for the SI-containing compounds relative to $\mathrm{CB}$ ones by about $50 \%$. The use of resins for the CB-compounds raises the tan $\delta$ values at $100^{\circ} \mathrm{C}$, while for the pure SI-compound it even leads to a small but significant further reduction. The effect in the SI-filled compounds is clearly the result of the chemical bonding of the rubber molecules to the silica surface by the coupling agent TESPT versus far less strong physical adhesion for the CB-reinforced compounds. It restricts release/adhesion or segmental motions of polymer segments on the filler surface and thus reduces mechanical loss phenomena on a molecular scale [21]. The filler-rubber interaction present in the SI-filled compounds acts in a similar manner as multifunctional chemical crosslinkers, next to the crosslinks created by sulfur vulcanization.

An important point of consideration for this overall very promising observation for the application in aircraft tire treads is, that the $\tan \delta$ is in fact a relative quantity between the lost and stored energy during deformation. It says nothing about the absolute values of the losses versus stored energy, as reflected by HBU. Although tan $\delta$ can be used as the first approximation of $\mathrm{HBU}$, it is therefore necessary and highly valuable to verify these results with real tire tests, which were out of the scope of the present study. 


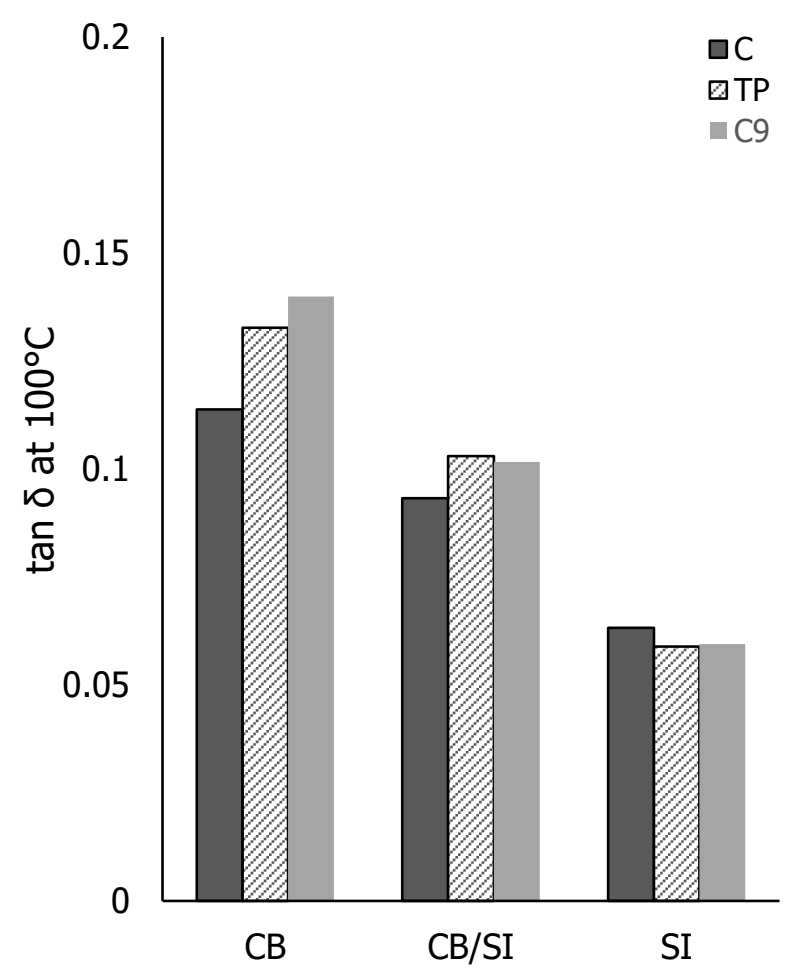

Figure 7.14 Tan $\delta$ at $100^{\circ} \mathrm{C}$ of the rubber with resins in comparison to the respective controls for different filler systems.

\subsubsection{MECHANICAL PROPERTIES OF THE VULCANIZATES}

Figures 7.15(a)-(c) show the mechanical properties for all vulcanizates. Although the M300\% reduces somewhat in going from CB- to SI-reinforcement, the tensile strength and elongation at break are significantly increasing. Slight increases in M300\% and tensile strength with no significant difference in elongation at break by the addition of resins in CB/SI- and SIfilled are observed. All vulcanizates show comparable hardness, as was aimed for in this study.

(a)

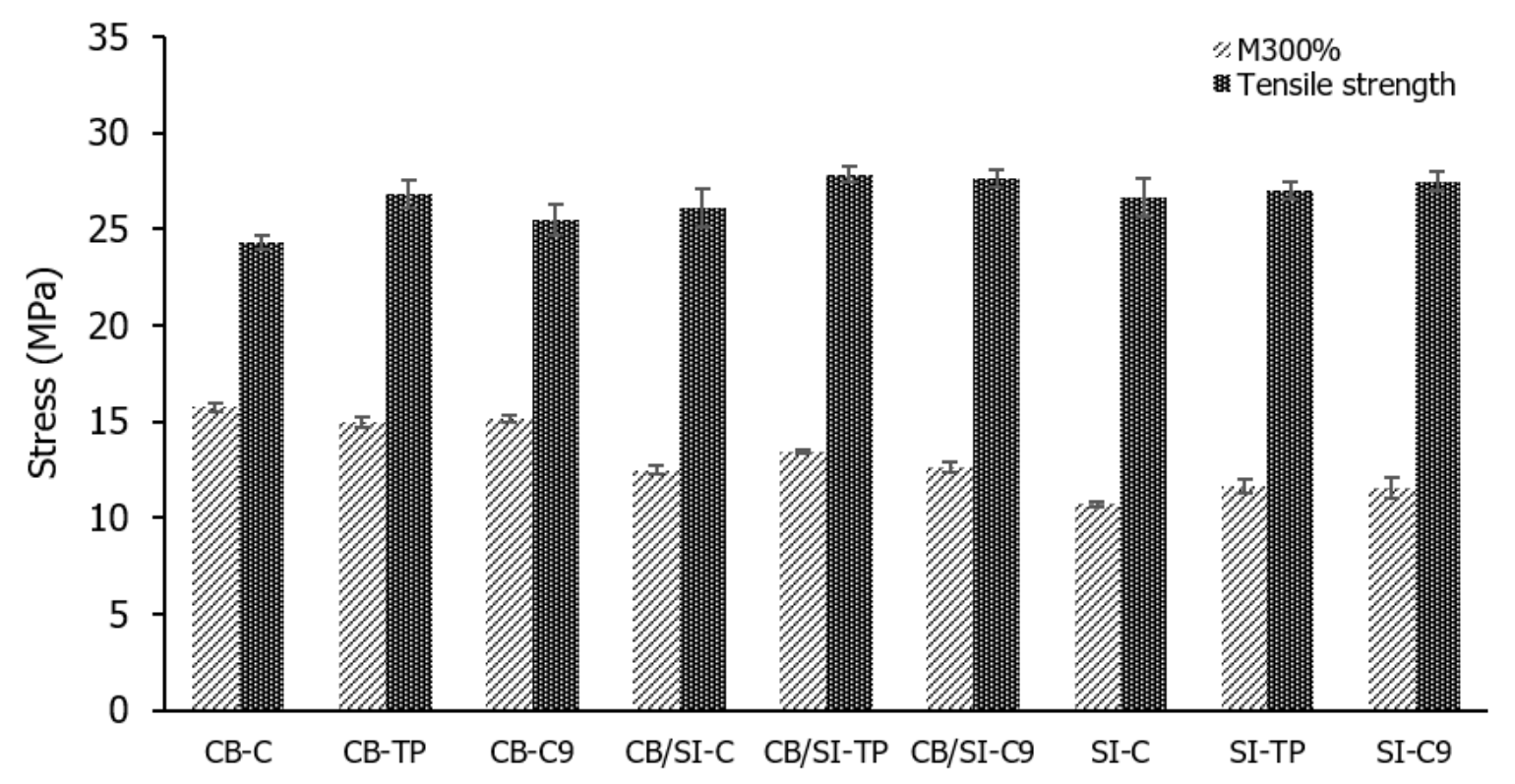




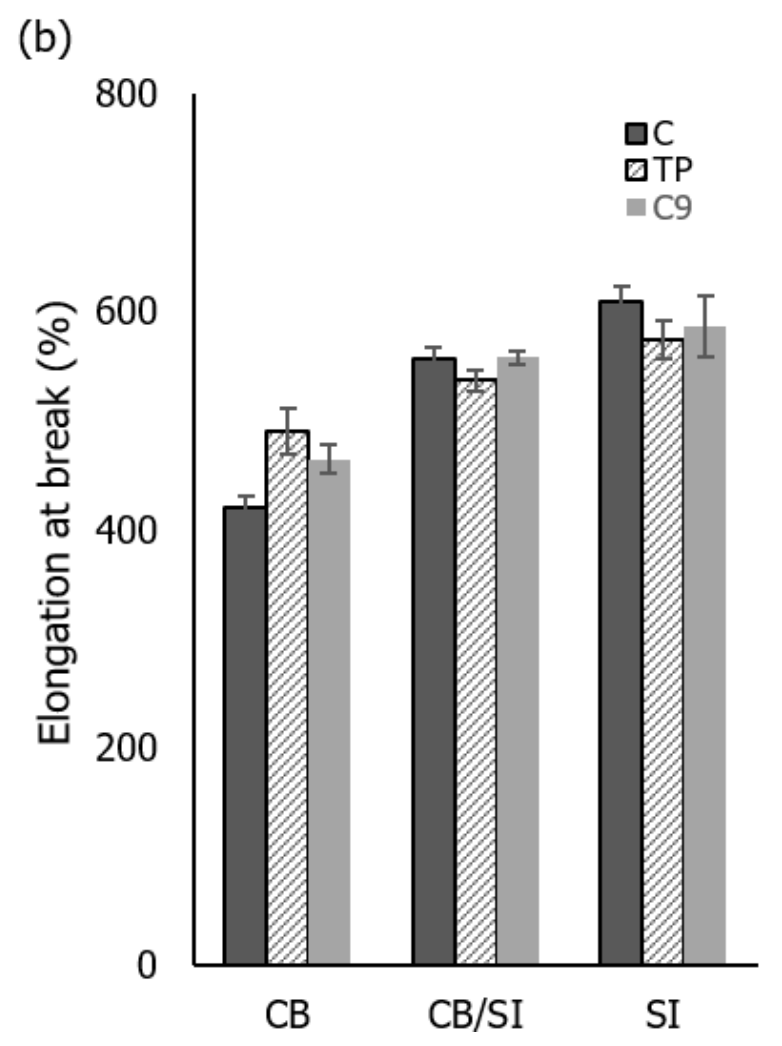

(c)

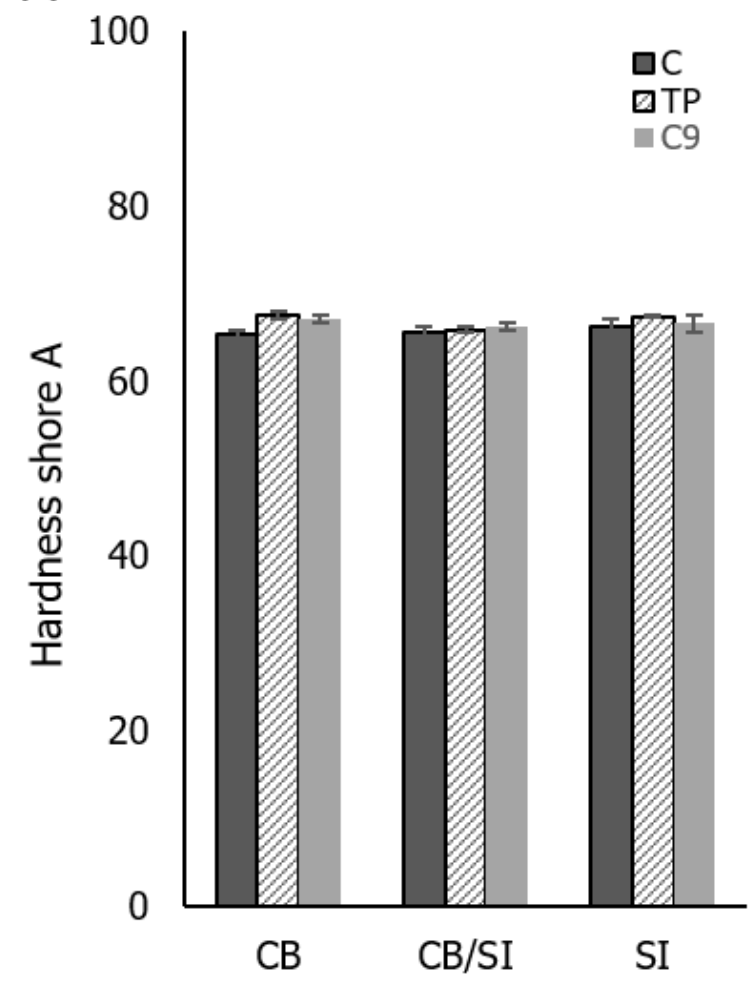

Figure 7.15 Mechanical properties for all materials: M300\% and tensile strength (a); elongation at break (b); hardness Shore A (c).

\subsection{CONCLUSIONS}

The addition of TP and hydrocarbon C9 resins in a NR/BR blend offers the potential to significantly improve ICT and WSR of aircraft tire tread formulations with CB-, SI- or dual $\mathrm{CB} / \mathrm{SI}$ filler systems, based on dynamic mechanical laboratory-based testing. Apart from a very positive effect of the switch from CB to SI on the tan $\delta$ at $100^{\circ} \mathrm{C}$ as indication for $\mathrm{HBU}$ as such of approximately $50 \%$, a further positive effect from the resins on HBU is only observed in the SI-filled system. In the specific aircraft tire retread formulation used in the present study, both TP and C9 show comparable performances in the low temperature range for ICT, as well as at high temperatures for $\mathrm{HBU}$ indication. In the intermediate temperature range between $0^{\circ} \mathrm{C}$ and $20^{\circ} \mathrm{C}$, the C9 resin promises a slightly better WSR in the SI-filled system. Apart from the influences from changing the filler system from CB to SI, the addition of 7.5 phr of resin to all reinforced systems has little influence on curing characteristics, and provides a slight improvement in tensile strength and $\mathrm{M} 300 \%$ with no significant difference in elongation at break. The use of resins improves the processing as well as the tackiness of compounds, which is an important factor for the retreading process. The results of this study provide a basis for optimization of aircraft tire treads in many functional aspects: ICT, WSR and $\mathrm{HBU}$, which deserve testing in real tires. 


\subsection{REFERENCES}

1. Wu, J., et al., Effect of Temperature on Wear Performance of Aircraft Tire Tread Rubber, Polym. Test., 79, 5, 1 (2019).

2. Caputo, F., et al., Investigation on the Static and Dynamic Structural Behaviours of a Regional Aircraft Main Landing Gear by a New Numerical Methodology, Frattura ed Integrità Strutturale, 12, 43, 191 (2018).

3. Wang, W.J., Dynamics and Energy Conversion of Aircraft Landing Gears at Touchdown, MATEC Web of Conferences, 77, 1 (2016).

4. Stuck, B., in Rubber Technology Compounding and Testing for Performance, Tackifying, Curing, and Reinforcing Resins, 2nd ed., Dick, J.S. and Annicelli, R.A., Ed., Carl Hanser Verlag GmbH \& Co. KG: Munich, Germany (2009).

5. Wake, W.C., Adhesion and the Formulation of Adhesives, 2nd ed., Applied Science Publishers: London (1979).

6. Hamed, G.R., Tack and Green Strength of Elastomeric Materials, Rubber Chem. Technol, 54, 3, 576 (1981).

7. Carvagno, T.R., et al., Performance Resins in Tire Compounding, Rubber World: Akron, Ohio, USA, 249, 27 (2014).

8. Class, J.B. and Chu, S.G., The Viscoelastic Properties of Rubber-Resin Blends. I. The Effect of Resin Structure, Appl. Polym. Sci, 30, 2, 805 (1985).

9. Kraton Chemical B.V., Sylvatraxx 6720, Available online: https://kraton.com/products/sdsDocs (accessed on 12 June 2021

10. Kraton Chemical B.V., Sylvatraxx 4401, Available online: https://www.karton.com/products/sdsDocs (accessed on 12 June 2021

11. Manoharan, P. and Naskar, K., Eco-Friendly Composites Derived from Naturally Occurring Molecules in Promoting Dispersion of Nanosized Silica Particulates, Polym. Compos., 40, 3, 1 (2018).

12. Mildenberg, R., et al., in Hydrocarbon Resins, Resin Structure and Properties, VCH Verlagsgesellschaft mbH/VCH Publishers: Weinheim (1997).

13. Petchkaew, A., et al., Petroleum-based Safe Process Oils in NR, SBR and their Blends: Study on Unfilled Compounds. Part I. Oil Characteristics and Solubility Aspects, Kautsch. Gummi Kunstst., 4, 43 (2013).

14. Forrest, M.J., in Rubber Analysis Polymers, Compounds and Products, Determination of Micellaneous Compound Additives, Rapra Technology Ltd.: Shawbury, UK (2001).

15. Barton, A.F.M., Handbook of Solubility Parameters and Other Cohesion Parameters, CRC Press: Boca Raton, Florida (1991).

16. Guo, Y., et al., A Combined Molecular Dynamics Simulation and Experimental Method to Study the Compatibility Between Elastomers and Resins, RSC Advances, 8, 26, 14401 (2018).

17. Starting Point Rubber Compounding Formulations, Available online: www.nocil.com (accessed on 10 August 2020).

18. Mikrut, M., et al., Silicone Rubber Tack I: Relation to Network Structure, J. Adhesion, 85, 7, 395 (2009).

19. Maghami, $\quad$ S., Silica-Filled Tire Tread Compounds: An Investigation Into the Viscoelastic Properties of the Rubber Compounds and Their Relation to Tire Performance, PhD thesis, Elastomer Technology and Engineering, University of Twente, The Netherlands (2016).

20. Nordsiek, K.H., The "Integral Rubber" Concept - an Approach to an Ideal Tire Tread Rubber, Kautsch. Gummi Kunstst., 38, 178 (1985).

21. Vleugels, N., et al., Understanding the Influence of Oligomeric Resins on Traction and Rolling Resistance of Silica-Reinforced Tire Treads, Rubber Chem. Technol., 88, 1, 65 (2015). 


\section{AGING PROPERTIES OF AIRCRAFT TIRE RETREADS}

\section{ABSTRACT}

The aging performance in terms of changing stress-strain properties, hardness and tan $\delta$ of vulcanizates at a temperature of $200^{\circ} \mathrm{C}$, close to the service conditions of aircraft tires, is investigated. The vulcanizates are based on Natural Rubber (NR) blended with different types of Butadiene Rubber (BR) and with different filler systems. In the first part of this study, four types of BR are used: High-Cis BR (HC BR), High-Cis Long Chain-Branched BR (HC LCB BR), Low-Cis BR (LC BR), and High-Vinyl BR (HV BR). In the second part, three different filler systems: Carbon Black (CB), a blend of Carbon Black and Silica (CB/SI), and pure Silica (SI) are used. Aging is performed in a hot air oven for up to twenty-five cycles, where one cycle consists of 5 minutes of aging (to mimic the duration of takeoff), 30 minutes rest at room temperature (approximate duration of cooling down of the tire), and 5 minutes of aging again (to approximate the duration of landing).

Comparing the various types of $\mathrm{BR}, \mathrm{CB} / \mathrm{SI}$-filled NR/HV shows lower $\tan \delta$ than the vulcanizates with the other types of BR. At the service temperature of $200^{\circ} \mathrm{C}$, the Modulus at $100 \%$ elongation (M100\%) and hardness of vulcanizates containing the HV BR with a high content of 1,2-vinyl units change more, as the crosslink density of this polymer increases relatively the most. Although NR/HV BR exhibits low hysteresis, it becomes stiff and less ductile after aging. Thus, it cannot be recommended for use in aircraft tire retreads. Comparing the various types of fillers in NR/HC LCB BR vulcanizates, the pure SI-filled material shows better retention of tensile strength, Elongation at Break (EAB), M100\% and $\tan \delta$ against aging compared to the other filler systems. The use of a silica-silane filler system in the NR/HC LCB BR blend results in covalent filler-rubber interaction by the comparatively stable coupling agent link. As the covalent bonds are thermally very stable and not prone to scission and rearrangements, this leads to better retention of tensile strength, $E A B, M 100 \%$ and $\tan \delta$ when compared to the pure CB-filled and CB/SI-filled vulcanizates. Based on the superior mechanical and dynamic properties after aging, pure SI-filled NR/HC LCB BR is preferentially recommended for use in aircraft tire retreads. 


\subsection{INTRODUCTION}

Aircraft (AC) tires are exposed to high forces during takeoff and landing. During taxiing and takeoff the deflection may reach more than $30 \%$, and on landing $45 \%$ deflection or more occur under impact conditions [1]. The most extreme conditions are present during landing due to a significant difference between the tangential velocity of the tire and the high speed of the heavy aircraft at touchdown.

The tires are forced to accelerate from zero to fully free rolling velocity in 0.1 seconds. At slipping, when the rotational velocity of the tire does not yet match the required tangential velocity in order to acquire free-rolling, the temperature of the tread can reach $190^{\circ} \mathrm{C}$ [2]. However, the largest amount of heat is generated when the tire is in full skidding. During skidding, the rotational velocity of the tire is zero, while it is in contact with the runway. Early research by NASA shows that the tread temperature in this case can instantaneously reach $315^{\circ} \mathrm{C}$ [2]. The temperature of the tread rubber is a function of friction and skidding speed [3]; there is no way to avoid either one at landing. Slipping and skidding cause a high accumulation of heat, enough to degrade the rubber locally [4].

The temperature increase causes degradation of the rubber. During degradation, double bonds break open [5]. These can lead to hardening or softening of the material, depending on the polymer. Degradation leads to a change in mechanical and dynamic properties as well as accelerated treadwear which is undesirable. As a consequence, tires need to be retreaded frequently or exchanged by new ones. Aircraft tires are in general retreaded seven or more times [6]. The tread has to be replaced with a new one after only a few hundred cycles. Less retreading and replacement of tires will reduce maintenance costs and downtime. Additionally, there is much pollution of particular matter by the degradation of the tread. Therefore, a rubber material with excellent dynamic and mechanical properties and a high stability against aging is desirable.

Commonly Natural Rubber/Butadiene Rubber (NR/BR) based blends are used in AC tire tread formulations. At high service temperatures, this type of blend undergoes rapid mechanical and dynamic property changes that can decrease the performance of the tread. In the present study of this thesis, selected rubber vulcanizates from previous chapters are aged to gain insight into the consequences of accelerated aging at temperatures close to the service conditions of $A C$ tires. 


\subsection{EXPERIMENTAL}

\subsubsection{MATERIAL AND COMPOUND PREPAPRATION}

Two series of rubber formulations were used for the aging study. In the first part of this investigation, blends of NR with various types of BR reinforced with a CB/SI-filled system were evaluated concerning their aging properties. The rubber ingredients used in this study were: NR: RSS\#1, and four types of BR: High-Cis BR (HC BR), High-Cis Long-Chain Branched (HC LCB BR), Low-Cis star branched BR (LC BR), and High-Vinyl BR (HV BR). The different BR-types have been extensively detailed in Chapter 6. In the second part of this investigation, the NR/HC LCB BR blend was used with three different filler systems: CB, 60/40 CB/SI, and pure SI.

For the first part of this investigation, the rubber formulation is shown in Table 6.3 in Chapter 6 . The CB/SI-filled NR/BR blends were prepared using the two-step mixing procedures as described in Chapter 5, with Zinc Oxide added in the first stage of mixing (Z1), and DPG added in the second stage of mixing (D2).

For the second part of the investigation, the formulations for the NR/HC LCB BR blend reinforced with different filler systems were specified in Table 7.6 in Chapter 7, for CB-C, $\mathrm{CB} / \mathrm{SI}-\mathrm{C}$, and SI-C. The mixing procedure was also described in Chapter 7.

\subsubsection{TESTING OF COMPOUND AND VULCANIZATE PROPERTIES}

Thermal degradation - The raw rubbers were tested concerning thermal degradation using a Thermo Gravimetric Analyzer (TGA). About 8 to $15 \mathrm{mg}$ of the sample was placed in a platinum pan. Analyses were performed under oxygen flow. The heating rate for the cycles was $7^{\circ} \mathrm{C} / \mathrm{min}$ from 30 to $850^{\circ} \mathrm{C}$.

Aging - The specimens were aged by making use of a hot-air oven. For stress-strain properties, specimens in the form of dumbbells type 2 were employed as described in ASTM 412, and for dynamic properties in tension the specimens used were according to DIN 53513. The specimens were placed in the hot-air oven at a temperature of $200^{\circ} \mathrm{C}$ for a specific time. The duration of aging was represented as the number of cycles. One cycle consisted of 5 mins of aging (representing aircraft takeoff), 30 mins of rest at room temperature, 5 mins of aging (representing landing). These conditions were chosen to mimic the actual service conditions.

Tan $\delta$ - Measurements were performed using a GABO Dynamic Mechanical Analyzer in a temperature sweep between $20^{\circ} \mathrm{C}$ and $120^{\circ} \mathrm{C}$, with $1^{\circ} \mathrm{C} /$ min increase rate at a dynamic strain of $3 \%$ and a static strain of $3 \%$, a frequency of $10 \mathrm{~Hz}$, in tension mode. 
All rubber vulcanizates were tested for tensile strength, Elongation at Break (EAB), Modulus at $100 \%$ elongation (M100\%), apparent crosslink density and tan $\delta$ at $100^{\circ} \mathrm{C}$ before and after aging. The stress-strain properties were tested using the procedure as described in Chapter 3. Apparent crosslink density measurements were performed using the method described in Chapter 4.

\subsection{RESULTS AND DISCUSSION}

Thermogravimetry curves are depicted in Figure 8.1. Pure NR shows the lowest thermal stability as NR starts to degrade at temperature of around $150^{\circ} \mathrm{C}$. Different from $\mathrm{NR}$, for which the thermal degradation is dominated by chain scission, the degradation of BR predominantly occurring by crosslinking of two radicals generated when BR is heated in the presence of oxygen. Figure 8.2 depicts the general mechanism of thermal degradation of elastomers including BR. HV BR shows higher thermal stability than the other types of BR. This is due to the fact that HV BR has many tertiary carbon atoms in addition to allylic hydrogen functionalities compared to the other three BR's. The hydrogen atom indicated with a * opposite of the 1,2-vinyl units is the easiest to be removed, and the carbon will be oxidized easily to generate more crosslinks than cis-1,4 or trans-1,4 units: Figure 8.3. Additionally, the 1,2-vinyl group itself is prone to react with oxygen radicals of all sorts, like given in Figure 8.2 , to result in multiple crosslinks per radical. Altogether HV BR strongly tends to crosslinking upon aging, whereas the other three do not. The rapid weight loss of the other three BR's above $450^{\circ} \mathrm{C}$ is due to the increase of volatile decomposition species produced and a corresponding decrease in molecular weight of these BR's.

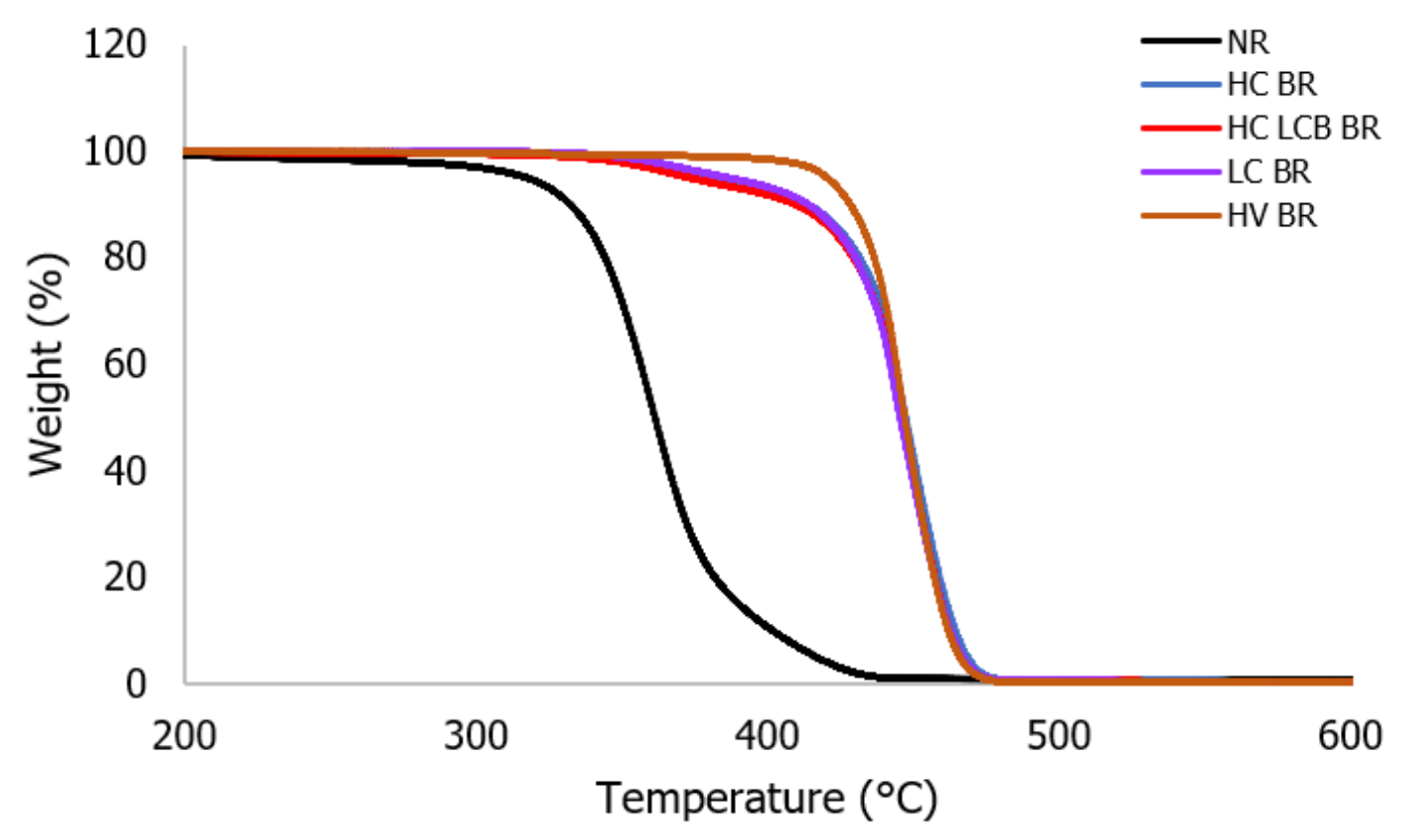

Figure 8.1 Thermogravimetry curves of NR and four types of BR. 


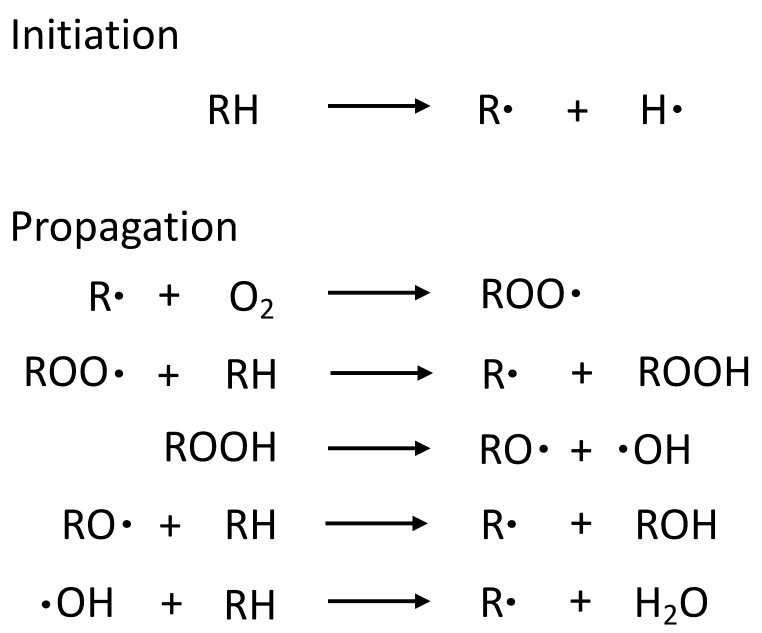

Termination

$$
\begin{aligned}
2 \mathrm{R} \cdot & \longrightarrow \mathrm{RR} \\
2 \mathrm{ROO} \cdot & \longrightarrow \\
\mathrm{R} \cdot+\mathrm{ROO} \cdot & \longrightarrow \mathrm{ROOR}+\mathrm{O}_{2} \\
\mathrm{R} \cdot+\mathrm{RO} \cdot & \longrightarrow \mathrm{ROOR} \\
\cdot \mathrm{OH}+\mathrm{ROO} \cdot & \longrightarrow \mathrm{ROR} \\
& \longrightarrow \mathrm{ROH}+\mathrm{O}_{2}
\end{aligned}
$$

Figure 8.2 Thermal oxidative degradation mechanism of rubber [5].

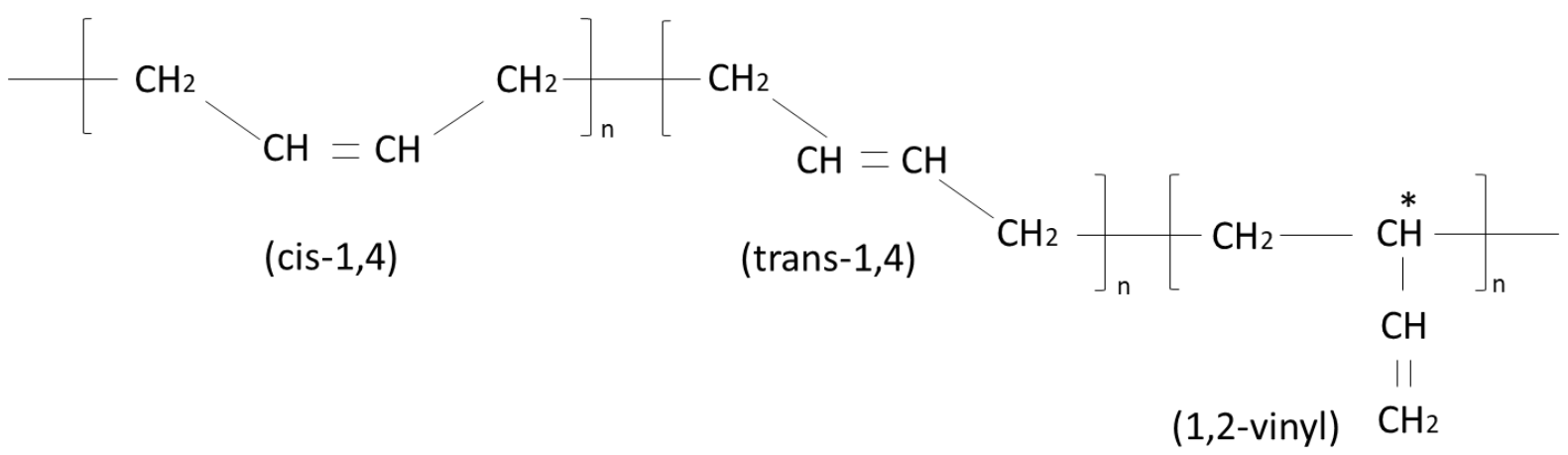

Figure 8.3 Structures of BR [7]. 
Figures 8.4(a)-(b) show the tensile strength and EAB of CB/SI-filled NR blends with the various types of BR. Tensile strength and $E A B$ of the vulcanizates decrease rapidly at the beginning of aging, and as aging continues the values gradually decrease further. NR/HV BR shows a slightly higher tensile strength but lower EAB compared to the other types of BR.

(a)

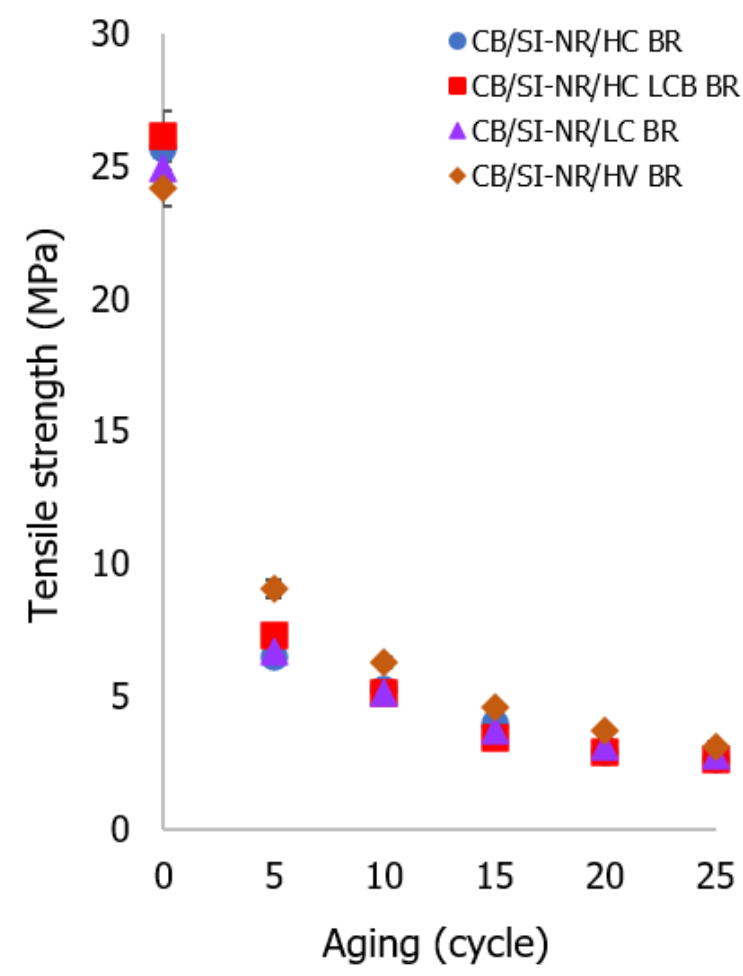

(b)

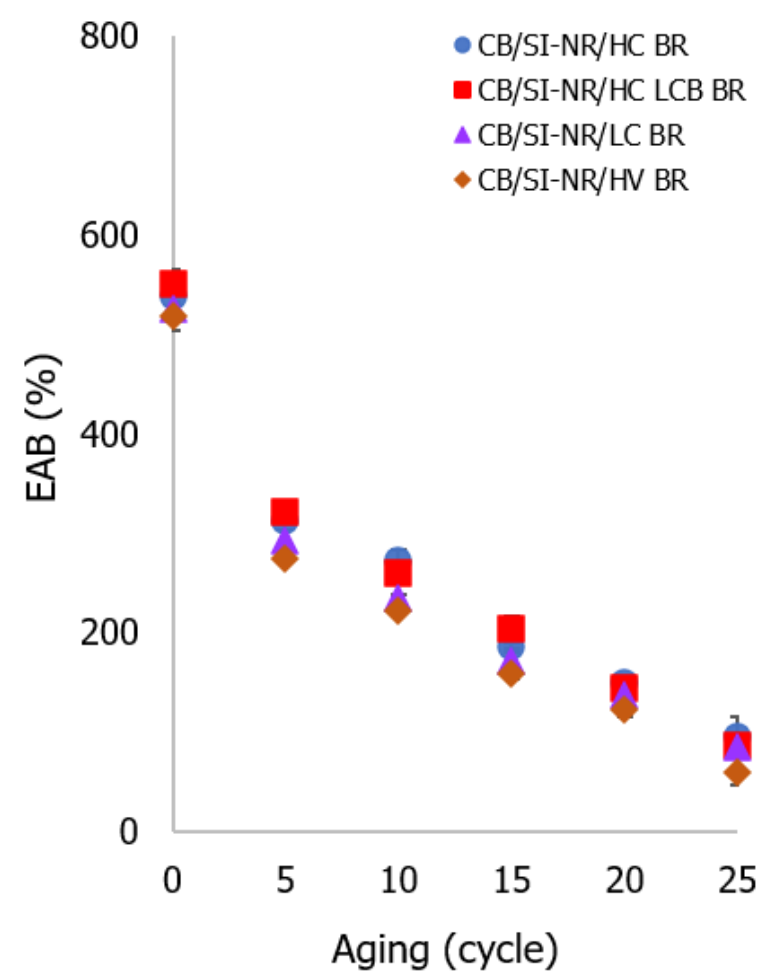

Figure 8.4 Tensile strength (a); $E A B(b)$ of $C B / S I$ filled NR blends with different types of $B R$ as a function of aging cycles.

NR generally has a lower thermal stability than BR: Figure 8.1 . Therefore, at $200^{\circ} \mathrm{C}$ and in the presence of oxygen, NR degrades already at the beginning of the aging procedure. Chain scission is more dominant in NR than re-crosslinking of polymers. In the presence of oxygen and accelerated by heat, an intermediate cyclic structure is formed in NR. Subsequent breakage of labile oxygen-oxygen bonds leads to chain scission and shorter polymer chains with carbonyl end groups [8]. The mechanism of NR softening/degradation is shown in Figure 8.5. NR contributes more to the tensile strength of the blend vulcanizates compared to BR due to its strain-induced crystallization. Therefore, when the NR degrades rapidly in the beginning of aging up to 5 cycles, the tensile strength decreases rapidly. For all types of BR crosslinking is more dominant than chain-scission: Figure 8.2. Consequently, the ratio of crosslinking to chain scission for all NR/BR blends increases as aging proceeds, but new chains created are shorter than the initial chain lengths. An increase of network density and more shorter chains lead to an overall decrease of tensile strength and flexibility, hence a lower EAB. 


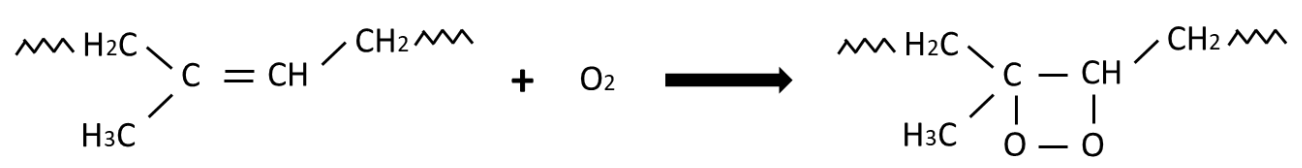

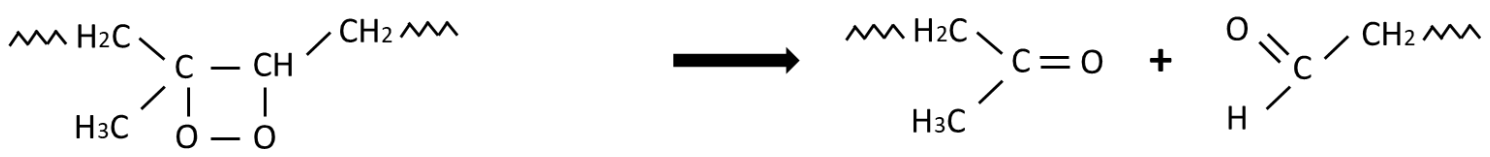

Figure 8.5 Oxidative chain-scission, softening of NR [8].

The $\mathrm{M} 100 \%$ of NR/HV BR is higher than for vulcanizates containing other types of BR, and the difference becomes more pronounced as aging proceeds, as shown in Figure 8.6(a). The longer the aging, the higher the network density generated as depicted in Figure 8.6(b). 1,2-vinyl units are more reactive than cis-1,4 and trans-1,4 units due to the tertiary versus allylic carbons and vinyl-functionalities themselves, thus react more readily with oxygen. At 25 cycles, NR/HV BR becomes too stiff, so that it cannot reach $100 \%$ elongation anymore: Figure 8.4(b). Similarly, the M100\% of NR/HV BR at 25 cycles cannot be measured anymore: Figure $8.6(\mathrm{a})$. Figure 8.7 shows a strong correlation between the apparent crosslink density and $\mathrm{M} 100 \%$ for all vulcanizates with different types of BR. The crosslink density is the prime governing factor for modulus, of which the $\mathrm{M} 100 \%$ is a representative: the higher the apparent crosslink density, the higher the M100\%.

(a)

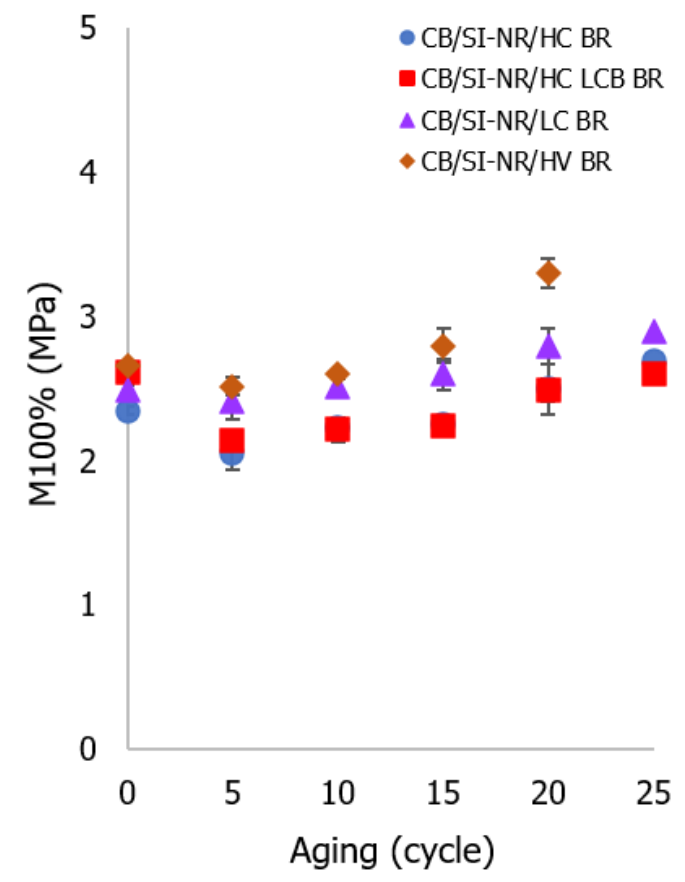

(b)

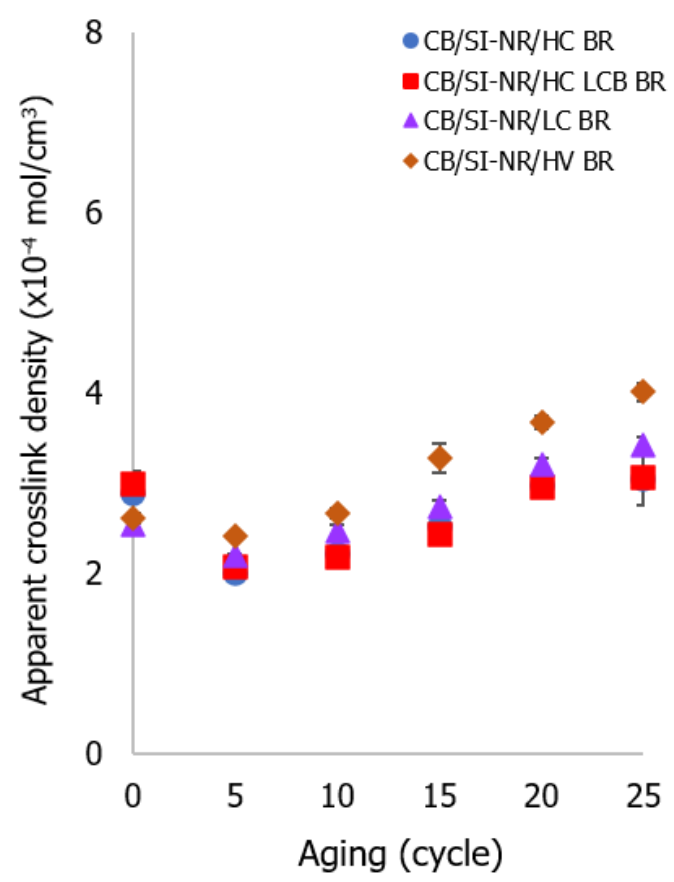

Figure 8.6 M100\% (a); apparent crosslink density (b) of CB/SI filled NR blends with different types of $B R$ as a function of aging cycles. 


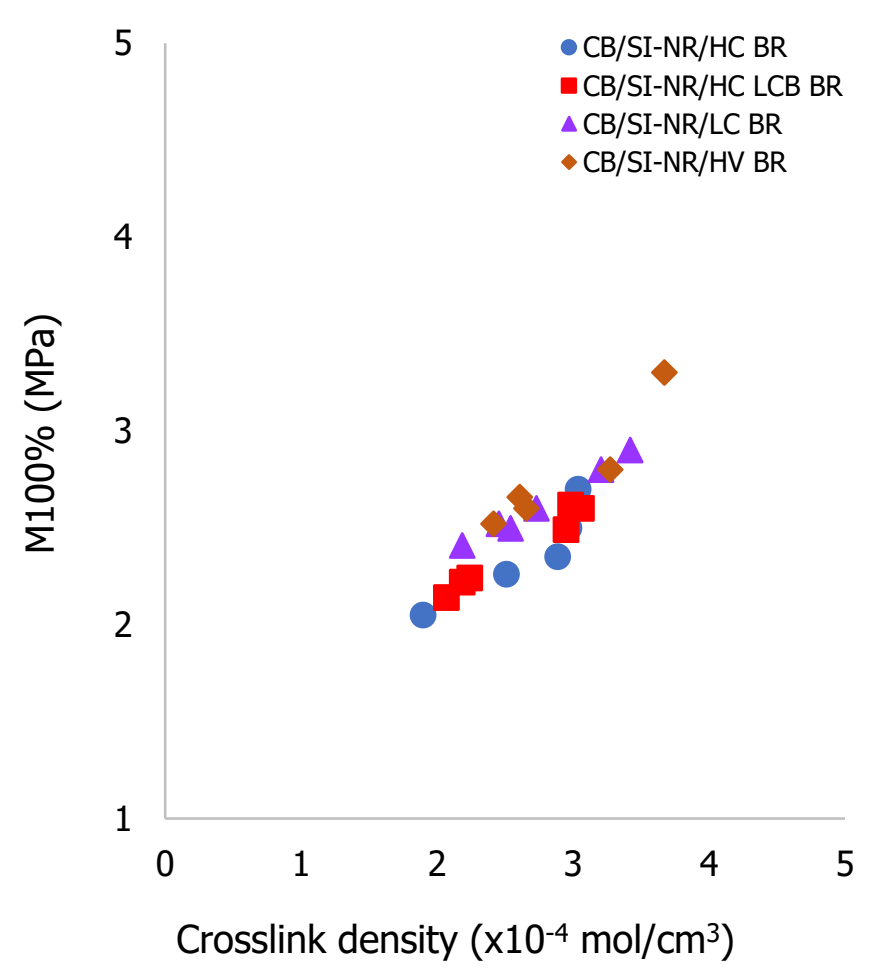

Figure 8.7 M100\% versus apparent crosslink density of CB/SI filled NR blends with different types of BR.

On comparing the differences in aging for the four different BR's in this first part of the investigation, primarily on basis of decay in tensile strength and $\mathrm{M} 100 \%$-data, the HighVinyl BR (HV BR) performs just a little better than the other three, although the differences are marginally small.

For the second part of this investigation with the High-Cis Long-Chain Branched BR (HC LCB BR) and variation in the filler systems: $C B, C B / S I$ and pure SI, Figure 8.8 shows the stress-strain properties of vulcanizates as a function of aging. As aging proceeds, the SI-filled $\mathrm{NR} / \mathrm{HC}$ LCB BR vulcanizate exhibits a slightly higher tensile strength and $E A B$ compared to $\mathrm{CB} / \mathrm{SI}$ - and $\mathrm{CB}$-filled vulcanizates. The CB-filled rubber clearly performs worst. Similar to what was already seen in Figure 8.6(a), Figure 8.9(a) shows even clearer that M100\% decreases in the beginning of aging, but later on increases again. As stated before, the governing principle is that the ratio of crosslinking to chain scission rises as the number of aging cycles increases: Figure 8.9(b). But the new network chains created become shorter than the initial chain length accompanying the increase in network density. The shorter network-chains lead to the decreases in tensile strength and EAB. As seen in the first part of this study, there is again a strong dependence of $\mathrm{M} 100 \%$ on apparent crosslink density, with a higher apparent crosslink density going together with a higher M100\%: Figure 8.10. 
(a)

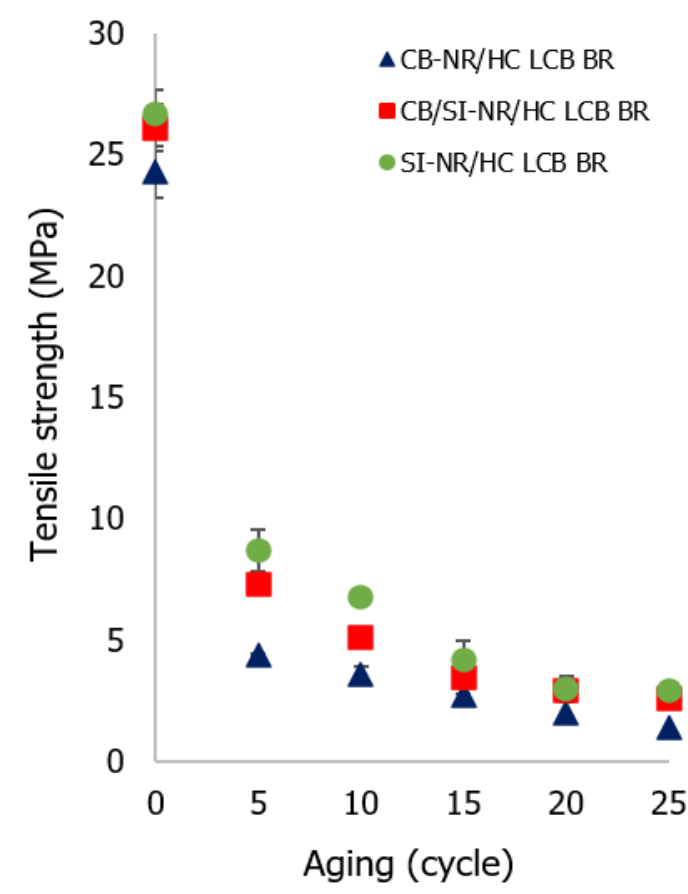

(b)

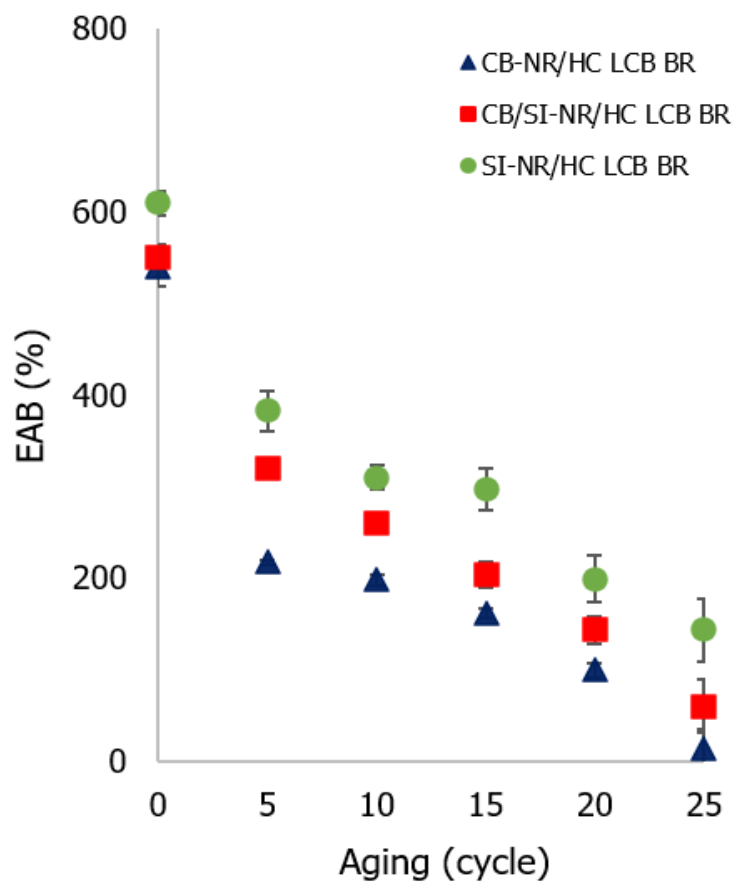

Figure 8.8 Tensile strength (a); EAB (b) of vulcanizates with different filler systems as a function of aging cycles.

The differences in apparent crosslink densities as shown in Figure 8.9(b) result from the contribution of polymer-polymer crosslinks and filler-polymer interactions. Although all filler systems result in comparable apparent crosslink densities, SI-vulcanizates show slightly superior stress-strain properties compared to the other filler systems. The noticeable difference between silica and CB lies in the type of interaction with the polymers. In the SIfilled material, the filler-rubber interaction is derived from covalent bonds between silica and the polymers via the silane coupling agent. In CB-filled rubber, two mechanisms of filler-rubber interaction are commonly proposed: the first mechanism is adsorption in which Van der Waals forces and chemisorption play the main roles [9]. The second mechanism states that bound rubber formation is attributed to a chemical process. It is based on the assumption that functional groups present on the CB surface can react with the rubber $[10,11]$, and/or by the reaction of rubber radicals formed by mechano-chemical degradation with the active sites of $\mathrm{CB}$ during mixing $[12,13]$. In the $\mathrm{CB} / \mathrm{SI}$-filled polymer, filler-rubber interaction comes from the combination of chemical and physical bonds.

Altogether this series of experiments shows that pure SI rubber and somewhat less $\mathrm{CB} / \mathrm{SI}$ material perform significantly better than pure $\mathrm{CB}$-filled vulcanizates in terms of aging on basis of tensile strength and EAB. As to $\mathrm{M} 100 \%$ and apparent crosslink density, no significant differences are seen as these two are mutually related. 
(a)

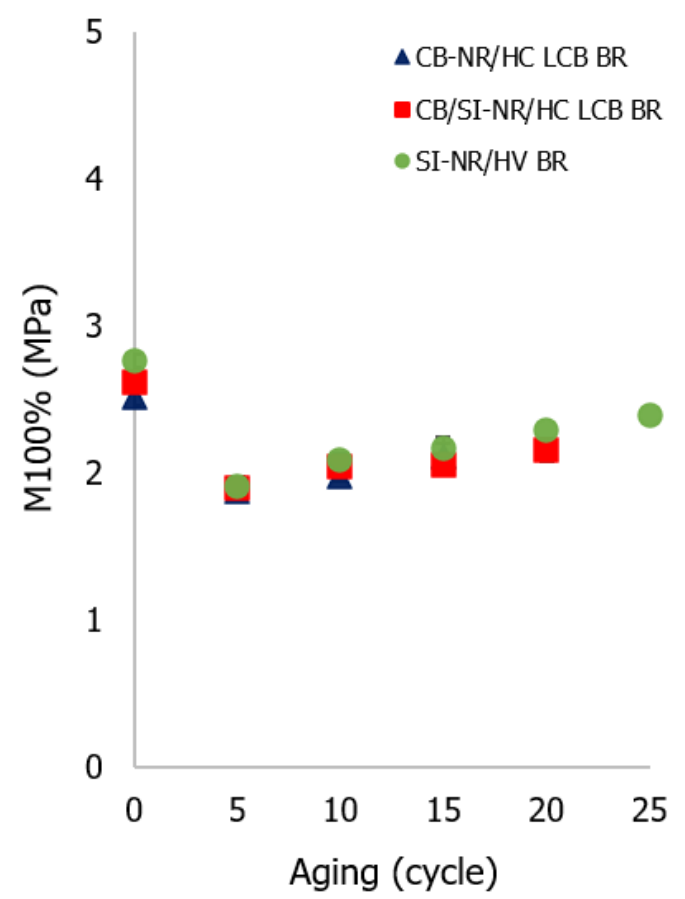

(b)

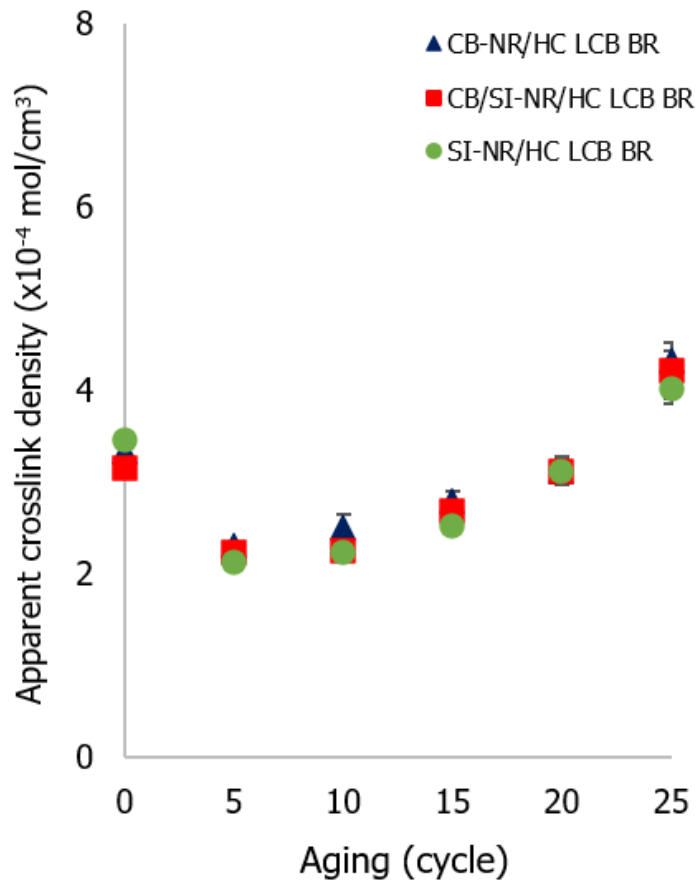

Figure 8.9 M100\% (a); apparent crosslink density (b) of vulcanizates with different filler systems as a function of aging cycles.

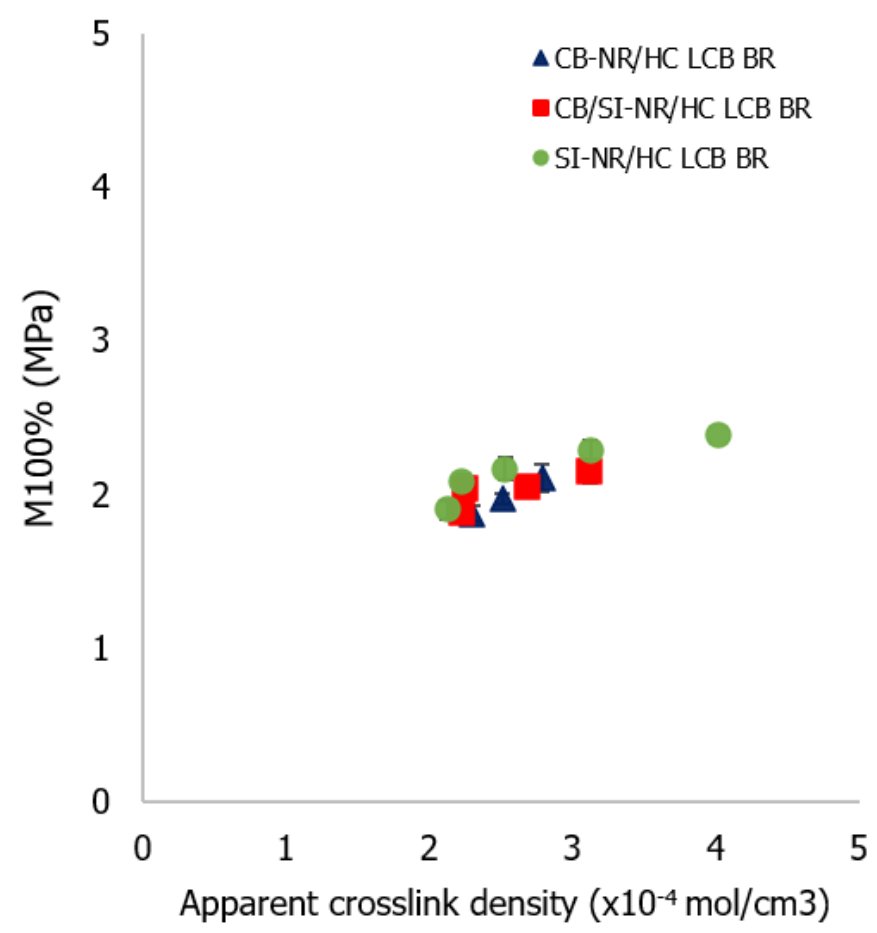

Figure 8.10 Apparent crosslink density versus M100\% of vulcanizates with different filler systems. 
Figure 8.11 shows the hardness as a function of aging cycles for both series of experiments combined: Figure 8.11(a) for the first series with variation in BR, and Figure 8.11(b) for the second series with variation in the filler system. The hardness of vulcanizates rises as aging increases. As hardness is directly related to modulus, the curves show the same trends as $\mathrm{M} 100 \%$ and apparent crosslink density: the higher the extent of crosslinking, the higher the hardness. NR/HV BR shows a slightly higher hardness compared to the other types of BR: Figure 8.11(a), like for the M100\% in Figure 8.6(a), due to the higher apparent crosslink density in Figure 8.6(b). Vulcanizates with different filler systems show comparable hardness as shown in Figure 8.11(b). The latter results are in line with the apparent crosslink density as depicted in Figure 8.9(b). Figures 8.12(a) and (b) show the dependences of hardness on apparent crosslink density for both series of investigations.

(a)

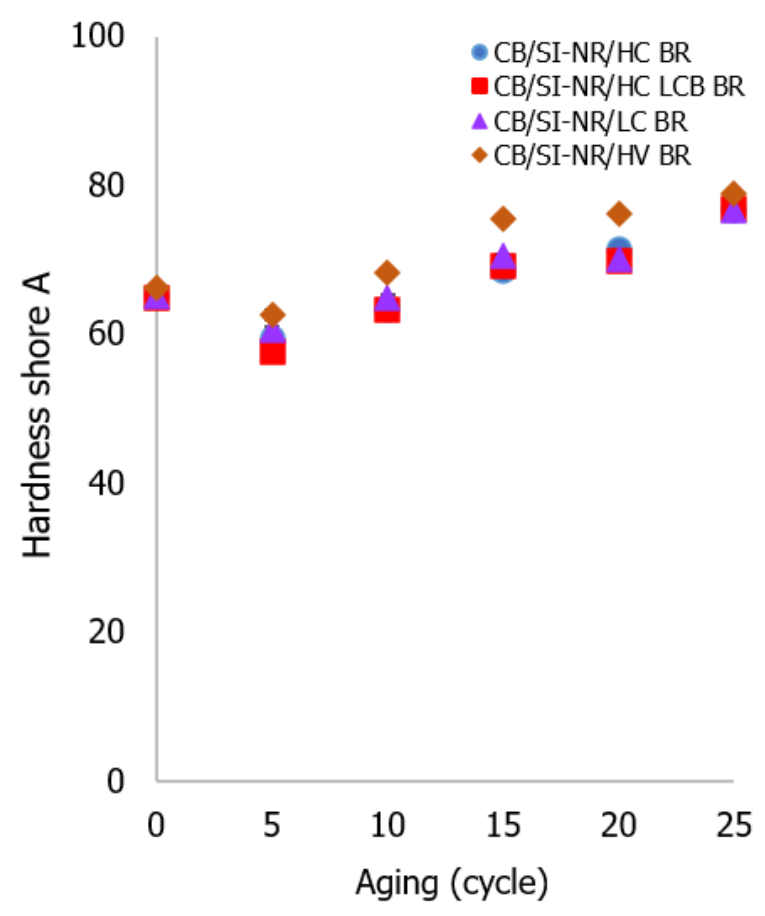

(b)

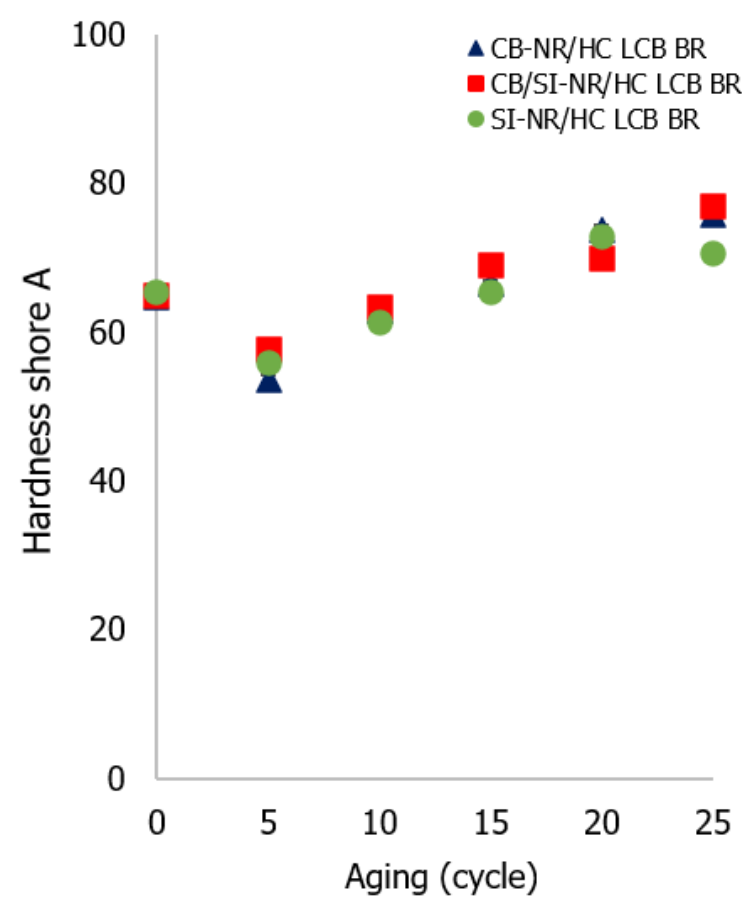

Figure 8.11 Hardness of CB/SI filled NR blends with different types of $B R(a)$; hardness of NR/HC LCB BR reinforced with different filler systems (b) as a function of aging cycles. 
(a)

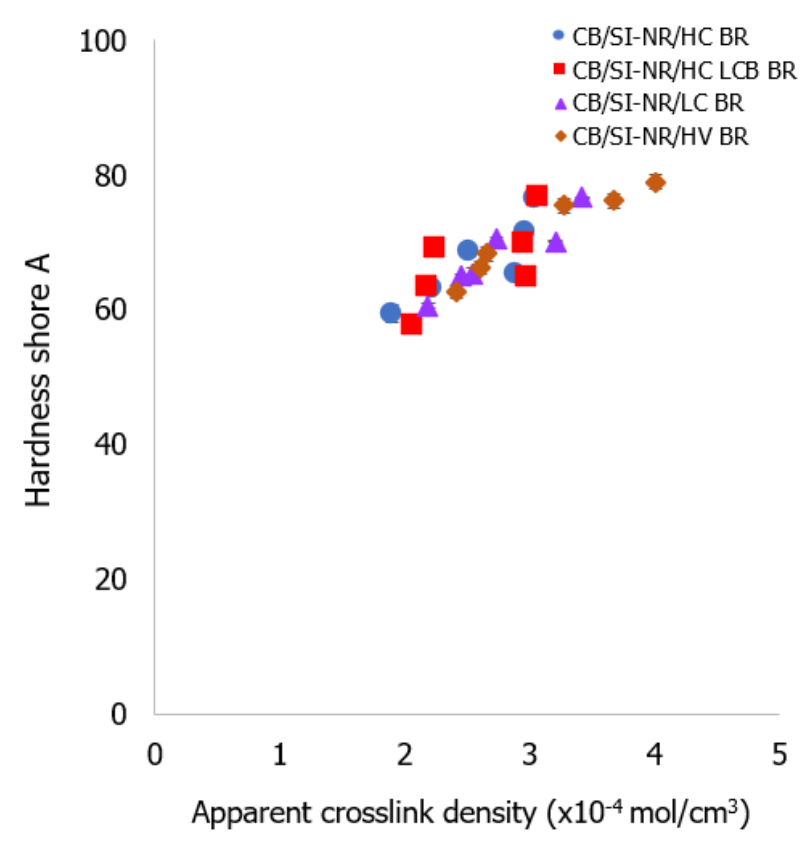

(b)

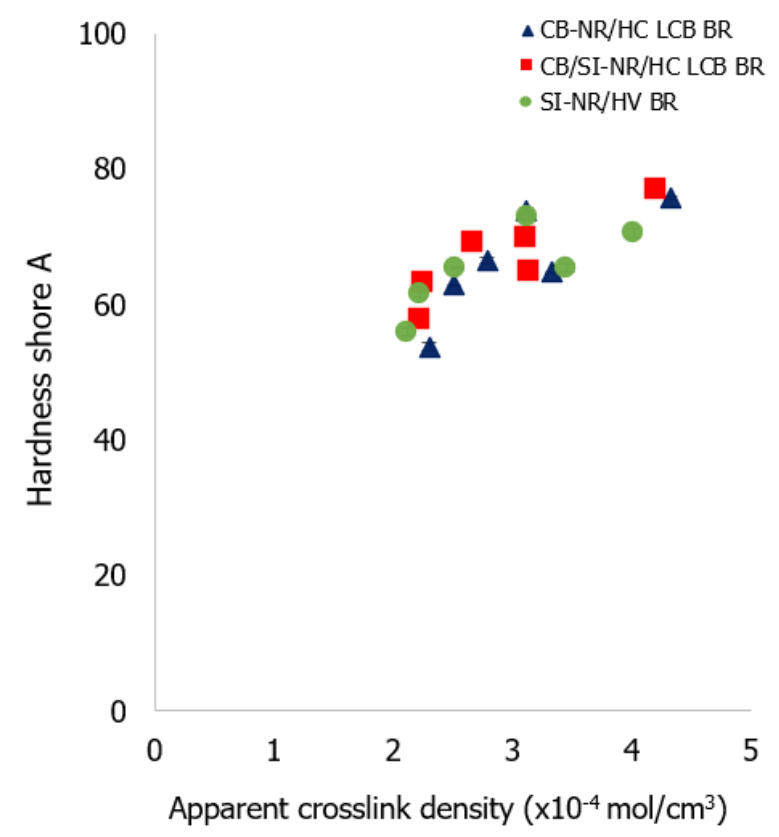

Figure 8.12 Apparent crosslink density versus hardness of: CB/SI filled NR blends with different types of BR (a); NR/HC LCB BR reinforced with different filler systems (b).

The $\tan \delta$ at $100^{\circ} \mathrm{C}$ values derived from the temperature sweep by DMA of vulcanizates with different types of BR as a function of aging is shown in Figure $8.13(\mathrm{a})$. The tan $\delta$ at $100^{\circ} \mathrm{C}$ was earlier used as indicator of Heat Build-Up (HBU). The values of tan $\delta$ for the different types of BR are highly influenced by crosslink density. The tan $\delta$ of NR/HV BR is the lowest among the other vulcanizates. This is in correspondence with the strongest crosslinking reactivity of HV BR compared to other types of BR, as seen before: Figure 8.6(b).

For the second series of experiments using the same rubber but different filler systems, the $\tan \delta$ of the vulcanizates reinforced by silica shows the lowest value compared to the two other filler systems as shown in Figure 8.13(b). As explained earlier, the interaction between filler and polymers in SI-filled rubber is mainly covalent of nature. Therefore, SI-filled compounds exhibit lower tan $\delta$ compared to the other filler systems.

The inverse trend between $\tan \delta$ and apparent crosslink density is shown in Figures 8.14(a)-(b). When the vulcanizates have densely crosslinked networks, the rubber chain mobility becomes highly restricted, less friction between polymer chains occurs, thus resulting in low tan $\delta$. The added covalent bonding of the SI-filler to the polymer clearly shows in the relatively low tan $\delta$ values versus apparent crosslink density in Figure 8.14(b). 
(a)

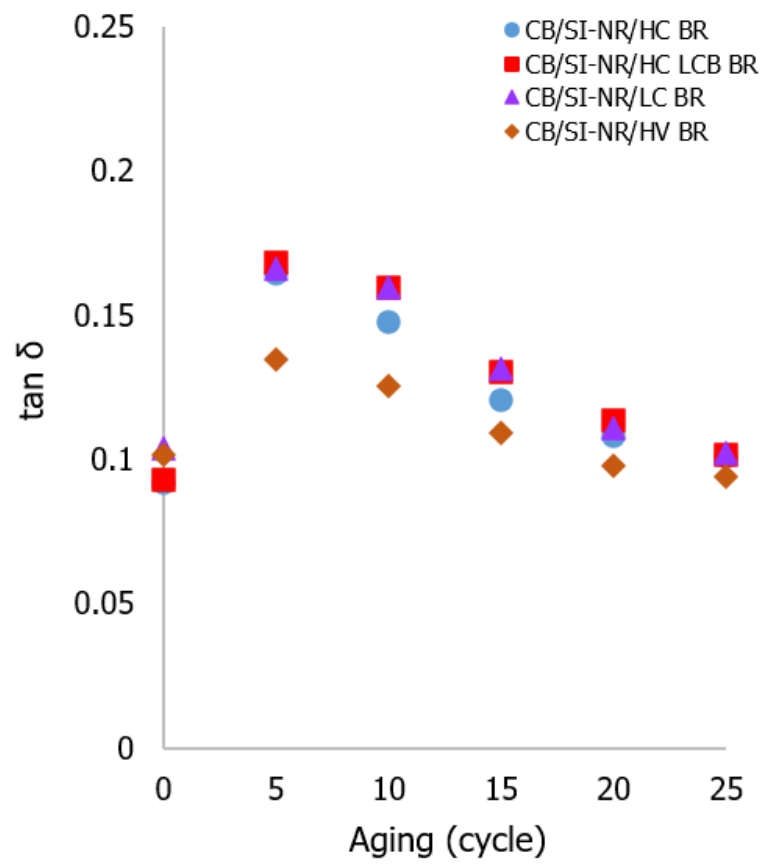

(b)

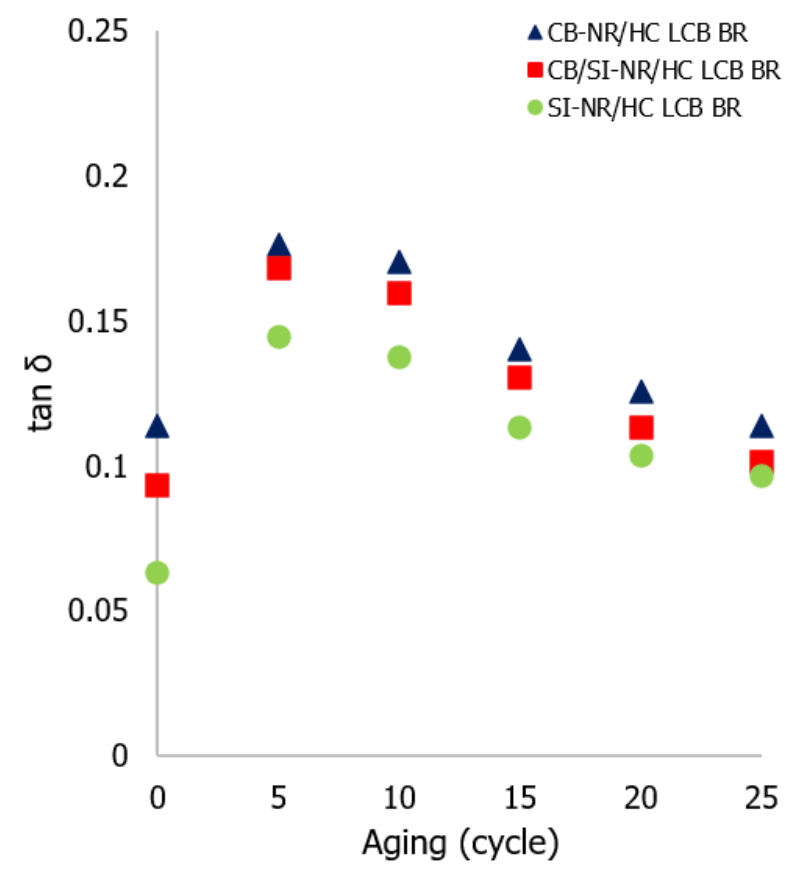

Figure 8.13 Tan $\delta$ of: CB/SI filled NR blends with different types of BR (a); NR/HC LCB BR reinforced with different filler systems (b) as a function of aging cycles.

(a)

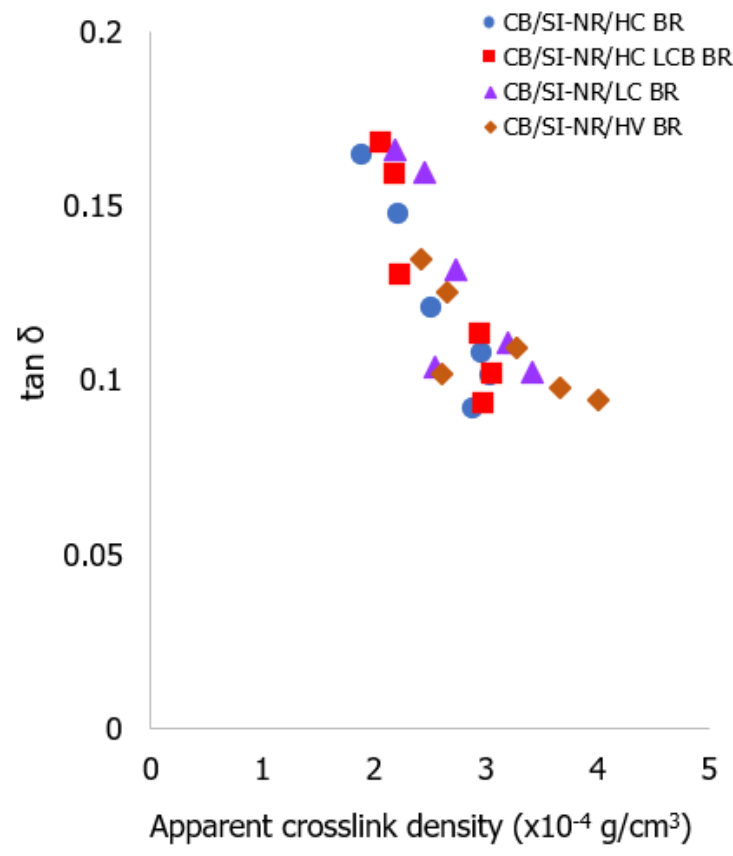

(b)

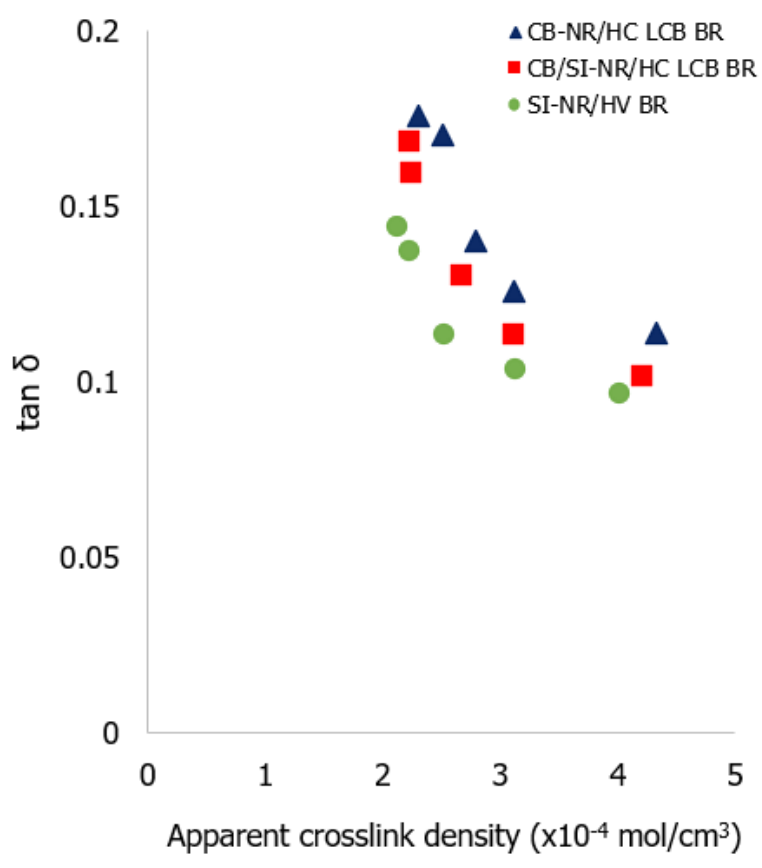

Figure 8.14 Apparent crosslink density versus $\tan \delta$ of: $C B / S I$ filled NR blends with different types of BR (a); NR/HC LCB BR reinforced with different filler systems (b). 


\subsection{CONCLUSIONS}

The aging properties of aircraft tire retreads were studied in the present chapter. In the first part, $\mathrm{CB} / \mathrm{SI}$-filled vulcanizates with different types of BR in blends with NR were compared. The NR/HV BR blend filled with $\mathrm{CB} / \mathrm{SI}$ shows the highest stiffness as indicated by $M 100 \%$ and lowest tan $\delta$ after aging compared to other types of BR in the blend. Crosslink density was assigned as the main governing property changing significantly during aging. At the high temperature of aging of $200^{\circ} \mathrm{C}$, close to the temperature of the AC tire tread during service, the 1,2 vinyl-BR becomes extra reactive, resulting in a rising crosslink density after a prior decrease of the blend with NR, which in turn leads to high $\mathrm{M} 100 \%$ and otherwise low $\tan \delta$. NR/HV BR therefore does show low HBU, the opposite point is that the rubber may become too stiff and hence loose more ductility after aging than the alternative three BR's. Therefore, it is less recommended for AC tire retreads.

In the second part of this study, the aim was to improve the aging properties of the $\mathrm{NR} / \mathrm{HC}$ LCB BR blend with varied filler systems. High-cis BR was chosen as this is by far the most common type of BR used in aircraft tire tread formulations. SI-filled NR/HC LCB BR turned out to be the most promising rubber formulation since it shows better aging properties with higher tensile strength and EAB compared to the other systems. The $\tan \delta$ of the SIreinforced rubber is the best, not only due to the crosslinking density but also due to a high silanization efficiency leading to high density of chemical filler-rubber bonds. A NR/HC LCB BR blend with a SI-filler therefore is the most suitable candidate for use in AC tire retread applications.

\subsection{REFERENCES}

1. Allmond, D.V. and Sobhanie, M.E., Bias Aircraft Tire, to Goodyear Tire and Rubber Co, EP1205316A2 (2002).

2. NASA Langley Research Center, Quasi-Static and Dynamic Response Characteristics of F-4 Bias-Ply and Radial-Belted Main Gear Tires, Washington, USA (1997).

3. Gehman, S.D., et al., Smearing of Vulcanized Rubber, Rubber Chem. Technol., 28, 2, 508 (1955).

4. Mok, K.L. and Eng, A.H., Characterisation of Crosslinks in Vulcanised Rubbers, in 25th Polymer Characterization, Kuala Lumpur, Malaysia (2017).

5. Thermal-Oxidative Degradation of Rubber, Available online: http://polymerdatabase.com/polymer\%20chemistry/Thermal\%20Degradation \%20Elastomers.html (accessed on 11 March 2020).

6. Retreading Airplane Tires, Available online: https://www.dunlopaircrafttyres.co.uk/ technical/retreading-process/ (accessed on 3 June 2020).

7. Noordermeer, J.W.M. and Spit, R.S.H., Elastomeric Technology, Dept. of Elastomer Technology and Engineering, University of Twente: The Netherlands (2011).

8. Fried, J.R., in Polymer Science and Technology, Chapter 6: Polymer Degradation and the Environment, Prentice Hall: Massachusetts, USA (2014).

9. Kraus, G., in Adv. Polym. Sci., Reinforcement of Elastomers by Carbon Black, In: Fortschritte der Hochpolymeren-Forschung, Springer: Berlin, Heidelberg (2005). 
10. Rivlin, D., Use of Lithium Aluminum Hydride in the Study of Surface Chemistry of Carbon Black, Rubber Chem. Technol., 36, 3, 729 (1963).

11. Rivlin, D., Surface Properties of Carbon, Rubber Chem. Technol., 44, 2, 307 (1971).

12. Watson, W.F., Combination of Rubber and Carbon Black on Cold Milling, Ind. Eng. Chem., 47, 6, 1281 (1955).

13. Gessler, A.M., Evidence for Chemical Interaction in Carbon and Polymer Associations. Butyl and Acidic Oxy Blacks. The Possible Role of Carboxylic Acid Groups on the Black, Rubber Chem. Technol., 42, 3, 850 (1969). 
CHAPTER 9

\section{SUMMARY}

Aircraft ( $A C$ ) tires are one of the primary components in an aircraft that have to undergo frequent replacement due to the harsh operating conditions. It is common practice to retread $\mathrm{AC}$ tires several times in order to reduce operating costs. To extend the service life of the AC tire tread, it is of utmost importance to optimize the performance. The key requirements are low hysteresis, excellent tensile and tear strength, high wear resistance, good adhesion to the reinforcing fabric, and good retreadability. The goals of the thesis are to develop an AC tire tread rubber with good processability and high tackiness for good retreadability, additionally to tailor the above-mentioned properties. A balanced performance in terms of low heat generation, which is associated with hysteresis, and high aging resistance with low loss in properties has to be achieved.

An introduction into $A C$ tires including retreading, the background and the aim of the thesis are given in Chapter 1. A literature review on the development of AC tires/retreaded tires, the structure of these tires, the service conditions, the retreading process and the procedure for testing and certification as well as other topics related to AC tire treads/retreads are discussed in the following chapter. The types of rubber and fillers, vulcanization systems and resins used in the formulations, as well as a few examples of compounding of AC tire treads based on patents are also presented in Chapter $\mathbf{2}$.

The experimental part starts in Chapter 3 by defining key factors of NR/BR based blends reinforced with Carbon Black (CB) to optimize the properties of $A C$ tire treads. Four factors are selected, namely type of Butadiene Rubber (BR), mixer set temperature, rotor speed, and mixing time. A Design of Experiments (DOE) evaluation is utilized, consisting of a two-level full factorial setup for initial screening, Response Surface Method (RSM) for optimization, and validation runs for confirmation. It is revealed that rotor speed and mixing time are the most significant factors that considerably improved Mooney viscosity, modulus at $300 \%$ elongation (M300\%), hysteresis/tan $\delta$ at $100^{\circ} \mathrm{C}$ as well as reduced Payne Effect. A high mixer set temperature has an adverse effect on tensile strength, hence a low temperature is preferable. Improvement in processability and filler dispersion are achieved by the use of High-Cis Long-Chain Branched BR (HC LCB BR) compared to High-Cis BR (HC BR), and the rubber has a low tan $\delta$ while still maintaining acceptable stress-strain properties.

Silica-silane filler systems have been employed in Passenger Car Tires (PCT) to replace $\mathrm{CB}$ in the tread compounds aiming at lower Rolling Resistance (RR), increased Wet Skid Resistance (WSR) and comparable abrasion resistance. Due to the excessive heat generation in AC tire treads during service, it is crucial to lower the hysteresis in order to lengthen the 
service life of the treads. With the goal of further decrease in hysteresis, silica-silane is utilized in the $A C$ tread compounds. To optimize the properties of the retreads for these tires, four factors are investigated in Chapter 4. These are the type of BR: HC BR and HC LCB BR, type of filler: $\mathrm{CB} / \mathrm{SI}$ and $\mathrm{SI}$, silanization temperature and time. The results show that there is a strong dependence of the properties on the silanization temperature and time. A high degree of silanization is important to enhance the hydrophobation of the silica by the silane, bis(TriEthoxySilyIPropyl) Tetrasulfide (TESPT), used as coupling agent. The use of HC LCB BR results in better processability by lowering the viscosity, and a more efficient silanization causes a lower Payne Effect (PE) compared to the HC BR counterpart. High filler-rubber interaction of $\mathrm{HC} \mathrm{LCB} \mathrm{BR}$ leads to a higher crosslink density, lower tan $\delta$ at $100^{\circ} \mathrm{C}$, and higher modulus at $300 \%$ elongation as well as tensile strength compared to those based on $\mathrm{HC} B \mathrm{BR}$. $\mathrm{CB} / \mathrm{SI}$-filled vulcanizates show slightly better stress-strain properties, but tan $\delta$ at $100^{\circ} \mathrm{C}$ is higher compared to the SI-filled vulcanizates, indicative for higher hysteresis and heat buildup of corresponding retreads..

The use of silica in combination with $\mathrm{CB}$ in rubber compounds shows potential to lower the hysteresis compared to compounds with $\mathrm{CB}$ as the only filler. When silica is incorporated in rubber compounds, the silanization reaction has to occur in order to create a covalent bond between silica and rubber through the coupling agent. Zinc Oxide ( $\mathrm{ZnO})$ and DiPhenyl Guanidine (DPG) are known as rubber ingredients which can influence the silanization reaction. Chapter 5 focuses on the effect of the addition sequence of these two additives during mixing of $\mathrm{AC}$ tire retread compounds. The addition of $\mathrm{ZnO}$ in the first stage of mixing of NR/BR based blends improves the processability by lowering the Mooney Viscosity (MV) of the compounds and results in a low Payne effect as indication of a low degree of filler-filler interaction. The addition of $\mathrm{ZnO}$ in the last stage of mixing results in a high filler-rubber interaction, signaling a high silanization efficiency. However, due to low reversion resistance, these vulcanizates undergo a stronger reduction in crosslink density compared to the vulcanizates with early addition of $\mathrm{ZnO}$. This occurs during curing, but also during service life. The addition of DPG in the last stage of mixing causes a short cure time and increases fillerrubber interaction. Low tan $\delta$ at $100^{\circ} \mathrm{C}$ and $200^{\circ} \mathrm{C}$ is achieved, when $\mathrm{ZnO}$ is added in the first stage of mixing and DPG in the last step. This addition sequence turns out to be the most promising way to optimize properties in mixing NR/BR based AC tire tread/retread compounds.

High-cis BR is the most common type of BR used in tire tread compounds, including AC tire treads/retreads. BR with a cis-content of more than $95 \mathrm{wt} \%$ is known for superior wear and cut growth resistance. Nevertheless, the balance between traction, hysteresis and stressstrain properties is also crucial for AC tire treads. Butadiene rubbers with different molecular architectures: High-Cis BR (HC BR), High-Cis Long-Chain Branched BR (HC LCB BR), Low-Cis star branched BR (LC BR), High-Vinyl BR (HV BR) are investigated in Chapter 6. The objective is to investigate the effect of the macro- and micro-structures of these BRs on the performance of $A C$ tire retreads in terms of the above-mentioned properties. The compounds are based on NR/BR blends reinforced with CB/SI. NR/HC LCB BR and NR/LC BR show better processability 
due to the effect of branching. NR blends with HC BR or HC LCB BR show shorter cure time, higher strength as well as increased apparent crosslink density. Tan $\delta$ at $100^{\circ} \mathrm{C}$ turns out to be lower compared to NR blends with LC BR or HV BR. This is due to the fact that cis-1,4 units show a higher reactivity towards TESPT used as coupling agent, which results in a lower Payne effect and higher filler-rubber interaction compared to a BR type with a high percentage of trans-1,4 and 1,2-vinyl units. The difference between NR/HC LCB BR and NR/HC BR concerning their effect on tan $\delta$ at $100^{\circ} \mathrm{C}$ is seen at low frequency, in which the former shows a slightly lower $\tan \delta$ than the latter due to branching. At a temperature of $200^{\circ} \mathrm{C}$, which can occur on the surface of AC tire treads during landing, NR/HV BR has the lowest $\tan \delta$. NR/HV BR shows a higher reversion resistance which leads to a higher crosslink density at the service temperature compared to the other types of BR. HV BR blends with NR disclose their potential for use in AC tire retread applications, since they provide a low tan $\delta$ at $200^{\circ} \mathrm{C}$ as an indication of low heat build-up (HBU).

Retreading of $A C$ tires is the most effective way to reduce the operation costs. For the new tread compound to be able to adhere properly to the carcass of the tire to be retreaded, and to retain the shape before curing, the compound should have high tackiness and green strength. Oligomeric resins are known as tackifiers. Chapter $\mathbf{7}$ investigates the effect of resins on tackiness and other properties of AC tire retreads. Two types of resin: terpene phenol and aromatic hydrocarbon $\mathrm{C} 9$ resin are added to compounds with three different filler systems: $\mathrm{CB}, \mathrm{CB} / \mathrm{SI}$, and SI. The addition of these resins slightly increases tensile strength, $\mathrm{M} 300 \%$ and Elongation at Break (EAB), independent of the filler system. The use of resins improves the tackiness of the compounds for each of the filler systems, which is beneficial for the retreading process. In the AC tire tread formulations used in the present project, the use of terpene phenol and aromatic C9 resin shows significant improvements in Ice Traction (ICT) and WSR for the three filler systems. Both resins result in comparable ICT, while the C9 resin provides a better WSR than the terpene phenol. A significant improvement of about $50 \%$ in $\tan \delta$ at $100^{\circ} \mathrm{C}$ as an indication of $\mathrm{HBU}$ is observed when switching from CB to the SI filler system. When resins are additionally used, only a slight improvement in HBU is observed in the SIfilled system. The use of resins not only improves processing and tackiness of the compounds, an important factor for the retreading process, but also shows promising results in terms of mechanical as well as dynamic properties of AC tire retreads.

The temperature reached on the surface of AC tire treads during service is so high that it can degrade the rubber. Degradation leads to a change in mechanical and dynamic properties as well as accelerated tread wear, which is unwanted. Accelerated aging at a temperature of $200^{\circ} \mathrm{C}$, which is close to the service temperature of the $\mathrm{AC}$ tire tread during landing, is investigated in Chapter $\mathbf{8}$ to see the performance of the tread rubber in terms of stress-strain properties, hardness, and tan $\delta$ during its lifetime. In the first investigation, NR is blended with different types of BR: $H C B R, H C L C B B R, L C B R$ and HV BR and reinforced with $\mathrm{CB} / \mathrm{SI}$. The vulcanizates of these compounds were aged in a hot air oven and underwent specific aging cycles. Crosslink density was determined as the main property change during 
aging. At an aging temperature of $200^{\circ} \mathrm{C}$, the 1,2 vinyl-BR becomes highly reactive, resulting in a rising crosslink density after a prior decrease, which in turn leads to higher $\mathrm{M} 100 \%$ and lower $\tan \delta$. NR/HV BR, therefore, does show low HBU; the downside is that the rubber may become too stiff and hence loses ductility to a higher degree after aging than the material with the alternative three BR's. Therefore, this BR type is less recommended for AC tire retreads. Among the different filler systems investigated in the second part, silica in a NR/HC LCB BR blend is proven to be the most favorable combination since it exhibits excellent aging properties with higher tensile strength and EAB compared to the other materials. The $\tan \delta$ of the SI-reinforced rubber is the lowest, not only due to the crosslink density but also due to a high silanization efficiency leading to a high density of chemical filler-rubber bonds. An $\mathrm{NR} / \mathrm{HC}$ LCB BR blend with silica as only filler, therefore, is the most promising candidate for use in $A C$ tire retread applications.

This thesis confirms the importance of the correct selection of rubber ingredients as well as processing parameters to optimize the properties of AC tire retreads. It was revealed that the determination and optimization of the most significant factors in the mixing process can effectively enhance the properties of AC tire retreads. DOE was proven to be a useful tool to elaborate the significant parameters which influence the properties of AC tire retreads. Hence DOE was utilized not only to predict the properties, but also to optimize them effectively. The correct addition sequence of ZnO and DPG can improve the properties of rubbers containing silica. The use of HC LCB BR can significantly improve the processability and the dispersion of fillers. The combination of HC LCB BR and silica as reinforcing filler can lower the hysteresis which is of crucial importance for AC tire treads. The aging properties also improve considerably when silica is added while maintaining high stress-strain properties. Tackiness can be enhanced by the incorporation of resins which is beneficial in the retreading process. The current investigatory study on the addition of resins shows a significant improvement in the overall performance of AC tire retreads, justifying more in-depth investigations into this possibility in real tires. Overall, from a technological point of view, the outcome of the thesis will be valuable as guiding principles for the further optimization of retread rubber for $A C$ tires. 


\section{SAMENVATTING}

Banden vertegenwoordigen een van de belangrijkste componenten van een vliegtuig, die regelmatig vervangen moeten worden vanwege de uiterst zware belastingen. Het is gebruikelijk om vliegtuigbanden meerdere malen van een nieuw loopvlak te voorzien omwille van de hoge kosten van nieuwe banden. Om de levensduur van het loopvlak van vliegtuigbanden te verlengen, is het noodzakelijk om hun belangrijkste functionele eigenschappen te optimaliseren. De belangrijkste eisen zijn lage hysterese, uitstekende treken scheursterkte, hoge slijtvastheid, goede hechting aan de versterkende koorden in het karkas en goede vernieuwbaarheid. De doelstelling van dit proefschrift was de ontwikkeling van rubber geschikt voor loopvlakvernieuwing van vliegtuigbanden, welke aan bovenstaande eisen voldoet, met goede verwerkbaarheid en hoge tack (spontane hechting bij het aanbrengen op het karkas voorafgaand aan vulkanisatie). Daarnaast moeten de gevolgen van veroudering beperkt blijven, zoals constante trek-rek-eigenschappen.

Een inleiding in het thema vliegtuigbanden inclusief loopvlakvernieuwing, de achtergrond en het doel van het proefschrift worden gegeven in Hoofdstuk 1. Een literatuuroverzicht over de ontwikkeling van vliegtuigbanden, de structuur van deze banden, de gebruiksomstandigheden, het vernieuwingsproces en de procedure voor testen en certificeren worden in Hoofdstuk 2 besproken, naast andere onderwerpen die verband houden met vliegtuigbanden. De soorten rubber en vulstof, vulkanisatiesystemen en harsen die in de formuleringen worden gebruikt; enkele voorbeelden van compoundering van loopvlakken voor vliegtuigbanden op basis van patenten worden ook beschreven in dit hoofdstuk.

Het experimentele deel begint in Hoofdstuk 3 met het definiëren van de sleutelfactoren van mengsels gebaseerd op NR/BR en versterkt met Roet/Carbon Black (CB), om de eigenschappen voor gebruik in loopvlakken van vliegtuigbanden te optimaliseren. $\mathrm{Er}$ worden vier factoren gekozen, namelijk het type Butadiëen Rubber (BR), mengtemperatuur, rotorsnelheid en mengtijd. Er wordt gebruik gemaakt van Design of Experiments (DOE) bestaande uit een 'two level full factorial setup' voor initiële screening, 'Response Surface Method' (RSM) voor optimalisatie en validatieruns om de uitkomst te toetsen. In dit deel van het onderzoek wordt duidelijk, dat rotorsnelheid en mengtijd de belangrijkste factoren zijn om Mooney-viscositeit, Modulus bij 300\% rek (M300\%), en hysterese/tan $\delta$ bij $100{ }^{\circ} \mathrm{C}$ aanzienlijk te kunnen verbeterden, evenals het Payne-effect. Een hoge mengtemperatuur heeft een nadelige invloed op de treksterkte en daarom verdient een lage mengtemperatuur de voorkeur. Verbetering van de verwerkbaarheid en een hogere dispersiegraad van de vulstof worden bereikt door het gebruik van High-Cis Long-Chain Branched Butadiëen Rubber (HC 
LCB BR) in plaats van High-Cis BR (HC BR), waarbij het rubber een lage tan $\delta$ heeft met behoud van goede trek-rek eigenschappen.

Silica-silaan vulstof systemen worden gebruikt voor personenwagenbanden in plaats van $\mathrm{CB}$ met als doel een lagere rolweerstand, verhoogde natte slipweerstand (WSR) en vergelijkbare slijtvastheid. Vanwege de overmatige warmteontwikkeling in het loopvlak van vliegtuigbanden tijdens gebruik is het van belang om de hysterese te verlagen en zo de levensduur van het loopvlak te verlengen. Om de hysterese te verminderen werd silica-silaan in plaats van roet als vulstof gebruikt in de vliegtuig-loopvlak compounds in Hoofdstuk 4. Voor verdere optimalisatie van de eigenschappen van de loopvlakken voor hernieuwing van vliegtuigbanden werden vier factoren onderzocht. Dit zijn het type BR: HC BR en HC LCB BR, het type vulstof: CB/SI en SI, de silanisatie-temperatuur en -tijd. De resultaten tonen aan dat het eigenschappenprofiel sterk afhangt van de silanisatie-omstandigheden. Een hoge silanisatiegraad is van doorslaggevend belang om hydrofobering van het silicaoppervlak door het silaan te bewerkstelligen. In het huidige onderzoek is bis-(TriEthoxySilyIPropyl)Tetrasulfide (TESPT) als 'coupling agent' gebruikt. Wordt HC LCB BR als polymeer gebruikt, dan resulteert dit in een betere verwerkbaarheid door verlaging van de viscositeit. Daarnaast verloopt de silanisatie efficiënter, wat resulteert in een lager Payne Effect (PE) in vergelijking met de $\mathrm{HC}$ BR-tegenhanger. Hoge vulstof-rubber interacties van HC LCB BR-mengsels leiden tot een hogere netwerkdichtheid, lagere tan $\delta \mathrm{bij} 100{ }^{\circ} \mathrm{C}$, hogere modulus bij $300 \%$ rek (M300\%) en hogere treksterkte in vergelijking met de eigenschappen die met HC BR worden gehaald. Met $\mathrm{CB} / \mathrm{SI}$ gevulde vulkanisaten vertonen iets betere trek-rek eigenschappen, maar de tan $\delta$ bij $100{ }^{\circ} \mathrm{C}$ is hoger in vergelijking met de SI-gevulde vulkanisaten, aanwijzing voor een hogere hysterese en warmte-ontwikkeling van desbetreffende loopvlakken gedurende de landing. Het gebruik van silica in combinatie met roet toont mogelijkheden om de hysterese te verlagen ten opzichte van alleen roet als vulstof.

Wanneer silica als versterkende vulstof wordt gebruikt, moet een silaniserings-reactie plaatsvinden om een covalente binding te creëren tussen silica en rubber door middel van het silaan. ZinkOxide ( $\mathrm{nO}$ ) en DiPhenyl Guanidine (DPG) staan bekend als rubberingrediënten die de silaniserings-reactie kunnen beïnvloeden. Hoofdstuk 5 richt zich op het onderzoeken van het effect van de volgorde van toevoeging van deze twee additieven tijdens het mengen van loopvlak-rubber mengsels. De toevoeging van $\mathrm{ZnO}$ in de eerste mengfase van mengsels op basis van NR/BR verbetert de verwerkbaarheid door de Mooney-viscositeit (MV) te verlagen, en resulteert in een laag Payne-effect als aanwijzing voor een lage vulstof-vulstof interactie. De toevoeging van $\mathrm{ZnO}$ in de laatste mengfase daarentegen resulteert in een hoge vulstof-rubber interactie, wat duidt op een hoge graad van silanisering. Door een hoge mate van reversie vertonen deze vulkanisaten echter een sterkere vermindering van de netwerkdichtheid in vergelijking met de vulkanisaten waarbij de toevoeging van $\mathrm{ZnO}$ in de eerste mengfase heeft plaatsgehad. Dit fenomeen zal zich ook voordoen tijdens het gebruik van de band, wanneer de temperastuur van het loopvlak stijgt bij de landing. De toevoeging van DPG in de laatste mengfase zorgt voor een korte vulkanisatietijd en verhoogt de interactie 
tussen vulstof en rubber. Een lage tan $\delta$ bij $100{ }^{\circ} \mathrm{C}$ en $200{ }^{\circ} \mathrm{C}$ wordt bereikt wanneer ZnO wordt toegevoegd in de eerste en DPG in de laatste mengfase. Deze volgorde bleek de meest veelbelovende manier om optimale op NR/BR gebaseerde mengsels voor loopvlakken van vliegtuigbanden te produceren.

BR met een hoog cis-gehalte is het meest gebruikte type BR in de rubbersamenstellingen van banden, met inbegrip van loopvlakken voor vliegtuigbanden. BR met een cis-gehalte van meer dan 95 gew.\% staat bekend om zijn superieure scheursterkte en weerstand tegen slijtage. De balans tussen tractie, hysterese en trek-rek eigenschappen is cruciaal voor het loopvlak van vliegtuigbanden. Butadiëen rubbers met verschillende moleculaire architecturen: High-Cis BR (HC BR), High-Cis Long-Chain Branched BR (HC LCB $B R)$, Low-Cis star branced BR (LC BR), High-Vinyl BR (HV BR) zijn het onderwerp van Hoofdstuk 6. Het doel was om het effect te onderzoeken van de macro- en microstructuren van deze BR's op de prestaties van vernieuwde bandenloopvlakken met betrekking tot bovengenoemde eigenschappen. De mengsels zijn gebaseerd op NR/BR-blends versterkt met roet of silica. NR/HC LCB BR en NR/LC BR vertonen betere verwerkbaarheid door het effect van 'branching'/vertakking. NR-mengsels met $\mathrm{HC}$ BR of $\mathrm{HC}$ LCB BR laten een kortere vulkanisatietijd zien en een hogere treksterkte naast verhoogde netwerkdichtheid. De tan $\delta$ bij $100{ }^{\circ} \mathrm{C}$ is lager in vergelijking met NR-mengsels met LC BR of HV BR. Dit komt door het feit dat cis-1,4-eenheden een hogere reactiviteit vertonen richting TESPT dat wordt gebruikt als koppelingsmiddel (coupling agent). Dit resulteert in een lager Payne-effect en een hogere vulstof-rubber interactie in vergelijking met een BR-type met een hoog percentage trans-1,4 en 1,2-vinyl-eenheden. Het verschil tussen NR/HC LCB BR en NR/HC BR betreffende hun effect op tan $\delta$ bij $100{ }^{\circ} \mathrm{C}$ komt naar voren bij lage frequenties, waarbij de eerste een iets lagere tan $\delta$ laat zien dan de laatste vanwege 'branching'. Bij een temperatuur van $200{ }^{\circ} \mathrm{C}$, een temperatuur die tijdens het landen van een vliegtuig in het loopvlak van de banden kan optreden, heeft NR/HV BR de laagste tan $\delta$. NR/HV BR vertoont een lagere reversie wat leidt tot een hogere netwerkdichtheid bij de gebruikstemperatuur in vergelijking met de andere $B R$ typen. HV BR-mengsels met NR tonen hun potentieel voor gebruik ten behoeve van vernieuwde loopvlakken voor vliegtuigbanden, aangezien zij een lage tan $\delta$ bij $200^{\circ} \mathrm{C}$ vertonen als indicatie voor lage warmteopbouw (HBU).

Het vernieuwen van vliegtuigbanden is de meest effectieve manier om kosten te besparen. Om ervoor te zorgen dat nieuwe loopvlakrubber goed hecht aan het oude karkas en zijn vorm behoudt voordat deze is gevulkaniseerd, moet het mengsel een hoge 'tack'/eigenkleverigheid en 'green strength' bezitten. Oligomere harsen staan bekend als kleefmiddelen. Hoofdstuk 7 onderzoekt het effect van harsen op de eigenkleverigheid en andere eigenschappen van belang voor loopvlakken van vernieuwde vliegtuigbanden. Twee soorten harsen: een terpeenfenol en een aromatische koolwaterstof C9-hars worden toegevoegd aan mengsels met drie verschillende vulstof-systemen: $\mathrm{CB}, \mathrm{CB} / \mathrm{SI}$ en $\mathrm{SI}$. De toevoeging van deze harsen verhoogt de treksterkte enigszins, resp. de modulus $300 \%$ en de rek bij breuk (EAB), onafhankelijk van de gebruikte versterkende vulstof. Het gebruik van harsen verbetert de eigenkleverigheid van de mengsels met elk van de vulstoffen, wat gunstig 
is voor het vernieuwingsproces. In de formuleringen van het loopvlak voor vliegtuigbanden zoals in dit project gebezigd, laat het gebruik van terpeenfenol en aromatische C9-hars een significante verbetering zien in Ice Traction (ICT) en Wet Skid Resistance (WSR) voor de drie vulstoffen. Beide harsen resulteren in vergelijkbare Ice Traction, terwijl de C9-hars een betere WSR geeft dan de terpeenfenol. Een significante verbetering van ongeveer $50 \%$ in $\tan \delta$ bij $100{ }^{\circ} \mathrm{C}$ als aanwijzing voor verlaagde $\mathrm{HBU}$ wordt gemeten als roet vervangen wordt door silica. Een lichte verbetering in HBU bij gebruik van beide harsen in vergelijking met een mengsel zonder hars wordt alleen waargenomen in de SI-gevulde rubber. Het gebruik van harsen verbetert niet alleen de verwerking en eigenkleverigheid van de mengsels - belangrijke factoren voor het vernieuwingsproces - maar levert ook veelbelovende resultaten met betrekking tot zowel mechanische als dynamische eigenschappen van vernieuwingsloopvlakken voor vliegtuigbanden.

De temperatuur, die tijdens het gebruik in het loopvlak van vliegtuigbanden optreedt, is hoog genoeg om tot rubber-degradatie te leiden. Dit geeft een verandering in mechanische en dynamische eigenschappen en versnelde slijtage van het loopvlak, hetgeen ongewenst is. Versnelde veroudering bij een temperatuur van $200{ }^{\circ} \mathrm{C}$ bij landing, dicht bij de gebruikstemperatuur van het loopvlak van de vliegtuigband, wordt onderzocht in Hoofdstuk 8; met name om de verandering in trek-rek eigenschappen, hardheid en $\tan \delta$ te zien. In het eerste onderzoek wordt NR gemengd met verschillende soorten BR: HC BR, HC LCB BR, LC $\mathrm{BR}$ en HV BR; als vulstof wordr CB/SI gebruikt. De vulkanisaten worden verouderd in een hete lucht oven met specifieke verouderingscycli. De netwerkdichtheid blijkt het meest gevoelig te zijn voor veroudering. Bij een verouderingstemperatuur van $200^{\circ} \mathrm{C}$ wordt 1,2 vinyl-BR zeer reactief, wat resulteert in een stijgende netwerkdichtheid na een eerdere afname, wat op zijn beurt leidt tot een hogere $\mathrm{M} 100 \%$ en lagere tan $\delta$. NR/HV BR vertoont daarom een lage HBU; het nadeel is dat het rubber te stijf kan worden en daardoor na veroudering in hogere mate z'n ductiliteit verliest dan de materialen met de andere drie BR's. Daarom wordt dit BR-type niet aanbevolen voor rubber voor vernieuwing van vliegtuigbanden. Van de verschillende vulstofsystemen, die in het tweede deel zijn onderzocht, blijkt silica in een NR/HC LCB BRmengsel de gunstigste combinatie te zijn, aangezien het uitstekende verouderingseigenschappen vertoont met een hogere treksterkte en EAB in vergelijking met de andere materialen. De $\tan \delta$ van het SI-versterkte rubber is het laagst, niet alleen vanwege de netwerkdichtheid maar ook vanwege een hoge silanisatie-efficiëntie die leidt tot een hoge dichtheid chemische vulstof-rubber bindingen. Een NR/HC LCB BR-blend met silica als vulstof is daarom de meest veelbelovende kandidaat voor gebruik in vernieuwingstoepassingen voor vliegtuigbanden.

Dit proefschrift bevestigt het belang van de juiste keuze van rubberingrediënten en verwerkingsparameters, om de eigenschappen van vernieuwde vliegtuigbanden te optimaliseren. Het is gebleken, dat de vaststelling en optimalisatie van de belangrijkste factoren in het mengproces de eigenschappen van vernieuwde vliegtuigbanden op effectieve wijze kan verbeteren. DOE bleek een nuttig hulpmiddel om de significante parameters uit te werken, die de eigenschappen van vernieuwings-loopvlakken van vliegtuigbanden 
beïnvloeden. Daarom werd DOE niet alleen gebruikt om de eigenschappen te voorspellen, maar ook om de eigenschappen te optimaliseren. De juiste volgorde van de toevoeging van ZnO en DPG tijdens mengen beïnvloedt de eigenschappen van rubbers met silica als vulstof, en het gebruik van HC LCB BR kan de verwerkbaarheid en de dispersie van vulstoffen aanzienlijk verbeteren. De combinatie van HC LCB BR en silica kan de hysterese verlagen, van groot belang voor de HBU van het loopvlak van vliegtuigbanden. Ook de verouderingseigenschappen verbeteren aanzienlijk wanneer silica wordt toegevoegd, terwijl de eigenschappen bij hoge spanning en rek behouden blijven. De 'tack' kan worden verbeterd door het inmengen van harsen, wat gunstig is bij het vernieuwingsproces. Het onderhavige onderzoek aan de toevoeging van harsen laat een significante verbetering zien in de algehele bruikbaarheid van vernieuwde loopvlakken voor vliegtuigbanden. Het rechtvaardigt meer verdiepend onderzoek naar de mogelijkheden voor automobiel-banden. Al met al zal vanuit technologisch oogpunt de uitkomst van het proefschrift waardevol zijn als leidraad voor de verdere optimalisatie van rubber voor vernieuwing van vliegtuigbanden. 


\section{SYMBOL}

${ }^{\circ} \mathrm{C}$

$\mathrm{E}^{*}$

$\mathrm{E}^{\prime \prime}$

$\mathrm{E}^{\prime}$

$E_{D}$

$E_{H}$

$E_{P}$

E

$E_{\text {coh }}$

$\mathrm{F}$

${ }^{\circ} \mathrm{F}$

G*

$\mathrm{G}^{\prime \prime}$

$\mathrm{G}^{\prime}$

$\Delta \mathrm{G}^{\prime}$

$\Delta \mathrm{H}_{\mathrm{vap}}$

$m_{1}$

$m_{2}$

$m_{r}$

$m_{f}$

$m_{p}$

$\mathrm{ML}(1+4)$

M100\%

$\mathrm{M} 300 \%$

$n+$

$n-$

$\mathrm{R}$

$\mathrm{S}_{\min }$

$\mathrm{S}_{\max }$

$\mathrm{S}_{\max }-\mathrm{S}_{\min }$

$S_{\text {final }}$

$\mathrm{T}$

\section{DESCRIPTION}

degrees Celsius

complex modulus

loss modulus

storage modulus

atomic dispersion force

hydrogen bonding

polar cohesive energy

total cohesion energy

cohesive energy

molar attraction constant

degrees Fahrenheit

complex modulus in shear

loss shear modulus

storage shear modulus

difference in storage modulus

enthalpy of vaporization

weight of polymer

weight of solvent in swollen sample

dry weight of sample

weight of filler

weight of rubber in the sample

Mooney viscosity after 1 minute of preheating and 4 minutes of measuring, measured with a large rotor

modulus at $100 \%$ elongation

modulus at $300 \%$ elongation

total number of experiments in level +1

total number of experiments in level -1

ideal gas constant

minimum torque

maximum torque

torque difference

torque at final measurement time

temperature 


\section{$\tan \delta$}

$\mathrm{Tg}$

$t_{90}$

$\mathrm{ts}_{2}$

$\mathrm{U}$

$\mathrm{V}$

$V_{2}$

$V_{r}$

$v$

$X_{c}$

$\chi$

$\mathrm{Y}+$

$Y-$

$\rho_{1}$

$\rho_{2}$

$\delta$

$\delta_{1}-\delta_{2}$ loss tangent

glass transition temperature

time needed to reach $90 \%$ vulcanization

scorch time ( $2 \mathrm{dN} . \mathrm{m}$ above minimum modulus)

molar vaporization energy

molar volume

molar volume of solvent

volume fraction of rubber

Poisson ratio

apparent crosslink density

Florry-Huggins parameter

the results of observed response in level +1

the results of observed response in level -1

density of polymer

density of solvent

solubility parameter

the difference in solubility parameter

\section{DESCRIPTION}

Aircraft

Analysis of Variance

Analysis System

Abrasion Resistance Index

American Society of Testing Materials

Aerei da Transporto Regionale

Brunauer-Emmet-Teller

Butadiene Rubber

Civil Aviation Regulation

Civil Aviation Safety Authority

Civil Aviation Safety Regulations

Carbon Black

N-Cyclohexyl-2-Benzothiazole Sulfenamide

Central Composite Circumscribed

Cobalt

Carbon Dioxide

Center Point

Cure Rate Index

Canadair Regional Jet

Cetyl-Trimethyl-Ammonium Bromide

Conventional Vulcanization

DiButylPhthalate 
df

DGCA

DIN

DOE

DPG

$E A B$

EASA

EDX

ESBR

EV

FAA

GIA

GMF

GPC

HAF

$\mathrm{HBU}$

$\mathrm{HC} B R$

HC LCB BR

HV BR

ICT

IP

IPPD

IRHD

ISAF

ISO

LAOS

LC BR

$\mathrm{Li}$

LPT

MBS

MES

mins.

$\mathrm{Mn}$

MRO

MS

$\mathrm{Mw}$

MWD

MV

$\mathrm{Nd}$

NDI

NG

$\mathrm{Ni}$ degrees of freedom

Directorate General Civil Aviation

Deutsches Institut für Normung

Design of Experiments

DiPhenyl Guanidine

Elongation at Break

European Aviation Safety Agency

Energy Dispersive X-ray

Emulsion Styrene Butadiene Rubber

Efficient Vulcanization

Federal Aviation Administration

Garuda Indonesia Airline

Garuda Maintenance Facility

Gel Permeation Chromatography

High Abrasion Furnace

Heat Build-Up

High-Cis Butadiene Rubber

High-Cis Long Chain Branched Butadiene Rubber

High-Vinyl Butadiene Rubber

Ice Traction

Ingress Protection

N-Isopropyl-N'-Phenyl-1,4-PhenylenDiamine

International Rubber Hardness Degree

Intermediate Super Abrasion Furnace

International Organization for Standardization

Large Amplitude Oscillation Strain

Low-Cis Butadiene Rubber

Lithium

Landing per Tread

2-(4-Morpholinothio)-Benzothiazole

Mild Extracted Solvate

minutes

number average molecular weight

Maintenance Repair and Overhaul

Mean of Squares

Weight average molecular weight

Molecular Weight Distribution

Mooney Viscosity

Neodymium

Non-Destructive Inspection

Next Generation

Nickel 


\begin{tabular}{|c|c|}
\hline NR & Natural Rubber \\
\hline NSA & Nitrogen Surface Area \\
\hline OEM & Original Equipment Manufacturer \\
\hline OFAT & One Factor At a Time \\
\hline OTR & Off-The-Road \\
\hline PCT & Passenger Car Tires \\
\hline PDI & Poly Dispersity Index \\
\hline PE & Payne Effect \\
\hline Phr & Parts per hundred rubber \\
\hline PMA & Part Manufacture Approval \\
\hline 6PPD & N-Phenyl-para-PhenyleneDiamine \\
\hline p-value & probability value \\
\hline RLT & Radial Light Truck \\
\hline RMT & Radial Medium Truck \\
\hline RPA & Rubber Processing Analyzer \\
\hline RSS & Ribbed Smoked Sheet \\
\hline SAF & Super Abrasion Furnace \\
\hline SBR & Styrene Butadiene Rubber \\
\hline SEM & Scanning Electron Microscopy \\
\hline SI & Silica \\
\hline SS & Sum of Squares \\
\hline STC & Supplementary Type Certificate \\
\hline STSA & Statistical Thickness Surface Area \\
\hline TBS & N-Tert-Butyl-2-Benzothiazole Sulfenamide \\
\hline TC & Type Certificate \\
\hline TDAE & Treated Distillate Aromatic Extract \\
\hline TESPT & bis-(TriEthoxySilyIPropyl)Tetrasulfide \\
\hline TGA & Thermo Gravimetric Analyzer \\
\hline THF & TetraHydroFuran \\
\hline $\mathrm{Ti}$ & Titanium \\
\hline TMQ & 2,2,4-TriMethyl-1,2-dihydroQuinoline \\
\hline TP & Terpene Phenol \\
\hline TS & Tensile Strength \\
\hline TSO & Technical Standard Order \\
\hline TSR & Technical Specified Rubber \\
\hline WLP & Wickert Laboratory Press \\
\hline WSR & Wet Skid Resistance \\
\hline $\mathrm{ZnO}$ & Zinc Oxide \\
\hline
\end{tabular}




\section{BIBLIOGRAPHY}

\section{JOURNAL ARTICLES}

1. Defining Key Factors in Carbon Black-Filled NR/BR Compounds for Balancing Aircraft Tire Tread Properties.

Indriasari, Wisut Kaewsakul, Wilma K. Dierkes and Anke Blume

J. Compos. Sci., 3, 2, 47 (2019), doi:10.3390/jcs3020047

2. Defining Key Factors in Carbon Black-Filled NR/BR Compounds for Balancing Aircraft

Tire Tread Properties

I. Indriasari, Wisut Kaewsakul, Wilma K. Dierkes and Anke Blume

Rubber World, 261, 2, 32 (2019)

3. Incorporation of Resins for Improving the Properties of Aircraft Tire Retreads

Indriasari, Wilma K. Dierkes, J.W.M. Noordermeer

J. Appl. Sci. (Manuscript ID: applsci-1376699)

\section{PRESENTATIONS}

\section{ORAL PRESENTATIONS}

1. Balancing properties of aircraft tire treads: Defining key parameters in processing and compounding

Indriasari, Wisut Kaewsakul, Wilma K. Dierkes and Anke Blume

European PhD Rubber Seminar on Rubber Technology, Lodz, Poland, April 23-25, 2018.

2. Balancing the properties of aircraft tire treads: Factors influencing heat generation of aircraft tire tread compounds

Indriasari, Wisut Kaewsakul, Wilma K. Dierkes and Anke Blume

Tire Technology Expo 2019, Hannover, Germany, November 7-9, 2019.

3. Defining Key Parameters for Balancing Aircraft Tread Properties by Utilizing Design of Experiments

Indriasari, Wisut Kaewsakul, Wilma K. Dierkes and Anke Blume

International Week, Wurzburg, 2019.

4. Tailoring Rubber Compounds Containing a Hybrid Carbon Black-Silica Filler for Aircraft Tire Treads: The Effect of Zinc Oxide and DPG Addition Sequence on Compound Properties and Hysteresis

Indriasari, J.W.M. Noordermeer, Wilma K. Dierkes and Anke Blume

The 196th Technical Meeting of the Rubber Division, ACS 2019, Cleveland, Ohio, USA, October 8-10, 2019.

Remark: Name with underline is speaker. 


\section{POSTER PRESENTATIONS}

1. Balancing the properties of NR/BR blends for aircraft tire tread compounds Indriasari, Wisut Kaewsakul, Wilma K. Dierkes and Anke Blume Dutch Polymer Days, April 12, 2018.

2. Balancing the Properties of Aircraft Tire Treads by Experimental Design: The Influence of $\mathrm{ZnO}$ and DPG Addition in Hybrid CB/SI-Filled NR/BR Compounds Indriasari, Wisut Kaewsakul, Wilma K. Dierkes and Anke Blume The $13^{\text {th }}$ Fall Rubber Colloquium (KHK 2018), Hannover, Germany, November 6-8, 2018. 


\section{ACKNOWLEDGEMENTS}

First of all, I would like to acknowledge the Ministry of Research, Technology, and Higher Education for making this PhD program possible by providing financial support through the scholarship program for Research and Innovation in Science and Technology Project (RISET-Pro). The program would not have also become a reality if I did not receive full support from my institution, The Agency for The Assessment and Application of Technology (now the National Research and Innovation Agency), where I work since 2009.

I recall my journey as a PhD candidate at the University of Twente as a long marathon and an endurance test. Especially during the Covid-19 outbreak that pushes me to adapt to the limitation and unpredictable situations. My biggest strength to accomplish the project is my commitment to all my sponsors and people that gave me trust and opportunity.

I would like to appreciate and express my respect to Prof. Dr. A. Blume who opens the door for me to be part of her team at the Elastomer Technology and Engineering (ETE) group. Thank you for giving me this valuable opportunity to accept me as a PhD candidate. My deepest gratitude to my supervisor, Prof. Dr. Ir. W.K. Dierkes for not giving up and always believe in me. You are not only my mentor, but more like a friend who always helps, encourages, and be there in my happy and sad moments. I appreciate the patience and the effort you made to reach the successful completion of this project in both scientific and applicable ways. My sincere gratitude to Prof. J.W.M. Noordermeer, who is willing to be my co-supervisor. I am thankful for the time that you have spent on helping me shaping the writing and discussing all challenging topics in this research work.

I would also like to appreciate and express my gratitude to Prof. Dr. Ir. H.F.J.M. Koopman, Prof. Dr. A.R. Thornton, Prof. Dr. Ir. J.E. ten Elshof, Prof. S. Wiessner, Prof. D. Katrakova-Krüger and Dr. J. Bertrand for being members of my graduation committee.

I want to thank the other staff members at the ETE group who have helped me. Dear Ceciel, thank you for helping me out with the administrative matters. Without you, the administrative work would stress me out. Sincere thanks to Dries for making all the lab works are possible to perform. You are such an incredible person who can solve all the problems in the lab. Wisut, I appreciate you being there for discussions and help, not only limited to research work but also personal matter.

It is quite challenging at the beginning to get to know people with different backgrounds and personalities. Thankfully by the time, I can adjust and spent some time with the wonderful ETE people from around the world. To all of my (past and present) colleagues in ETE: Jin, Ayush, Dorota, Gina, Marzieh, Amir, Sun, Priyanka, Marcel, Hans, Rounak, Anmol, Choi, Jan-Wilhelm, Arqam, Rafal, Fabian, Pilar, Neven, Stefan, Marnick, Rick, Ania, Maja, Andrea. Thank you very much for your sincere help and friendship during my stay in the 
Netherlands. I appreciated all of the activities that we had done together. Sincere thanks to my close friends Chai, Akansha, Carmela, Zuzanna, Chigusa, Marcin, Chesidi, Xiaozhen. You made my days overseas more colorful. Spending some time together made me feel like we were family and helped me ease my difficulties. Thank you for accepting me as who I am. It is a pleasure to be able to get to know all of you personally. My special thanks to Carmela and Zuzanna for being my paranymphs. Thank you for lending me your hands, time and made this graduation runs smoothly and possible to do even when I am not there physically.

My sincere thanks to my superiors in Indonesia: Prof. Dr. Ir. Eng. Eniya L. Dewi, former deputy of Information, Energy and Materials Technology, Dr. Ir. Ade Sholeh Hidayat, the head of Center for Material Technology for full support to finish my PhD program. My special thanks to my best friends: Sri, Winda, Rias, Wiku, Deka, Nuning, Tami, Ika for shared happiness and sadness together. To Ina and Dwi, thank you for helping me with the administrative matters.

Last but not least, my utmost gratitude to my beloved family; my father, my mother, my brother and sister, and also my beloved relatives. Thank you for giving me your unconditional love, endless pray and being by my side, and supporting me. 


\section{CURRICULUM VITAE}

Indriasari was born in Banyumas, Indonesia on April 9, 1979. She obtained her bachelor's degree in chemical engineering from Universitas Pembangunan Nasional "Veteran" Yogyakarta in 2003. Her thesis title was the manufacturing of glycerol from crude palm oil capacity 180,000 tons/year. She worked in several companies from 2003 until 2008. From 2009 until now, she works as a government staff in the Center for Material Technology, the Agency of Assessment and Application of Technology (now the National Research and Innovation Agency). In 2013, she continued her study in chemical engineering, at the University of Twente with the funding from the StuNed scholarship. She received her Master of Science (MSc) degree in 2015 with the thesis on a design of experiments Taguchi approach for studying the effect of selected factors on enhancing bonding of short aramid fibers reinforced rubber compounds at Elastomer Technology and Engineering (ETE) group under the supervision of Prof. Dr. J.W.M. Noordermeer. In 2016, she continued to pursue her PhD at the ETE group with the funding from the scholarship program for Research and Innovation in Science and Technology Project (RISET-Pro). 
Sametimes the best thing

you can do is not think.

not wonder, not imagine.

not alsess.

gust breathe and have faith

that everything will wark out

for the best

\#peacefuldiaries 
